GA-A20783

\title{
ALTERNATE APPROACHES TO VERIFYING THE STRUCTURAL ADEQUACY OF THE DEFENSE HIGH LEVEL WASTE SHIPPING CASK
}

\author{
by \\ A. Zimmer and M. Koploy
}

Prepared under

Contract DE-AC04-80SF10791

for the Department of Energy

DECEMBER 1991

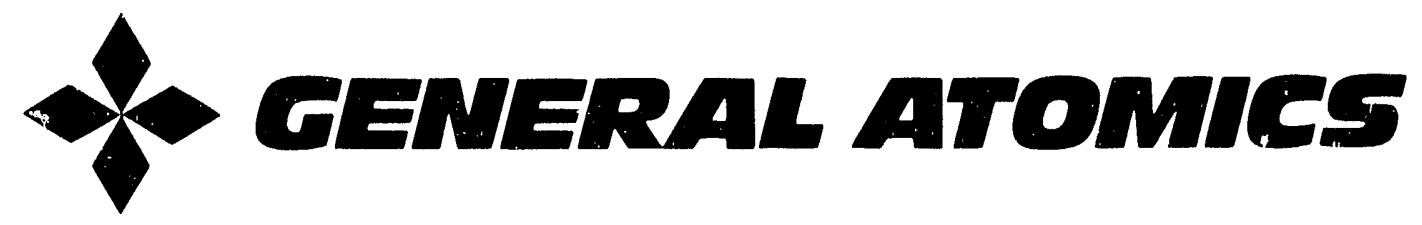




\section{DISCLAIMER}

This report was prepared as an account of work sponsored by an agency of the United States Government. Neither the United States Government nor any afjency thereof, nor any of their employees, makes any warranty, express or implied, or issumes any legal liability or responaibility for the accuracy, completeness, or usefulness of any information, apparatus, product, or process disclosed, or represents that its use would not infringe privately owned rights. Reference herein to any specific commercial pmduct, process, or service by trade name, trademark, manufacturer, or otherwise, does not necessarily constitute or imply its endorsement, recommendation, or favoring by the United States Government or any agency thereof. The views and opinions of authors expreased herein

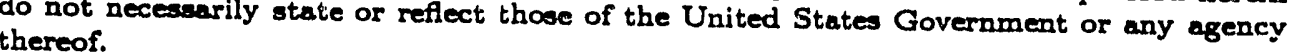




\title{
ALTERNATE APPROACHES TO VERIFYING THE STRUCTURAL ADEQUACY OF THE DEFENSE HIGH LEVEL WASTE SHIPPING CASK
}

\author{
by \\ A. Zimmer and M. Koploy
}

Prepared under

Contract DE-AC04-80SF10791

for the Department of Energy

DECEMBER 1991

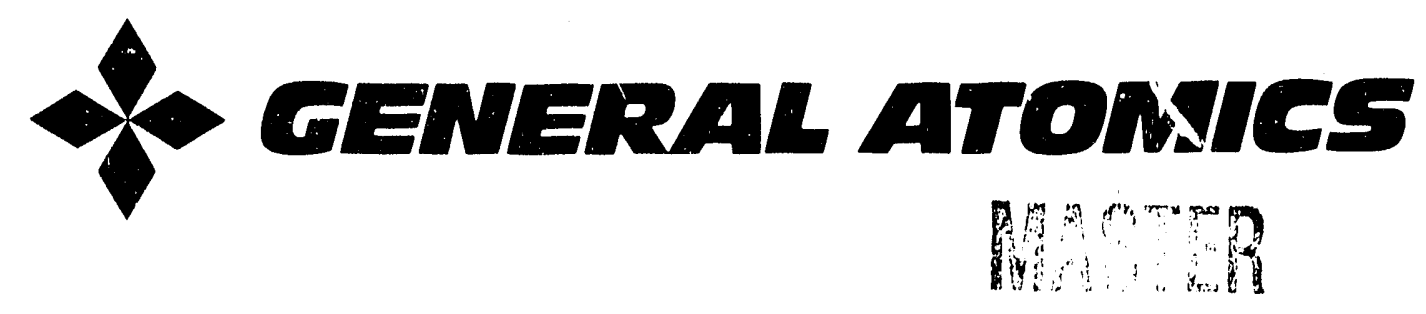




\section{DISCLAIMER}

This report was prepared as an account of work sponsored by an agency of the United States Government. Neither the United States Governmen', nor any agency thereof, nor any of their employees, makes any warranty, expmss or implied, or assumes any legel liability or responsibility for the accuracy, completeness, or usefulness of any information apparatus, product, or process disclosed, or represents that its use would information, privately owned rights. Reference herein to suy secific commerciol product infringe or service by trade name, trademark, constitute or imply its en trademark, manufacturer, or otherwise, does not necessarily Government or any agency thereof. recommendation, or favoring by the United States do not necessarily state or reflect those views and opinions of authors expressed herein therecf. 
GA-A20783

\title{
ALTERNATE APPROACHES TO VERIFYING THE STRUCTURAL ADEQUACY OF THE DEFENSE HIGH LEVEL WASTE SHIPPING CASK
}

\author{
by \\ A. Zimmer and M. Koploy
}

\author{
Prepared under \\ Contract DE-AC04-80SF10791 \\ for the Department of Energy
}

GENERAL ATOMICS PROJECT 3324

DECEMBER 1991

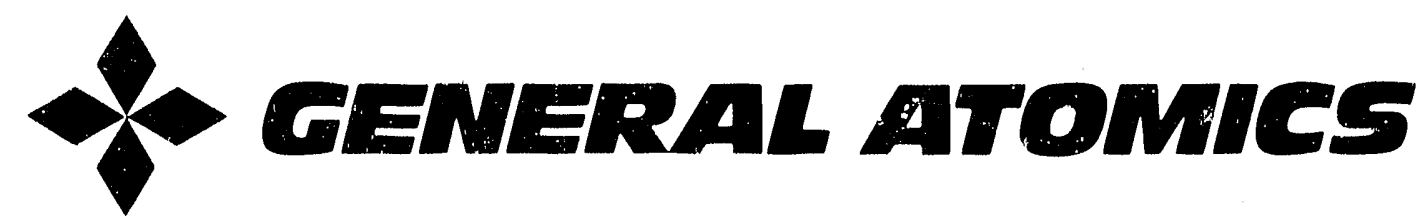


General Atomics (GA) wishes to individually acknowledge the Sandia National Laboratories (SNL) personnel responsible for supporting the defense high level waste (DHLW) cask program. SNL provided technical oversight to the Department of Energy (DOE) (Ken Golliher, Project Manager) and was responsible for the fabrication and testing of the DHLW half-scale model, impact limiter model testing, and other engineering tests. SNL, under thelr base technology program, developed the notched impact 1imiter that was incorporated into the DHLW cask.

\author{
Baynes, E. \\ Bronowsk1, D. R. \\ Glass, R. E. \\ Madsen, M. M. \\ Stenberg, D. R. \\ Uncapher, W. L.
}




\section{CONTENTS}

1. INTRODUCTION ..................... . . . 1-1

1.1. Background . . . . . . . . . . . . . . . $1-1$

1.2. DHLW Cask Description ... . . . . . . . . . . 1-1

1.3. Approach to Structural Design Verffication . . . . . 1-5

1.4. Summary of Analyses and Tests . . . . . . . . . . . 1-7

2. INELASTIC ANALYSIS . . . . . . . . . . . . . . 2-1

2.1. Structural Criteria . . . . . . . . . . . . 2-1

2.1.1. Description ................ 2-1

2.1.2. Comparison of GA and ASME Code Inelastic

Allowables............. 2-3

2.2. Analytical Methods .... . . . . . . . . 2-6

2.2.1. General Methodology ............ 2-6

2.2.2. Two-Dimensional HONDOII Finfte Element. Analysis .............. 2- 2-7

2.2.3. Three-Dimensional DYNA3D Finite Element Analysts.............. . 2-9

2.3. Cask 9-m $(30-f t)$ Drop Analyses ............ 2-10

2.3.1. Nine-Meter $(30-\mathrm{ft})$ Bottom End Flat Drop Analysts . . . . . . . . . . . . 2-10

2.3.2. Nine-Meter $(30-f t)$ Closure End Drop Analys1s . 2-23

2.3.3. Nine-Meter (30-ft) Center of Gravity Over Closure Corner Drop Analysis ....... 2-37

2.3.4. Nine-Meter (30-ft) Center of Gravity Over Bottom Corner Drop Analysis ........ 2-48

3. ELASTIC ANALYSIS . . . . . . . . . . . . . . . . 3-1

3.1. Structural Criteria . . . . . . . . . . . . . 3-1

3.2. Analytical Methods................ . 3-1

3.2.1. Theory of Modeling . . . . . . . . . . 3-5

3.2.2. Verification.............. 3-10

3.3. Cask Analysis .. . . . . . . . . . . . . 3-12

3.3.1. Impact Limiter Load-Deflectin Curve Pests . . 3-16

3.3.2. Thtrty-Foot Free Drop Elastic Analys1s... . 3-69 
4. HALF-SCALE MODEL TEST DATA . . . . . . . . . . . 4-1

4.1. Mode1 Description ................. 4-1

4.2. Test Sequence and Procedure ........... . 4-5

4.3. Testing and Results ................ 4-28

4.3.1. Scaling Laws .............. . 4-28

4.3.2. Information Gathered from Tests ....... 4-29

4.3.3. Test Results................ 4-33

5. COMPARISON OF TEST RESULTS WITH ANALYTICAL RESULTS . . . . . 5-1

5.1. Accelerations and Duration... . . . . . . . . . 5-1

5.2. Strains . . . . . . . . . . . . . . . 5-3

5.3. Displacements .. . . . . . . . . . . . 5-8

5.4. Matertal Properties . . . . . . . . . . . 5-13

6. REFERENCES ..................... 6-1

\section{FIGURES}

1-1. DHLW cask cutaway . . . . . . . . . . . . 1-3

1-2. Section through DHLW truck cask............. 1-4

2-1. Allowable straln energy . . . . . . . . . . . . . 2-4

2-2. DHLW two-dimensional bottom end drop, finite element model ....................... 2-12

2-3. DHLW two-dimensional bottom end drop, bottom end of model shown ..................... 2-13

2-4. Deformation of bottom end of cask during a 9-m (30-ft) bottom end drop $4.8 \mathrm{~ms}$ after initlal impact . . . . . 2-17

2-5. Nire-meter (30-ft) bottom end drop analysis, kinetic energy versus time .................. 2-18

2-6. Critical sections for DHLW bottom end $9-m(30-f t)$ drop . . 2-19

2-7. DHLW 9-m (30-ft) bottom end drop primary membrane stress time history at the cask body bottom plate edge under the shield liner ................... 2-21

2-8. DHLW 9-m (30-ft) bottom end drop time history of stresses in element with highest local membrane plus bending stresses . . . . . . . . . . . . . . . . . 2-22

2-9. Components of DHI.W shipping cask 9-m (30-ft) closure end analytical model ................. 2-. 25

2-10. Complete model used in $9-\mathrm{m}(30-\mathrm{ft})$ closure end drop analysis ................... 2-26 


\section{FIGURES (Continued)}

2-11. Primary membrane stress for cask neck critical

Section 4.................... 2-30

2-12. DHLW two-dimensional closure end drop model at $1 \mathrm{~ms} \cdot$. . 2-31

2-13. DHLW two-dimensional closure end drop model at $4 \mathrm{~ms} . . \cdot 2-32$

2-14. DHLW two-dimensional closure end drop model at $6 \mathrm{~ms}$. . . 2-33

2-15. DHLW two-dimensional closure end drop model at $9 \mathrm{~ms} .$. . 2-34

2-16. Blow up of closure end showing critical sections chosen during 9-m (30-ft) closure end drop analysis ..... 2-35

2-17. Closure end 9-m (30-ft) drop analysis finite element model showing locations of critical sections . . . . . . . 2-36

2-18. Finite element model (cut by $x-y$ plane at $y=0$ ) for $C G$ over closure corner $9-\mathrm{m}(30-\mathrm{ft})$ drop analysis.... . . 2-40

2-19. CG over closure corner $9-\mathrm{m}(30-\mathrm{ft})$ drop analysis, total kinetic energy for half the cask versus time .. . . . 2-45

2-20. Deformed shape plot of the top of the model during a CG over closure corner $9-\mathrm{m}(30-\mathrm{ft})$ drop . . . . . . . . . 2-46

2-21. Critical sections for CG over closure corner drop analysis .... . . . . . . . . . . . . 2-47

2-22. Closure corner 9-m $(30-f t)$ drop analysis. Primary membrane stress for most critical section in cask flange.. 2-50

2-23. Closure corner 9-m $(30-\mathrm{ft})$ drop analysis. Individual effective stresses for critical Section 1 located in top of cask flange at point of impact... . . . . . . 2-51

2-24. Undeformed fintte element model used in three-dimensional analysis of cask during a CG over bottom corner 9-m

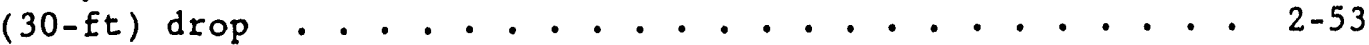

2-25. Exploded view of cask model used 1 a CG over bottom corner 9-m (30-ft) drop analysis.............. 2-54

2-26. Bottom corner 9-m (30-ft) drop analysis total kinetic energy for half the cask versus time . . . . . . 2-57

2-27. Exploded view of cask body showing area enlarged for contour plots.................. 2-58

2-28. Effective stress contour plots of the inside of the cask body (part 1)..................... 2-59

2-29. Effective stress contour plots of the inside of the cask body (part 2).................... 2-60

2-30. Location of critical sections in cask body part 1 in CG over bottom corner 9-m $(30-f t)$ analysis........ 2-61 
FIGURES (Continued)

2-31. Location of critical sections in cask body part 2 in CG over bottom corner $9-\mathrm{m}(30-\mathrm{ft})$ drop analysis . . . . . 2-62

2-32. Bottom corner $9-\mathrm{m}(30-\mathrm{ft})$ drop analysis primary membrane stress of critical Section 11... . .'. . . . . . 2-65

2-33. Bottom corner $9-m(30-f t)$ drop analysis for individual effertive stresses for critical Section 11 . . . . . . . 2-66

3-1. Model of DHLW cask using lumped mass and beam representation .. . . . . . . . . . . . . 3-4

3-2. Different types of section properties input accepted by GACAP . . . . . . . . . . . . . . . . . . 3-9

3-3. GACAP provides both the flexible body and rigid body dynamic solutions.................. 3-11

3-4. GACAP model used for verification with DYNA3D . . . . . 3-13

3-5. Comparison of GACAP and DYNA3D nodal displacement and beain moment results......... .. . . . . 3-14

3-6. 1/6-scale notched and lower end Impact limiter test article................... . 3-17

3-7. 1/6-scale notched and lower end impact limfter test article................... 3-18

3-8. 1/3-scale circumferential honeycomb test article and fixture................... 3-19

3-9. 1/3-scale circumferential honeycomb test article and fixture................ . . 3-20

3-10. Notched impact limiter, $45 \mathrm{deg}$ test. . . . . . . . . 3-22

3-11. Lower end impact 1imiter, 15 deg test.......... . 3-23

3-12. Notched impact limfter test articles after tests . . . 3-24

3-13. Lower end impact limiter test articles after tests . . . 3-25

3-14. Circumferential impact limtter showing 0 deg crish footprint and ready for 12 deg test .. . . . . . . . 3-26

3-15. 1/6-scale notched impact 1imiter, load-deflection curve at 0 deg .............. . . 3-27

3-16. 1/6-scale notched impact 1imiter, load-deflection curve at $73.4 \mathrm{deg}$. . . . . . . . . . . . . . . . 3-28

3-17. 1/6-scale notched impact limiter, load-deflection curve at $60 \mathrm{deg}$.................... . . . 3-29

3-18. 1/6-scale notched Impact limiter, load-deflection, curve at $45 \mathrm{deg} . . .3$. . . . . . . . . . . 3-30 
3-19. 1/6-scale notched impact limiter, load-deflection curve

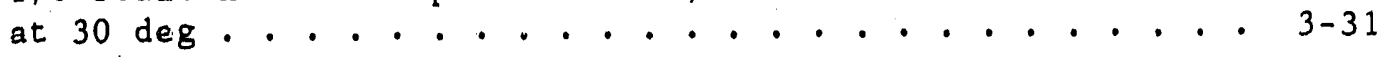

3-20. 1/6-scale notched impact 1imiter, load-deflectlon curve

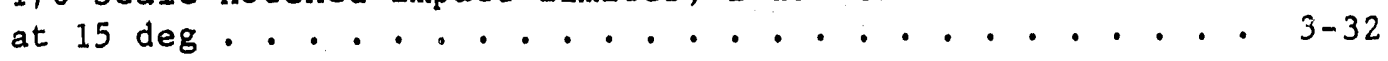

3-21. 1/6-scale lower end impact 1imiter, load-deflection curve at $90 \mathrm{deg} . . .3$. . . . . . . . . . . . . 33

3-22. 1/6-scale lower end Impact 1imiter, load-deflection curve at $75.7 \mathrm{deg}$. . . . . . . . . . . . . 3-34

3-23. 1/6-scale lower end impact 1imiter, load-deflection curve at $60 \mathrm{deg}$....................... 3-35

3-24. 1/6-scale lower end impact 1imiter, load-deflection curve

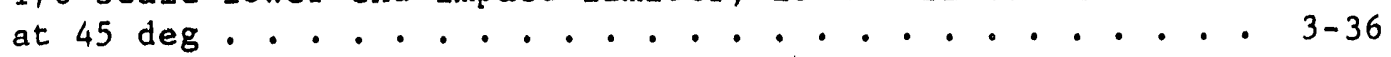

3-25. 1/6-scale lower end impact limiter, load-deflection curve

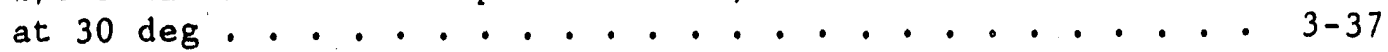

3-26. 1/6-scale lower end impact limiter, load-deflection curve

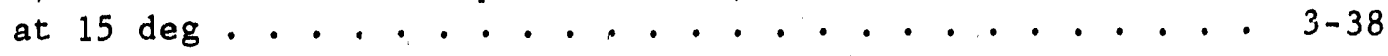

3-27. 1/3-scale circumferential impact limiter, load-deflection curve at 0 deg ................ 3-39

3-28. 1/3-scale circumferential impact 1imfter, load-deflection curve at $12 \mathrm{deg}$. . . . . . . . . . . . . . . . 3-40

3-29. 1/3-scale circumferential impact limiter, load-deflection curve at $24 \mathrm{deg} . . .3$. . . . . . . . . . . 3-41

3-30. Notched impact limiter load-deflection curve (ful1-scale), 90 deg orientation . . . . . . . . . . . . . . 3-44

3-31. Notched impact limfter load-deflection curve (full-scale), 73.4 deg ortentation . . . . . . . . . . . 3-45

3-32. Notched 1mpact limiter load-deflection curve (full-scale), $60 \mathrm{deg}$ orientation .. . . . . . . . . . . 3-46

3-33. Notched impact limiter load-deflection curve (full-scale), $45 \mathrm{deg}$ orfentation .. . . . . . . . . . . . 3-47

3-34. Notched 1mpact limiter load-deflection curve (full-scale), 30 deg orlentation . . . . . . . . . . . 3-48

3-35. Notched Impact limiter load-deflection curve (full-scale), $15 \mathrm{deg}$ orlentation ............... . . 3-49

3-36. Lower end impact limiter load-deflection curve (fullscale), 90 deg orientation ............... 3-50

3-37. Lower end impact limiter load-deflection curve (ful1scale), 75.7 deg orientation .. . . . . . . . . 3-51 
FIGURES (Continued)

3-38. Lowe: end impact 11miter load-deflection curve (ful1scale), 60 deg orfentation . . . . . . . . . . . 3-52

3-39. Lower end impact limiter load-deflection curve (fullscale), 45 deg orientation . . . . . . . . . . 3-53

3-40. Lower end impact limiter load-deflection curve (fillscale), 30 deg orientation . . . . . . . . . . . 3-54

3-41. Lower end impact limiter load-deflection curve (ful1scale), 15 deg ortentation ........... 3-55

3-42. Upper circumferential impact 1imiter, load-deflection curve (ful1-scale), 0 deg side drop orientation . . . . 3-57

3-43. Upper circumferential impact limiter, load-deflection curve (ful1-scale), 12 deg side drop orientation . . . . 3-58

3-44. Upper circumferential impact 1imiter, load-deflection curve (full-scale), $24 \mathrm{deg}$ side drop orientation ... . 3-59

3-45. Upper c1rcumferential impact limiter, load-deflection curve (full-scale) from ILMOD, 0 deg side drop orlentation . . . . . . . . . . . . . . 3-60

3-46. Upper circumferent1al impact limiter, load-deflection curve (ful1-scale) from ILMOD, 12 deg side drop orientation ................ 3-61

3-47. Upper circumferential impact 1imiter, load-deflection curve (full-scale) from ILMOD, $24 \mathrm{deg}$ side drop orfentation . . . . . . . . . . . . . . 3-62

3-48. Lower cfrcumferential impact limiter (small diameter), load-deflection curve (full-scale) from ILMOD, 0 deg side drop orientation... . . . . . . . . . . 3-63

3-49. Lower cfrcumferential impact limiter (small diameter), load-ileflection curve (full-scale) from ILMOD, $12 \mathrm{deg}$ side drop orientation.............. . 3-64

3-50. Lower circumferentlal impact limiter (small diameter), load-deflection curve (full-scale) from ILMOD, $24 \mathrm{deg}$ side drop orientation... . . . . . . . . . . 3-65

3-51. Lower circumferential impact limiter (large diameter), load-deflection curve (full-scale) from ILMOD, 0 deg side drop orientation... . . . . . . . . . 3-66

3-52. Lower circumferential impact limiter (large diameter), load-deflection curve (full-scale) from ILMOD, 12 deg side drop orientation... . . . . . . . . . . 3-67 


\section{FIGURES (Continued)}

3-53. Lower cfrcumferential impact limiter (large diameter), load-deflection curve (full-scale) from ILMOD, 24 deg side drop orientation............ . 3-68

3-54. DHLW cask GACAl model with mass nodal point loading. . . 3-70

4-1. Half-scale test model ................. 4-2

4-2. DHLW casle half-scale model components used during testing . . . . . . . . . . . . . . . . 4 4-3

4-3. Bottom end drop test setup . . . . . . . . . . . . 4-9

4-4. Damage to lower end impact limiter . . . . . . . . . 4-10

4-5. Proliminary rtgging in preparation for closure-end úrop test... .................. 4-11

4-6. Cask on top of target after 9-m (30-ft) closure-end drop test ................... 4-12

4-7a. Notched impact limiter and closure before closure end $9-m(30-f t)$ drop test............... 4-13

4-\%. Notched Impact limiter and closure after closure end $9-\mathrm{m}(30-f t)$ drop test . . . . . . . . . . . . 4 4-14

4-8. Cask and puncture pin after gas sample/leakage test port puncture drop ... . . . . . . . . . . . . 4-15

4-9. Damage to thermal barrier after gas samp1e/leakage test port puncture drop . . . . . . . . . . . . 4-16

4-10. Condition of closure (port area) after gas sample/leakage test port puncture drop . . . . . . . . . . . . 4-17

4-11. Test canisters . . . . . . . . . . . . . . 4-18

4-12. Cask being raised into position before first side drop test ..................... 4-19

4-13. Cask after first side drop test... . . . . . . . . 4-20

4-14. Honeycomb from lower circumferential impact limiter after first side drop test . . . . . . . . . . . . 4-21

4-15. Test setup before center puncture drop . . . . . . . . 4-22

4-16. Bottom end of cask after complete test sequence. . . . 4-23

4-17. Damage to upper circumferential impact limiter after second side drop test............... . 4-24

4-18. Cask after complete test sequence............ . 4-25

4-19. Shield sleeve after compiete test sequence . . . . . . . 4-26

4-20. Interior of cask body after complete test sequence . . . . 4-27

4-21. Schemalic of test instrumentation........... 4-35 


\section{FIGURES (Continued)}

4-22. Average of peak strains from strain gauges at each level recorded during bottom end drop test . . . . . . . . 4-42

4-23. Inner surface cask body strains during CG over bottom corner 9-m $(30-f t)$ drop . . . . . . . . . . . . . . . 4-44

4-2.4. Outer surface cask body strkins during CG over bottom corner 9-m (30-ft) drop............ 4-45

4-25. First side drop test circumferential impact limiter deformation.... . . . . . . . . . . . 4-54

4-26. Circumferential impact limiter deformation after second side drop test. . . . . . . . . . . . . . . . 4-55

5-1. Half-scale model CG over bottom corner 9-m (30-ft) drop acceleration ... . . . . . . . . . . . 5-4

5-2. Elastic-plastic bottom end 9-m (30-ft) drop acceleration. 5-5

5-3. Comparison of strain results in cask body during bottom end drop . . . . . . . . . . . . . . . . . 5-7

5-4. CG over bottom corner strain analyrical results.... . . 5-9

5-5. Comparison of deformations during bottom end drop . . . . 5-12

5-6. Comparison of material test results with analytical properties used . . . . . . . . . . . . . . . 5-14

\section{TABLES}

1-1. Commarison of inelastic and elastic analyses and half-scale test results... . . . . . . . . . . . 1-8

2-1. Containment bounciary allcwable stresses for elastic-plastic analysis . . . . . . . . . . . . . . . 2-2

2-2. Summary of maximum stresses at critical sections in containment boundary due to bottom end 9-m (30-ft) drop . 2-20

2-3. Summary of maximum stresses at critical sections in containment boundary due to closure end $9-\mathrm{m}(30-\mathrm{ft})$ drop . . . . . . . . . . . . . . . . . . 2-38

2-4. Closure bolts material properties used on CG over closure corner 9-m $(30-f t)$ drop analysis . . . . . . . . . . 2-44

2-5. Summary of maximum stresses at critical sections in containment boundary due to CG over closure corner 9-m $(30-f t)$ drop .................. . 2 $2-49$

2-6. Summary of maximum stresses at critical sections in containment boundary due to CG over bottom corner 9-m $(30-f t)$ drop . . . . . . . . . . . . . . . 2-64 
TABLES (Continued)

3-1. Containment boundary allowable stresses for elastic analysts .................... 3-2

3-2. Containment boundary bult stress allowables....... . 3-3

3-3. Comparison of results between SCANS and GACAP . . . . . . 3-15

3-4. Moment and stress components for maximum primary stress intensity 1-ft closure end orientation drop - DHLW cask maximum crush strength .............. 3-73

3-5. Moment and stress components for maximum primary stress intensity 30-ft closure end orientation drop - DHLW cask maximum crush strength ............. . 3-74

3-6. Moment and stress components for maximum primary stress intensity 30-ft closure end orientation drop - DHLW cask mintmum crush strength .............. 3-75

3-7. Moment and stress components for maximum primary stress Intensity $30-\mathrm{ft}$ closure end orientation drop - DHLW cask maximum crush strength lower circumferential impact limiter with large diameter.............. 3-76

3-3. Moment and stress components for maximum primary stress intensity 1-ft bottom end orientation drop - LHLW cask maximur crush strength ............... 3-77

3-9. Moment and stress components for maximum primary stress intensity $30-\mathrm{ft}$ bottom end orientation drop - DHLW cask maximum crush strength ............ 3-78

3-10. Moment and stress components for maximum primary stress intensity 30-ft bottom end orientation drop - DHLW cask maximum crush strength lower circumferential. impact limiter with large diameter... . . . . . . . 3-79

3-11. Moment and stress components for maximum primary stress intensity $30-\mathrm{ft}$ bottom end orientation drop - DHLW cask minimum crush strength ............. 3-80

4-1. Test sequence . . . . . . . . . . . . . . 4-6

4-2. Instrumentation for 30-ft drop and puncture tests of the half-scale DHLW cask ............... 4-31

4-3. Test results - accelerometer data . . . . . . . . . 4-38

4-4. Test resules - accelerometer and impact duration data. . 4-39

4-5. Strains and strain-offsets measured during second side drop test................... . . 4-46

5-1. Comparison of inelastic and elastic analyses and halfscale test results . . . . . . . . . . . . . . . 5-2 


\section{INTRODUCTION}

\subsection{BACKGROUND}

In the early 1980s, the U.S. Department of Energy/Defense Programs (DOE/DP) Initiated a project to develop a safe and efficient transportation system for defense high level waste (DHLW). A long-standing objective of the DHLW transportation project is to develop a truck cas that represents the leading edge of cask techrology as well as one that fully complies with all applicable DOE, Nuclear Regulatory Commission (NRC), and Department of Transportation (DOT) regulations. General Atomics (GA) designed che DHLW Truck Shipping Cask using srate-of-the-art analytical techniques verffled by model testing performed by Sandia National I sboratories (SNL). The analytical techniques include two approaches, inelastic analysis and elastic analysis. This topical report presents the results of the two analytical approaches and the model testing results. The purpose of this work is to show that there are two viable analytical alternatives to verify the structural adequacy of a Type B package and to obtain an NRC license. In addition, this data will help to support the future acceptance by the NRC of inelastic analysis as a tool in packaging design and licensing.

\subsection{DHLW CASK DESCRIPTION}

The DHLW shipping system meets the legal truck weight limit of $36,288 \mathrm{Kg}(80,000 \mathrm{lb})$. It consists of a cylindrically-shaped cask that is tied to a dedicated semitraller and pulled by a standard tractor. The cask holds one canister of solidifled DHLW produced by the Defense Waste Processing Facility (DWPF) at the Savannah River Plant (SRP) in South Carolina and later produced by Hanford, INEL, and West Valley. 
The canister contains sludge and supernate in a borosilicate glass mat $r i x$.

The cask, shown in Figs. $1-1$ and $1-2$, is 97.8 to $168.9 \mathrm{~cm}(38.5$ to $66.5 \mathrm{fn.})$ in diameter and $410.8 \mathrm{~cm}$ (161.75 in.) In length. The cask outer body is Type 304 stainless steel and has an Inner gamma shleld liner of depleted uranium contained by inner and outer shells of stainless steel. The 7.5- to 10-cm (3- to 4-1n.) thick stainless steel walls of the cask body ensure the structural integrity of the cask and provide some radiation shielding. The cask body, in conjunction with the outer c.losure and double elastomer 0-ring seals, forms the primary contalnment boundary. The cask has four external integral impact limiters that protect the cask during free drops. All are nonremovable which reduces handling and operating time. During impacts on the bottom of the cask, the lower end Impact 1imiter, a $5.08-\mathrm{cm}(2-1 \mathrm{n}$.$) thick by 12.7-\mathrm{cm}$ (5-in.) long ring that is integral with the cask body acts as an energy absorber. The notched impact limiter, a stainless steal notched ring, provides the primary protection to the closure area. The notched impact limiter is $26.7 \mathrm{~cm}$ (10.5 in.) long with circumferential notches on the Inside diameter of the $5.08-\mathrm{cm}(2-\mathrm{in}$. $)$ thick wall and is welded to the top of the cask body. The upper and lower circumferential aluminum honeycomb impact limiters protect the cask from side impacts. These impact 1 imiters are bonded to the cask outer dlameter surface and are enclosed with 304 stainless steel face sheets. The honeycomb has a crush strength of 6500 poi.

Depleted uranim (DU) in the form of a removable shield liner provides radiation shielding. The shield liner wall is $4.22 \mathrm{~cm}(1.66 \mathrm{in.})$ of depleted uranium encased in a $3.0 \mathrm{~cm}(1.17 \mathrm{in.})$ Inner and a $1.88 \mathrm{~cm}$ $(0.74 \mathrm{in.})$ outer 304 stainless steel shell. Since the liner is removable, the cask has the versatility to be used for other waste forms by adding different. amounts of shfelding. A segmented shear ring that extends into a circumferential groove machined in the inside wall of the cask body restratins it from axial movement, transferring all dynamic loading directly to the cask body instead of the closure. 


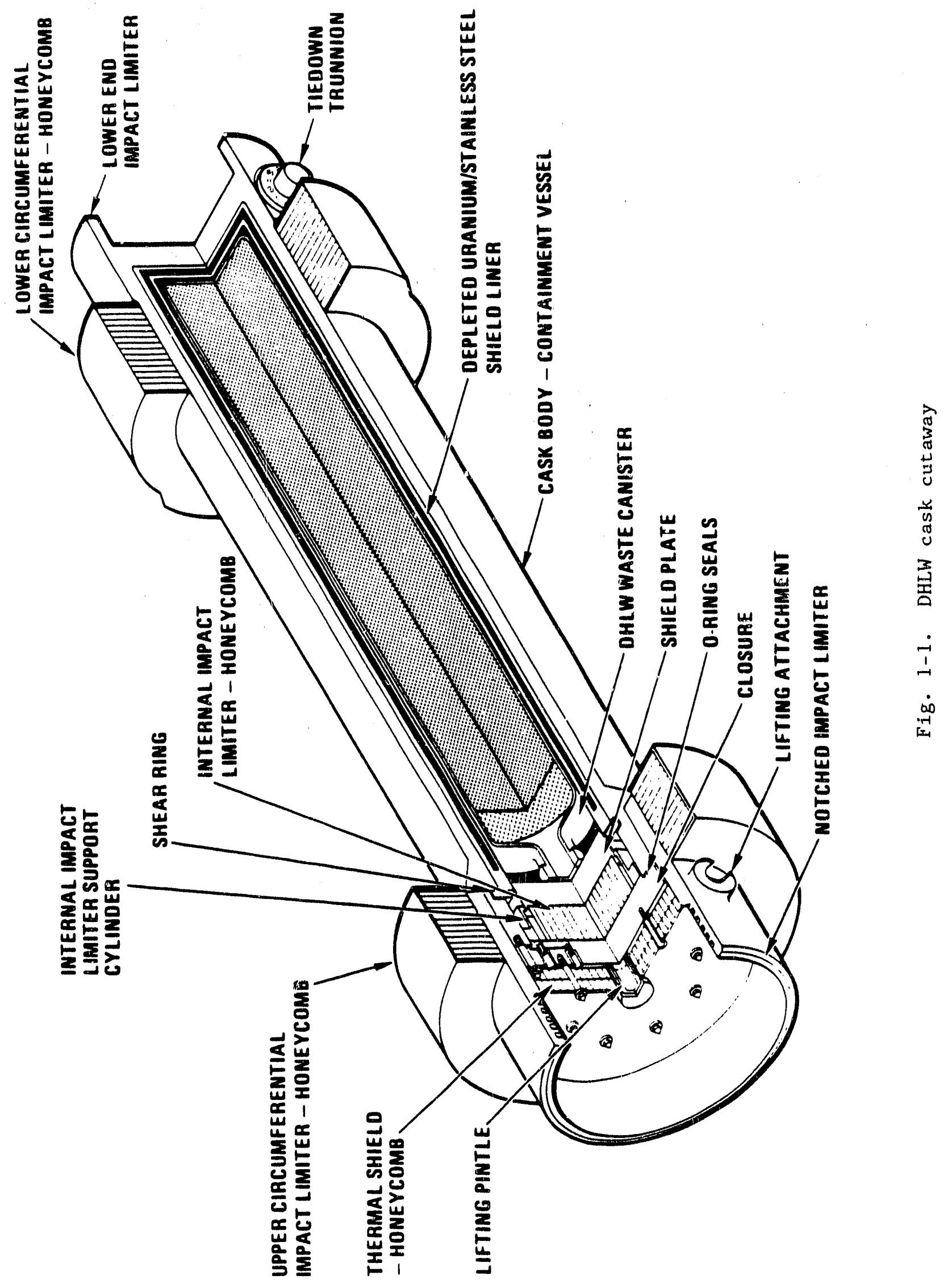




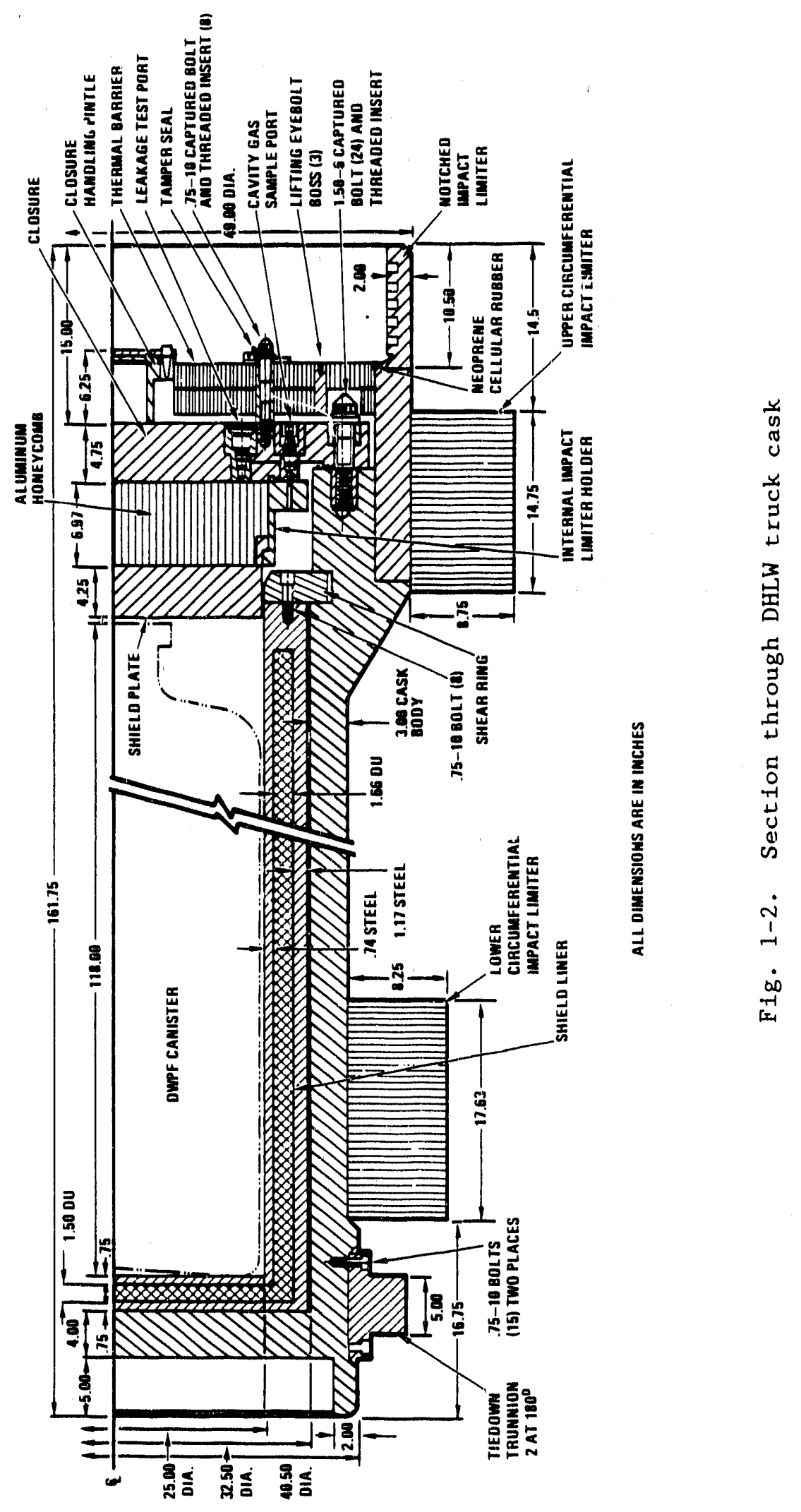


The closure assembly, which is part of the containment boundary, consists of a $12.07-\mathrm{cm}(4.75-\mathrm{in}$.) thick stainless steel plate that Includes a double 0-ring seal, a leak test port, and a gas sample port. It is secured to the cask body by 24 captured Inconel 718 bolts. An Internal aluminum honeycomb impact limiter assembly bolted to the inner face of the closure limits the load transmitted to the closure and closure bolts during a $9-m(30-f t)$ free drop onto an unylelding surface.

The stainless steel honeycomb thermal barrier protects the elastomer 0-ring seals in the closure from excessive temperatures during the hypothetical accident condition thermal event. The thermal barrier is bolted to the outside of the closure.

\subsection{APPROACH TO STRUCTURAL DESIGN VERIFICATION}

The DHLW design presents the opportunity to use aid analytical approach that differs from traditional cask designs with "soft" impact limiters such as foan or wood. Designers use simplifled methods to analyze the impact loading on these traditlonal casks. The base the Impact limiter loading on the load-deflection curves which are calculated using tests or known material properties. The casks are designed so that the impact limiters absorb all the free drop kinetic energy and the cask containment boundary remains within the USNRC Regulatory Guide 7.6 elastic allowables. This approach requires the use of soft impact limiters which deliver low g-levels. The thick-walled DHLW cask and impact limiter designs are unique and offer a new approach to packaging design and analysis. The notched stalnless steel impact limiter at the closure end of the cask, the stainless steel ring impact limiters at the bottom of the cask, and the honeycomb circumferential impact limiters at the top and bottom of the cask absorb energy through plastic deformation or crushing. The notched and honeycomb impact 1 imiters limit the decelerations during a free drop so that the containment boundary stresses remain within elastic allowables in the walls and closure end. However, the ruggedness of the cask allows for a much more 
rigld lower end ring impact limiter. It develops relatively ingh decelerations during the free drops which result in localized stresses at the lower end of the cask, far removed from the primary seals, that exceed elastic stresses. The stres'ses in the cask away from the seal area were compared against structural criterla developed from the ASME Code Section III, Division 1, Appendix F. The seal area was required to remain below plasticity so that the leakage criterion could be met. Half-scale model testing confirmed the acceptability of this design approach. Even though high $g$-levels were produced during the bottom end drops, there were no sifnificant deformations of the containment boundary and even multiple diops in the bot.tom end did not compromise the integrity of the cask. Since the post-elastic behavior of the impact limiters is much more complex than the traditional "soft" impact limiteis, GA utilized inelastic analysis as well as elastic analysis and half-scale testing to validate the design. GA used Inelastic analyses to develop deformations, decelerations, and stresses in the cask for the 1- and 30-ft drop loading as reported in Ref. 1-1 (references are listed in Section 6). The Inelastic analysis modeled the post-elastic behavior of the lower end and notched Impact limiters as well as the cask body.

GA also performed a more traditional elastic analysis using impact limiter load-deflection curves based on scale model tests performed at SNL. GA used the GA Cask Analysls Program (GACAP), an elastic two-dimensional, lumped-mass, single axis beam representation of the cask, to analyze free drops at different heights and angles (Ref. 1-2). The stresses in the cask were compared against the USNRC Regulatory Guide 7.6 elastic allowables.

GA planned a half-scale model testing program and SNL procured the model and performed the tests. Tests were performed for the $9-\mathrm{m}(30-\mathrm{ft})$ free drop and the $1-m(40-i n$.$) puncture tests. The tests confirmed that$ the DHLW cask meets the safety requirements of TIt le 10 of the Code of Federa1 Regulations Part 71 (10CFR71). 
During the half-scale test program the DHLW cask model was severely tested by performing multiple 9-ri $(30-f t)$ drops without replacing the lower end Impact limiter. The same lower end impact IImiter was tested during a bottom end drop, a CG over bottom corner drop and a 10 deg slapdown with the lower end circumferential impact limiter removed. There was no damage to the contalnment boundary. This demonstrates that the lower end impact limiter and containment boundary are robust, have large margins of safety, and can withstand extra-regulatory events.

\subsection{SUMMARY OF ANALYSES AND TESTS}

Sections 2, 3, and 4 describe in detall the inelastic and elastic analyses and the half-scale model tests, respectively. The results of the analyses and tests show that the cask meets 10CFR71 accident condition relfuirements. The inelastic analyses show that the stresses in the cask meet the inelastic stress criterla outlined in Section 2.1 .1 of this report. In addition, the elastic analyses show that the elastically computed stresses meet the USNRC Regulatory Guide 7.6 elastic stress criterla except for a local area at the bottom of the cask far removed from the seal area. The half-scale test results confirmed the safety of the cask for the $9-m(30-f t)$ free drop and puncture drop. Selected results are compared to confirm that both analytical methods conservatively verify the structural adequacy of the design.

Table 1-1 summarizes comparisons of several parameters between the inelastic and elastic analyses and the half-scale model test results. Following is a description of the comparisons for each parameter.

\section{G Leve1s}

The results show good comparison between the accelerations obtained by test and elastic and inelastic analyses. The cask body accelerations are summarized in Table 1-1. The differences were expected and 


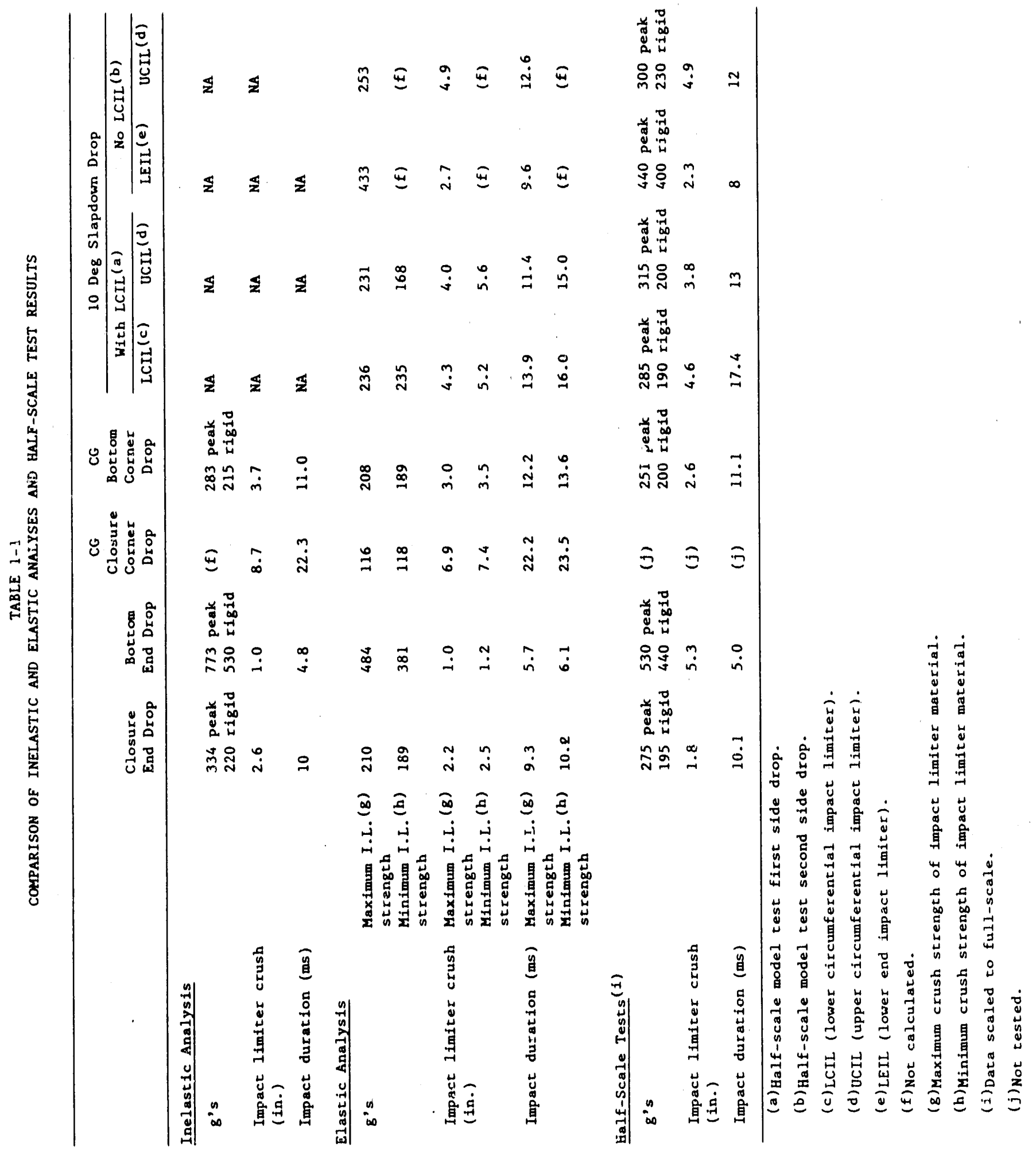


explained as follows: the inelastic analysis and test acceleration information were filtered at the same full-scale frequency $(1000 \mathrm{~Hz})$, but still contain high frequency accelerations in addition to the rigid body acceleration, which produce temporary peaks. These temporary peaks are caused by ringing, chattering, and wave propagation. The elastic analys.s $g$ levels are rigtd body accelerations and therefore should be and ari less than the peak Inelastic analysis and half-scale test $g$ levels. In order to do a more valld comparison, we estimated the rigld body acielerations for the test and inelastic analyses by drawing a Iine through the rigid body portion of the curves as shown in Section 5 . 'able 1-1 shows that the rigld body test and Inelastic analys is g's compare well with the GACAP rigid body $g$ 's. The inelastic analysis $g$ levels are higher than the test $g$ levels because the analysis does not Include internal damping and friction that occur in the test.

\section{Impact Duration}

The definition of the impact duration reported in Table 1-1 is slightly different for each type of analysis and test. Test and inelastic analysis impact durations were deterained by measuring the width of the acceleration pulse. GACAP analysis impact durations were measured at the point of zero force on the impact limiter. In spite of the differences in the time definition, the times correlate closely. This Indicates that both the analyses and the test model have similar dynamic behavior.

\section{Impact Limiter Crush Deflection}

Comparisons in Table 1-1 show that the elastic and ineiastic analytical deformations are consistently larger than the measurements on al1 tests. Most of the deformation occurred in the area of the Impact limiters. The cask body deformations were minimal, and there was negligible deformation on the closure seal area as had been predicted by 
analysis. It was expected that the analysis would produce higher deformation than the test because the modeling of the contents was very conservative and there was no friction between interfaces and no material damping modeled in the analyses. These analytical assumptions are conservative because the energy of the drop cannot be absorbed by any other mechanism except displacement.

\section{Summary of Results}

Comparison of the half-scale test results with the inelastic and elastic analyses results shows that there is good agreemenc un the alternate verification methods. The results show tiat the analytical approaches are conservative and that both inelastic and elastic analyses can be used to analyze a cask during the $9-m(30-f t)$ drop hypothetical accident events. Results also show that the inelastic structural criterla based on the ASME Code can be used for the containment boundary away from the sealing surfaces and results in a safe cask.

The exhaustive analyses and tests performed on the DHLW cask with its compact integral impact limiters show that the design is rugged and safe. Multiple tests without replacing impact limiters demonstrate that the cask has a substantial margin of safety. As described in Section 2, the thick contalnment boundary wall offers added safety, since the austenitic stalnless steel can absorb large amounts of energy when subjected to extra-regulatory events. 


\section{INELASTIC ANALYSIS}

2.1. STRUCTURAL CRITERIA

\subsubsection{Description}

The criteria for inelastic analysis are based on Appendix F, Subparagraph F-1341.2 of the American Society of Mechanical Engineers Boller and Pressure Vessel Code (ASME Code), Section III, Division 1 , Rules for Construction of Nuclear Power Plant Components. These cr1teria prevent ductile rupturing, tearing, and shearing. The stress allowables shown in Table 2-1 were reduced from those permitted by the ASME Code using the method developed by Cooper for the Nuclear Power Division of the Electric Power Research Institute to prevent the posslbility of two-dimensional plastic Instability (Ref. 2-i). The ASME criteria were modified by requiring that the stresses in the seal area remain below yleld. This criterion ensures that the cask leakage criterion is met.

The Inelastic criteria were designed to be applied to large deformation, true-stress, true-strain, Inelastic analysis. Since truestresses are produced when using finfte element analyses, rather than engineering stresses, the stress allowables were transformed as required by Subparagraph F-1322.2 (b) of Appendix F of the ASME Code.

The results of these calculations, as described in Section 2.1.2, show the stress allowables to be lower than ASME values by $9.9 \%, 8.3 \%$, and $1.5 \%$ on meluirane plus bending, primary membrane, and primary shear, respectively.

The criteria are conservatively based on an externally applied load rather than capacity to absorb energy. The critical loadings of the 
TABLE 2-1

CONTAINMENT BOUNDARY ALLOWABLE STRESSES FOR ELASTIC-PLASTIC ANALYSIS

\begin{tabular}{ll}
\hline \multicolumn{1}{c}{ Stress Category } & Accident Conditions \\
\hline Primary membrane stress intensity & $\mathrm{S}_{\mathrm{y}}+1 / 3\left(\mathrm{~S}_{\mathrm{uT}}-\mathrm{S}_{\mathrm{y}}\right)$ \\
Primary membrane + bending stress intensity & Greater of $0.7 \mathrm{~S}_{\mathrm{uT}}$ \\
& $\mathrm{S}_{\mathrm{y}}+1 / 3\left(\mathrm{~S}_{\mathrm{uT}}-\mathrm{S}_{\mathrm{y}}\right)$ \\
Bearing stress & $\mathrm{S}_{\mathrm{y}}$ for seal surfaces \\
Pure primary shear stress & $\mathrm{S}_{\mathrm{uT}}$ elsewhere \\
Bolt - membrance stress & $0.31 \mathrm{~S}_{\mathrm{uT}}$ \\
& Lesser of $\mathrm{S}_{\mathrm{y}}$ and \\
Bolt - membrane + bending stress & $0.7 \mathrm{~S}_{\mathrm{u}}$ \\
\hline
\end{tabular}

$S_{y}=$ Yleld stress.

$\mathrm{S}_{\mathrm{uT}}=$ U1timate true stress. 
cask occur during the free drops, and therefore the impact limiters and the cask body are designed to absorb impact energy through plastic strain. Consequently, the true measure of the conservatism of the criteria is not the peak stress that occurs but rather the amount of energy that the cask can absorb through plastic strain. Figure 2-1 presents the stress-strain curve for the cask body material based on test data, the stress-strain curve used in the analysis, the maximum stress permitted by the criteria, the maximum allowable strain energy, and the maximum available strain energy. As shown in the figure, the energy that the cask absorbs is limited by the criteria to less than $5 \%$ of the capacity of the material. The stress criteria are also conservative in that they do not treat compressive stresses differently than tensile stresses. The energy required to rupture the cask by compressive forces is much greater than the energy required to rupture the cask by tensile forces.

\subsubsection{Comparison of GA and ASME Code Inelast1c Allowables}

The analytical computer codes used for the inelastic analysis generate true stresses and strains. Therefore, in order to compare these stresses with allowables, we converted the engineering allowables to true stress allowables using the following equations:

$$
\begin{aligned}
& \sigma_{t}=\sigma(1+\epsilon), \\
& \epsilon_{t}=\ln (1+\epsilon), \\
& \sigma=\sigma_{t} /(1+\epsilon), \\
& \epsilon=e^{\epsilon_{t}}-1 .
\end{aligned}
$$

$A=$ mentioned in Section 2.1.1, we reduced the stress allowables to prevent the posstbility of two-dimensional plastic instability. Following is a comparison of the GA and ASME Code Appendix F allowables. 


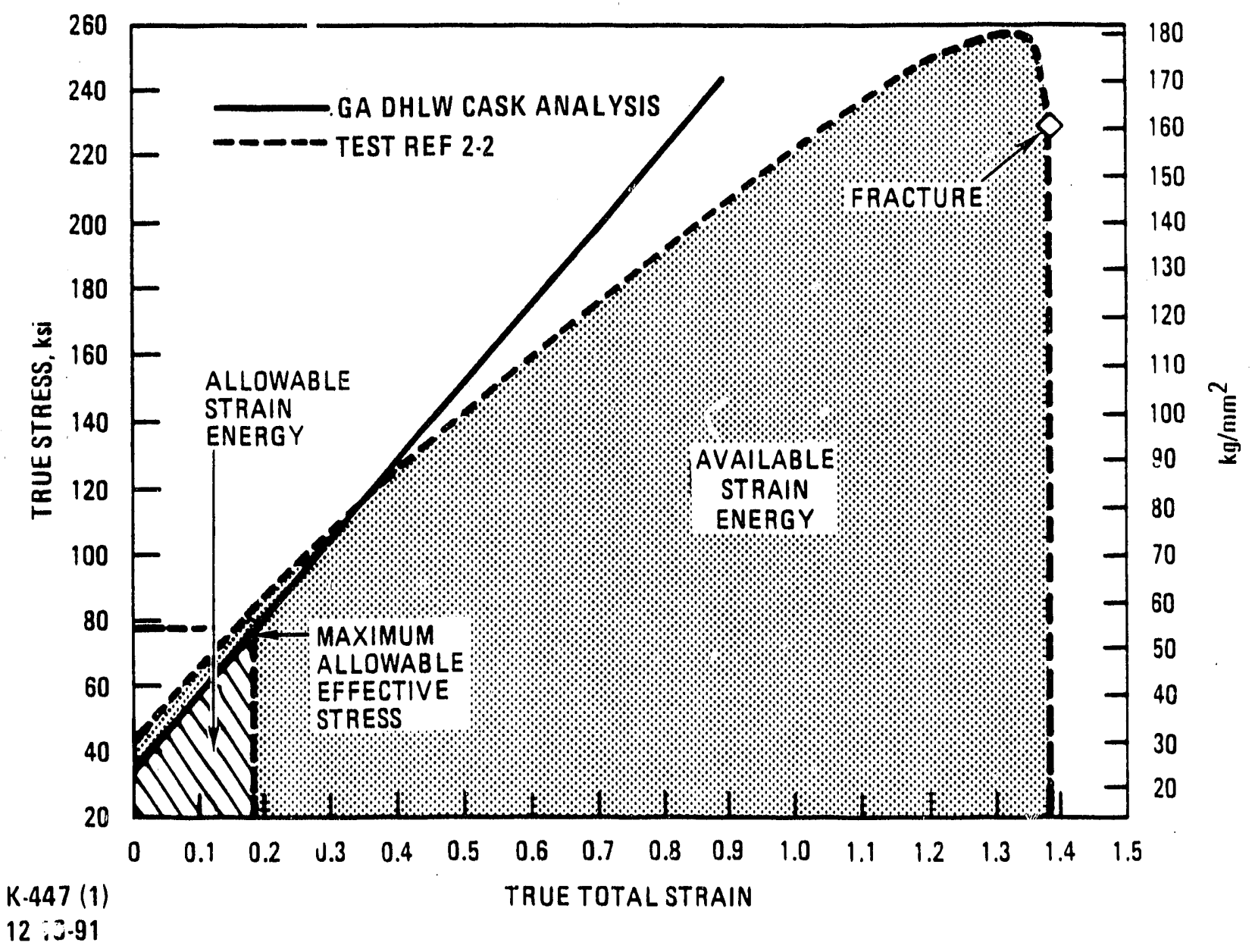

rig. 2-1. Allowable strain energy 


\section{Primary Membrane Plus Bending:}

ASME. Allowable $=0.9 \mathrm{~S}_{\mathrm{u}}=65.34 \mathrm{ksl}$ (engineering) ,

where at $160^{\circ} \mathrm{F} \mathrm{S}=\sigma_{\mathrm{u}}=72.6 \mathrm{ks} 1$.

GA. Allowable $=0.7 \mathrm{~S}_{\mathrm{ut}}=71.12 \mathrm{ks}$ (true) $=\sigma_{\mathrm{t}} /(1+\epsilon)$

$=71.12 /(1+0.20867)=58.84 \mathrm{ks} 1$ (englneering),

where at $160^{\circ} \mathrm{F} \mathrm{S}$ ut $=\sigma_{u t}=101.6 \mathrm{ksi}$,

$$
\begin{aligned}
\mathrm{S}_{\mathrm{y}} & =\sigma_{\mathrm{y}}=\sigma_{\mathrm{yt}}=27,000 \mathrm{ps} 1, \\
\mathrm{E} & =27.7 \times 10^{6} \mathrm{ps} 1, \\
\mathrm{E}_{\mathrm{t}} & =234,000 \mathrm{ps} 1, \\
\epsilon_{\mathrm{t}} & =\sigma_{\mathrm{y}} / \mathrm{E}+\left(\sigma_{\mathrm{t}}-\sigma_{\mathrm{y}}\right) / \mathrm{E}_{\mathrm{t}}, \\
& =(27,000) /\left(27.7 \times 10^{6}\right)+(71,120-27,000) /(234,000), \\
& =0.00097+0.18855=0.18952 \mathrm{in} . / \mathrm{ln} ., \\
\epsilon & =e^{\epsilon_{\mathrm{t}}-1}=0.20867 \mathrm{in} . / \mathrm{In} .
\end{aligned}
$$

Therefore, the GA allowable is $9.9 \%$ lower than the equivalent ASME code primary membrane plus bending allowable.

\section{Primary Membrane:}

ASME. Allowable $=0.7 \mathrm{~s}_{\mathrm{u}}=50.82 \mathrm{ks} 1$ (engineering) .

GA. Allowable $=S_{y}+\left(S_{u t}-S_{y}\right) / 3=51.87 \mathrm{ks} 1$ (true) $=\sigma_{t} /(1+\epsilon)$ $=51.87 /(1+0.11321)=46.59 \mathrm{ks} 1$ (engineering),

$$
\text { where } \begin{aligned}
\epsilon_{t} & =\sigma_{y} / E+\left(\sigma_{t}-\sigma_{y}\right) / E_{t}, \\
& =(27,000) /\left(27.7 \times 10^{6}\right)+(51,870-27,000) /(234,000), \\
& =0.00097+0.10628=0.10725 \mathrm{in} . / \mathrm{in} ., \\
\epsilon & =e^{\epsilon_{t}-1}=0.11321 \mathrm{in} . / \mathrm{in} .
\end{aligned}
$$


Therefore, the GA allowable is $8.3 \%$ lower than the equivalent ASME code primary membrane allowable.

\section{Primary Shear:}

ASME. Allowable $=0.42 \mathrm{~s}_{\mathrm{u}}=30.49 \mathrm{ks}$ (engineering) .

GA. Allowable $=0.31 \mathrm{~S}_{\mathrm{ut}}=30.50 \mathrm{ksi}$ (true) $=\sigma_{t} /(1+\epsilon)$

$=30.50 /(1+0.01606)=30.02 \mathrm{ksi}$ (englneering),

$$
\text { where } \begin{aligned}
\epsilon_{\mathrm{t}} & =\sigma_{\mathrm{y}} / \mathrm{E}+\left(\sigma_{\mathrm{t}}-\sigma_{\mathrm{y}}\right) / \mathrm{E}_{\mathrm{t}} \\
& =(27,000) /\left(27.7 \times 10^{6}\right)+(30,500-27,000) /(234,000), \\
& =0.00097+0.01496=0.015932 \mathrm{in} . / \mathrm{in} . \\
\epsilon & =e^{\epsilon_{\mathrm{t}}-1}=0.01606 \mathrm{in} . / \mathrm{in} .
\end{aligned}
$$

Therefore, the GA allowable is $1.5 \%$ lower than the equivalent ASME code primary shear allowable. These comparisons show that the allowables used in these analyses are conservative compared to the ASME code approach for pressure vessels.

\subsection{ANALYTICAL METHODS}

\subsubsection{General Methodology}

Nonlinear finite element computer programs were used to perform inelastic analyses of the DHLW cask for the 10CFR71 hypothetical accident condition 30-ft free drop. They use true stress and large displacement analysis that accounts for the increased cross section of the crushed area due to large deformation of the notched and lower end impact limiters. The DU was modeled as an elastic mass which does not contribute significantly to the structural strength of the cask. The programs used to analyze the cask are HONDOII (Ref. 2-3) and DYNA3D (Ref. 2-4). These codes are in the public domain and are widely used and accepted. HONDOII was used to analyze the closure end and bottom 
end $9-m(30-f t)$ drops. DYNA3D was used to analyze the center of gravity (CG) over bottom and closure corner drops.

\subsubsection{Two-Dimensional HONDOII Finite Element Analysis}

The HONDOII code is an explicit finite element code used for analyzing the large deformation dynamic response of axisymmetric solids. The equations of motion are Integrated by the central difference method. The code continuously monitors time step size and adjusts it to keep the calculation stable.

Four node isoparametric quadrilateral elements were used in the analyses. Each element has four integration points. The code contains five material models. The analyses used the finite strain elasticplastic material model with strain hardening and the crushable foam model. The pertinent structural features of the cask were built into a two-dimensional finite element model. HONDOII uses slidelines which represent boundaries between components that can allow intercomponent gaps to close and/or components to slide past each other but prevent submeshes from penetrating each other. To define these interfaces for HONDOII input, numbers of the nodes along the interface from each of the sliding meshes must be listed along with the backup node number of the node directly behind (orthogonal to) the node along the slideline. HONDOII uses the penalty function slideline definition. The slidelines work by applying a restoring force to those nodes along a sliding interface rhich have penetrated the slideline. The force is calculated using the restoring force moduli assigned to each side of the slideline.

The valldity of the HONDOII results were checked in several ways. The following characteristics of the cask were studied:

- Kinetic energy.

- Deformation.

- Component periods.

- Stress chect. 
Kinetic energies of the cask were checked to make sure that mass and velocity input were correct.. A check of HONDOII deformation plots showed reasonable deformations and showed only slight penetration of submeshes at boundaries where the restoring force moduli of the two sides were of different magnitudes. This indicates that the sliding interface data is correct. Time history plots of effective, axial, radial, hoop, and shear stresses showed no unusual or discontinuous results.

Another check on HONDOII operation involved finding the decelerations and natural perfods of selected nodes for varfous components in the cask system. Predicted natural frequencles of thick circular plates were compared to actual frequencies (obtained from graphical results) in the closure and bottom plate. The theoretical and predicted values were close in magnitude and confirm the proper operation of the HONDOII code.

In addition, the stresses were checked using simplifled strength of material calculations. This method confirms that the general behavior of the cask is correct.

Data Reduction. To find the primary membrane stress intensity $\left(P_{m}\right)$ for a critical section, the radial, axial, hoop, and shear stress components were averaged individually for all elements along the critical section. Then, the effective stress (Von Mises) of the averaged components was calculated as a function of time. The effective stress is defined by Eqs. 2-1 or 2-2. This primary membrane stress intensity definition follows the guidelines of the ASME Code, NB-3221.1, NB-3221.2, and Appendix F-1322.3(d) (Ref. 2-5). The maximum primary membrane stresses were compared to allowables to determine the acceptablitty of the design.

$$
\begin{aligned}
\sigma_{e f f} & =\frac{1}{\sqrt{2}}\left[\left(\sigma_{1}-\sigma_{2}\right)^{2}+\left(\sigma_{2}-\sigma_{3}\right)^{2}\right. \\
& \left.+\left(\sigma_{3}-\sigma_{1}\right)^{2}\right]^{1 / 2},
\end{aligned}
$$


which becomes

$$
\begin{aligned}
\sigma_{e f f}= & \frac{1}{\sqrt{2}}\left[\left(\sigma_{r}-\sigma_{z}\right)^{2}+\left(\sigma_{z}-\sigma_{\theta}\right)^{2}\right. \\
& \left.+\left(\sigma_{\theta}-\sigma_{r}\right)^{2}+6 \tau_{r z}{ }^{2}\right]
\end{aligned}
$$

in an axisymmetric state of stress,

where $\sigma_{1}, \sigma_{2}$, and $\sigma_{3}=$ principal stresses,

$\sigma_{r}, \sigma_{z}$, and $\sigma_{\theta}=\operatorname{radial}$, axlal, and hoop stress component.,

$$
\tau_{\mathrm{rz}}=\text { shear stress component. }
$$

Individual element time history plots of effective stresses and stress components were obtained. These plots were used to study areas of high stress in detall. The individual element effective stresses (Von Mises) were used as the primary local membrane plus bending stress intensities $\left(P_{1+b}\right)$. This definition is more stringent than the ASME Code NB-3221.3, because it includes secondary and peak stresses deve1oped at corners or discontinuities in the model. Equations 2-1 or 2-2 were used to calculate the stress intensities. The maximum stress in any element in the section was compared to allowables.

\subsubsection{Three-Dimensional DYNA3D Finite Element Analysis}

DYNA3D is an explictt, three-dimensional finite element code for analyzing the large deformation response of inelastic solids. The code employs constant stress eight node solid elements, and uses a central difference time integrator.

The DYNA3D analyses used the elastic-plastic strain hardening material model and the soll and crushable foam material model. DYNA3D uses slidelines to realistically model the drop event. 
Color or contour stress plots were used to display threedimensional stress or strain data from the DYNA3D analyses. These plots were used to locate the areas of high stress and to choose the critical sections that were studied in detail.

To find the primary membrane stress intensity $\left(P_{m}\right)$ for a critical section each of the stress components from all the elements in the section were averaged individually. Then, the effective stress (Von Mises) of these averaged stress components was calculated.

The Von Mises effective stress in three-dimensions is defined by Eq. 2-1. This equation becomes

$$
\begin{aligned}
\sigma_{\text {eff }}= & \frac{1}{\sqrt{2}}\left[\left(\sigma_{\mathrm{x}}-\sigma_{\mathrm{z}}\right)^{2}+\left(\sigma_{\mathrm{x}}-\sigma_{\mathrm{y}}\right)^{2}+\left(\sigma_{\mathrm{y}}-\sigma_{\mathrm{z}}\right)^{2}\right. \\
& \left.+6 \tau_{\mathrm{xy}}{ }^{2}+6 \tau_{\mathrm{xz}}^{2}+6 \tau_{\mathrm{yz}}{ }^{2}\right]^{1 / 2}
\end{aligned}
$$

where $\sigma_{x}, \sigma_{y}$, and $\sigma_{z}=$ stress components in $x, y$, and $z$ direction, respectively,

$\tau_{\mathrm{xy}}, \tau_{\mathrm{xz}}$, and $\tau_{\mathrm{yz}}=$ shear stress components.

The maximum primary membrane stresses were compared to allowables.

To find the primary local membrane plus bending stress intensity $\left(P_{1+b}\right)$, the effective stress (Von Mises) of the elements in each critical section was computed as a function of time. Equation 2-3 was used to compute the effective stresses. The maximum stress in any element in the section was compared with the allowable stresses.

\subsection{CASK 9-m $(30-f t)$ DROP ANALYSES}

\subsubsection{Nine-Meter $(30-\mathrm{ft})$ Bottom End Flat Drop Analys 1s}

2.3.1.1. Introduction. A two-dimenstonal finite element analysis of the cask was performed using HONDOII to determine if the containment. 
boundary of the cask can conservatively meet the structural criterla described in Section 2.1 .1 during a $9-\mathrm{m}(30-\mathrm{ft})$ bottom end flat drop. During this event, the lower impact limiter absorbs energy by deforming plastically. Since the cylindrical lower impact limiter has a solid 5-cm (2-in.) thick wall, the cask experiences high decelerations, causIng high stresses locally at the Interface between the ring Impact 1im1ter and the cask body. This is also a severe test for the buckling strength of the cask body.

The procedures used for this analysis are presented in Section 2.2 .2 .

The results of the analysis show that the contalnment boundary meets all of the design criteria and will not fall due to a 9-m (30-ft) bottom end drop.

\subsubsection{Mode1 Description.}

\section{$\underline{\text { Mesh }}$}

A two-dimensional finite element model was used for this analysis since the cask and the loading are axisymmetric. The mesh has 1504 nodes and 1070 four-node quadrilateral elements. Small elements (0.5-in. sides) are concentrated in the lower third of the cask body, shield liner, support cylinder, and closure. The model is shown in Figs. 2-2 and 2-3. Elements in noncritical locations were reasonably small with aspect ratios close to unfty to ensure steady shock wave propagation through the elements.

The following simplifying assumptions were made when developing the mode1:

1. Components, such as the trunnions, shear ring, circumferential Impact limiters, and the thermal barrier, were omitted because 


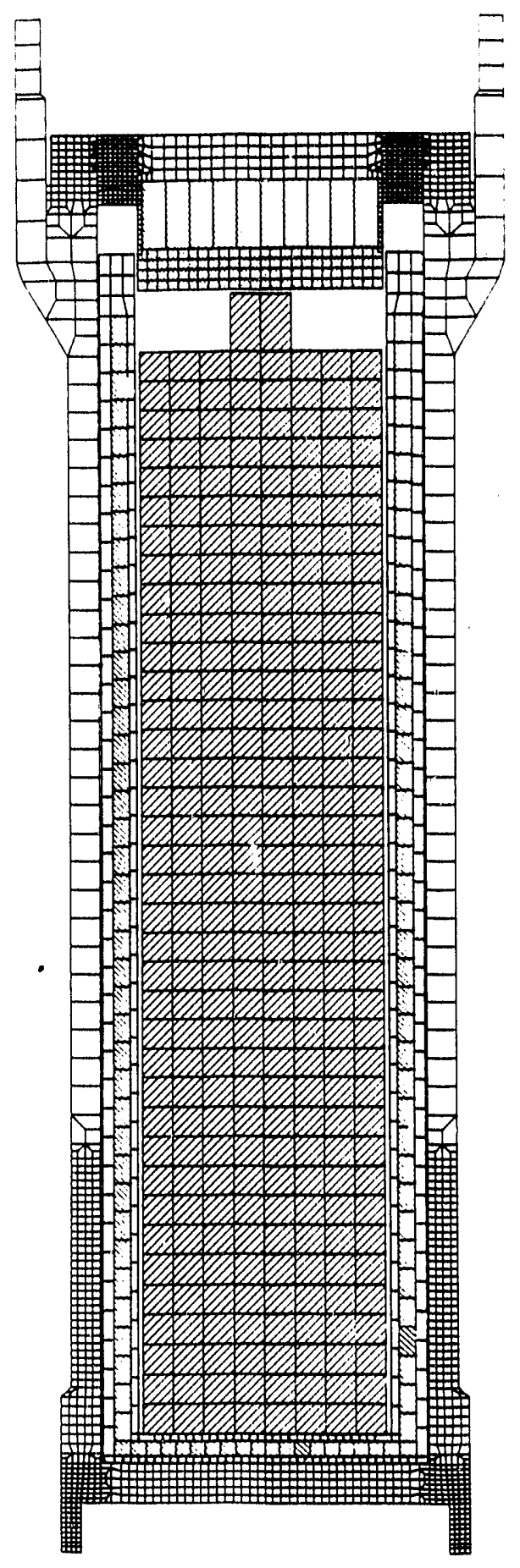

Fig. 2-2. DHLW two-dimensional bottom end drop, finite element model 


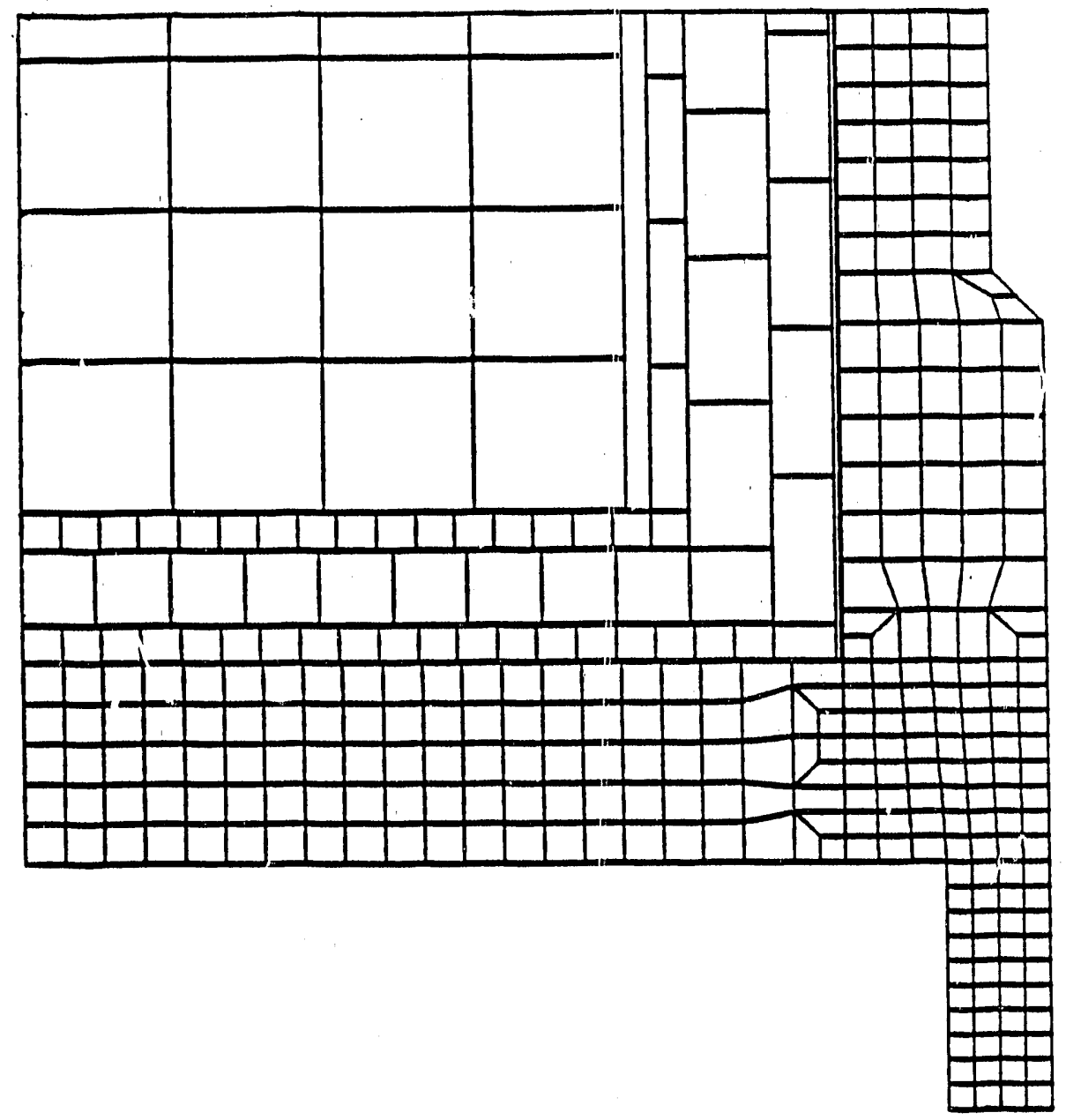

Fig. 2-3. DHLW two-dimensiona1 bottom end drop, bottom end of model shown 
they do not affect the dynamic response or loads delivered to contalnment boundary components.

2. The shield plate and support cylinder were modeled as one unit. This simplifled the model so that correct loads are delivered to the containment boundary.

3. The waste contents were assumed to behave perfectly elastically in order to not absorb energy. This is the most conservative case. The denstty was modeled so that the welght of the contents is $2495 \mathrm{~kg}(5500 \mathrm{lb})$ to envelop potential increase in glass density.

4. The reduced weight of the cask model due to omission of components mentioned in 1 above is compensated by increasing the density of stainless steel by $4 \%$, bringing the total weight. of the model to about $22,045 \mathrm{~kg}(48,600 \mathrm{lb})$ which is within $1 \%$ of the cask theoretical weight. This adjustment changes the stress wave propagation velocity in the model less than $2 \%$.

5. The closure bolts and the Internal impact limiter support cylinder bolts are modeled as rings with equivalent axial stiffness. The bolt element overlays elements of both the closure and flange of the cask body and shares some of the nodes on these elements. During this drop orientation the highest stresses in the bolts occur during the rebound of the cask from the unylelding target. However, the closure bolts are luaded moie sisverely during the closure end and CG over closure corner drop orientations than during the bottom end drop. This assumption was confirmed during the half-scale model tests.

6. The DU was modeled as an elastic material with no yleld point so that 1 would not absorb a significant amount of energy, 
but would provide a realistic load to the contalnment boundary. Since the DU bottom plate is only $4.5 \%$ as atiff in bendIng as the cask bottom plate, it essentlally acts as a nonstructural mass in loading the cask bottom plate.

\section{Boundary Conditions}

The cask is dropped onto an essentially unylelding surface. Since some amount of surface stiffness is required for proper mathematical functioning of the HONDOII code, a stiff spring constant is defined to describe the contact boundary. This rigid wall defintion functions so that all of the energy transmitted to the wall is returned to the body. Each of the nodes along the surface of impact is theoretically attached to a spring of a given constant as shown below:

$$
\begin{aligned}
& K_{b}=(0.9) M_{n} / \Delta t^{2}, \\
& K_{b}=3.45 \times 10^{8} \quad 1 b f / 1 n .
\end{aligned}
$$

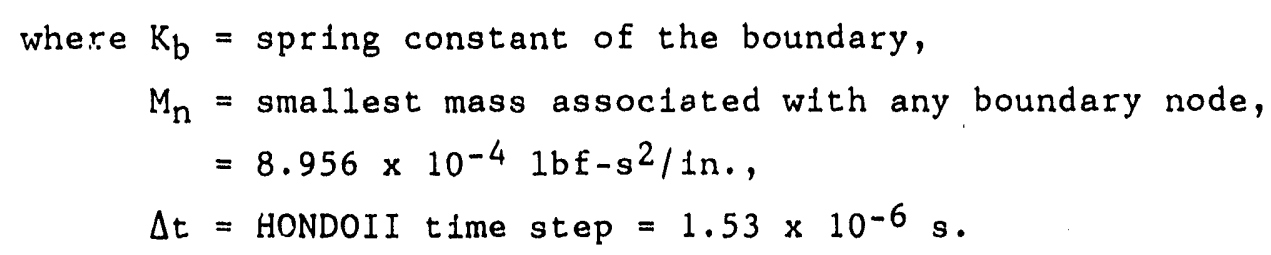

The other boundary condtion ts that there is no radial displacement for the nodes along the cask centerline, since the model is axisymmetric.

\section{Loads on Model}

The only loads on the cask result from the 9-m (30-ft) free drop. The inftial velocity at the time of impact is described by the following equation:

$$
v=(2 g h)^{1 / 2},
$$




$$
\text { where } \begin{aligned}
\mathrm{v} & =527 \mathrm{ln} \cdot / \mathrm{s}, \\
\mathrm{g} & =386 \mathrm{in} \cdot / \mathrm{s}^{2}, \\
\mathrm{~h} & =30 \mathrm{ft} .
\end{aligned}
$$

No internal pressure or thermal stresses were included.

2.3.1.3. Results. The results of the HONDOII analysis were studied to determine the response of the cask unciar this accident condition. A deformation plot is shown in Fig. 2-4. The HONDOII analysis w is run until minimum kinetic energy was reached at $5 \mathrm{~ms}$. Figure 2-5 shows the plots "global cask kinetic energy versus time.

\subsubsection{Containment Boundary - Ductile Rupture and Tearing. To} determine whether any part of the cask exceeds the criteria described in Section 2.1.1, several critical sections were chosen, based on color graphics contour plots. The location of the critical sections is shown in Fig. 2-6.

Table 2-2 sumnarizes the primary membrane and local membrane plus bending stresses for the critical sections in the contalnment boundary. All design criterla are met. The highest stresses that occur in the containment boundary are membrane stresses at the edge of the cask body bottom plate under the shielding sleeve. Figure 2-7 shows the membrane stress time history plot for the most critical section. The maximum membrane stress of $33 \mathrm{ksi}$ has a design margin of +0.57 . The highest local membrane plus bending stress (effective stresses) occurs at the inside corner between the cask body bottom plate and the cask body side wall. Figure 2-8 shows the effective stress time history plot for this element; the maximum effective stress of $61 \mathrm{ks} 1$ has a design margin of +0.17. It is conservative to compare this stress to the primary 1ucal membrane plus bending stress because it includes a stress concentration factor due to the corner effect. 


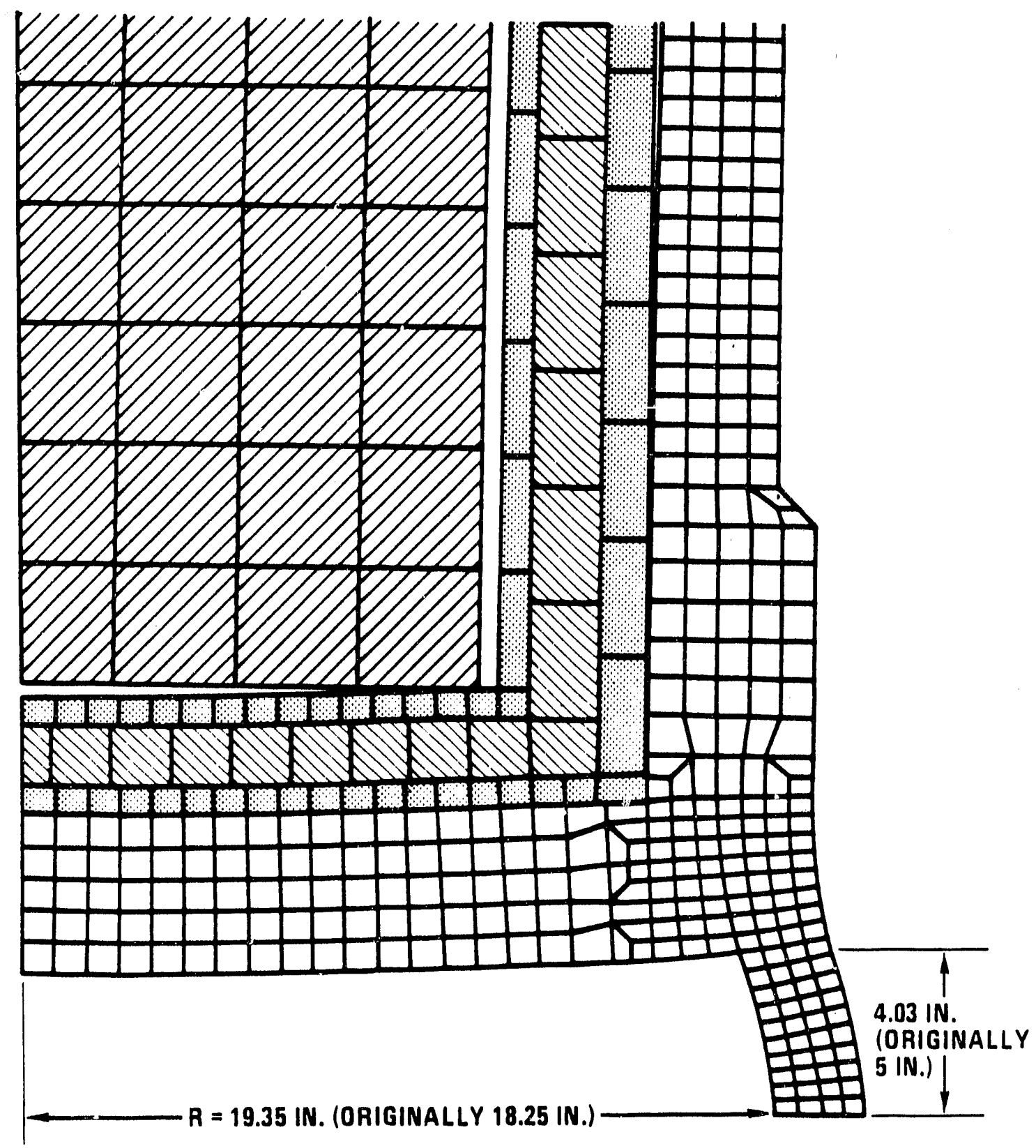

Fig. 2-4. Deformation of bottom end of cask during a 9-m (30-ft) bottom end drop $4.8 \mathrm{~ms}$ after inftial impact 


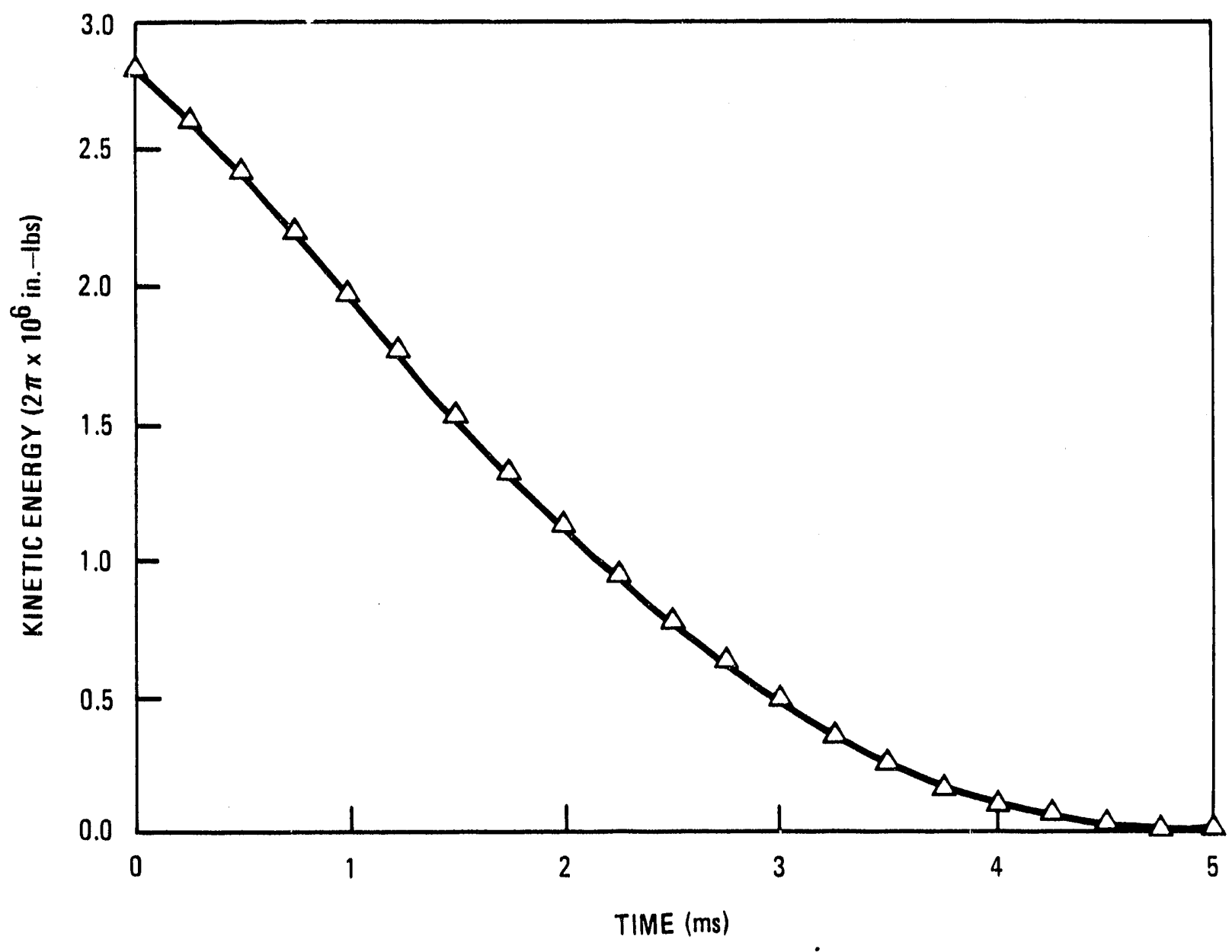

Fig. 2-5. Nine-meter (30-ft) bottom end drop analysis, kinetic energy versus time 


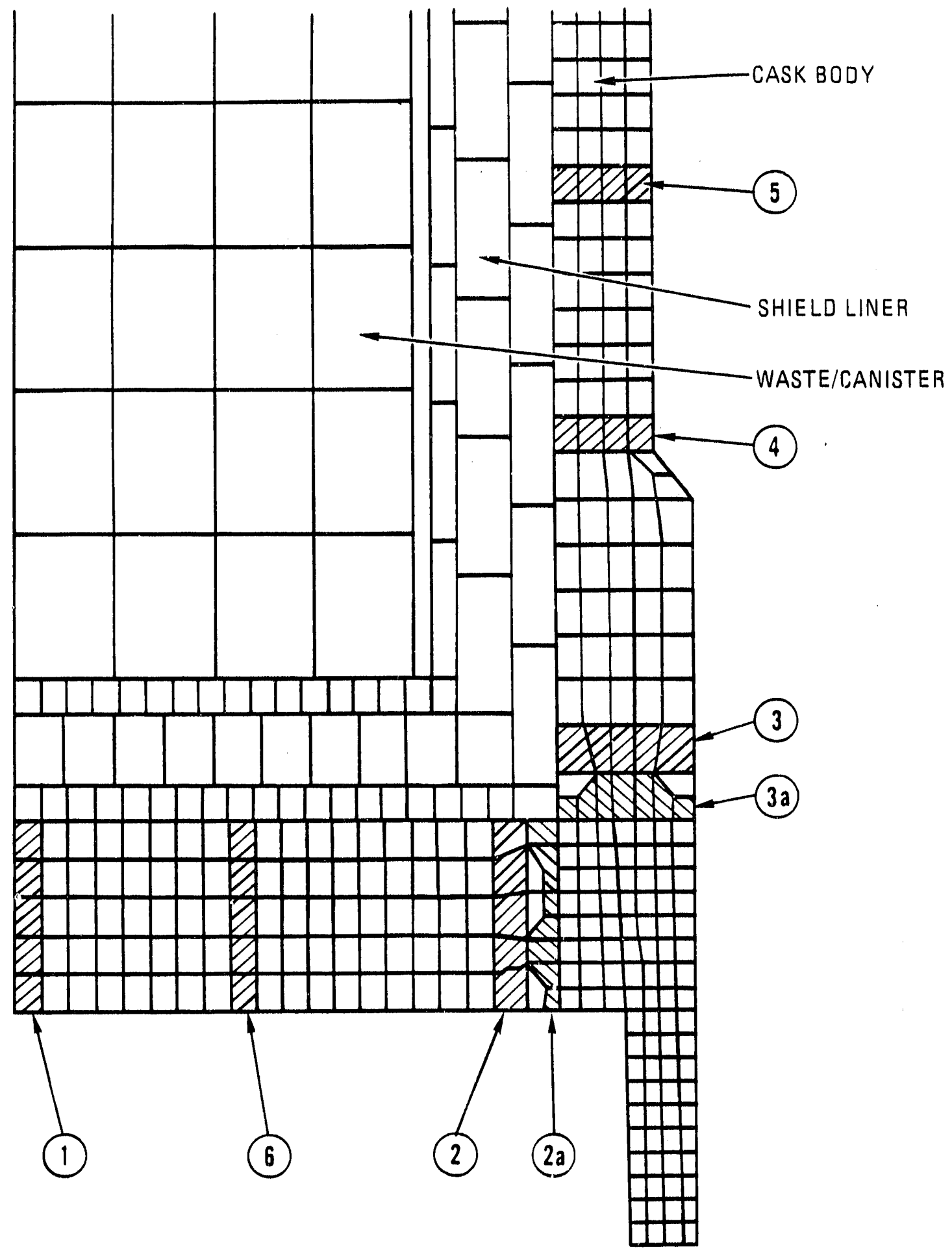

F1g. 2-6. Critical sections for DHLW bottom end 9-m (30-ft) drop 


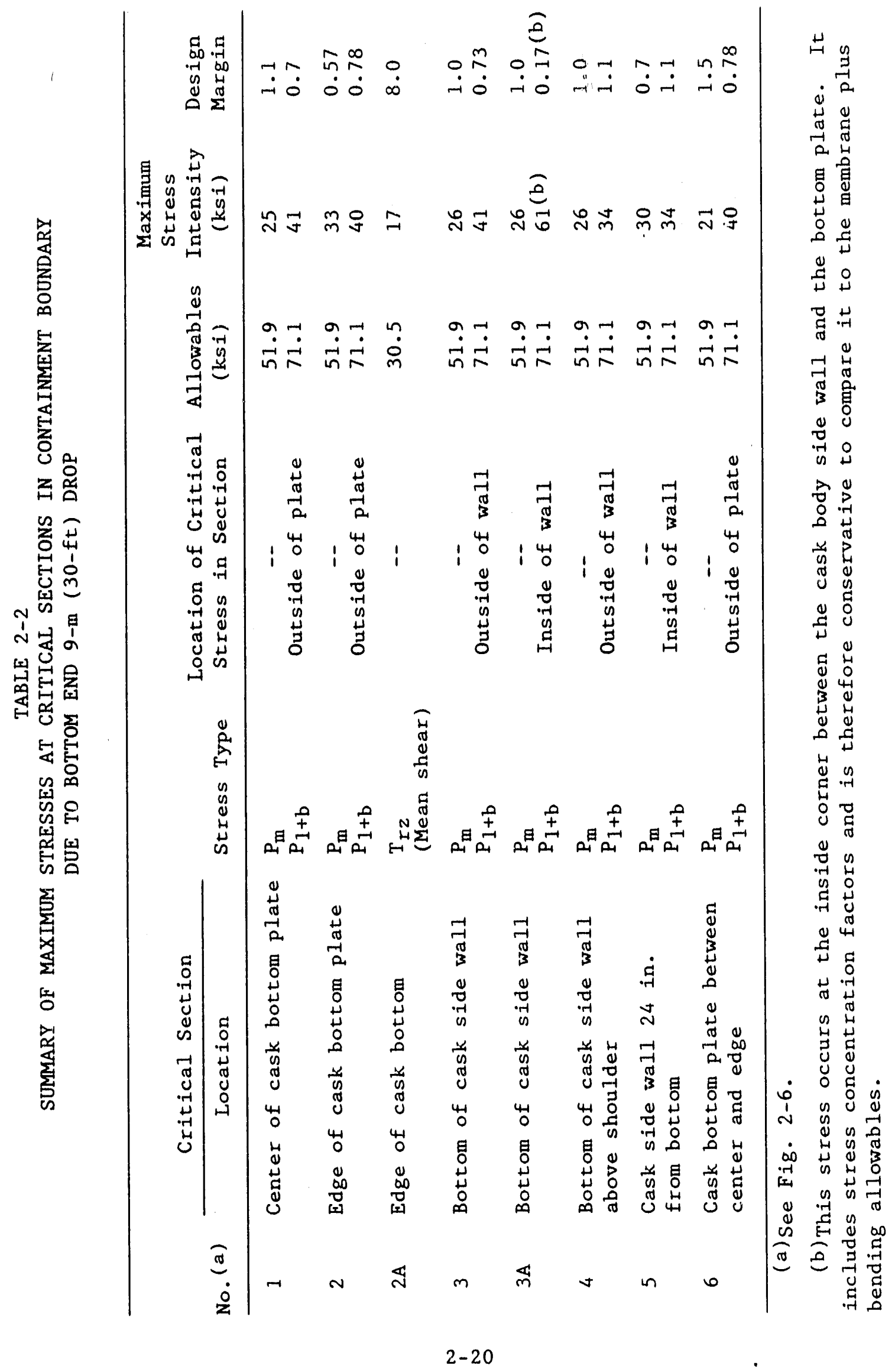




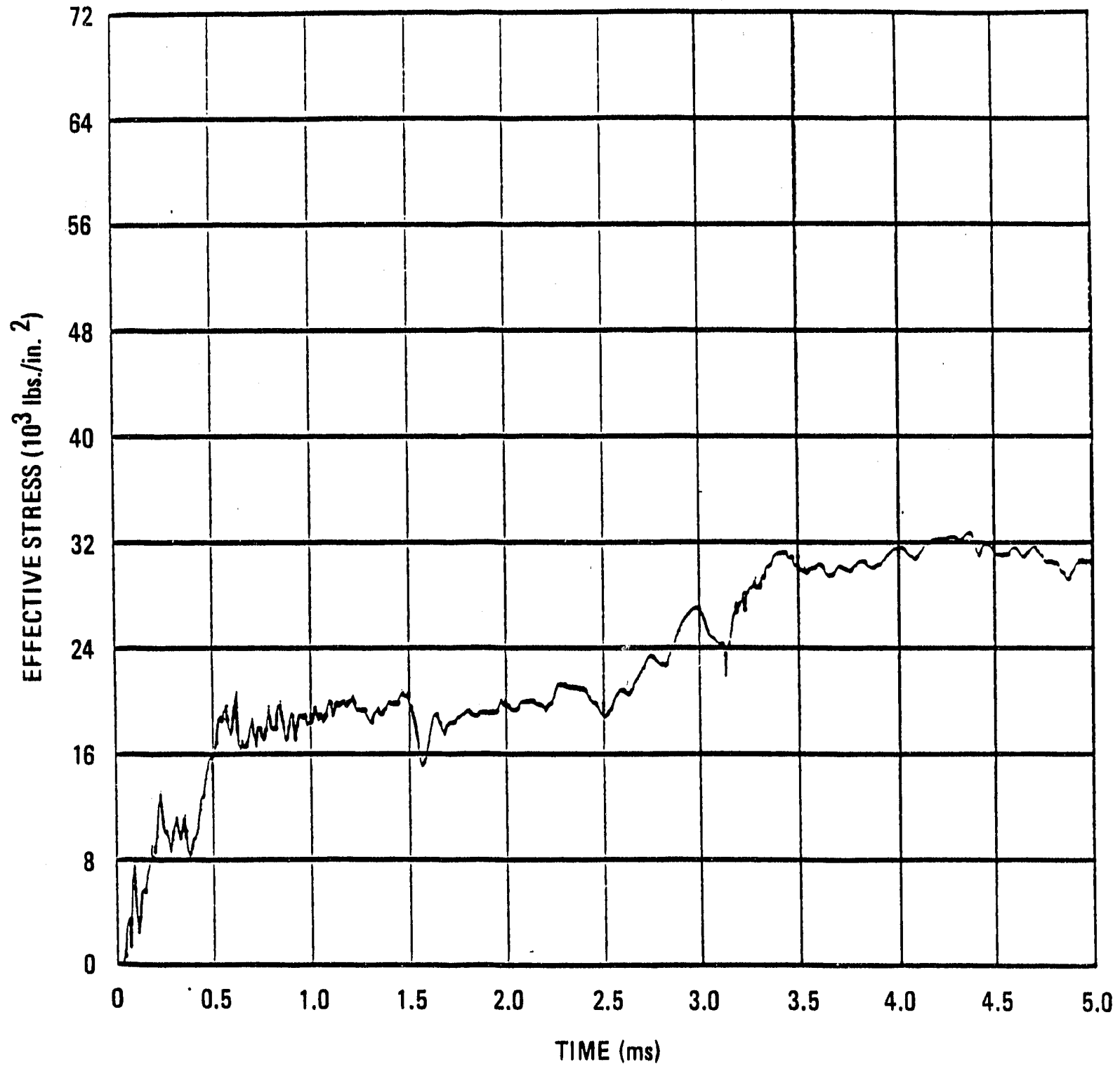

Fig. 2-7. DHLW 9-m (30-ft) bottom end drop primary membrane stress time history at the cask body bottom plate edge unier the shield liner. 


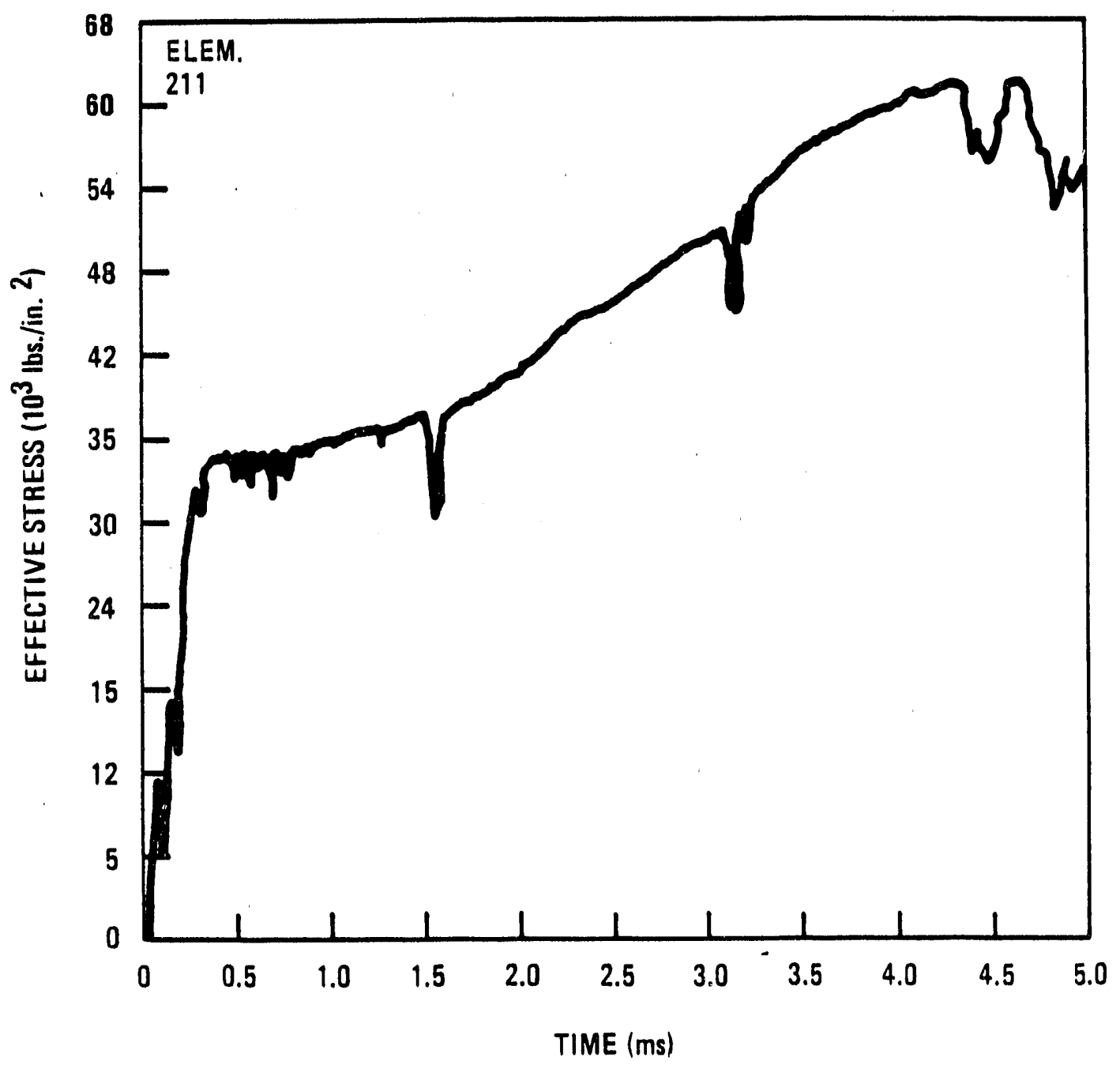

Fig. 2-8. DHLW 9-m (30-ft) bottom end drop time history of stresses in element with highest local membrane plus bending stresses (corner element between cask body bottom plate and cask body side, inside critical Section $3 \mathrm{~A}$ ) 


\section{Conclusions}

The DHLW cask was analyzed and was found to meet the structural design criteria for the hypothetical 9-m (30-ft) bottom end drop accident condition for all containment boundary components. The results of the HONDOII inelastic analysis at the critical section in the containment boundary showed maxtinum membrane plus bending stresses with a minimum design margin of 0.17 . This stress is the effective stress at the inside corner between the cask body bottom plate and the cask side wall. It includes the stress concentration of the corner and is therefore conservative. The maximum membrane stress occurs in the bottom plate with a minimum design margin of +0.57 . The cask ylelds only near the bottom impact limiter. The remainder of the cask remains elastic.

\subsubsection{Nine-Meter $(30-\mathrm{ft})$ Closure End Drop Analysis}

2.3.2.1. Introduction. The hypothetical accident event of a $9-\mathrm{m}$ $(30-f t)$ free drop of the DHLW shipping cask onto the closure end produces critical loads for the shear ring, closure plate, closure bolts, and closure seal. The cask impacts on the notched impact limfter which decelerates the cask in a controlled manner. The DWPF canister impacts the Internal honeycomb impact limiter, which in turn loads the closure plate and closure bolts and tends to open the closure seal. At the same time, the downward motion of the shield liner is restrained by the shear ring.

The HONDOII computer code was used to determine the stresses and deformations of the cask due to the $9-\mathrm{m}(30-\mathrm{ft})$ closure end drop. The methodology is discussed in Section 2.2.2.

The results of the analysis demonstrate that the cask and cask components meet all of the design criteria and will not fail due to a 9-m $(30-f t)$ closure end drop. 


\subsubsection{Mode1 Description.}

Mesh

The analysis was performed using the axisymmetric model shown in F1gs, 2-9 and 2-10. The mesh is made up of 11 submeshes, 1505 nodes, and 1079 four-node quadrllateral elements. Small elements are concentrated in the lower quarter of the model where the stresses are the highest. The minimum size of an element was chosen such that no element had a side which was less than $1.27 \mathrm{~cm}(0.5 \mathrm{in}$.). The integration time step was automatically calculated by HONDOII. Elements in noncritical locations were reasonably small and aspect ratios were close to unity to ensure steady shock wave propagation through the elements.

The following simplifications were made when developing the model:

1. Components, such as the trunnions and the thermal bartier, which do not have a structural role were omitted from the model. However, their masses were included in the model to ensure proper impact loads.

2. The waste content of the canfster was modeled as a perfectly elastic mass. This is conservative since 1 minimizes the energy absorbed by the waste contents and maximizes the loading on the internal impact limiter and closure. The neck of the waste canister is actually not rigid and deforms which reduces the loading on the internal impact limiter. The weight of the waste was modeled at $2495 \mathrm{~kg}$ ("5500 lb) to envelope any potential increase in glass density.

3. The 24 closure bolts (1.5-6 UNC), which hold the closure to the cask body, were modeled as a solid ring with the equivalent axial stiffness of the bolts and a reduced hoop stiffness. 


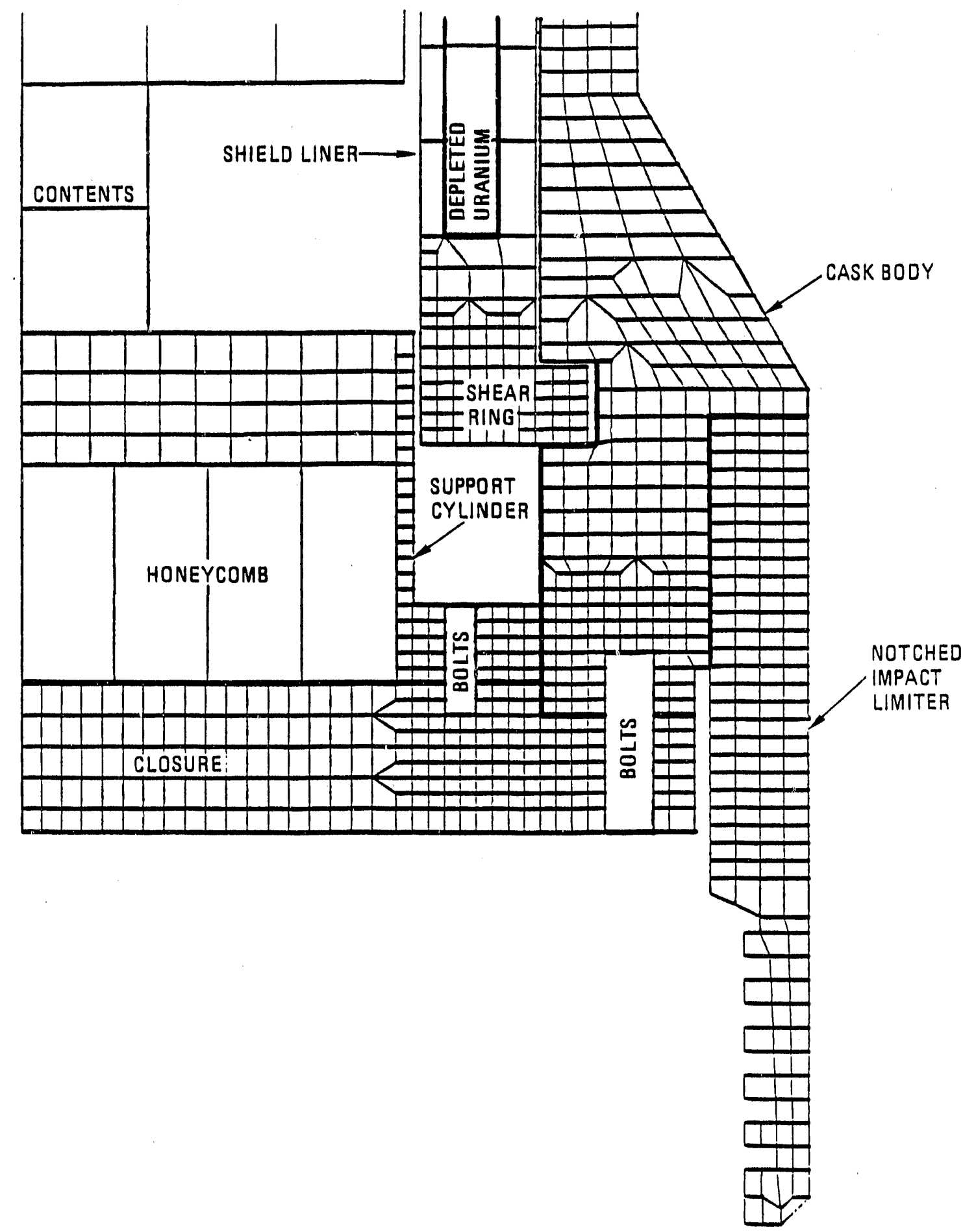

F1g. 2-9. Components of DHLW shipping cask 9-m (30-ft) clusure end analytical model 


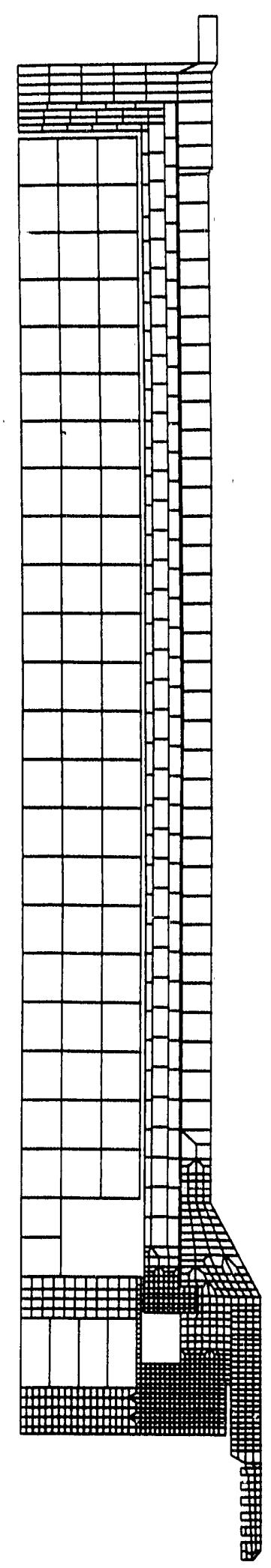

Fig. 2-10. Complete model used in $9-\mathrm{m}(30-\mathrm{ft})$ closure end drop analysis 
4. Shear Ring Modeling. The actual shear ring is sectioned to facilitate installation and, consequently, has no hoop stiffness. In the finfte element model, the shear $r$ ing is modeled as a continuous ring. To eliminate coupling between axial and hoop stresses, Polsson's ratio for the shear ring was set to 0.0 .

5. The lifting attachment was not modeled for this analysis. The omission of this feature does not significantly change the behavior of the cask during this event; the volume involved is small compared to the total notched impact limiter volume. The changes occur at the lower end of the notched part of the Impact limfter and Into the "thick" part of the limiter.

As shown by the analyses and test results, the drop energy is absorbed by plastic bending and closing of the first few notches in the impact 1imiter. In the test, as discussed in Section 4.3, only the first three notches closed up, while in this analysis four notches closed up. Adding the lifting attachment to the prototype adds material to the limiter; thus, the affected areas are not weakened and the behavior of the limiter is not affected significantly.

6. The circumferential impact limiters were not modeled. This omission does not change the analysis results because these limiters are not active during the closure end drop. The upper clrcumferential impact limfter is located well into the "thick" part of the notchod impact limiter where minimal deformations occur during the closure end drop. The total weight of the model was $21,910 \mathrm{~kg}(48,300 \mathrm{lb})$ which is within $1 \%$ of the cask theoretical weight.

7. The internal honeycomb impact limiter is modeled as a crushable foam or soll type element with a low shear mcidulus so 
that all crush loads are normal to the closure to simulate honeycomb behavior. The model assumes an elast1c, perfectly plastic load deflection curve with a maximum crush strength of 1060 psi.

\section{Boundary Cond1tions}

The essentially unyielding surface was modeled by a spring which is sufficlently stiff to represent the unyielding surface, but not so stiff that it causes numerical integration problems. The following equation ylelds a spring constant that meets these criterla. It was derived such that the spring constant produced causes the highest natural frequency associated with a boundary element to have a perfod that is at least six times longer than the integration time step that is automatically computed by HONDOII. This rigld wall definition functions so that all of the energy transmitted to the wall is returned to the body. The spring constant is shown below:

$$
\begin{aligned}
& K_{b}=(0.9) M_{n} / \Delta t^{2}, \\
& K_{b}=3.45 \times 10^{8} 1 \mathrm{~b} / \mathrm{in} .,
\end{aligned}
$$

where $\mathrm{k}_{\mathrm{b}}=$ spring constant of the boundary,

$$
\begin{aligned}
M_{n} & =\text { smallest mass associated with any boundary node, } \\
& =8.956 \times 10^{-4} \mathrm{lbf-s^{2 }} / \mathrm{ln} ., \\
J_{t} & =\text { HONDOII time step }=1.53 \times 10^{-6} \mathrm{~s} .
\end{aligned}
$$

The other boundary condition is that there is no radial displacement for the nodes along the cask centerline, since the model is axisymmetric. 


\section{Loads on Mode1}

The only loads on the cask result from the $9-m(30-f t)$ free drop. The Inftial velocity at the time of impact is described by the following equation:

$$
v=\sqrt{2 g h},
$$

$$
\begin{aligned}
& \text { where } \mathrm{v}=527 \mathrm{in.} / \mathrm{s} \text {, } \\
& \mathrm{g}=386 \mathrm{\textrm {n }} \cdot / \mathrm{s}^{2}, \\
& \mathrm{~h}=30 \mathrm{ft} \text {. }
\end{aligned}
$$

No Internal pressure or thermal stresses were included.

2.3.2.3. Results. The results of the HONDOII analysis were studied to determine the response of the cask under this accident condition. The HONDOII analysis was run until $91 \%$ of the kinetic energy had been absorbed at $10 \mathrm{~ms}$. As shown by the time history plot of the critical stress in Fig. 2-11, at this time the maximum stress values had already been attained.

\section{Impact Limiter}

The results of the HONDOII analysis show that the notched impact limiter performed as expected. Figures 2-12 through 2-15 show the deformation of the limiter as it decelerates the cask.

\section{Containment Boundary}

Ductile Rupture and Tearing. To determine whether any part of the cask exceeds the structural criteria described in Section 2.7.1, several critical sections were chosen, based on color graphic contour plots, as explained in Section 2.2.1. The locations of the critical sections are shown in Figs, 2-16 and 2-17. 
PRIMARY MEMBRANE STRESS FOR CASK NECK CAITICAAL SECTION 4

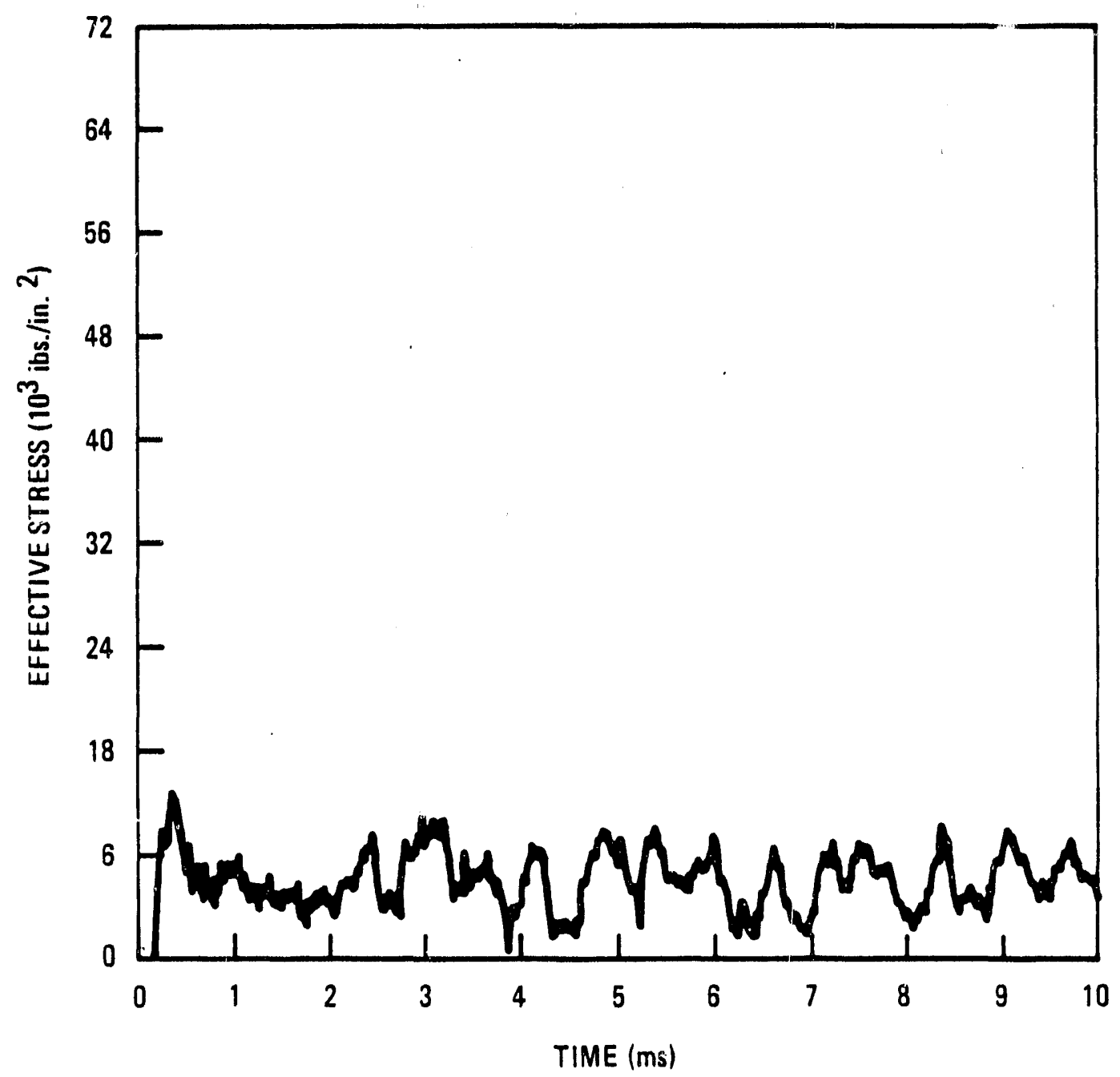

F1g. 2-11. Primary membrane stress for cask neck critical Section 4. (This section has the highest primary membrane stress in the cask.) 


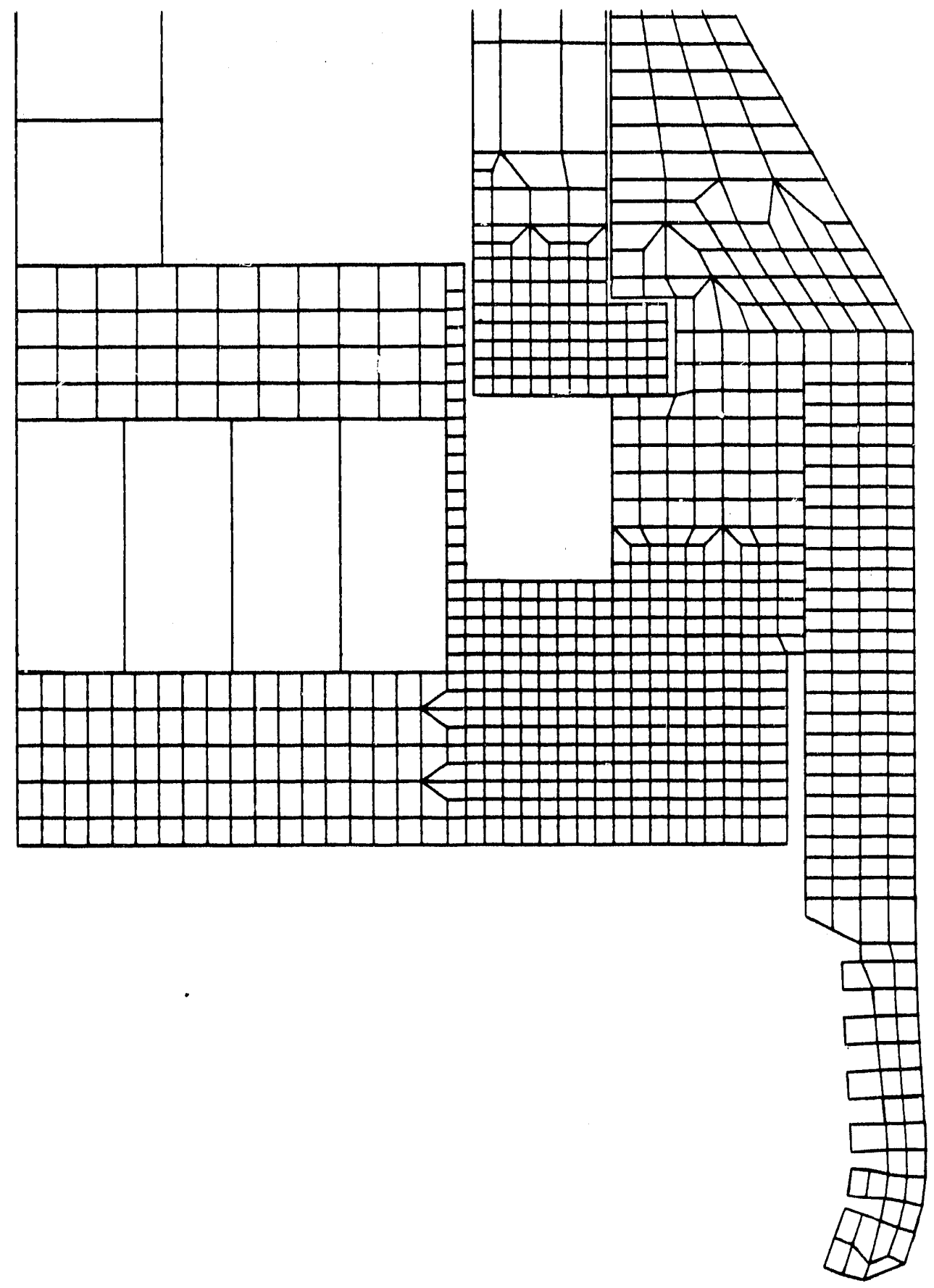

Fig. 2-12. DHLW two-dimensional closure end drop model at $1 \mathrm{~ms}$ 


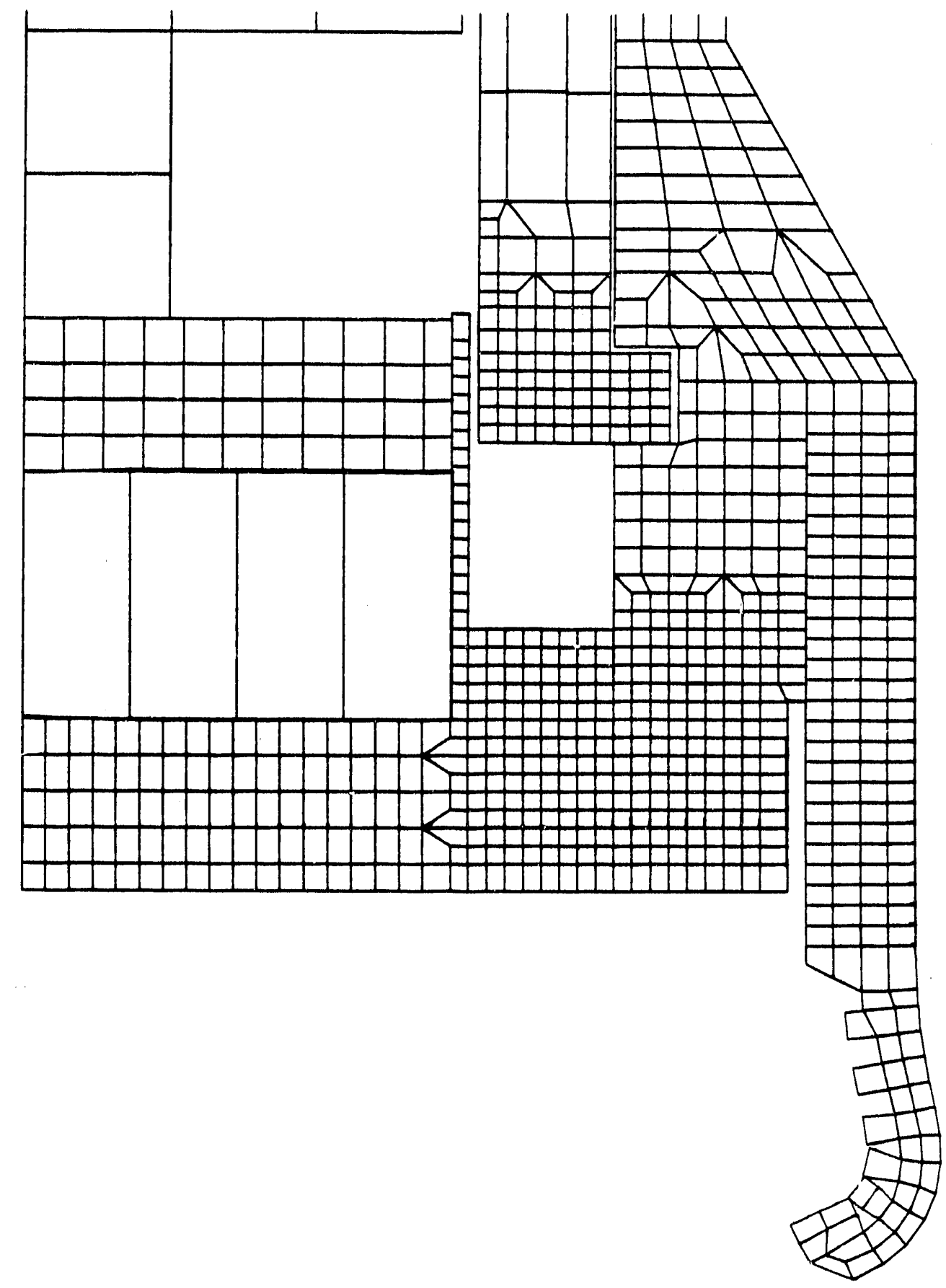

Fig. 2-13. DHLW two-dimensional closure end drop model at $4 \mathrm{~ms}$ 


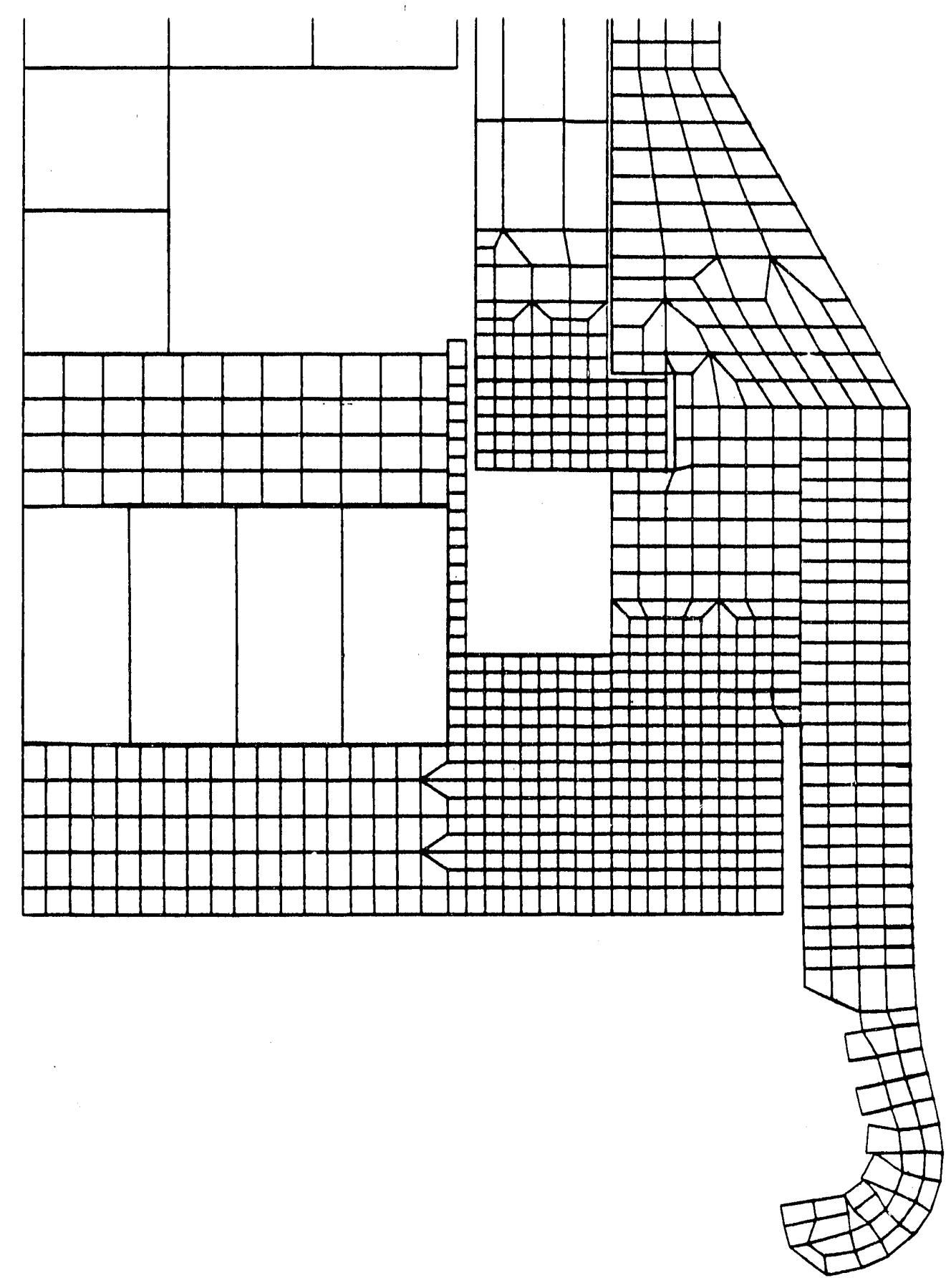

Fig. 2-14. DHLW two-dimensional closure end drop model at $6 \mathrm{~ms}$ 


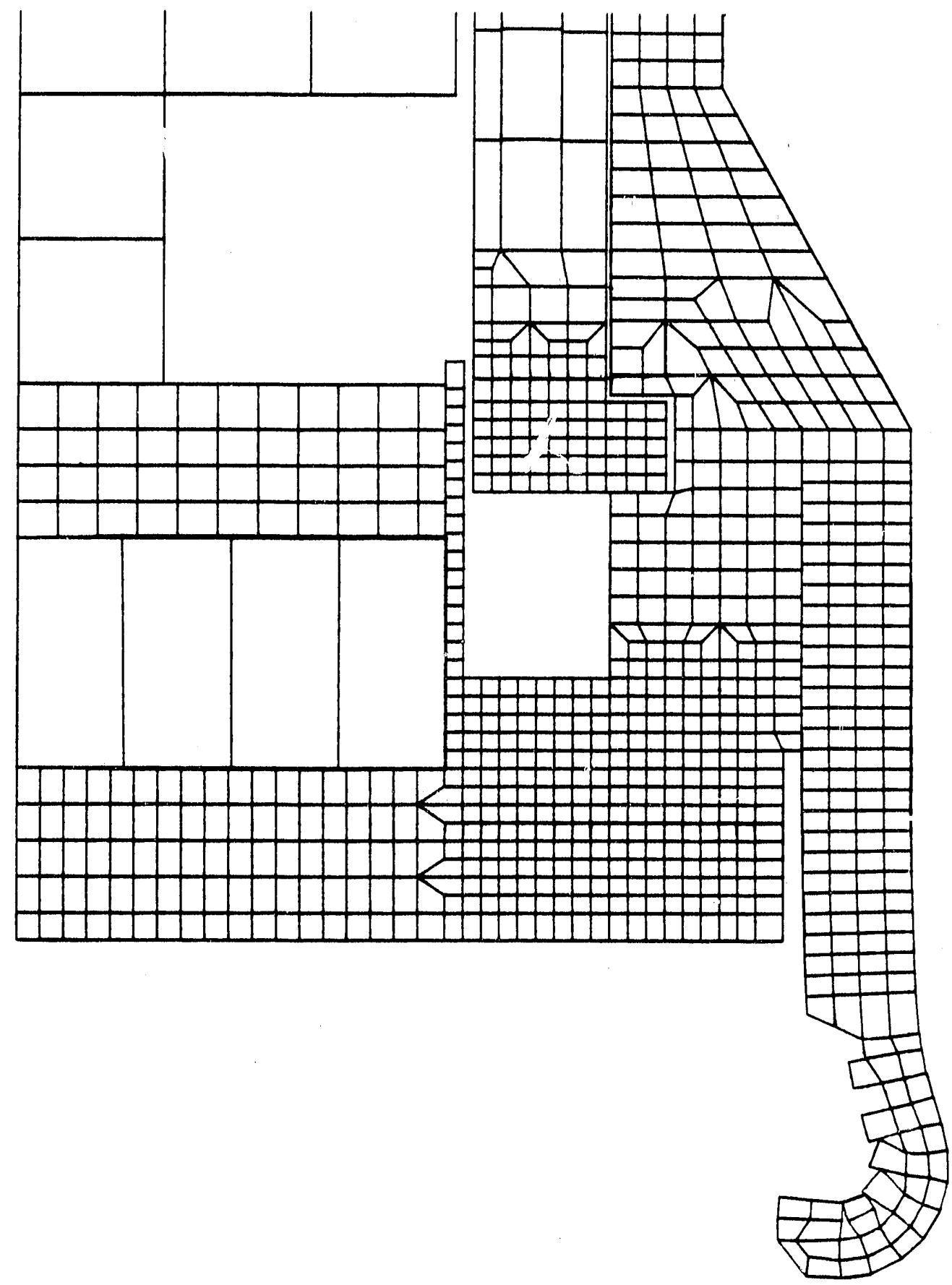

F1g. 2-15. DHLW two-dimensional closure end drop model at $9 \mathrm{~ms}$ 


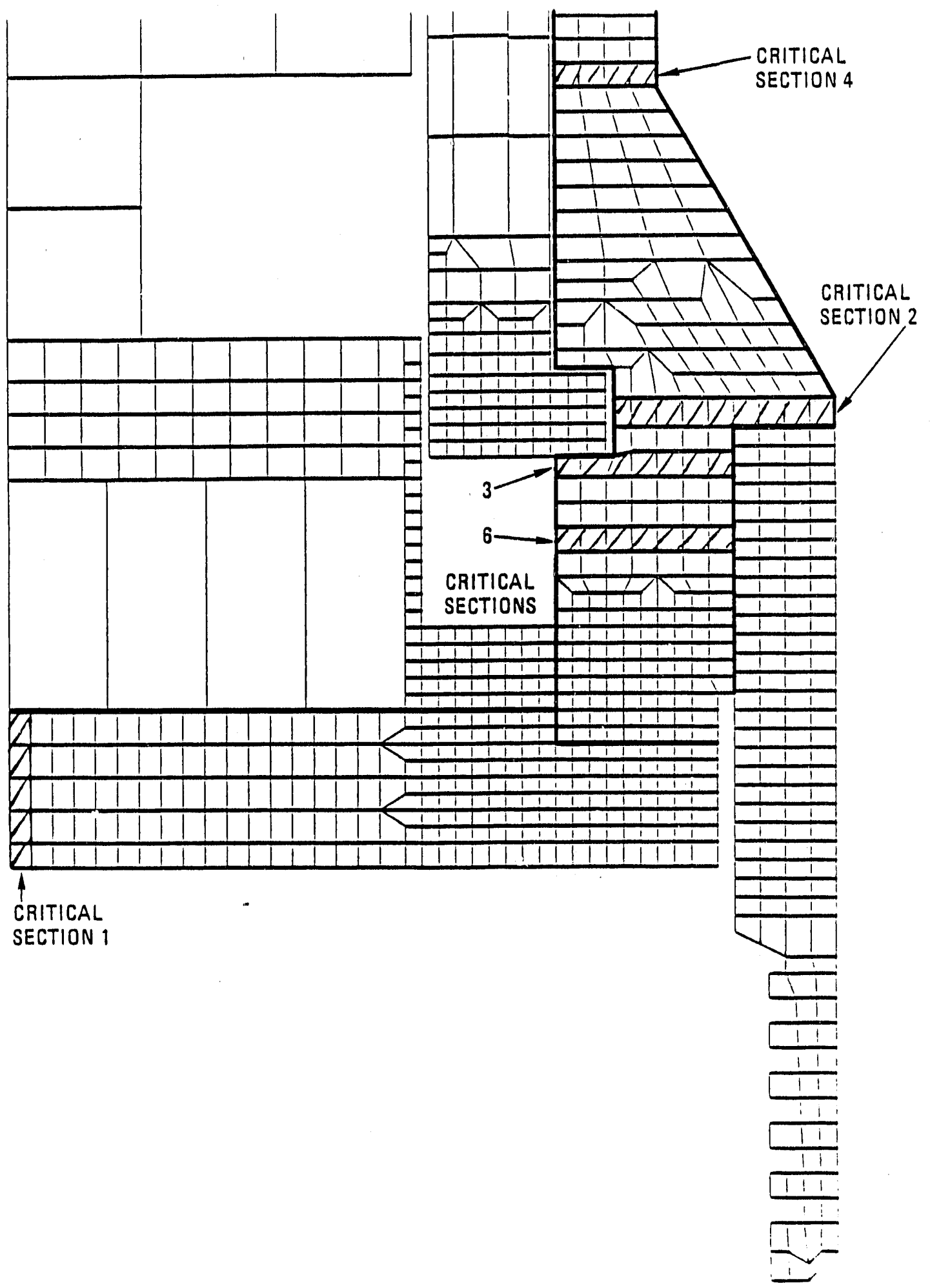

Fig. 2-16. Blow up of closure end showing critical sections chosen during 9-m (30-ft) closure end drop analysts 


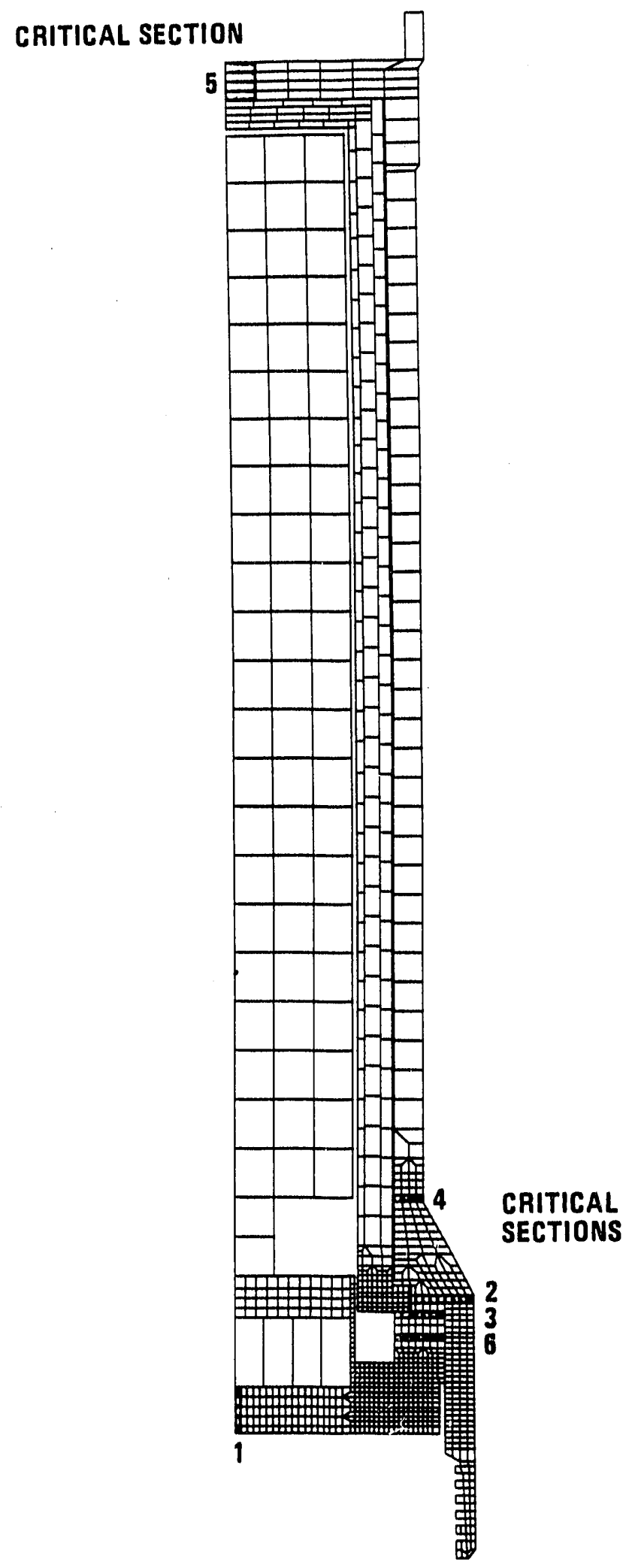

Fig. 2-17. Closure end 9-m (30-ft) drop analysis finite element mode1 showing locations of critical sections 
Table 2-3 summarizes the primary membrane stresses and local membrane-plus-bending stresses for these critical sections and compares them to the allowable stresses. All design criterfa dre met. The highest primary membrane stress ( $13 \mathrm{ks} 1$ ) occurs at the cask neck function and is $26 \%$ of the allowable stress $(51.9 \mathrm{ks} 1)$; see Fig. $2-11$. The highest local membrane-plus-bending stress ( $35 \mathrm{ksl}$ ) occurs at the closure surface nearest the contents and centerline of the closure and is $49 \%$ of the allowable stress $(71.1 \mathrm{ks} 1)$. These maximum values were obtained from computer-generated time history plots.

2.3.2.4. Conclustons. The DHLW truck cask was analyzed for the hypothetical accident condition of a $9-m(30-f t)$ closure end drop. The results show that the cask and components meet all of the structural design criteria. The results of the inelastic analysis at the critical sections in the containment boundary showed stresses with a minimum design margin of +1.0 . The components of the DHLW truck cask function as designed and deformations are of reasonable magnitudes. Closure seal integrity is malntained and closure bolt stresses have a design margin of +0.60 .

\subsubsection{Nine-Meter $(30-\mathrm{ft})$ Center of Gravity Over Closure Corner Drop Analysis}

\subsubsection{Introduction. The hypothetical accident event of a $9-\mathrm{m}$} $(30-\mathrm{ft})$ free drop with the center of gravity (CG) over the closure corner produces highly localized stresses and displacements at the impact point. Ovalization of the notched impact limfter results from this event. The center of gravity of the cask and the impacting corner of the notched impact limiter form a line normal to the unylelding target surface. Large deformations occur in the notched impact limiter which decelerates the cask in a controlled manner. The stresses and deformations were computed using the three-dimensional computer code DYNA3D. The methodology is discussed in Section 2.2.3. 


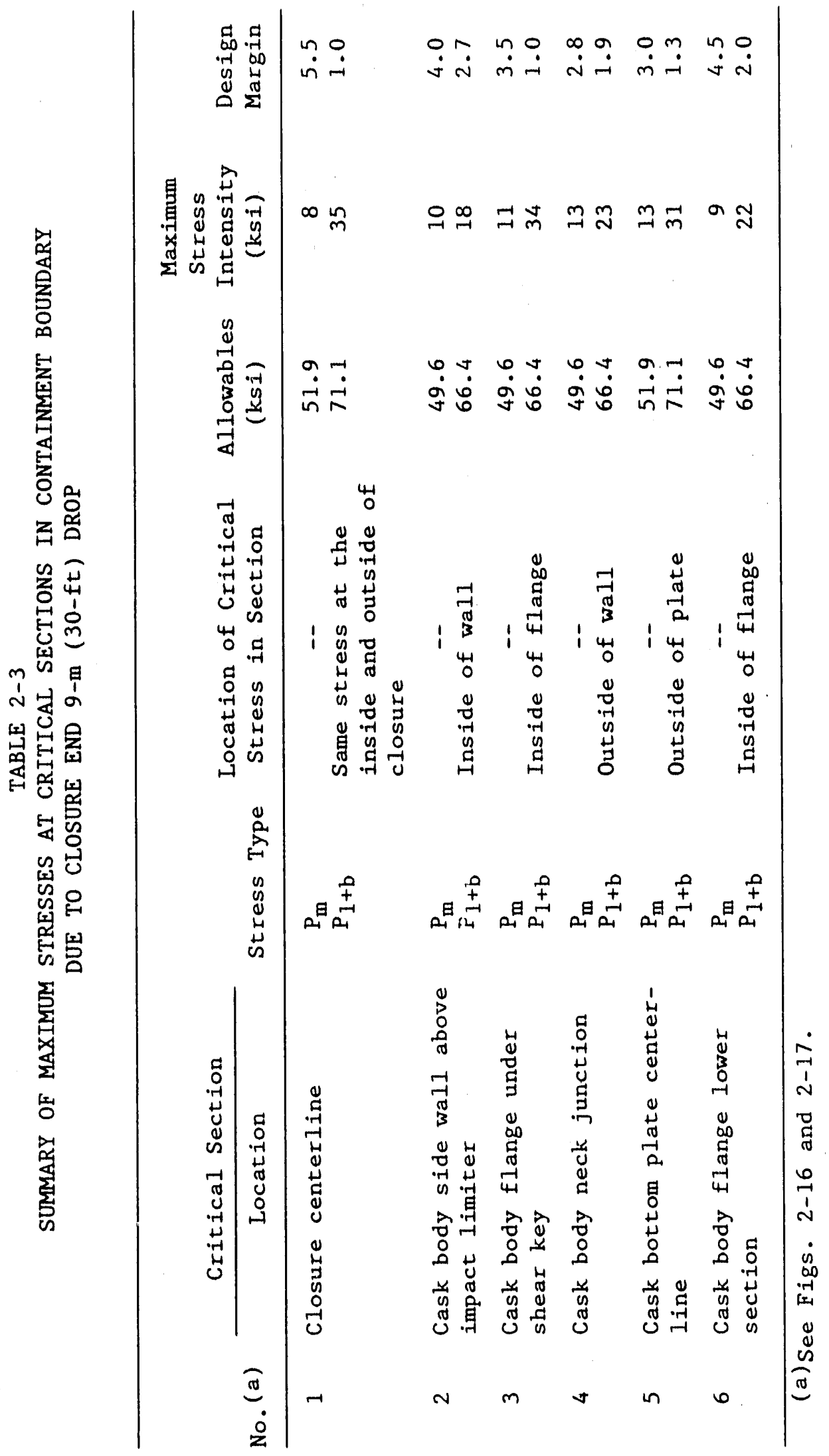


The results of the analysis demonstrate that the cask containment boundary meets al1 of the design cilterla and will not fall due to a 9-m (30-ft) CG over closure corner drop.

\subsubsection{Mode1 Description.}

Mesh

Since the mesh and the loading are symmetrical, only half of the cask was modeled. A cut of the mesh through the $y=0$ plane $1 \mathrm{~s}$ shown In F1g. 2-18. The mesh contains 16,976 nodal points and 11,077 , 8-node solid elements. There is a higher concentration of elements in the upper third of the cask model where most of the deformation is expected. The finfte element mesh is a collection of submeshes which include the cask body, the closure, the shield liner, the contents, the internal impiact limiter, the shielding plate and the support cylinder. These submeshes are separated by slidelines which allow contact and release between submeshes but prevent penetration. Additionally, a specialized slideline algorithm called tied sildelines is used, which facilitates mesh bullding by eliminating the need for transition regions in the mesh.

The following simplifications were made when creating the model:

1. Nonstructural Components. Components, such as the trunnions, the lower end impact 1imiter, the circumferential impact 1 imiters, and the thermal barrier, which do not have a structural role in the primary impact of this event, were omitted from the model. The density of the contalnment boundary stalnless steel was adfusted so the total welght of the model was about $21,863 \mathrm{~kg}(48,2001 \mathrm{~b})$.

2. Waste Content of the Canister. The waste content of the canister was modeled as a perfectly elastic mass. This is conservative since 1 t minimizes the energy absorbed by the waste. 


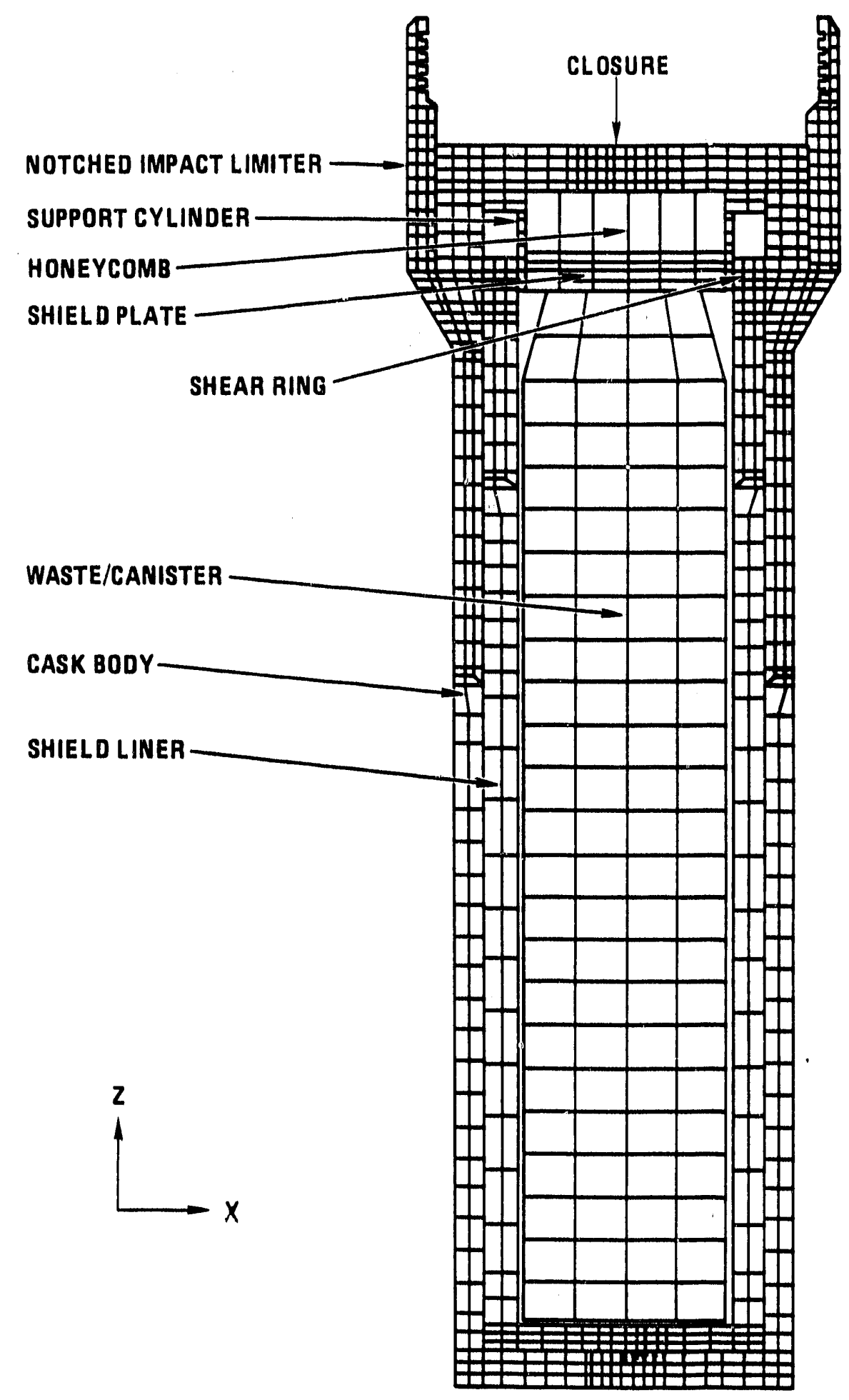

Fig. 2-18. Finite element model (cut by $x-y$ plane at $y=0$ ) for CG over closure corner $9-\mathrm{m}(30-\mathrm{ft})$ drop analysis 
The welght of the waste was modeled at $2494 \mathrm{~kg}(5500 \mathrm{lb})$ to cover any potential increase in glass density.

3. Bolt Model. The bolts connecting the closure to the cask body were modeled as 11 elements instead of 12 bolts because of the number of sectors in the model. The total bolt stiffnes in the axial direction was malntained. The bolt elements shared nodes with elements in the closure and cask body.

4. Shield Liner Modeling. The shield liner was modeled as a solld plece. There were no slidelines between the steel and DU layers. Most of the shleld liner wall was modeled with only two elements through the thickness. Therefore "smear" properties were used in this area instead of modeling the steel and the DU cylinders. The bottom of the shield liner was modeled with three equal sized elemerits through the thickness. The properties of each section were calculated to maintain equivalent membrane stiffness between the model and the cask design in order to provide the proper load into the containment boundary.

5. Closure Relief Cut. The actual cask has a $0.15 \mathrm{~cm}(0.06 \mathrm{ln}$. rellef on the underside of the closure flange which extends from the outside diameter of the bolt holes to the outside diameter of the closure plate. The purpose of this relief cut is to avold prying on the bolts due to bending of the closure. This analysis did not model this rellef cut, allowing prying between the closure and the cask body, about the outside perimeter of the closure. This approach is conservative since It increases both the tenslle loads on the bolts and the opening of the closure/flange/seal interface.

6. The lifting attachment was not modeled during this analysis. The closure end drop analysis reported earlier, and the CG 
over closure corner drop analys 1s without the lifting attachment, envelop the extreme loadings for the contalnment boundary. In the analysis for the CG over closure corner drop, the Impact pattern, "footprint," ts the smallest. As discussed in Section 2.3.2.2, the lifting attachment adds materlal to the IImiter, thus the affected areas are not weakened.

7. The upper circumferentlal impact limfter was not modeled in the analysis. This does not change the analysis results because the 1imiter is located adjacent to the "thlck" part of the impact 1imiter where minimal deformations occur. Its presence could only serve to stiffen the notched Impact $11 \mathrm{~m}-$ iter upper base, forcing the energy to be absorbed in the notched area as described above.

\section{Boundary Conditions}

The only boundary conditions required by DYNA3D are no hoop displacements at the plane of symmetry and a rigld wall definition. The rigid wall is defined by a plane perpendicular to the vector connecting the impact point and CG for the cask. The rfgld wall plane is $16.62 \mathrm{deg}$ from the X-Y plane of the model. The X-Y plane runs along the top of the undeformed notched impact limiter.

\section{Loads on Mode1}

The only loads on the cask result from the 9-m (30-ft) free fall. The inftial velocity given to each node in the model is equal to the velocity of the cask at the time of 1mpact. This velocity is found by equating the potential energy of a $9-m(30-f t)$ drop to the kinetic 
energy and then solving for the velocity. Since the Impact occurs at an angle, the following directional veloctties were assigned to each node:

$$
\begin{aligned}
& V_{x}=150.86 \mathrm{in} . / \mathrm{s}, \\
& v_{z}=505.42 \mathrm{in} . / \mathrm{s} .
\end{aligned}
$$

No Internal pressure or thermal stresses were included.

\section{Materlal Properties}

The closure bolt elements' material properties are presented in. Table 2-4. The material properties were set up so the axlal siffiness of the bolt elements was the same as the axial stiffness of the actual bolts.

2.3.3.3. Results. The results of this analysis were studied to determine the response of the actual cask containment boundary under this accident condition. The DYNA3D analysts was run for more than $22 \mathrm{~ms}$ after Impact. The kinetic energy at this time was close to minimum. As shown in F1g. 2-19, only $10 \%$ of the Initial energy is left after $22 \mathrm{~ms}$. Color stress plots for the cask were generated at several times. These plots were used to select the critical sections for detalled study. These plots also show the deformed shape of the cask. Figure 2-20, shows spectfically the deformed shape of the top of the model. Large plastic deformation occurred locally, near the point of impact in the notched impact limiter. The remalnder of the cask did not deform signiflcant $1 y$.

\section{Conta1:ament Boundary}

Ductile Rupture and Tearlng. To show that all parts of the cask meet the structural criteria presented in Section 2.1.1, several critical sections were chosen. The locations of the critical sections are shown in F1g. 2-21. Time history plots were made of stresses at these 
TABLE $2-4$

CLOSURE BOLTS MATERIAL PROPERTIES USED ON CG OVER CLOSURE CORNER 9-m $(30-\mathrm{ft}$.) DROP ANALYSIS

\begin{tabular}{lcc}
\hline \multicolumn{1}{c}{ Material Property } & Cask & Model \\
\hline $\begin{array}{l}\text { Number of bolts/elements } \\
\text { (for half of the cask) }\end{array}$ & 12.0 & 11.0 \\
Area per bolt/element. (In. $\left.{ }^{2}\right)$ & 1.405 & 4.75 \\
Young's modulus (psi $\left.\times 10^{6}\right)$ & 28.3 & 8.8 \\
liensity (1bm/in. $\left.3 \times 10^{-4}\right)$ & 7.5 & 3.39 \\
\hline
\end{tabular}




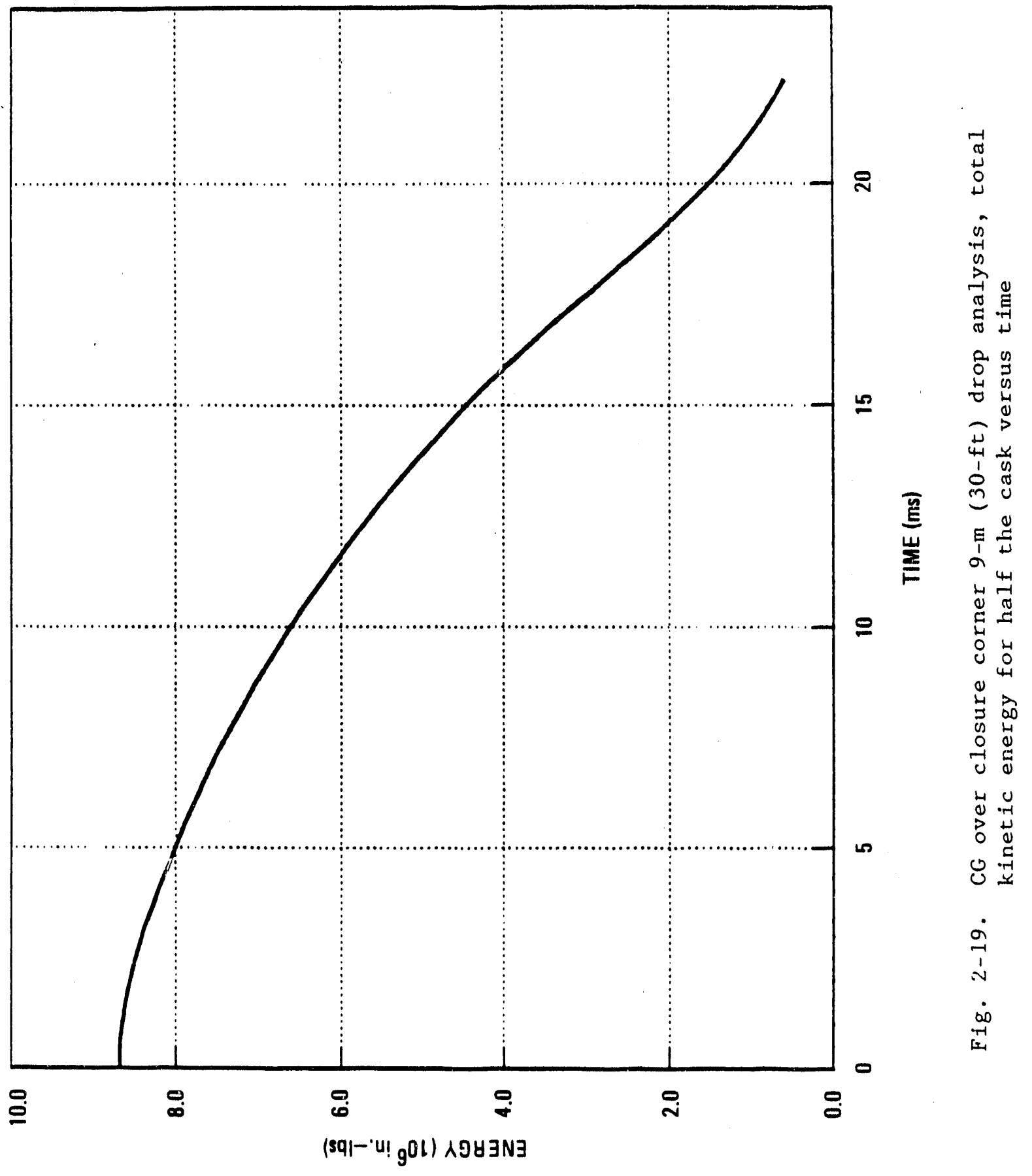




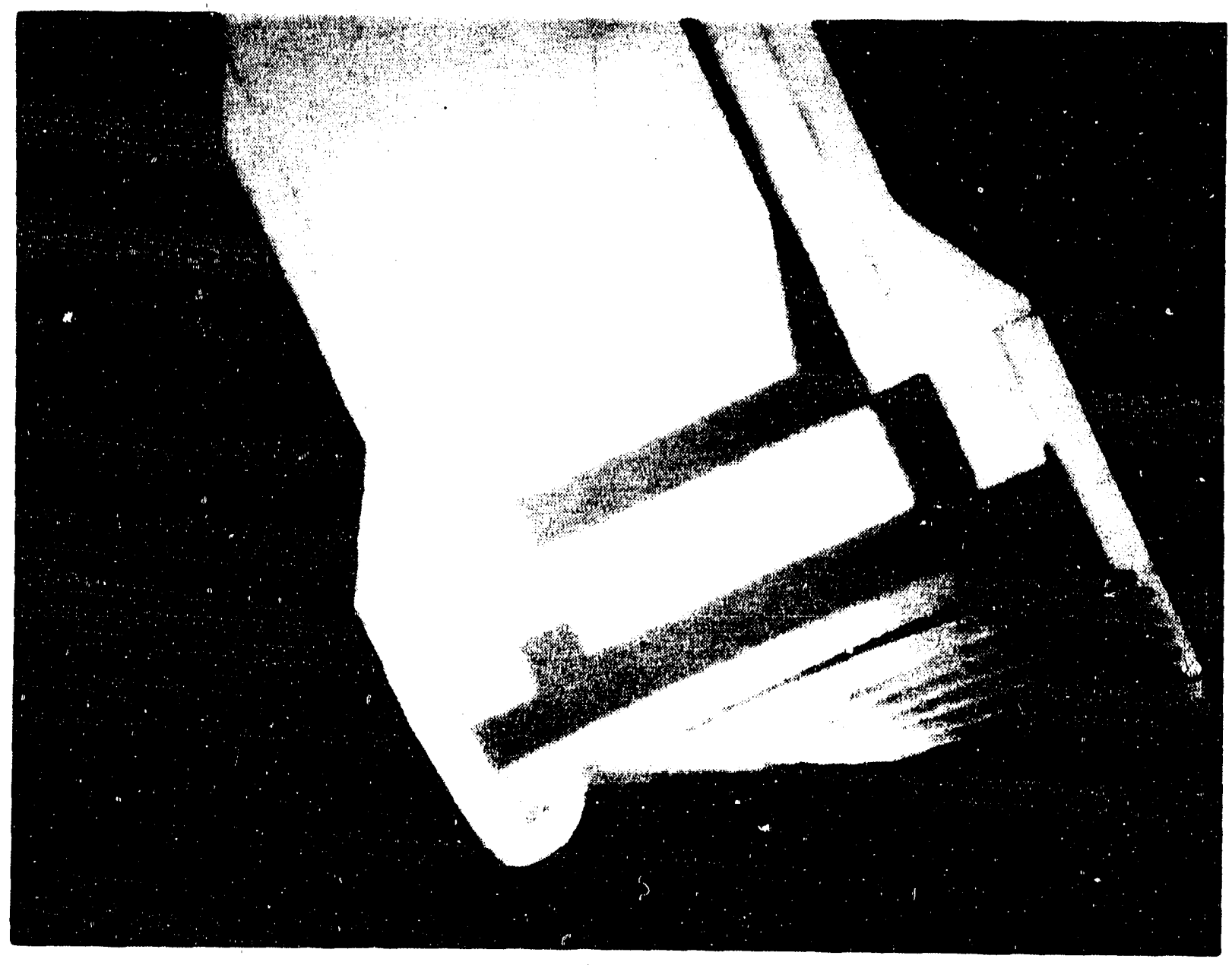

Fig. 2-20. Deformed shape plot of the top of the model during a CG over closure corner 9-m (30-ft) drop 


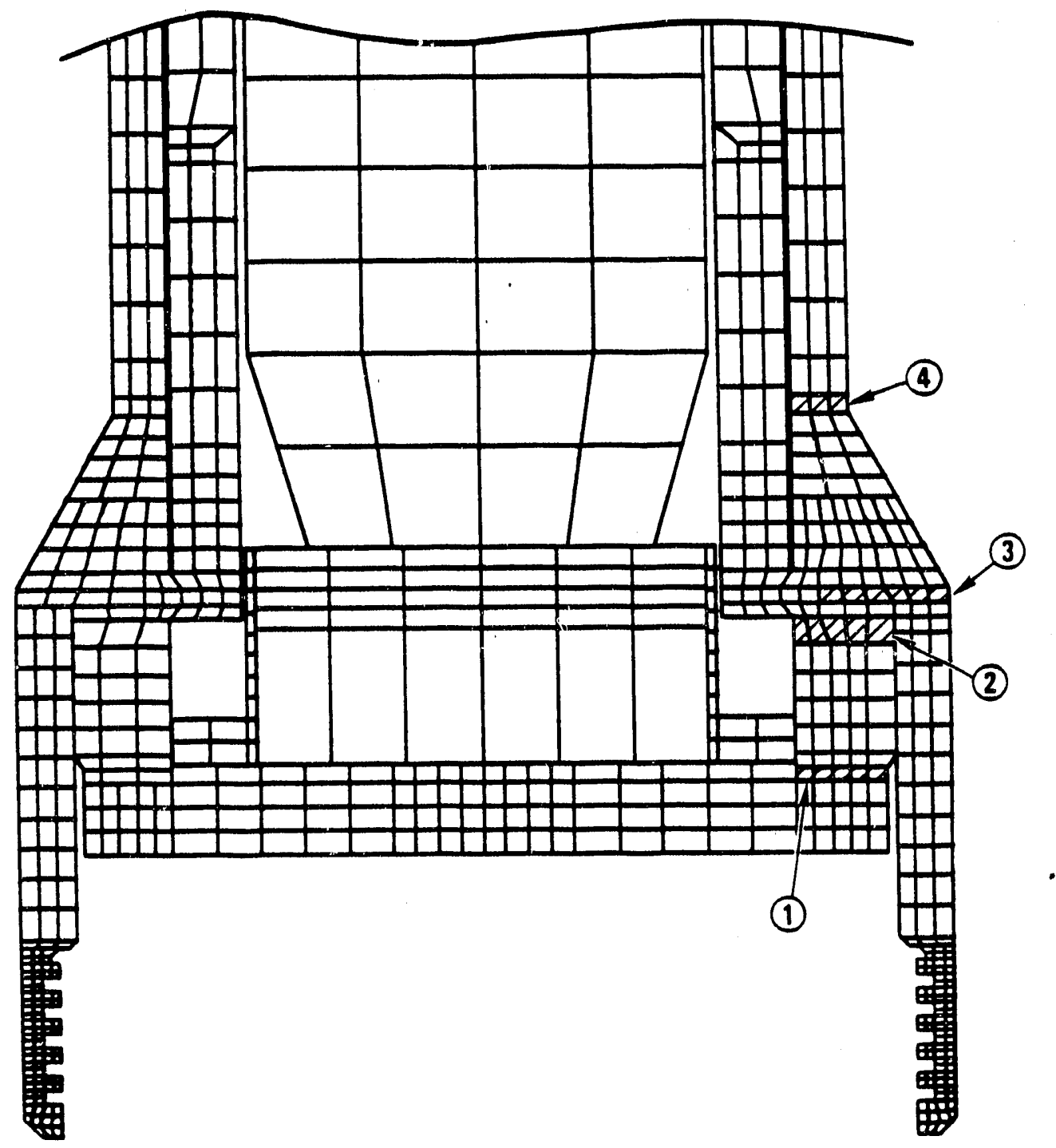

Fig. 2-21. Critical sections for CG over closure corner drop analysis 
sections at several angles. Table 2-5 summarizes the highest primary membrane stresses and local membrane plus bending stresses found in the model, and 1 compares them to the allowable stresses. The table also Indicates the circumferential location (angle from the impact point) at which these stresses occurred. The results show that all structural design criteria are met. The highest primary membrane stress occurs at the top of the cask flange and is $22 \mathrm{ksi}$, or $44 \%$ of the allowable. The highest local membrane plus bending stress occurs at the inside corner of the cask body flange, at the interface with the closure and under the notched impact 1imiter. It is $36 \mathrm{ks} 1$ or $54 \%$ of the allowable. These maximum values were obtained from computer-generated time history plots. Figures 2-22 and 2-23 show the time history plots for the maximum primary membrane stress and the maximum local membrane-plus-bending stress. The stresses in the closure and cask bottom plate are below yleld.

The other ductile rupture criterla concerns shear stress intensities. In the cask body shouldei area, typical shear stresses reach $2.7 \mathrm{ksi}$. This is an order of magnitude less than the $42.7 \mathrm{ks} 1$ allowable. The cask easily meets the shear criteria.

2.3.3.4. Conclusions. The cask was analyzed for the hypothetical accident condition of a $9-\mathrm{m}(30-\mathrm{ft})$ free drop of the cask with CG over the closure corner. The results show that the cask contalnment boundary and the critical components meet all of the structural design criteria. The results of the inelastic analysis at the critical sections in the containment boundary showed stresses with a minimum design margin of +0.84 . The components of the cask function as designed, and deformations are of reasonable magnitudes. Closure seal integrity is maintained, and closure bolt stresses have a design margin of +1.2 .

\subsubsection{Nine-Meter $(30-\mathrm{ft})$ Center of Gravity Over Bottom Corner Drop Analysis}

2.3.4.1. Introduction. A three-dimensional finite element analysis of the cask was performed using DYNA3D to determine if the cask contalnment 


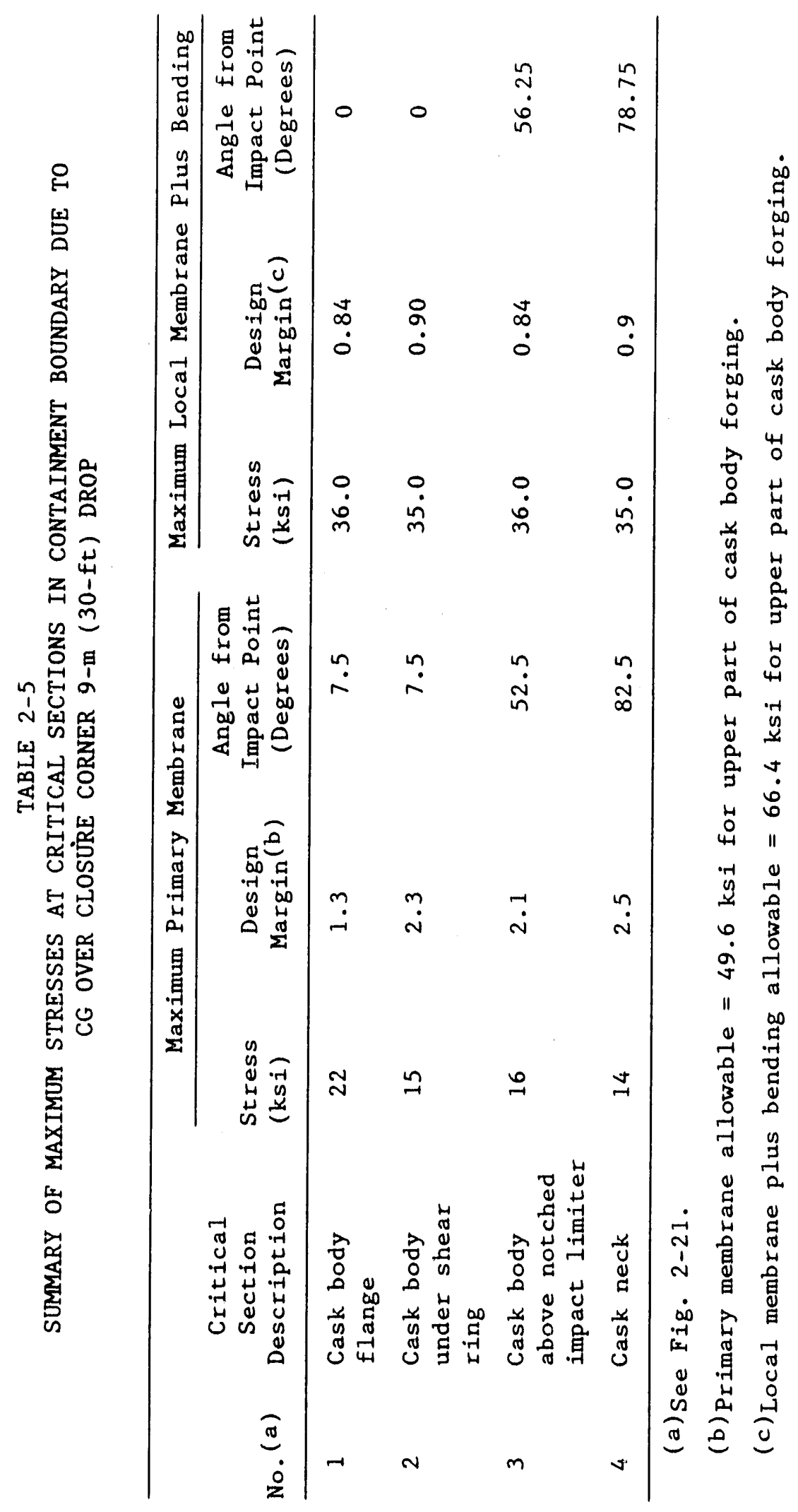




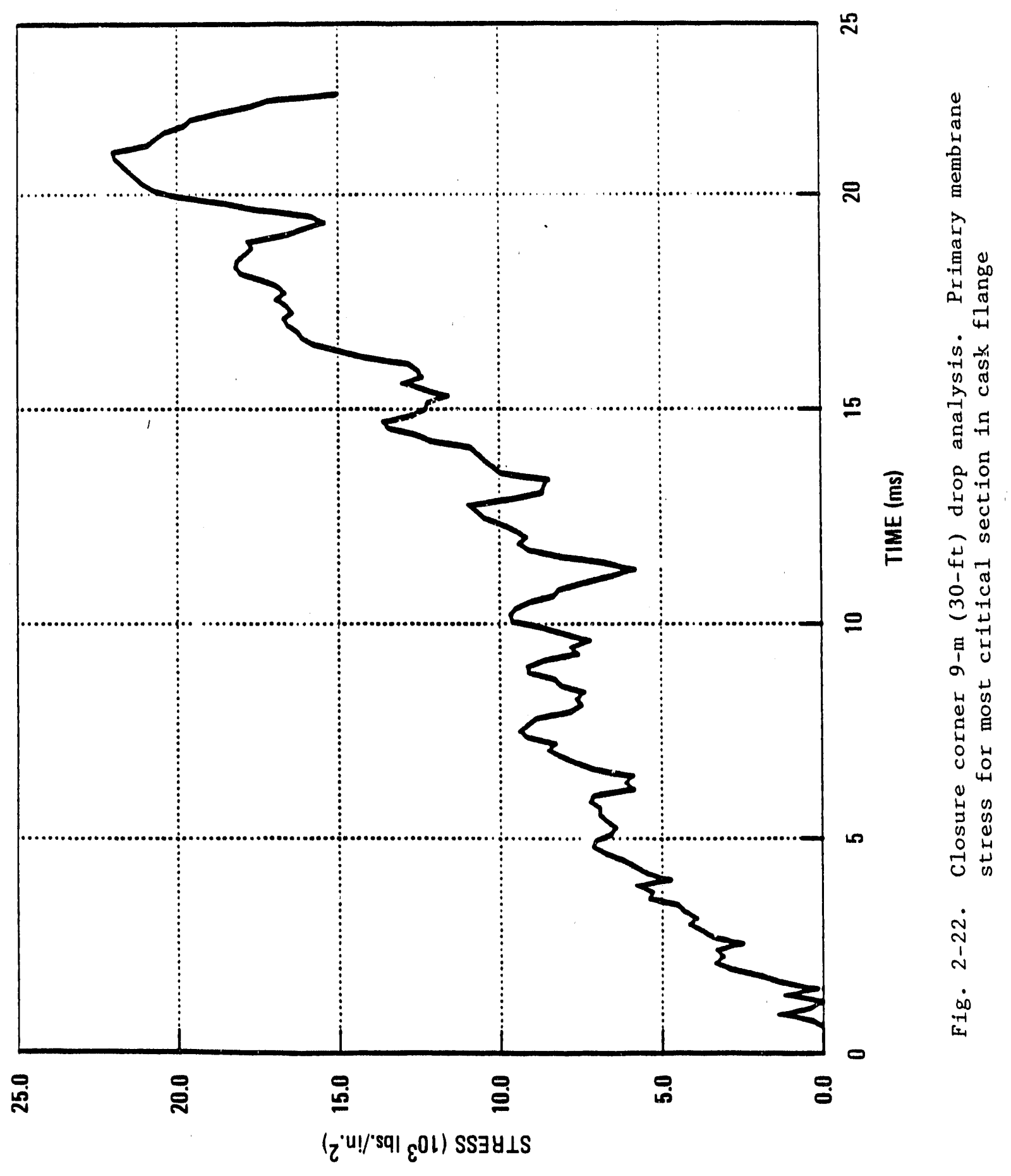




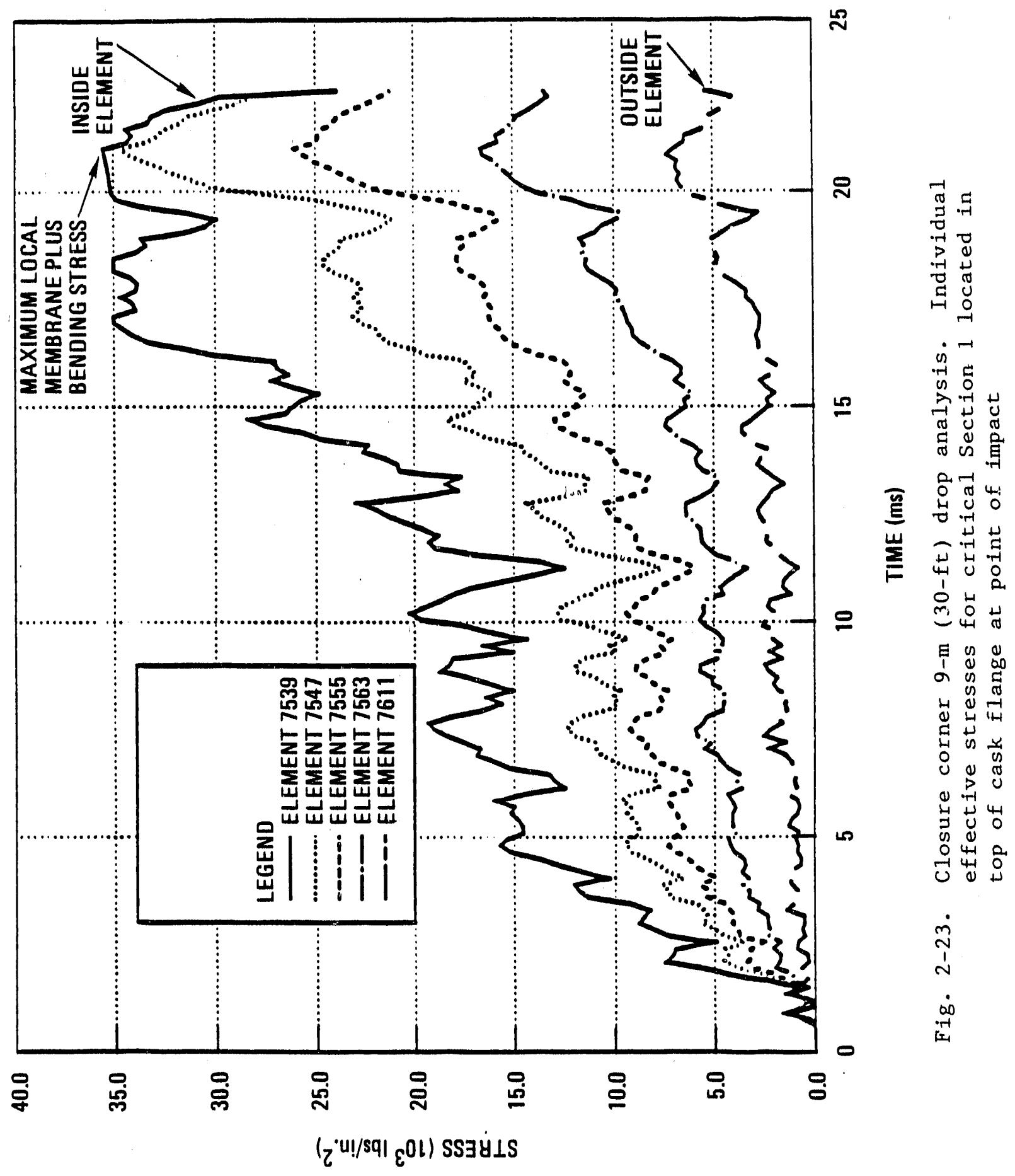


boundary can meet the structural criterla described In Section 2.1.1

during the primary impact of a $9-\mathrm{m}(30-\mathrm{ft})$ center of gravity over bottom corner drop. In this drop orlentation, the loading applied to the cask body is highly localized. Only part of the lower impact 1imiter plastically deforms during this event. The methodology is discussed in Section 2.2.3.

\subsubsection{Mode1 Description.}

$\underline{\text { Mesh }}$

Since the cask and the loading are symmetric, only half of the cask was modeled, as shown in FIg. 2-24. The mesh has 8,992 elements and 13,921 nodes. The $180 \mathrm{deg}$ model is divided into 24 equally stzed sectors. The jottom of the model and a 60 deg sector of the cask body, starting from the impacting corner of the model, were constructed with small elements because the maximum stresses and deformations are expected in this area (cask body part 1 in Fig. 2-25). The element aspect ratios in this area are $3: 1$ and the minimum element dimension, which controls the time step and cost, is $0.02 \mathrm{~m}$ (0.67 in.). The model shown in Figs. 2-24 and 2-25 is a collection of five submeshes; cask body Including impact limiter, shield liner, support cylinder, closure, and contents. These submeshes are separated by slidelines. These allow contact and release between submeshes but prevent penetration. Additionally, a specialized slideline algortthm called a tied slideline facliftates mesh bullding by eliminating the need for transition regions in the mesh.

The cask was simplifled before being divided into pleces for the finite element mesh. The following modifications were made to keep the model a reasonable size and still capture the essential cask behavior.

1. No thermal barter or shear ring was modeled. The density of the materials was adjusted so the total welght of the model is 


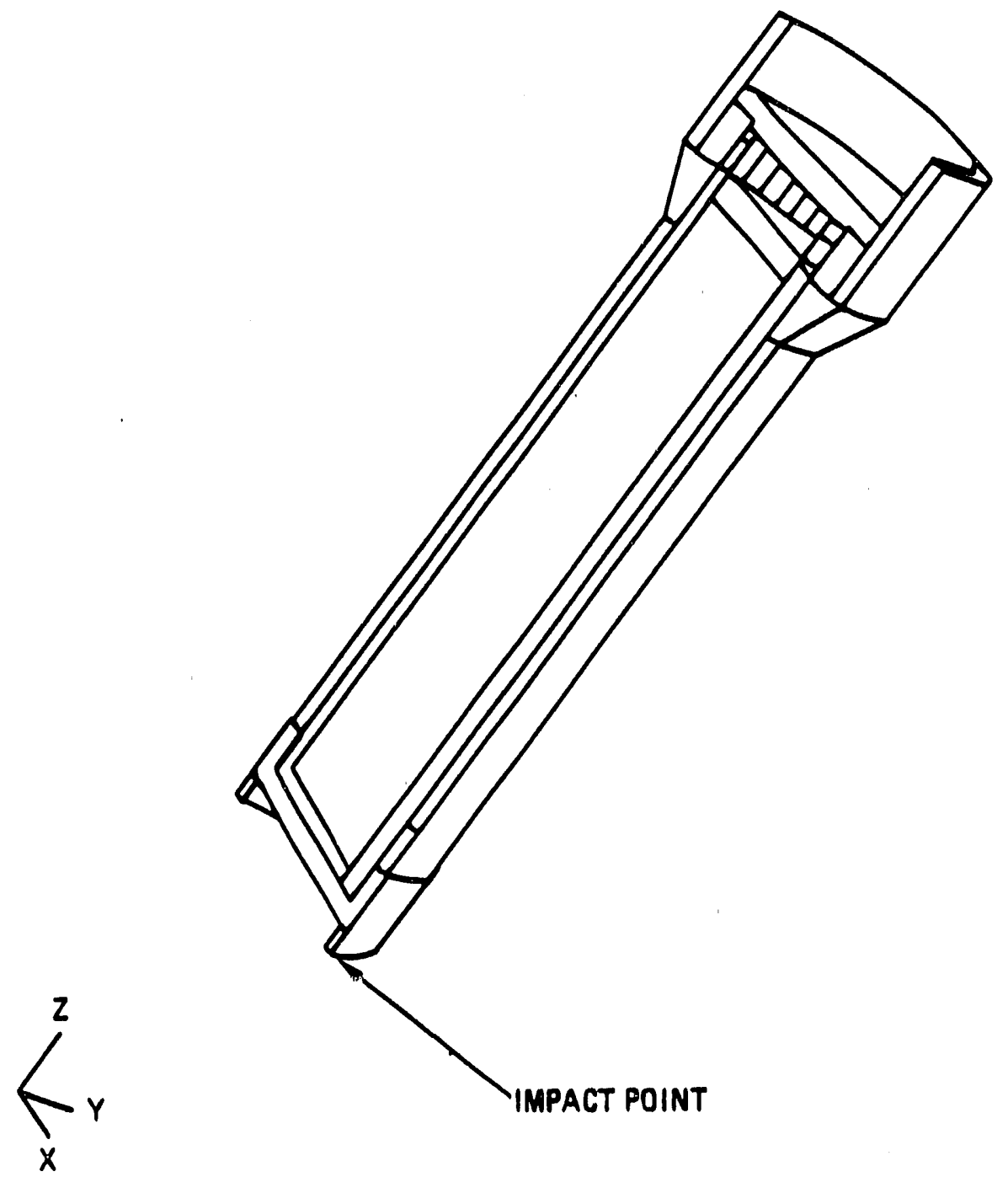

Fig. 2-24. Undeformed finlte element model used in three-dimensional analysis of cask during a CG over bottom corner 9-m (30-ft) drop 


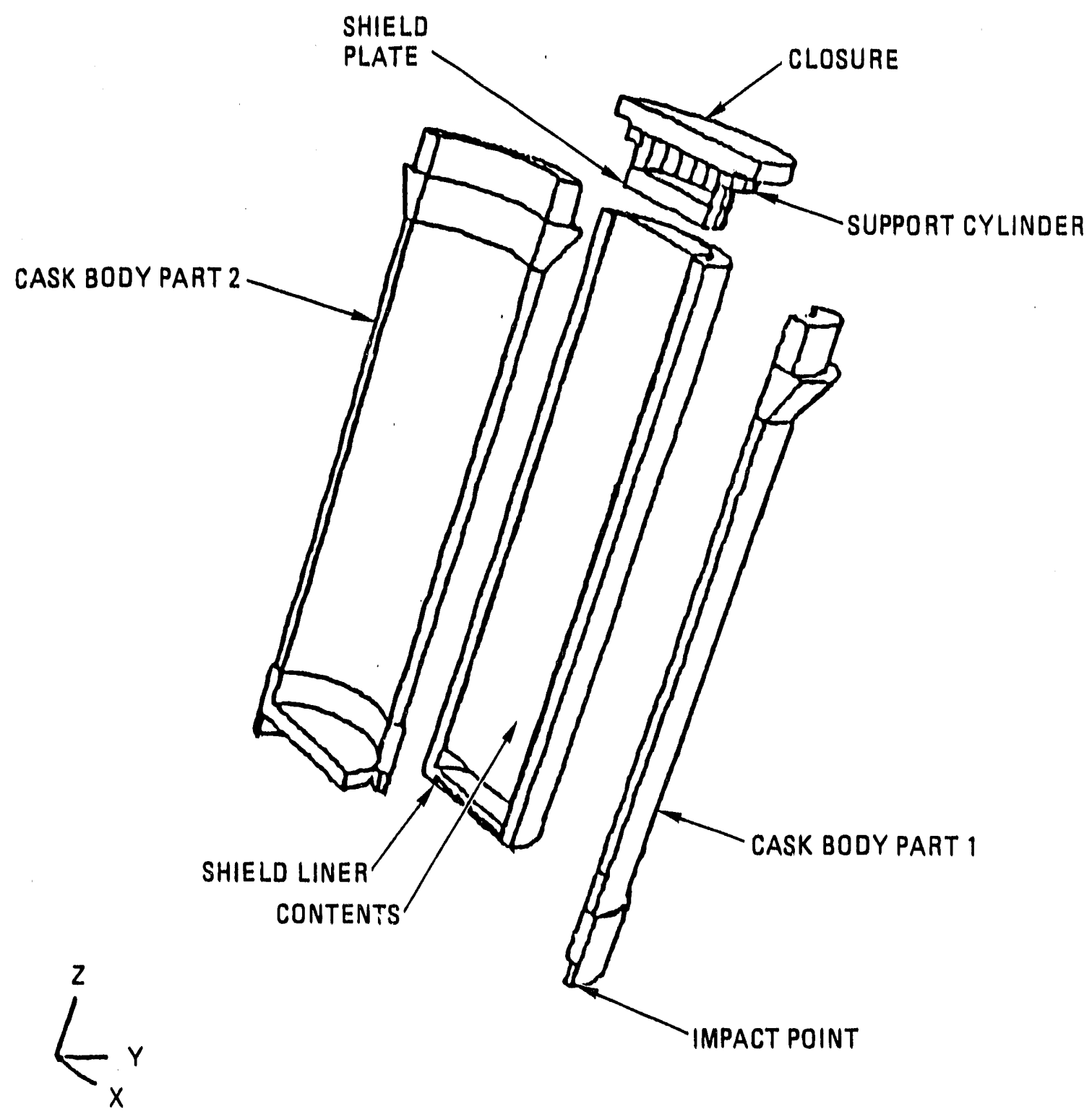

F1g. 2-25. Exploded view of cask model used in CG over bottom corner $9-m(30-f t)$ drop analysis 
about $21,864 \mathrm{~kg}(48,100,1 \mathrm{~b})$. Note that the shear ring is not loaded in this ortentation.

2. No closure or suppor cylinder bolts are modeled. The tied sildeline option of DYNA3D was used to hold the parts together during the drop. Thls drop ortentation does not present the most severe test for these parts of the contalnment boundary since they are only loaded during the rebound phase of the event. This assumption was verified by the half-scale test results presented in Section 4.

3. No Internal honeycomb impact limiter is included in the model. The honeycomb will not be loaded during this drop except during the rebound phase of the event.

4. No trinnions were modeled. Their weight was included in the cask body.

5. The notched impact 1 imfter was not modeled in detall and the c1rcumferential Impact limfters were omfted because they are not structurally active during the primary impact in this event.

6. The shfeld liner is modeled as a solfd plece without the shear ring since this is not active during this event. There are no slidelines between the steel and depleted uranfum layers. This increases the bending stiffness of the liner and delivers a more conservative load to the cask boundary.

\section{Boundary Conditions}

The only boundary conditions required by DYNA3D are no hoop displacement at the plane of symmetry, and a rigld wall definition. The 
rigld wall is defined by a plane perpendicular to the vector connecting the Impact point and center-of-glavity for the cask.

\section{Loads on Mode 1}

The only loads on the cask result from the $9-m(30-f t)$ free drop. The Inftial velocity given to each node in the model is found by equatIng the potential energy of a $9-m(30-f t)$ drop to the kinetic energy and solving for the velocity. The following directional veloctties were assigned to each node:

$$
\begin{aligned}
& V_{x}=129.9 \mathrm{in} . / \mathrm{s}, \\
& V_{z}=-511.2 \mathrm{in} . / \mathrm{s},
\end{aligned}
$$

2.3.4.3. Results. The results of this analysis wer studied to determine the response of the actual cask contalnment boundary under this accident condition. The DYNA3D analysis was run for $15 \mathrm{~ms}$ until minimum kinetic energy was reached and the cask rebounded from the unylelding target. Figure 2-26 shows a time history plot of the total kinetic energy of the cask. It shows that the cask rebounds between 11 and 12 ms after Initlal impact. Contour stress plots for the cask were generated at several times and used to select. the areas of highest stress (critical sections). Figures 2-27 through 2-29 show some of the contour plots used to select the critical sections. These contour plots also show the deformed shape of the cask. As shown, large plastic deformation occurred locally in the impact limiter near the point of impact in an area less than $120 \mathrm{deg}$ around the impact point. These figures also show that the remainder of the cask did not deform significantly.

\section{Ductile Rupture and Ductile Tearing}

The locations of the most critical sections studied are shown in Figs. 2-30 and 2-31. A11 of the sections chosen were in the impact area 


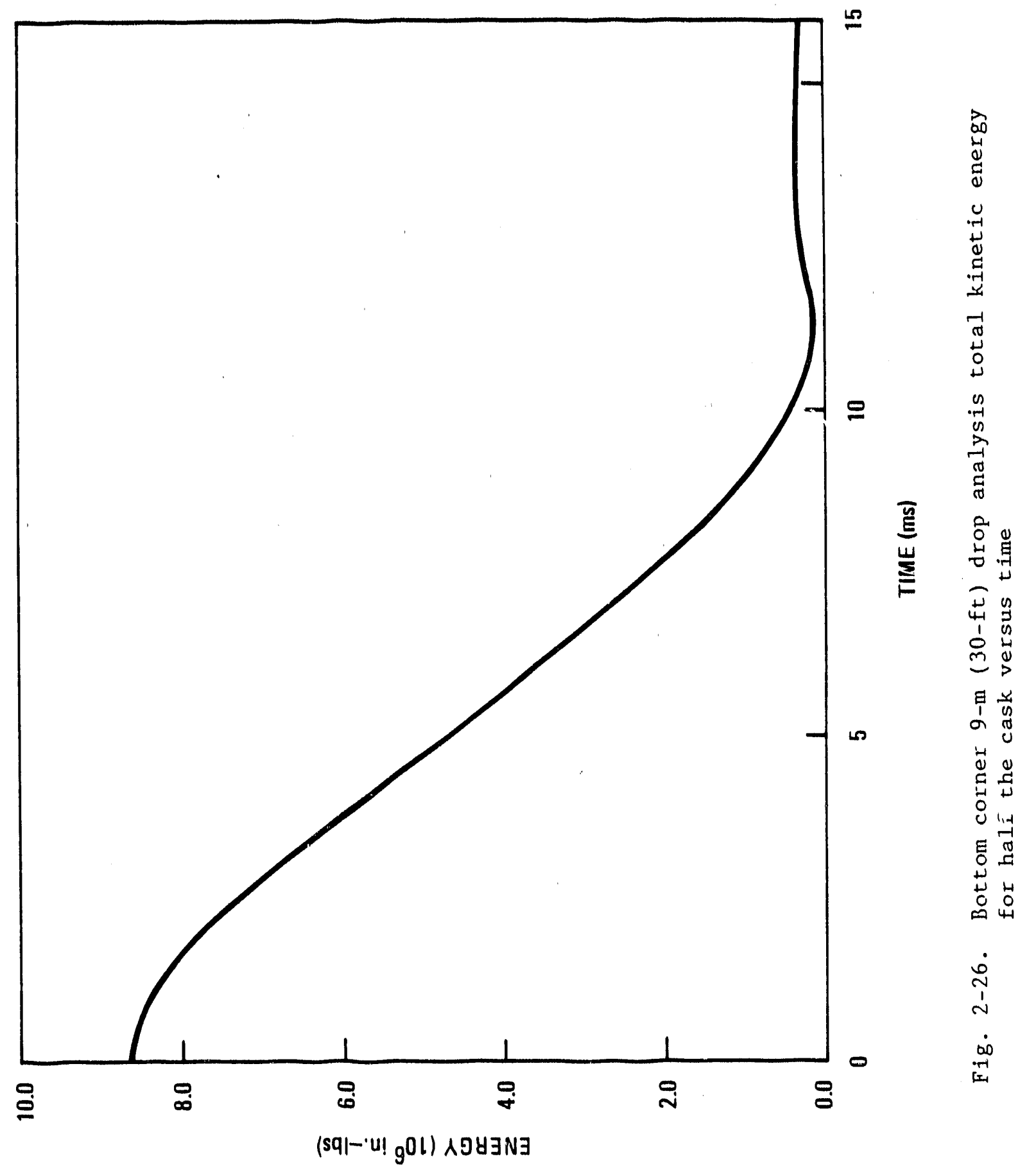




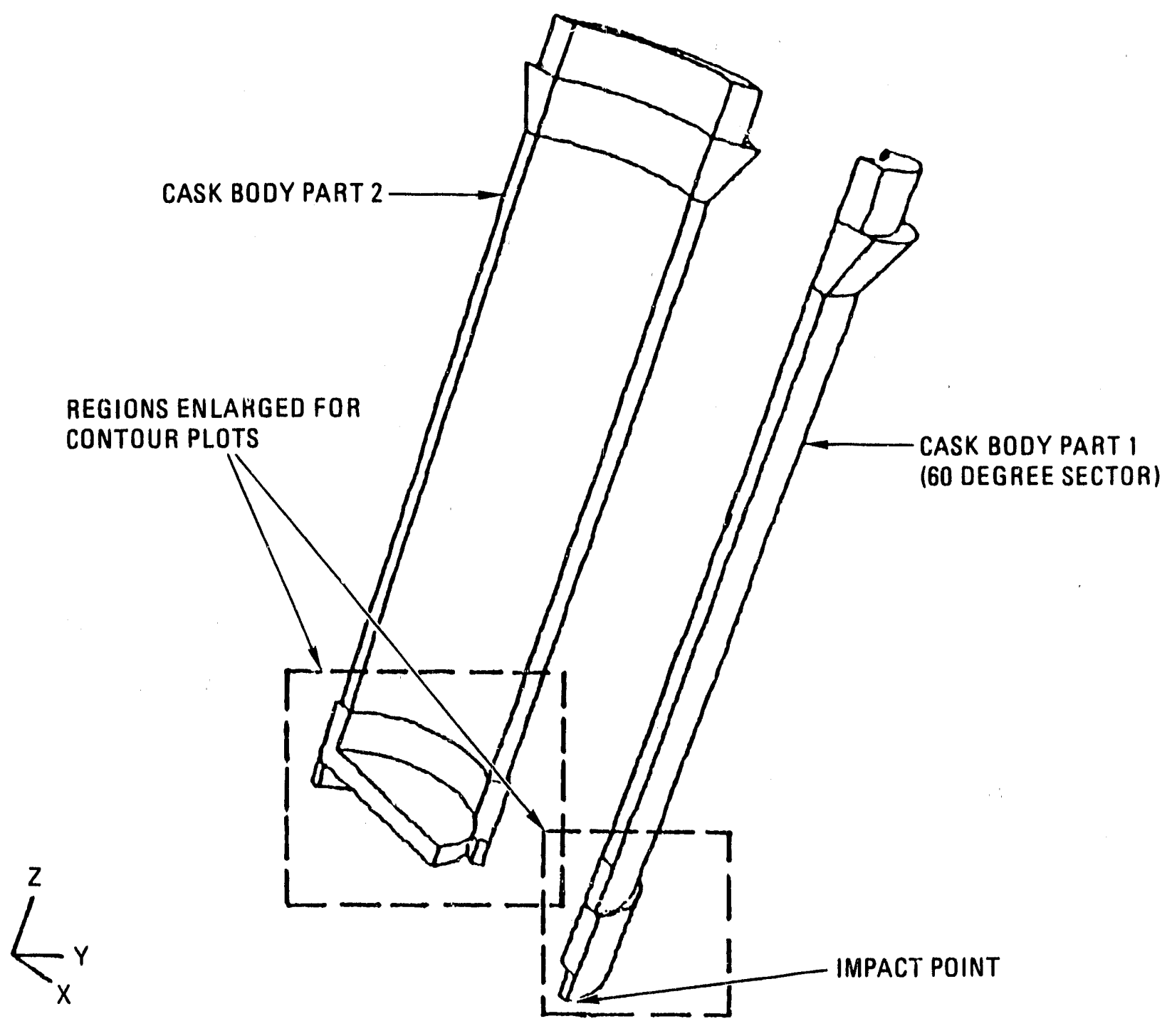

Fig. 2-2\%. Exploded view of cask body showing area enlarged for contour plots 

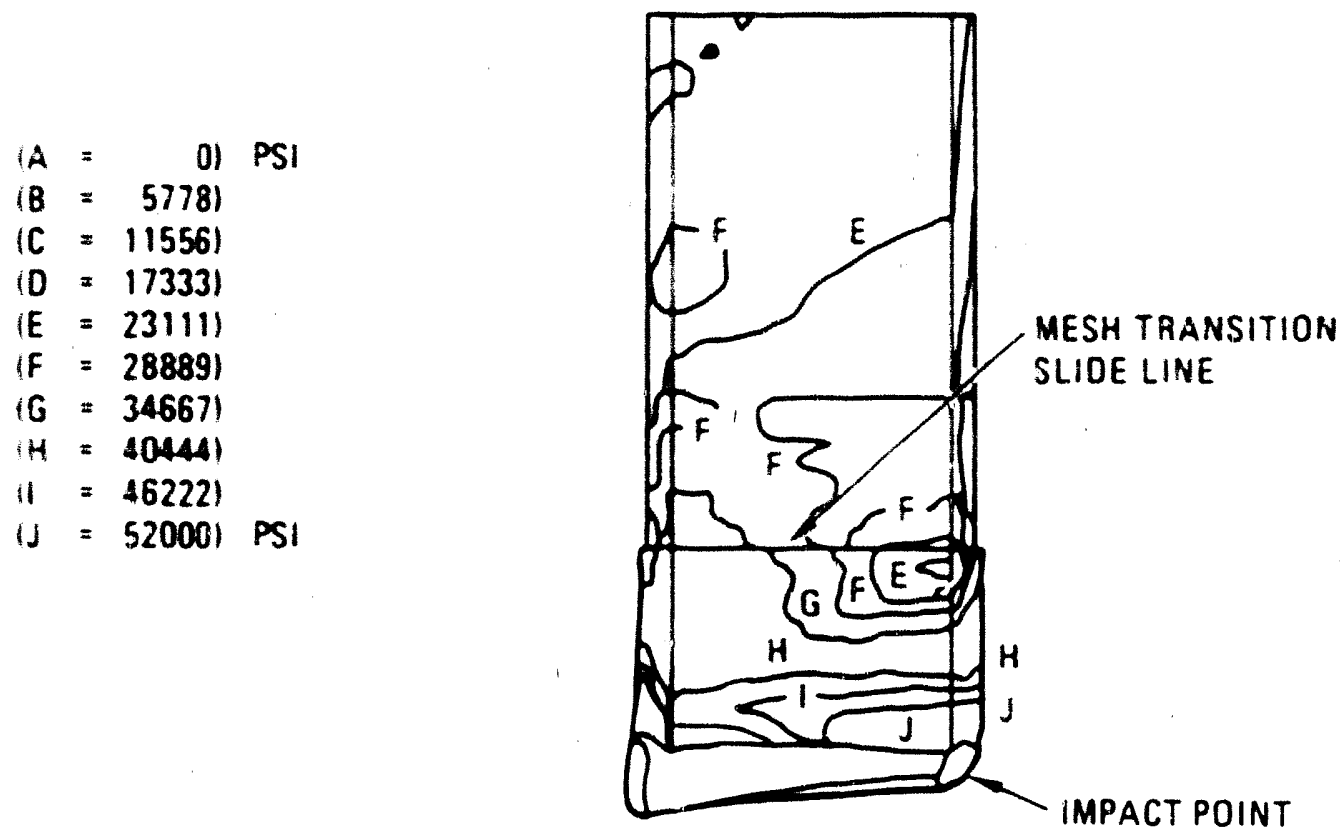

10 MSEC AFTER IMPACT

$y+L_{x}^{2}$

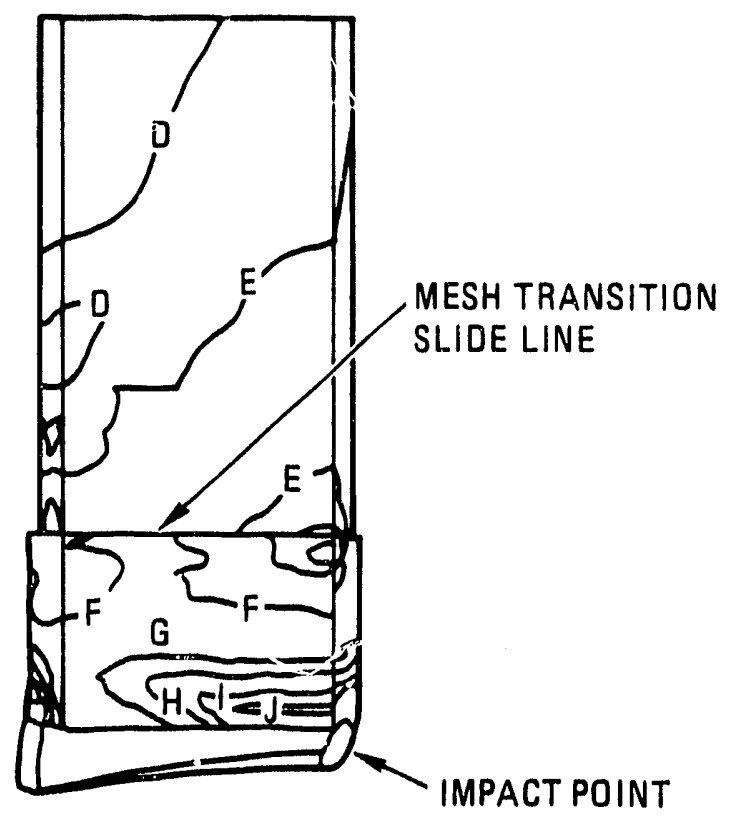

$y+x$

12 MSEC AFTER IMPACT

Fig. 2-28. Effective stress contour plots of the inside of the cask body (part 1) 


$$
\begin{aligned}
& (A=0) \text { PS } \\
& (B=5778) \\
& (C=11556) \\
& (D=17333) \\
& (E=23111) \\
& (F=28889) \\
& (G=34667) \\
& (H=40444) \\
& (1=46222) \\
& (J=52000) \text { PSi }
\end{aligned}
$$<smiles>[Z]C([Y])([X])[X]</smiles>

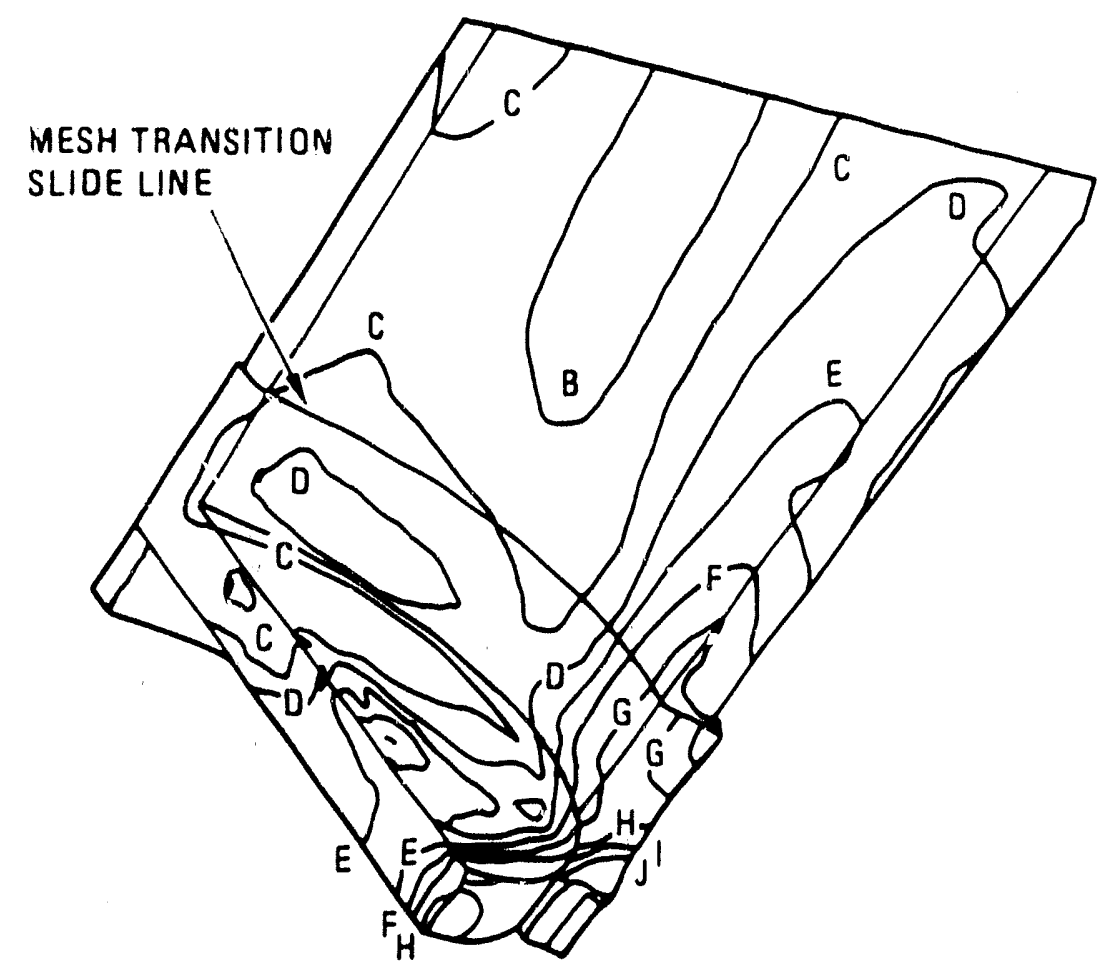

10 MSEC AFTER IMPACT
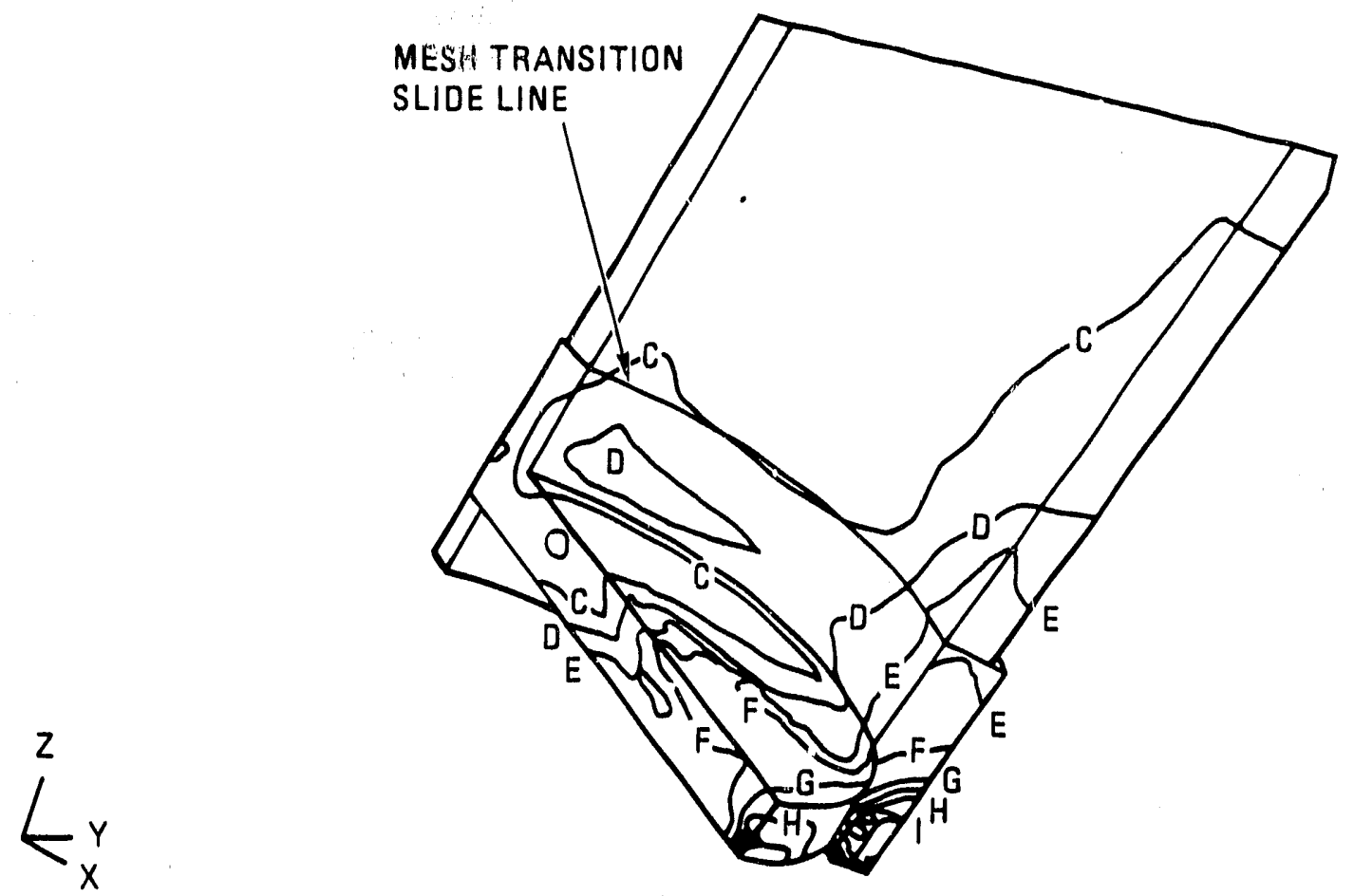

12 MSEC AFTER IMPACT

F1g. 2-29. Effective stress contour plots of the inside of the cask body (part 2) 


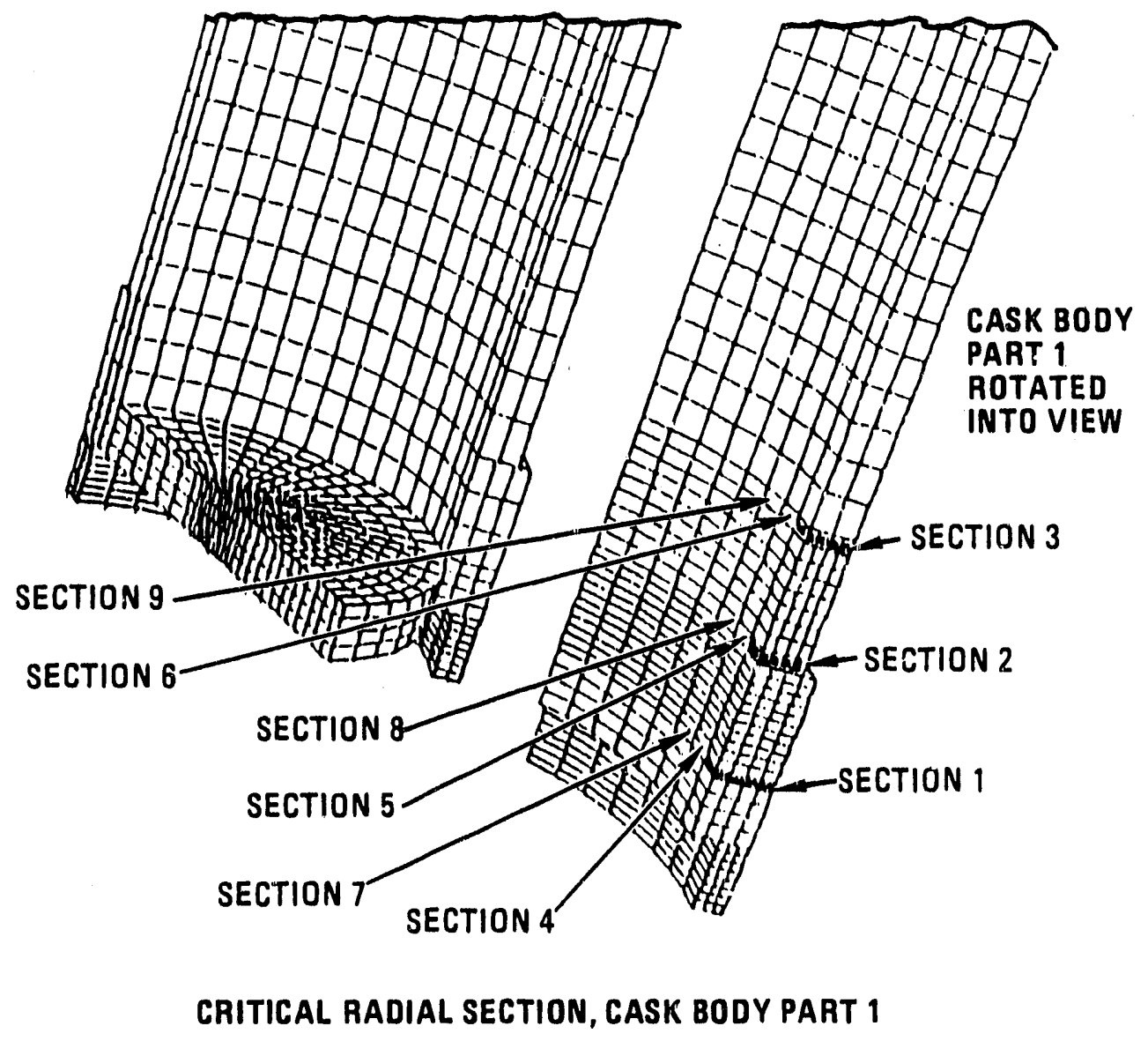

I'ig. 2-30. Location of critical sections in cask body part 1 in CG over bottom corner $9-m(30-f t)$ analysis 


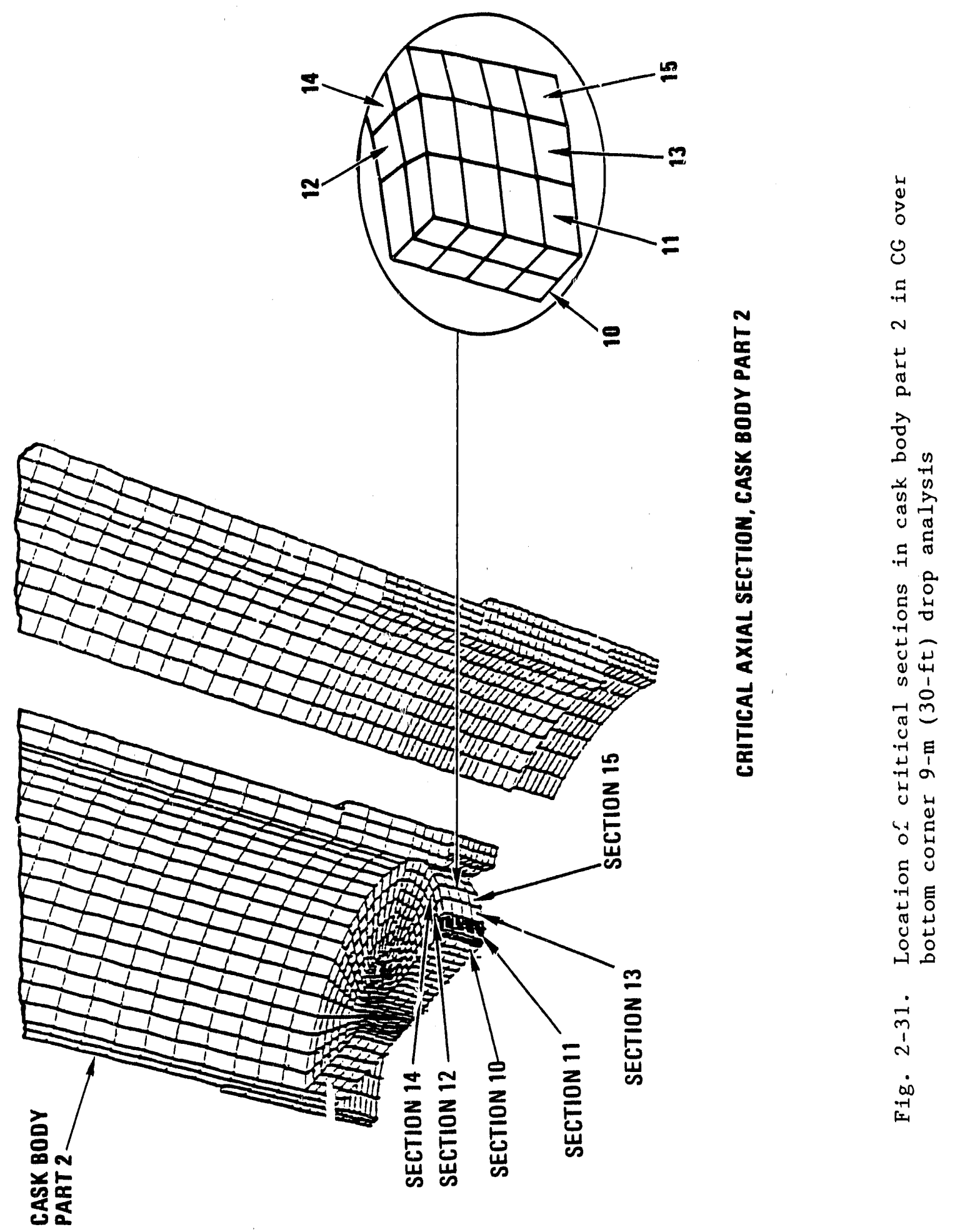


of the cask body. The time history effective stresses of the chosen elements and sections were plotted as detalled in Section 2.2.3. The peak primaxy membrane and local membrane plus bending stresses were chosen from the time history plots and are summarized in Table 2-6. The maximum value for both types of ats occurs in the bottom plate at the junction with the cask sidewali. Thy primary membrane stress has a design margin of +0.11 and the local membrane plus bending stress has a design margin of +0.27 . These stresses occur in the bottom plate, critical section 11 , at the junction with the cask sidewall. This section is in line with the inftial impact. As shown by the sections around 1t, critical Sections 10 and 12 through 15 , these stresses are highly localized. The time histories for the highest primary membrane stress and Local membrane plus bending stress are shown In F1gs. 2-32 and $2-33$.

No sections of this model are subject to pure shear so this design criterion does not apply.

2.3.4.4. Conclusions. The finfte element analys is of the cask during a center of gravity over bottom corner 9-m (30-ft) drop showed that large plastic deformations occur on the lower impact 1 imiter in an area about $120 \mathrm{deg}$ around the impact point. The results on the containment boundary were-compared to the requirements of Section 2.1 for ductile rupture, tearing, and shearing. It meets the criteria for all these failure modes. The half-scale model test program verifies that the cask does not buckle. 
TABLE 2-6

SUMMARY OF MAXIMUM STRESSES AT CRITICAL SECTIONS IN CONTAINMENT BOUNDARY DUE TO CG OVER BOTTOM CORNER $9-\mathrm{m}(30-\mathrm{ft})$ DROP

\begin{tabular}{|c|c|c|c|c|c|}
\hline \multirow[b]{2}{*}{$\begin{array}{l}\text { Critical } \\
\text { Section No. }\end{array}$} & \multirow[b]{2}{*}{ Location } & \multicolumn{2}{|c|}{$\begin{array}{c}\text { Maximum Primary } \\
\text { Membrane }\end{array}$} & \multicolumn{2}{|c|}{$\begin{array}{c}\text { Maximum Local } \\
\text { Membrane + Bending }\end{array}$} \\
\hline & & $\begin{array}{l}\text { Stress } \\
\text { (ks1) }\end{array}$ & $\begin{array}{c}\text { Design } \\
\operatorname{Margin}(a)\end{array}$ & $\begin{array}{l}\text { Stress } \\
\text { (ks } 1)\end{array}$ & $\begin{array}{l}\text { Design } \\
\operatorname{Margin}(b)\end{array}$ \\
\hline \multicolumn{6}{|c|}{ Cask Body S1dewa11 Above Bottom Plate } \\
\hline 1 & $\begin{array}{l}0 \text { to } 7.5 \mathrm{deg} \\
\text { above } z=9.0 \mathrm{in} .\end{array}$ & 35.8 & +0.45 & 43.2 & +0.65 \\
\hline 2 & $\begin{array}{l}0 \text { to } 7.5 \mathrm{deg} \\
\text { above } Z=16.75 \mathrm{in} .\end{array}$ & 22.6 & +1.3 & 35.4 & +1.01 \\
\hline 3 & $\begin{array}{l}0 \text { to } 7.5 \mathrm{deg} \\
\text { above } Z=25.75 \mathrm{fn} .\end{array}$ & 34.6 & +0.50 & 35.0 & +1.03 \\
\hline 4 & $\begin{array}{l}7.5 \text { to } 15 \mathrm{deg} \\
\text { above } Z=9.0 \mathrm{deg}\end{array}$ & 35.8 & +0.45 & 43.2 & +0.65 \\
\hline 5 & $\begin{array}{l}7.5 \text { to } 15 \mathrm{deg} \\
\text { above } z=16.75 \mathrm{in} .\end{array}$ & 28.8 & +0.80 & 35.4 & +1.01 \\
\hline 6 & $\begin{array}{l}7.5 \text { to } 15 \mathrm{deg} \\
\text { above } Z=25.75 \text { in. }\end{array}$ & 34.4 & +0.51 & 35.0 & +1.03 \\
\hline 7 & $\begin{array}{l}15 \text { to } 22.5 \mathrm{deg} \\
\text { above } Z=9.0 \mathrm{in} .\end{array}$ & 35.0 & +0.48 & 44.3 & +1.60 \\
\hline 8 & $\begin{array}{l}15 \text { to } 22.5 \mathrm{deg} \\
\text { above } Z=16.75 \mathrm{in} .\end{array}$ & 31.8 & +0.63 & 35.6 & +1.00 \\
\hline 9 & $\begin{array}{l}15 \text { to } 22.5 \mathrm{deg} \\
\text { above } Z=25.75 \mathrm{in} .\end{array}$ & 33.7 & +0.54 & 35.0 & +1.03 \\
\hline \multicolumn{6}{|c|}{ Bottom Plate at Junttion with Cask Sidewa11 } \\
\hline 10 & $\begin{array}{l}0 \text { to } 7.5 \mathrm{deg} \\
R=15.14 \mathrm{in} .\end{array}$ & 22.6 & +1.3 & 41.6 & +0.71 \\
\hline 11 & $\begin{array}{l}0 \text { to } 7.5 \mathrm{deg} \\
R=16.25 \mathrm{in} .\end{array}$ & 46.8 & +0.11 & 55.9 & +0.27 \\
\hline 12 & $\begin{array}{l}7.5 \text { to } 15 \mathrm{deg} \\
R=15.14 \mathrm{in} .\end{array}$ & 23.2 & +1.24 & 40.0 & +0.78 \\
\hline 13 & $\begin{array}{l}7.5 \text { to } 15 \mathrm{deg} \\
\mathrm{R}=16.25 \mathrm{in} .\end{array}$ & 44.2 & +0.17 & 52.5 & +0.35 \\
\hline 14 & $\begin{array}{l}15 \text { to } 22.5 \text { deg } \\
R=15.14 \mathrm{in} .\end{array}$ & 26.6 & +0.95 & 37.9 & +0.88 \\
\hline 15 & $\begin{array}{l}15 \text { to } 22.5 \mathrm{deg} \\
R=16.25 \mathrm{in} .\end{array}$ & 37.9 & +0.37 & 47.4 & +0.50 \\
\hline
\end{tabular}

(a) Primary membrane allowable is $51.9 \mathrm{ks} 1$.

(b) Local membrane plus bending allowable is $71.1 \mathrm{ks}$. 


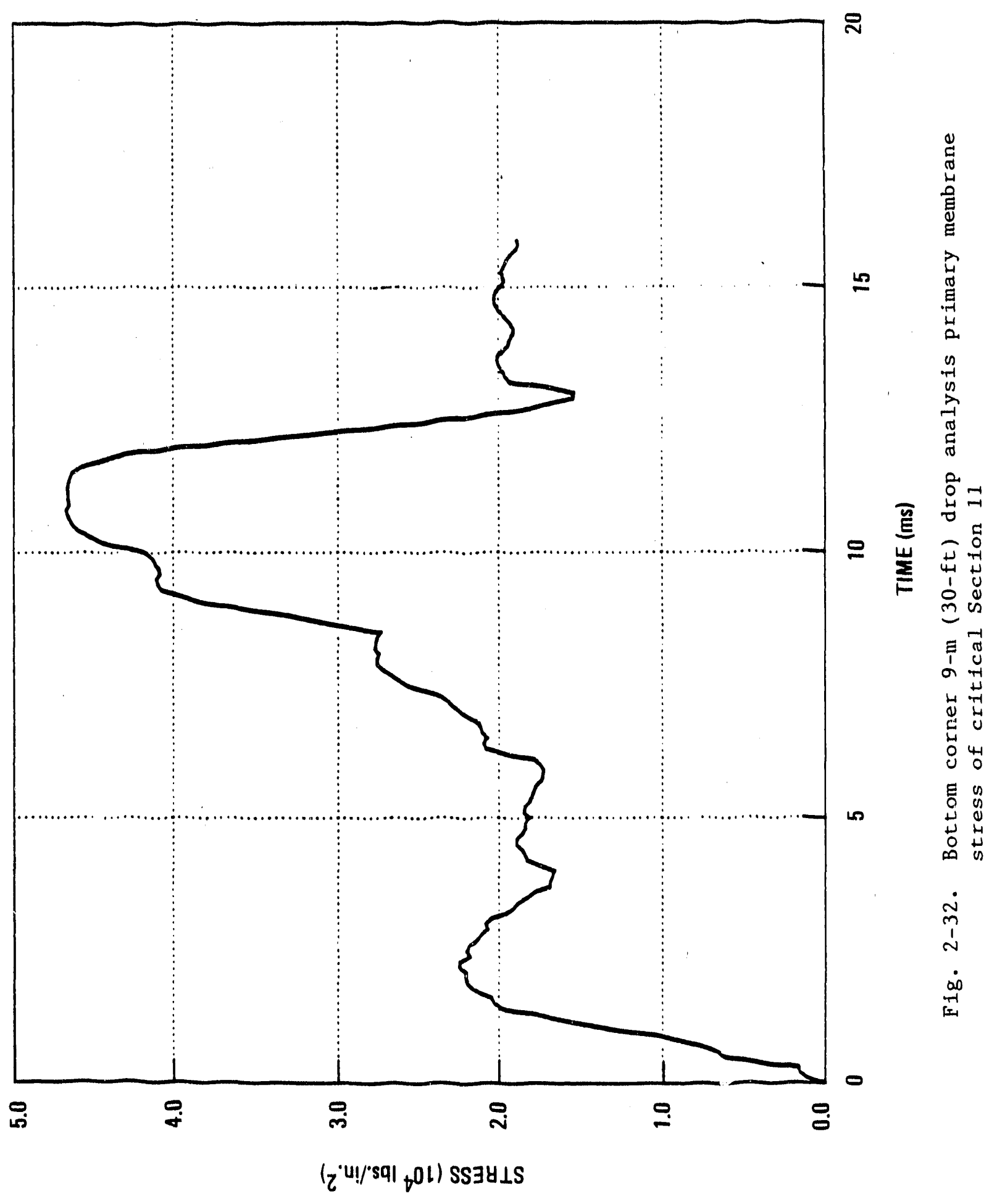




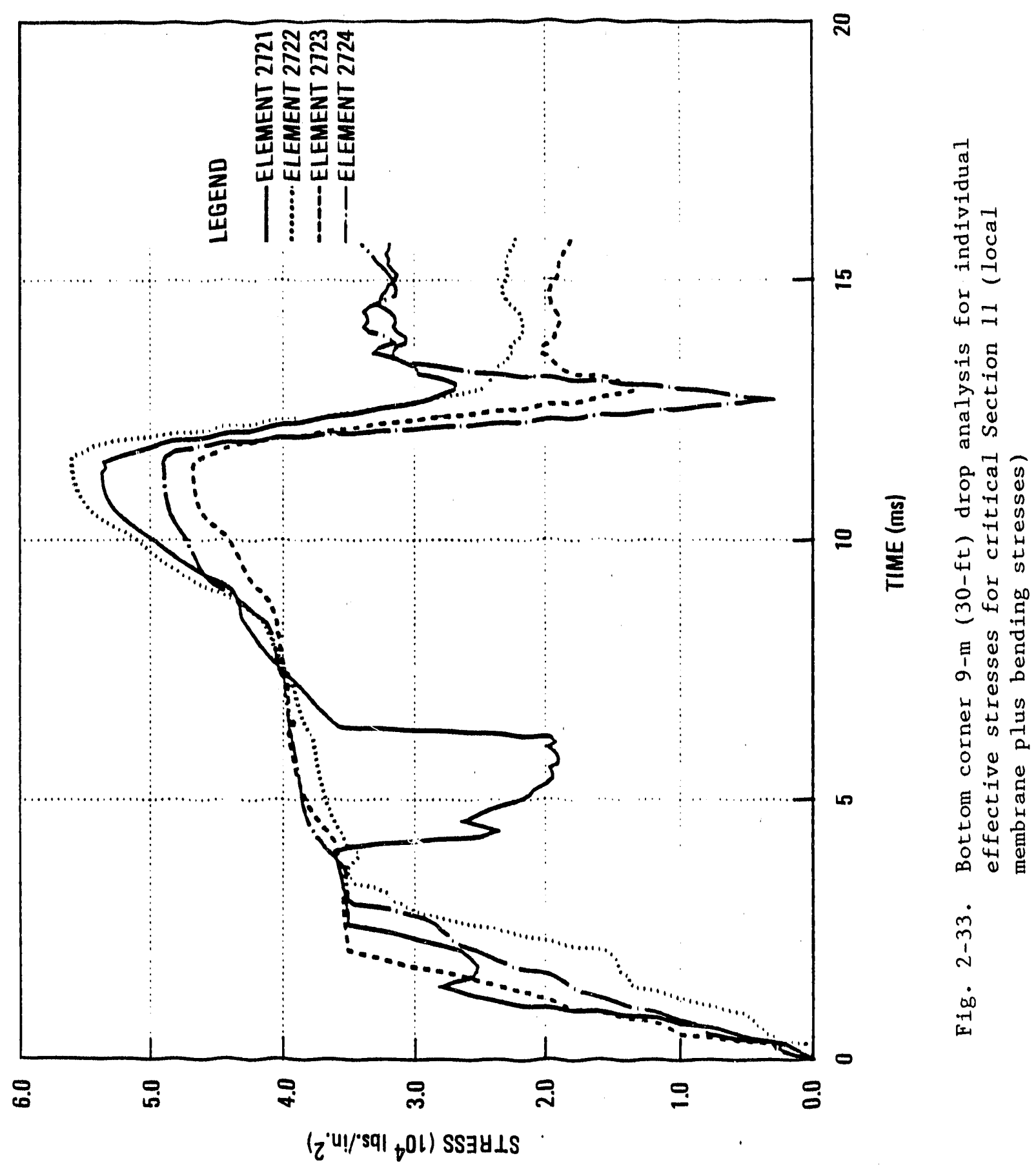




\section{ELASTIC ANALYSIS}

\subsection{STRUCTURAL CRITERIA}

The elastic analysis criterla presented in Regulatory Guide 7.6 were used for all analyses except for localized areas of the cask far removed from the closure seals for the bottom-end and $C G$ over bottom corner free drops. These elastic allowables are summarized in Tables 3-1 and 3-2. The material property data used in the analysis correspond to the design stress values, $S_{m}$; yleld strengths, $S_{y} ;$ and ultimate strengths, $S_{u} ;$ given in Appendix I of the ASME Code.

\subsection{ANALYTICAL METHODS}

The GACAP code (Ref, 1-2) developed at GA was used to analyze the kinematic response of casks during a free drop event. The GACAP code uses an elastic beam treatment of the cask. It has a single axis with multiple beams and is limited to small deformations in the beam elements while going through large rigid body motions of the whole cask. There is no damping allowed in the beam elements. All inelastic absorption of drop energy takes place in the impact absorbers. The calculation is an explicit step-by-step time integration. "igure 3-1 shows a typical cask model.

GACAP prints cask node motions and beam and impact limiter luads at user-specifled time intervals. A summary of maximum values is provided at the end of the run. Also, the code outputs the full energy state information. The energy state informs the user of the makeup of the remaining kinetic potential and elastic energy. 
TABLE 3-1

CONTAINMENT BOUNDARY ALLOWABLE STRESSES FOR ELASTIC ANALYSIS

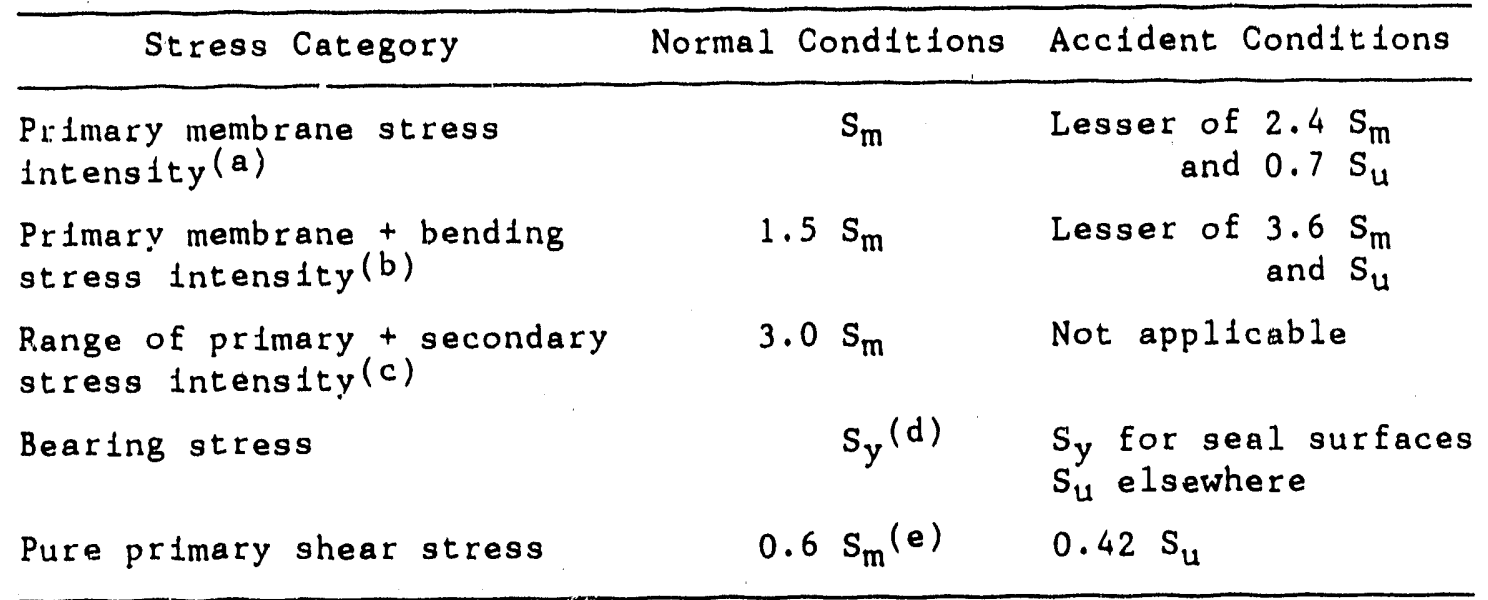

(a) Definition per NRC Regulatory Guide 7.6, Paragraph B.4, and ASME Code NB-3221.1. Example: average stress across cask body at middle of cask wall and at the rounded corners.

(b) Definition per NRC Regulatory Gulde 7.6, Paragraph B.3, B.4, ASME Code NB-3221.3. "xample: membrane component of primary siress for the cask under an upplied moment across the cask cross section shall be the stress proportional to the distance from the cask centrold.

(c) Definttion per NRC Regulatory Gulde 7.6, Faragraph C.4.

(d) From ASME NB-3227.1

(e) From ASME NB-3227.2 
TABLE 3-2

CONTAINMENT BOUNDARY BOLT STRESS ALLOWABLES

\begin{tabular}{|c|c|c|c|}
\hline Stress Category & Norma1 & Condilions & Accident Conditions \\
\hline $\begin{array}{l}\text { Membrane stress due to } \\
\text { Internal pressure(a) }\end{array}$ & & $\mathrm{S}_{\mathrm{m}}$ & Not applicable \\
\hline Membrane stress(a) & & $2.0 \mathrm{~S}_{\mathrm{m}}$ & $\begin{array}{r}\text { Lesser of } \quad \mathrm{S}_{y} \\
\text { and } 0.7 \mathrm{~S}_{\mathrm{u}}\end{array}$ \\
\hline $\begin{array}{l}\text { Membrane + bending } \\
\text { stress }(a)\end{array}$ & & $3.0 \mathrm{~s}_{\mathrm{m}}$ & $\mathrm{s}_{\mathrm{y}}$ \\
\hline Pure shear & $0.6 \quad 2.0$ & $\left.\mathrm{~S}_{\mathrm{m}}\right)=1.2 \mathrm{~S}_{\mathrm{m}}$ & $\begin{aligned} \text { Lesser of } & 0.6 \mathrm{~S}_{\mathrm{y}} \\
\text { and } & 0.42 \mathrm{~S}_{\mathrm{u}}\end{aligned}$ \\
\hline
\end{tabular}

(a) Not considering stress concentrations. 


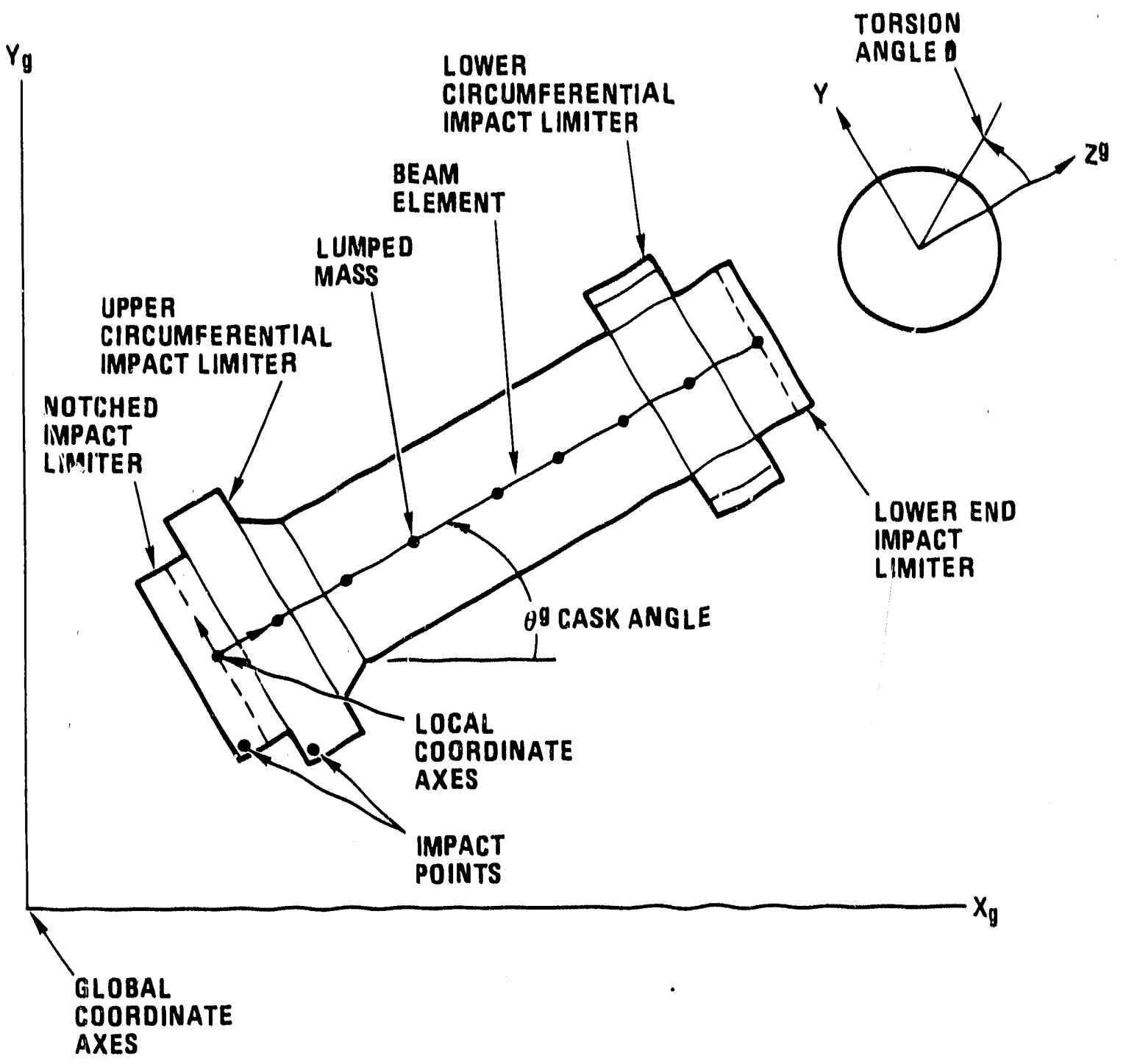

Fig. 3-1. Mode1 of DHLW cask using lumped nass and beam representation 
GACAP provides the user with the resultant beam loads from the rigld-body and flextble-body modes. The output also includes stress values at midlength in the mldwall. The code and theory are well documented in Rnf. 1-2. It is verifled by comparisons with the DYNA3D (Ref. 2-4) and SCANS (Ref. 3-1) codes. As discussed in Section 3.3.2.3, test results showed that the flextble-body results are very conservative and the rigid-body results are more representative of the actual response of the cask. Therefore, the rigld-body results are used to reprusent the cask stress state during the impact events.

\subsubsection{Theory of Modeling}

\section{Formulation}

The code models the cask with a series of aligned beam elements and mass nodes numbered from left to right. The basic mass and stffiness formulations of the code are standard. Equation 3-1 characterizes the equations of motion in the local coordinate system for a straight line of massless beam elements and $n$ lumped node masses (each with three degrees of freedom, $X, Y, \theta)$.

$$
[M]\{\ddot{X}\}=\left\{F_{11 m}\right\}+\left\{F_{g}\right\}+[K]\{X\},
$$

where

$$
\begin{aligned}
& {[M]=} \text { the mass/mass moment of inertia matrix, which is } \\
& \text { diagonalized, } \\
&\{\ddot{\mathrm{X}}\}= \text { the displacement and rotation acceleration vector, } \\
&\{\mathrm{X}\}= \text { the displacement and rotation vector, } \\
&\left\{\mathrm{F}_{1 \mathrm{Im}}\right\}=\text { the force vector Imposed by the limfters, } \\
&\left\{\mathrm{F}_{\mathrm{g}}\right\}=\text { the body force vector from the acceleration of gravity, } \\
& {[\mathrm{K}]=\text { the stiffness matrix of the beam structure. } }
\end{aligned}
$$

This equation is in the local beam coordinate system which has the coordinates and directions of node 1 of the cask model. There are 
$3 *^{*}$ degrees of freedom in Eq. 3-1. The sequence is $X_{1}, Y_{1}, \theta_{1}, X_{2}, Y_{2}$, $\theta_{2} \ldots X_{n 1}, Y_{n}, \theta_{n}$.

The stiffness mat $: 1 \mathrm{x}[\mathrm{K}]$ is assembled from the $6 \times 6$ stiffness matrices of the individual beam elements. This $6 \times 6$ symmetric element matrix can be characterfzed for element 1 as

$$
\left[\begin{array}{ll}
A_{1} & B_{1} \\
B_{1}^{T} & C_{1}
\end{array}\right] \quad \begin{aligned}
& \text { where } A, B \text {, and } C \text { are } 3 \times 3 \text { submatrices and } B^{T}, \\
& \text { 1s the transpose of } B .
\end{aligned}
$$

The element stiffness matrices are assembled into the total stiffness $\operatorname{matrix}[K]$

$$
\{F\}=[K]\{X\} .
$$

Here $\{X\}$ vector $X_{1}, Y_{1}, \theta_{1}$ are the coordinates of the nodes in the local coordinate system and the $\{F\}$ vector $F_{X_{1}}, F_{Y_{1}}, M_{\theta_{1}}$ are the resultant loads on the nodal points also in the local system.

Equation 3-1 is used to compute the accelerations in the directions of the local coordinete system. The local accelerations are then rotated into the directions of the global coordinate system and integrated to obtain incremental displacements:

$$
\begin{gathered}
\left\{\ddot{x}_{j}^{g}\right\}=\left[R_{j 1}\right]\left\{\ddot{x}_{1}\right\}, \\
\{3 * n, 1\}\{3 * n, 3 * n]\{3 * n, 1\}
\end{gathered}
$$

where

$\mathrm{n}=$ the number of nodes, $\{\ddot{x} g\}=$ the acceleration vector in the global coordinate system, $\left\{\ddot{\mathrm{X}}_{1}\right\}=$ the acceleration vector in the local coordinate system, $\left[R_{j 1}\right]=$ the rotation matrix. 
GACAP solves these equations explicitly using central difference integration of the accelerations. The local deformed state of the beam is updated using the resulting deflection and rotation.

The local displacement/rotation yector $\{X\}$ is then multiplied by the stiffness matrix $[\mathrm{K}]$ to produce the furces and moments imposed by the beams on the nodes.

\section{Impact Limiter Forces}

GACAP provides the user with flexibility in the treatment of the impact limiters. The impact limiter is "slaved" to a node by a rigid cortuestion between the impact limiter contact point and the node. The impact limiters are massless in the model. Their masses are lumped into the respective nodal mass. The limiters impose forces and moments on specified model nodes. The model for the impact limiter can be seen in Fig. 3-1. The left side limiter is shown connected to node 1; however, limiters can be connected to any node in the model. The model can also include several impact limiters connected to different nodes, each with their own load-deflection tables. The code positions the cask vertically so that the inftial impacting limiter just contacts the impact plane at the start of the run.

The impact limiter normal force will always act at the contact point, producing moments on the connected cask node. The code calculates the impact limiter force by interpolating from the user-defined force-deflection tables, using the vertical displacement overlap of the contact point with the impact plane.

The code accommodates impact limfter designs in which the behavior can change depending on the direction (torsion angle, see Fig. 3-1) relative to the cross section of the cask. Each force deflection table for an impact limiter is associated with a cask angle $\theta \mathrm{g}$ and a torsion angle $\phi$ (see Fig. 3-1). Since the model is two-dimensional, the initial 
torsion angle is used throughout the calculation. A linear interpolation of the tables is made for both the cask angle and the torsion angle. For the DHLW cask, the torsion angle ts set equal to zero since the cask cross section is circular. Cask angle specification for the tables must be between 0 and $90 \mathrm{deg}$. Different load-deflection curves were input for cask angles $\theta$ at every $15 \mathrm{deg}$.

The user may include a horizontal friction force in the GACAP analysis. This force is dependent on the magnitude of the impact limfter normal force. The code treats the friction force at each limiter as a viscous damper which opposes the horizontal velocity of the limiter on the impact plane. No friction was used since the NRC requires that the kinetic energy be absorbed only by crushing of the impact limiters and not by other means.

\section{Section Properties}

GACAP provides the user with flexibility to input the desired section properties. The program computes stiffness properties for the circular cylinder and the rounded-corner square box. For the DHLW cask, only the cylinder cross section input is required. The user may also input the properties of the beam sections as shown in Fig. 3-2.

The code allows for mixed multiple beam input, between adjacent nodes. The parallel beam stiffnesses are simply added together to create the model. The user may define the properties of the beams between adjacent nodes independantly. Therefore, the code can be used to analyze cask designs with variable cross sections. For the DHLW analyses it was chosen to let the code calculate the cylinder properties.

The code allows the user to either input directly the mass moment of inertia of each node or to have the code calculate this parameter. The latter option was used during the DHLW analyses. The user may also 


\begin{tabular}{|l|l|}
\hline CROSS SECTION & TYPE OF INPUT \\
\hline CYLINDERS & $\begin{array}{l}\text { ROUNDED-CORNER } \\
\text { BOX SECTIONS }\end{array}$ \\
\hline $\begin{array}{l}\text { ARBITRARY } \\
\text { SHAPE }\end{array}$ & \\
\hline
\end{tabular}

WHERE

$E=$ ELASTIC MODULUS $L=$ LENGTH OF BEAM

$A=$ AREA OF THE CROSS SECTION $G=$ SHEAR MODULUS

$I=$ MOMENT OF INERTIA $f=$ SHEAR FORM FACTOR

J. $025(16)$

4.6-89

Fig. 3-2. Different types of section properties input accepted by GACAP 
provide a value for the shear form factor in order to calculate the appropriate shear deformation of the beam. A value of one was used in the analyses. This includes the full value of the shear form factor calculated by the code in the stiffness matrix formulation.

\section{Flexible- and Rigid-Body Beam Loads}

Along with the beam loads from the flexible-element analysis, the code also provides beam loads based on the cask acting as a single rigid body with three degrees of freedom, see Fig. 3-3. In the flexible-element mode1, each node has its own accelerations computed from the $3 * n$ degree of freedom model. A comparison of the rigid-body results with the flexible-element results provides information on the dynamic amplification factor (DAF).

To calculate the beam loads from the rigid-body accelerations, each node is given accelerations in the local coordinate system dependent on its position from the CG. The rigfid-body nodal accelerations are used to compute body forces and moments on the nodes. The body forces along with the forces imposed by the impact limiters and gravity compitse the rigid body force-moment loading on the cesk.

The printout for the rigid-body beam loads conforms with that of the dynamic beam loads.

\subsubsection{Vertfication}

\section{Verification with DYNA3D}

GACAP was initially verified using DYNA3D. DYNA3D can perform some of the same cask calculations as GACAP. However, since DYNA3D is a generai code developed for very complex geometries and varled problems, it is more difficult to use than GACAP and has significant limitations for cask analysis. 


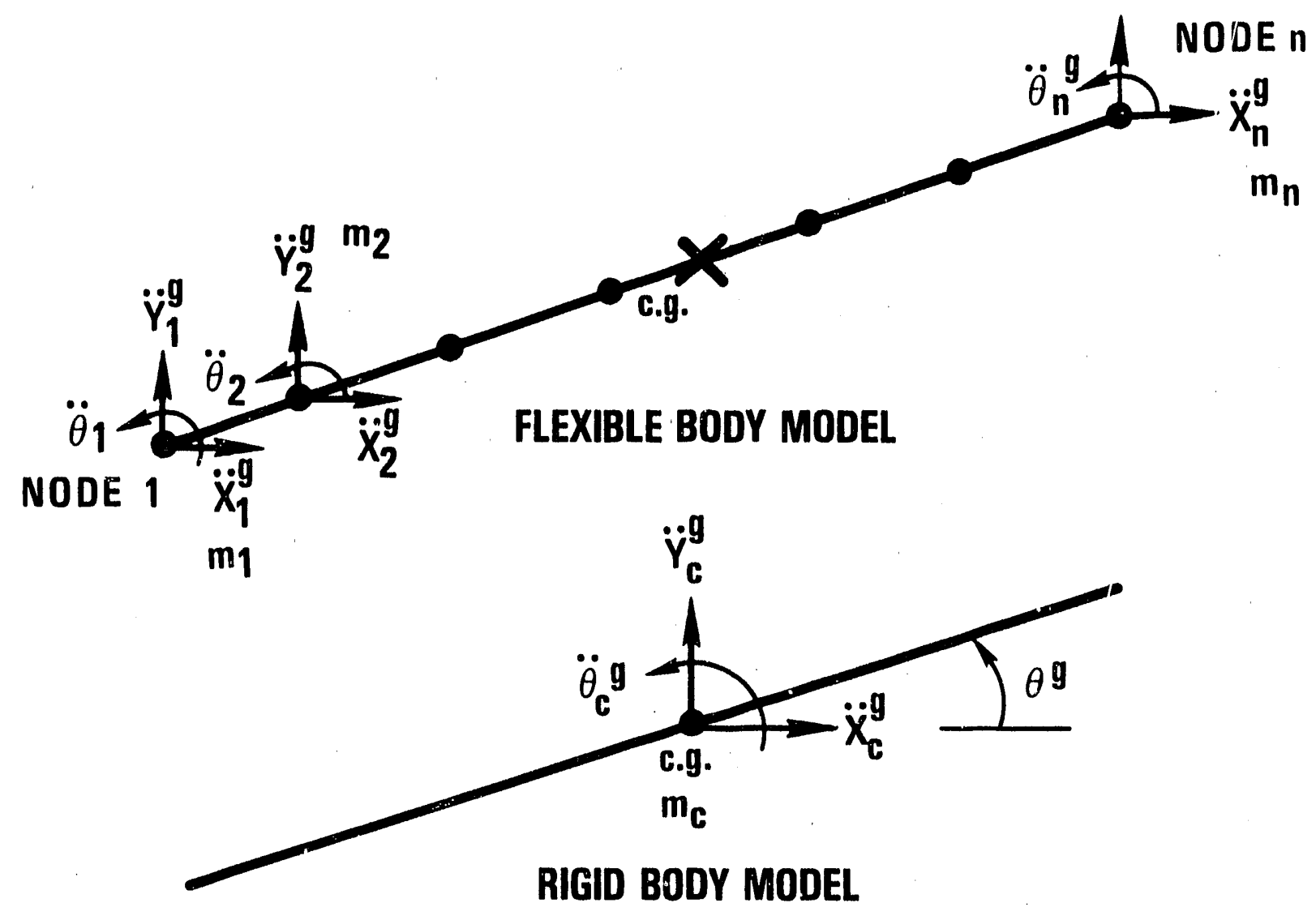

$\mathrm{J}-025(4)$

BOTH SOLUTIONS ARE DYNAMIC

4-3-89

F1g. 3-3. GACAP provides both the flexible body and rigid body dynamic solutions 
Figure 3-4 shows the model run in both GACAP and the DYNA3D code. The cask impacts from a $30-\mathrm{ft}$ height at $30 \mathrm{deg}$ from the horizontal plane. There are two impact 1imiters. GACAP and DYNA3D use identical geometry, inftial conditions, nodal masses, and mass moments of inertia. The DYNA3D model simulates the Impact limiters using the discrete spring input.

Figure 3-5 shows the motion of the end nodes 1 and 7 for the GACAP and DYNA3D models. The movement is essentially identical. This plot confirms that the impact limiters are performing correctly. The more meaningful correlation is the comparison of the time variation of beam loads where the high frequency beam structure modes appear. These have been plotted for beam element $6 \mathrm{in} \mathrm{FIg.} \mathrm{3-5.} \mathrm{The} \mathrm{correlation} \mathrm{is} \mathrm{exce1-}$ lent and verifies the GACAP code. The verification is explained in deta11 in Ref. 1-2.

\section{Comparison with the SCANS Code}

GACAP has also been compared with the Lawrence Livermore Laboratory SCANS code (Ref, 3-1). SCANS is based on the same formulation as GACAP. Table 3-3 shows that both codes give equivalent results during primary Impact or when the cask does not rebound.

The primary difference between GACAP and SCANS results arises from the fact that SCANS eliminates the beam dynamics during the free flight of the cask (rebound). If this assumption is simulated in GACAP, the secondary impacts also compare identically.

\subsection{CASK ANALYSIS}

The DHLW cask was evaluated for the $30-\mathrm{ft}$ free drop for varlous drop orientations. GACAP (Section 3.2) was used to perform this elastic analysis. The analysis was performed for drop orientations rangin: from 0 to 90 deg at 15 deg intervals, including CG over corner drops and at 

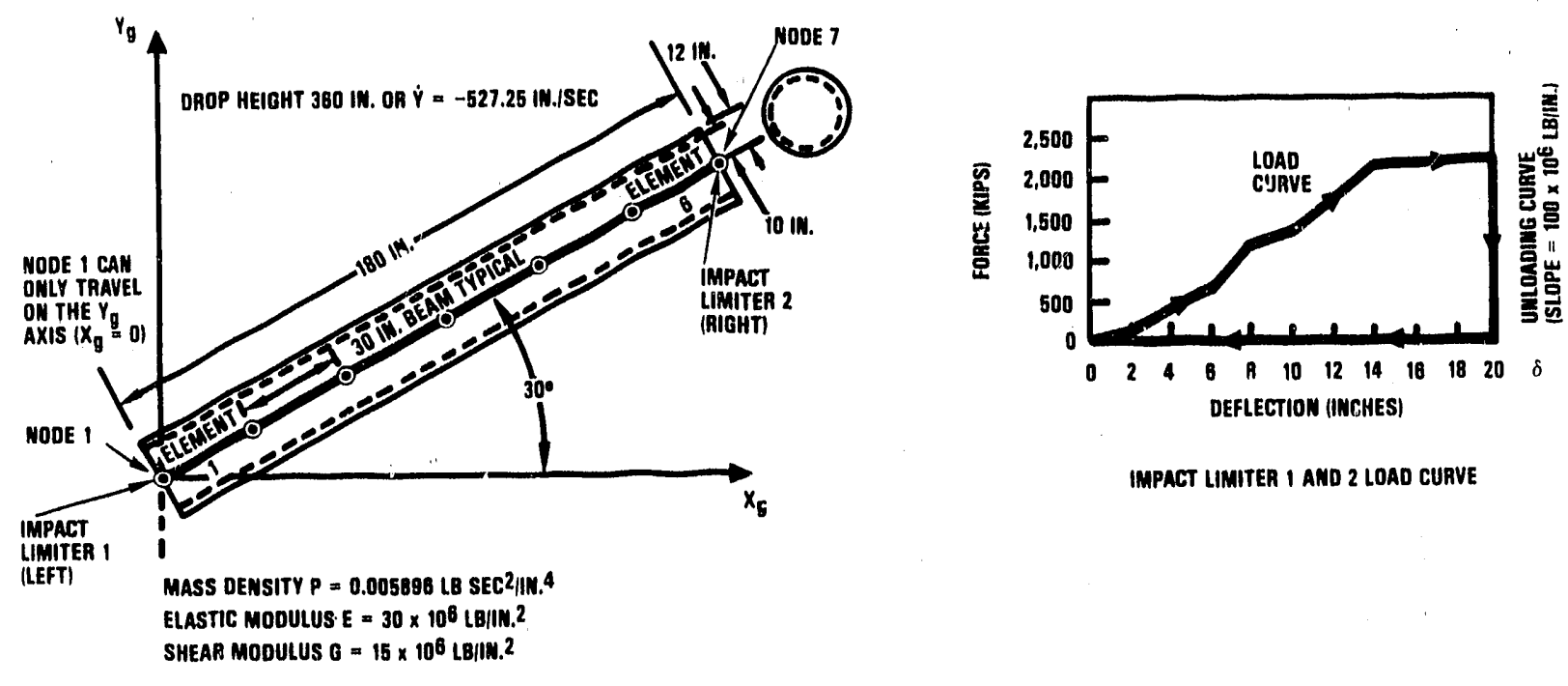

IMPACT LIMITER I AND 2 LOAD CUAVE

Fig. 3-4. GACAP model used for verification with DYNA3D 

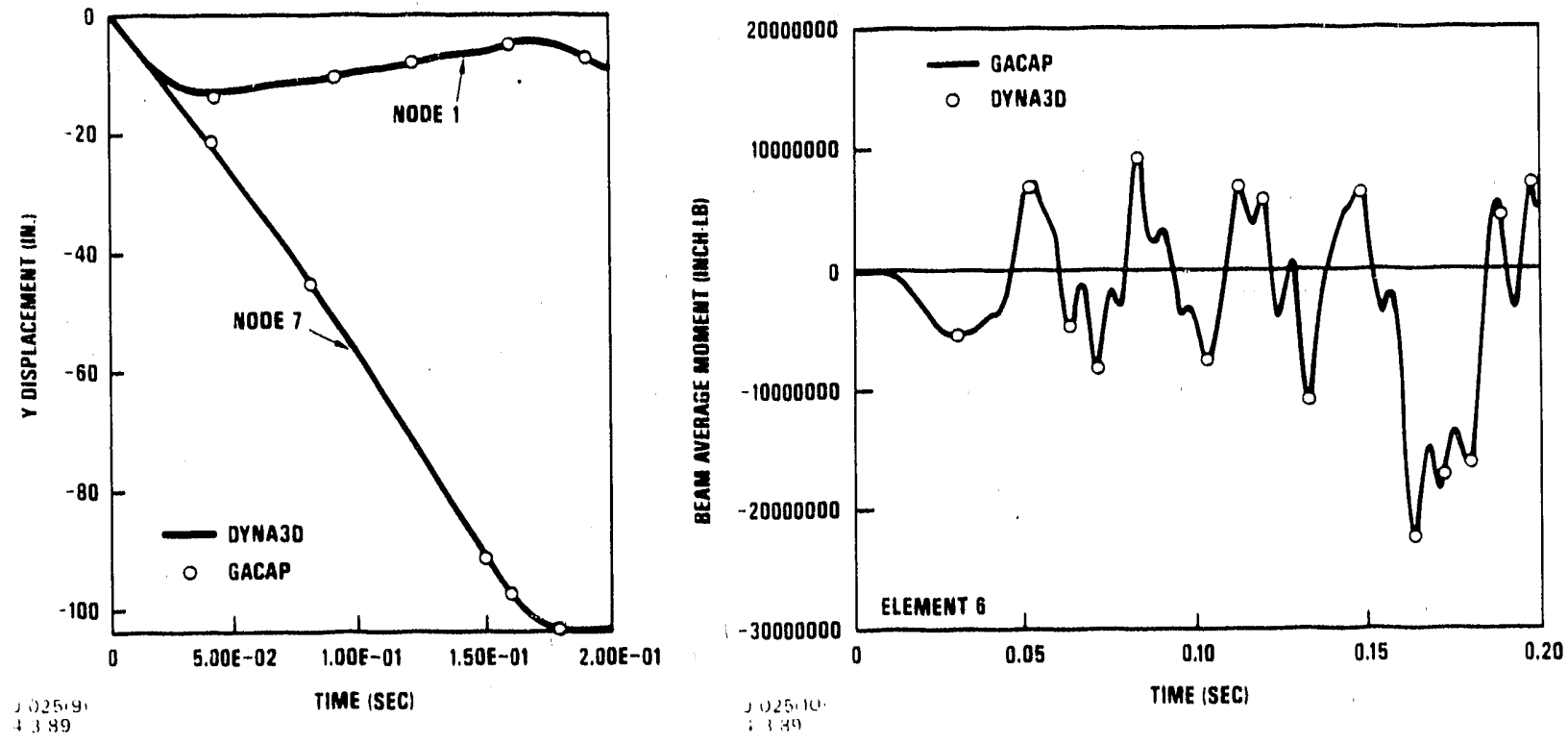

F1g. 3-5. Comparison of GACAP and DYNA3D nodal displacement and beam moment results 
TABLE 3-3

COMPARISON OF RESULTS BETWEEN SCANS AND GACAP

\begin{tabular}{lll}
\hline \multicolumn{1}{c}{ Identical 30 ft Side Drop Analyses } & SCANS & GACAP \\
\hline Crush (in.) & & \\
Top & 10.5 & 10.5 \\
Bottom & 10.5 & 10.5 \\
Maximum dynamic moment (in.-kip) (center node) & 71868 & 71930 \\
Maximum dynamic shear (kip) & 1134 & 1132 \\
\hline
\end{tabular}


10 deg to simulate the slapdown tested with the half-scale model. The first step in the analysis was to generate load-deflection curves for all impact limiters for all drop orfentations whish were then used in the GACAP analysis.

\subsubsection{Impact Limiter Load-Deflection Curve Tests}

3.3.1.1. Introduction. The DHLW shipping cask has four external impact limiters that are designed to protect the cask during the normal condition $0.3-\mathrm{m}(1-\mathrm{ft})$ free drops and during the hypothetical accident condition 9-m (30-ft) free drops. These impact limiters include (1) the lower end impact limiter, (2) the notched impact 1initer, (3) the lower circumferential impact limiter, and (4) the upper circumferential impact limiter. The GACAP analysis for the free drops requires the forcedeflection characteristics of the impact limiters.

3.3.1.2. Test Description. SNL performed the tests in their laboratories sccording to written test procedures provided by GA. SNI measured the load-deflection curves for the impact limiters by gradually applying a compressive load to scale models of the impact 1 imiters, and recording the applied load versus deflection of the test articles. The GACAP analysis required that the tests be performed for a range of angles that represent all possible impact angles of the cask as 1 isted below (90 deg represents an end drop orientation):

1. Lower end impact 11m1ter - $15,30,45,60,75.7$, and 90 deg.

2. Notched impact 1 Imiter - 15, 30, 45, 60, 73.4, and $90 \mathrm{deg}$.

3. Upper circumferential impact limiter - 0, 12, and $24 \mathrm{deg}$.

\subsubsection{Test Articles and Fixtures. The test articles were 1/6-scale} for the notched and lower end impact limiters and 1/3-scale for the circumferential impact limfter. GA designed and procured the test articles and shipped them to SNI for testing. SNL generated test procedures based on a GA test specification. Figures 3-6 through 3-9 show the test 


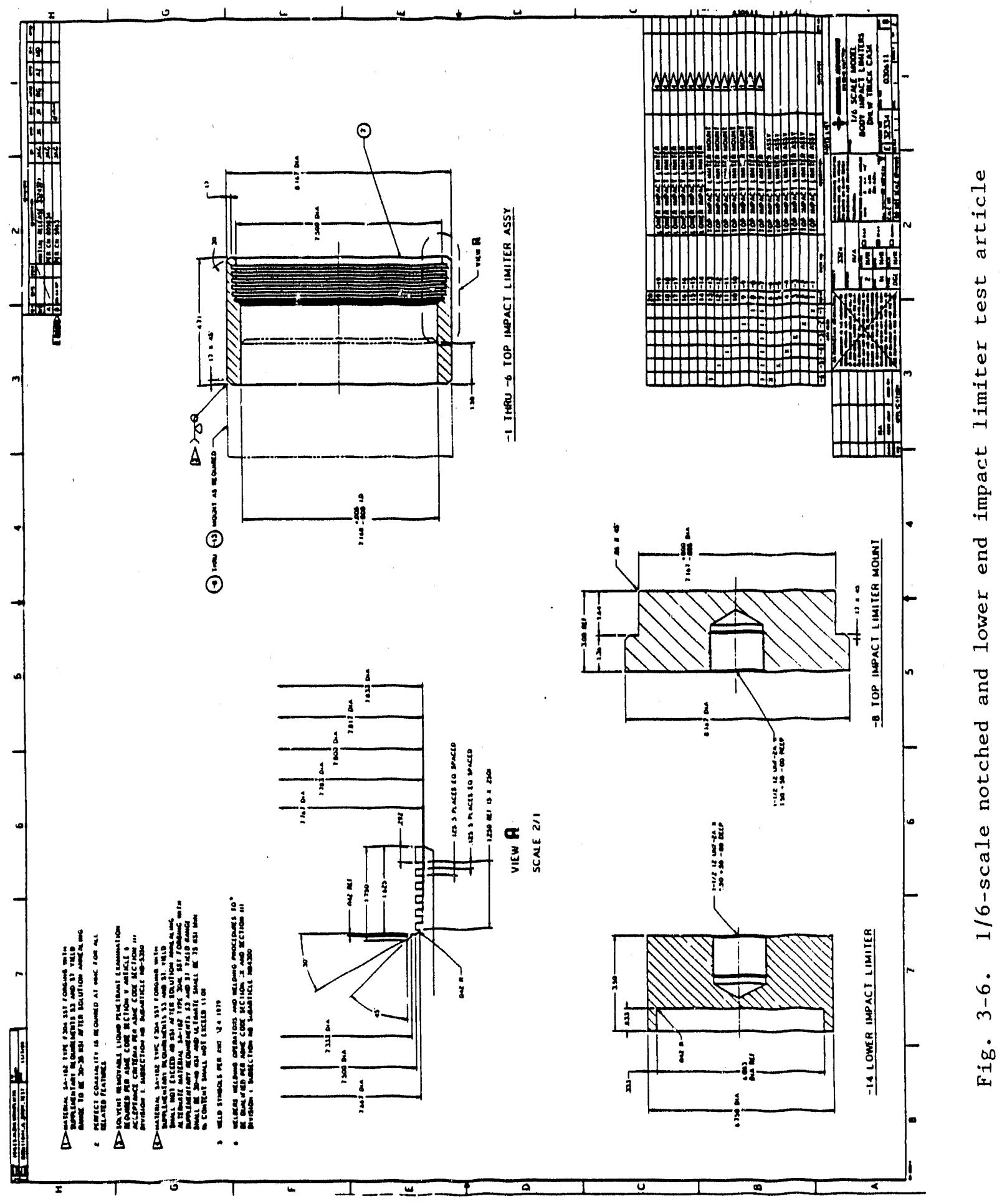




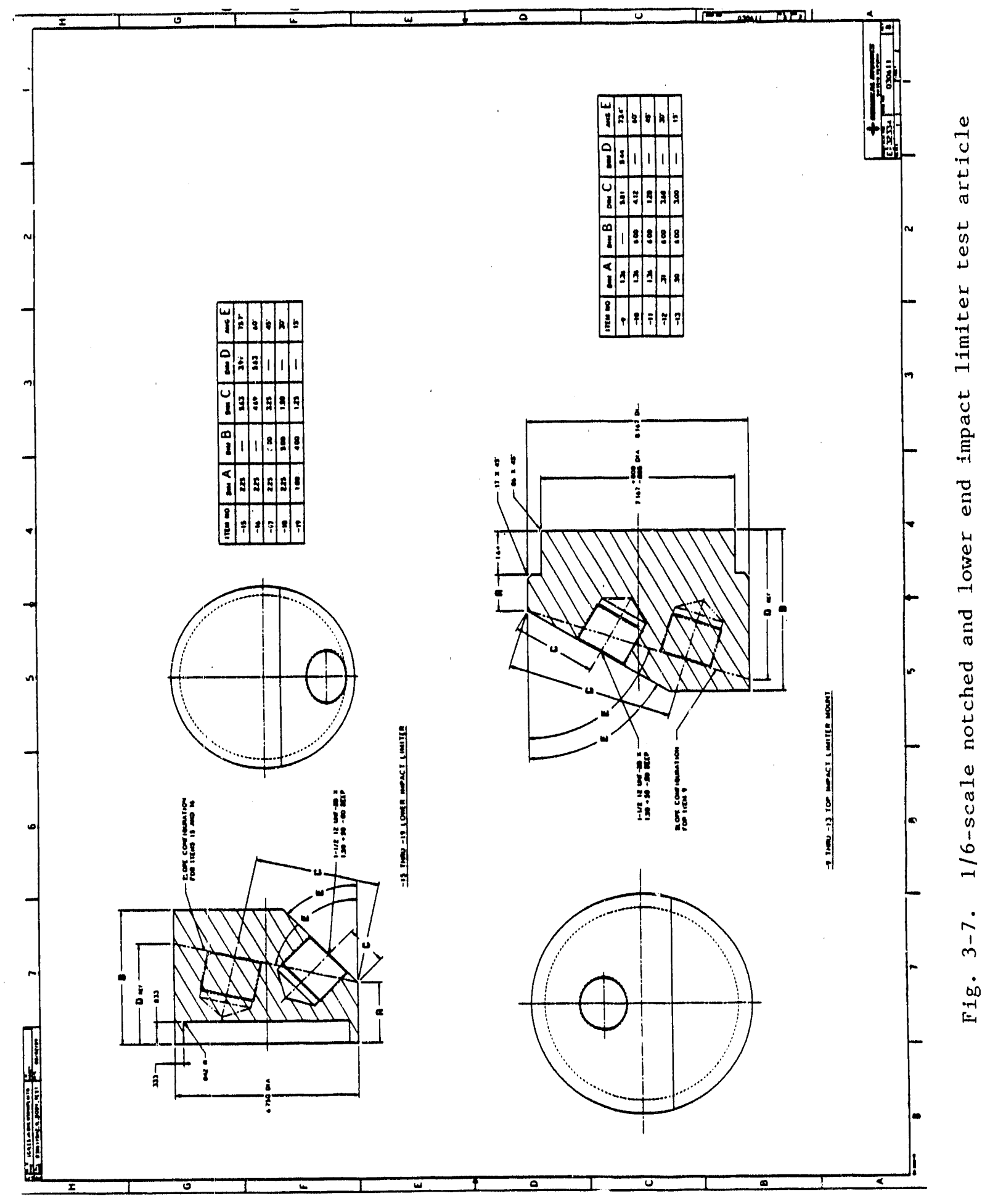




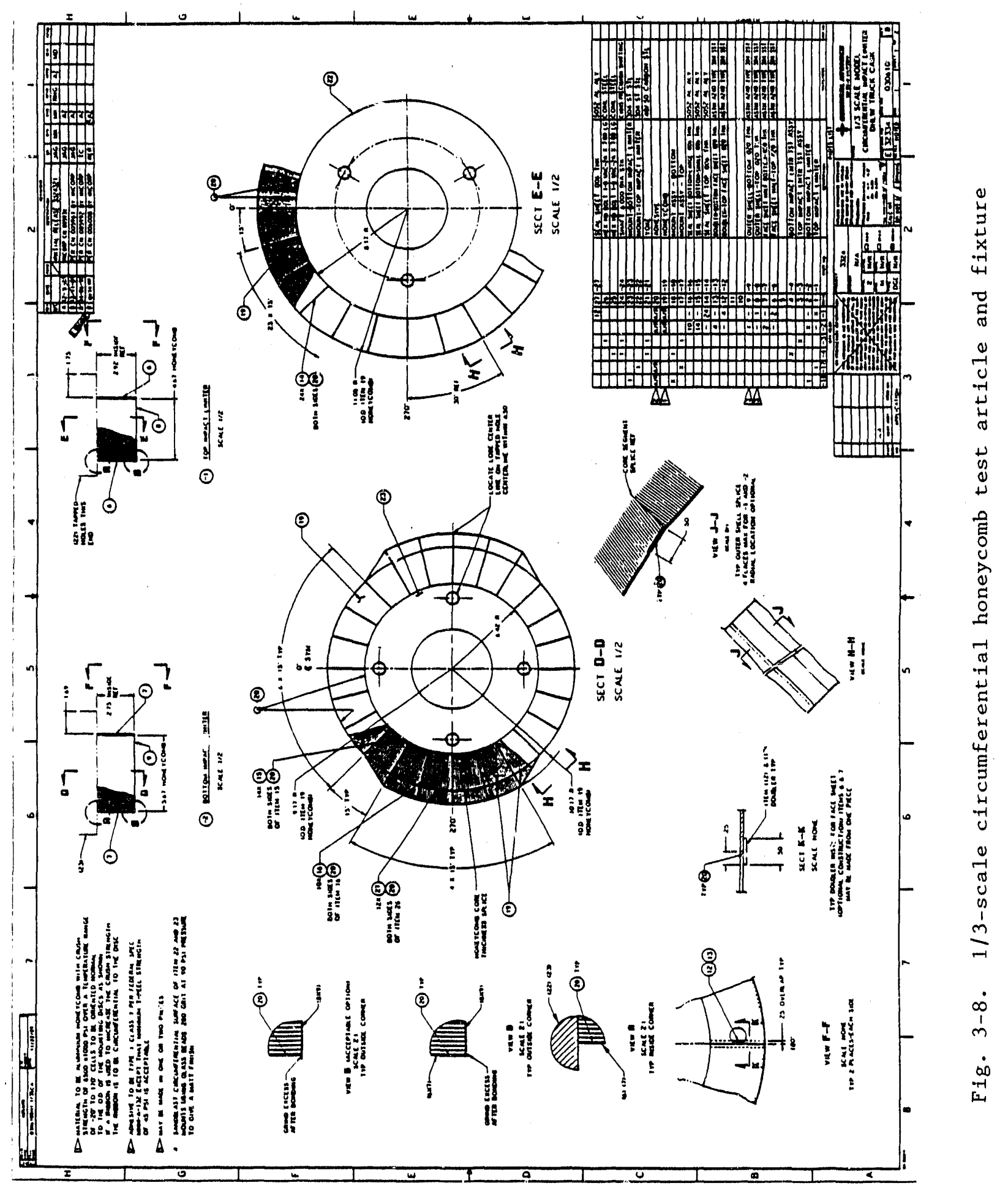




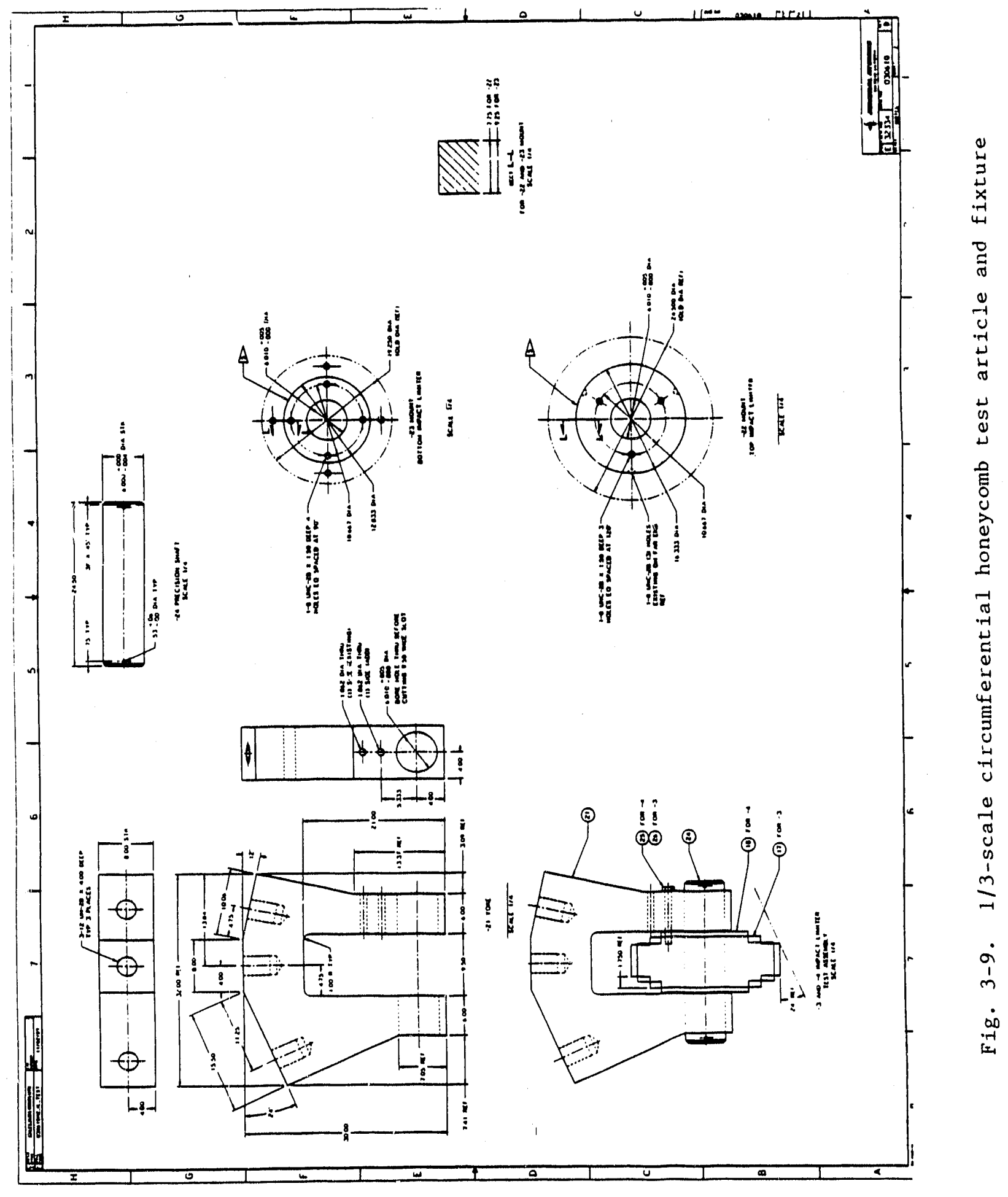


article and fixture drawings. The lower end impact limiter test articles include the ring impact limfier which is integral with a thick rigid plate that is beveled at the six test angles. The notched impact Iimiter is an exact $1 / 6$-scale model which is welded to a thick rigid plate which is beveled at the six test angles. The upper circumferential honeycomb impact limiter test article includes a 1/3-scale honeycomb impact limfter bonded to a rigid stainiess steel plate which represents the cask. A mandrel is used to load the impact limiter at the three test angles through a shaft through the center of the stainless steel plate as shown on F1g. 3-9.

3.3.1.4. Instrumentation. SNL used two deflection transducers to mea. sure deflection. To measure load, the testing machine hydraulic pressure is converted to a force. SNL calibrated the testing machine (Tinius/01sen with $600,000 \mathrm{lb}$ capacity) just before they performed the tests. During the test, a strip chart recorder plotted the load verses deflection using one of the two deflection transducers. Figures 3-10 and 3-11 show the notched impact limiter 45 deg test and the lower end impact limiter 15 deg test with the vires connected to the two deflection transducers, one on the left of the test article and one on the right.

3.3.1.5. Test Results and Evaluation. Figures $3-12$ and $3-13$ show the notched and lower end impact limiters after the tests. Figure 3-14 shows the circumferential impact limiter after the tests. Figures 3-15 through 3-26 show plots of the raw data for the notched and lower end impact limiter test articles. Figures 3-27 through 3-29 show plots of the raw data for the circumfeiential impact limiter. Note that there are two curves, one for each deflection transducer. 


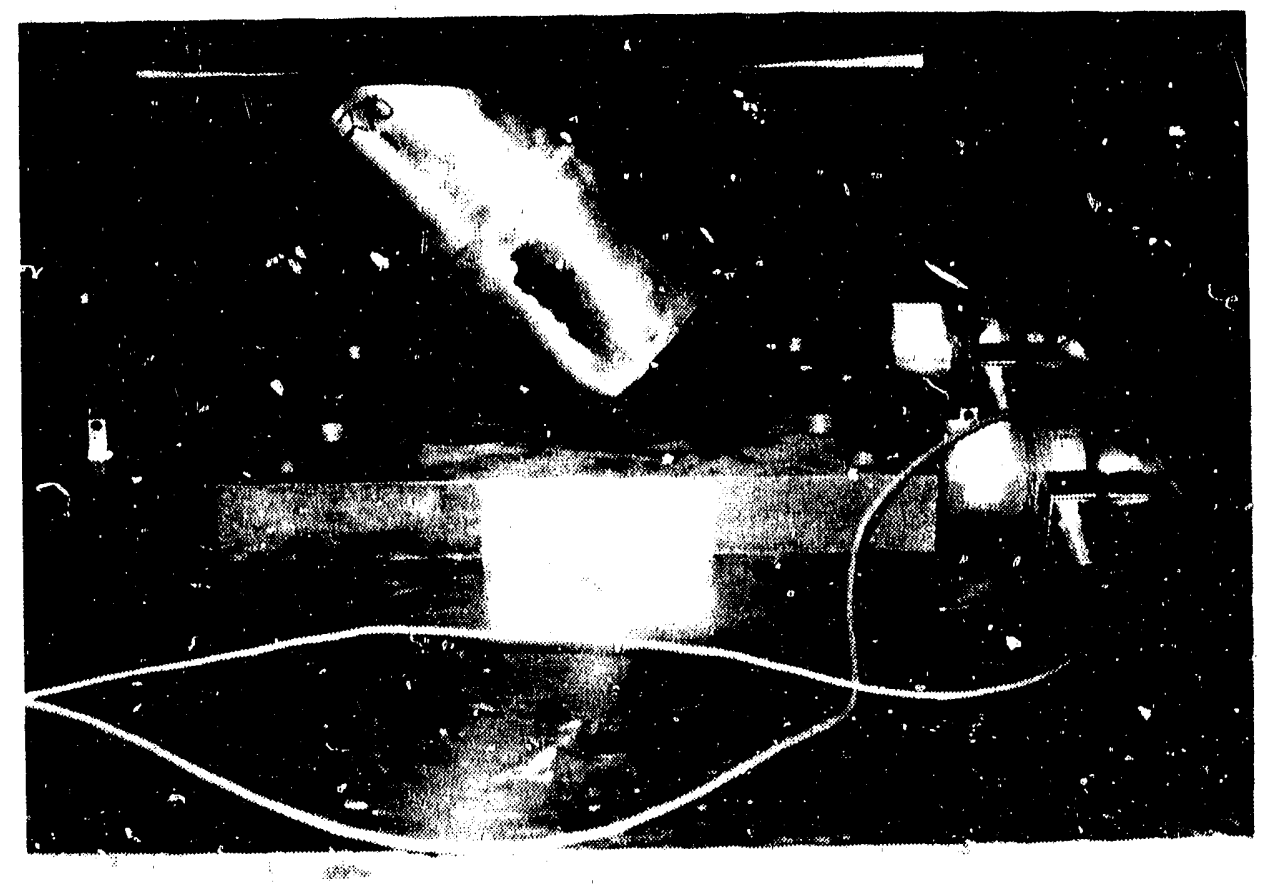

Fig. 3-10. Notched Impact 1imiter, 45 deg test 


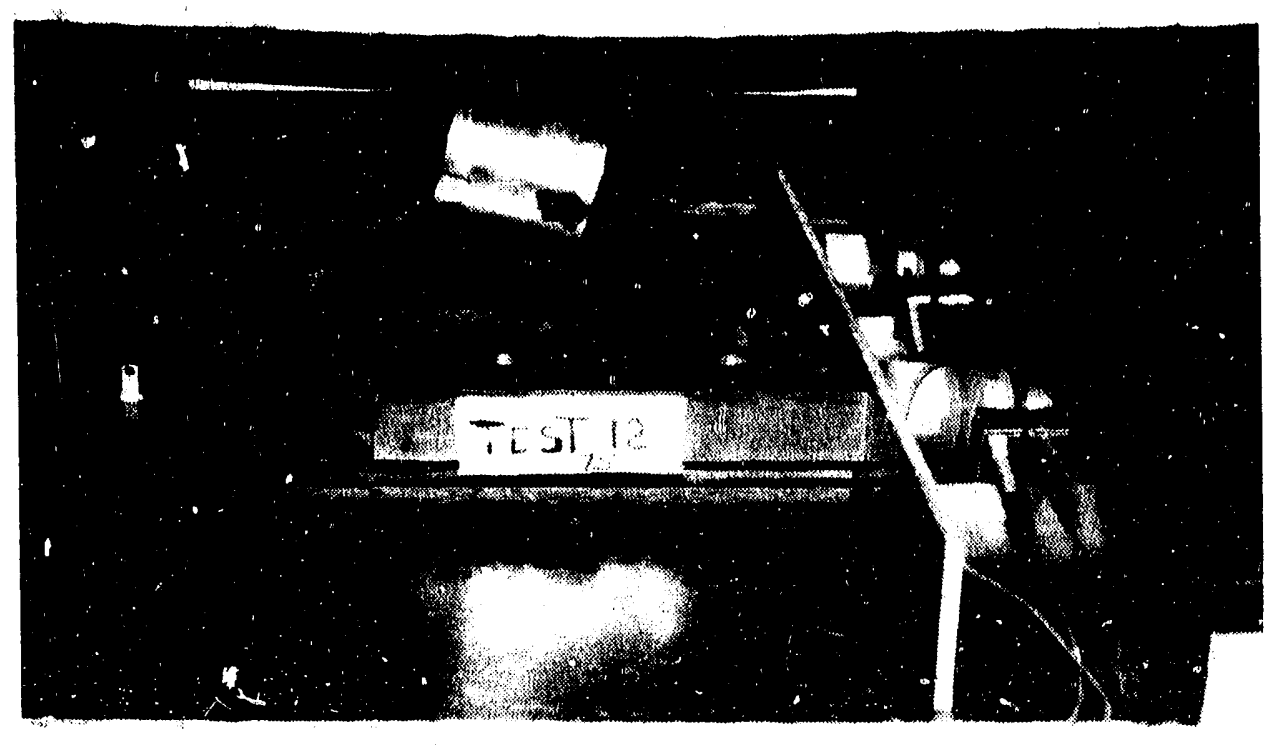

Fig. 3-11. Lower end impact limiter, 15 deg test 


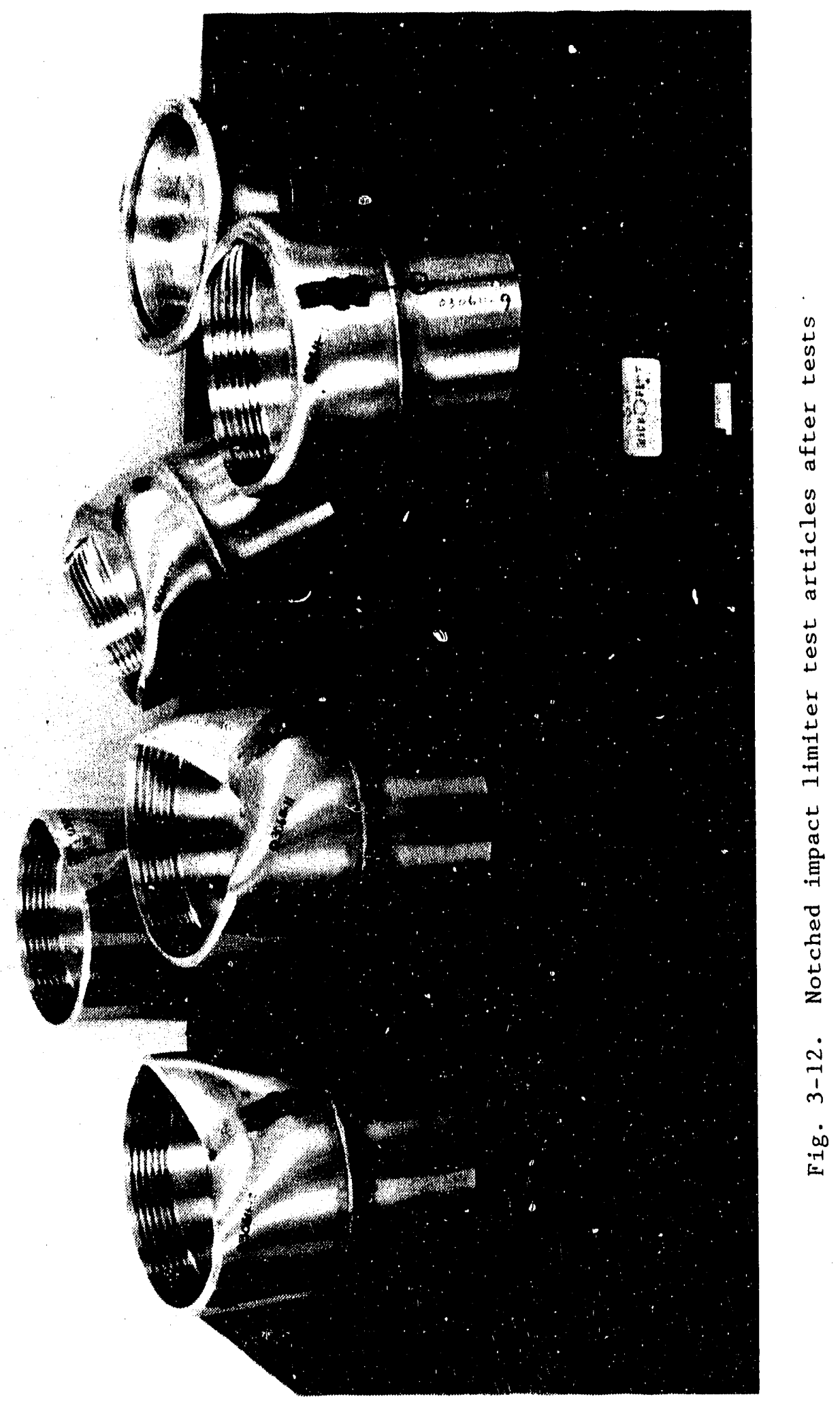




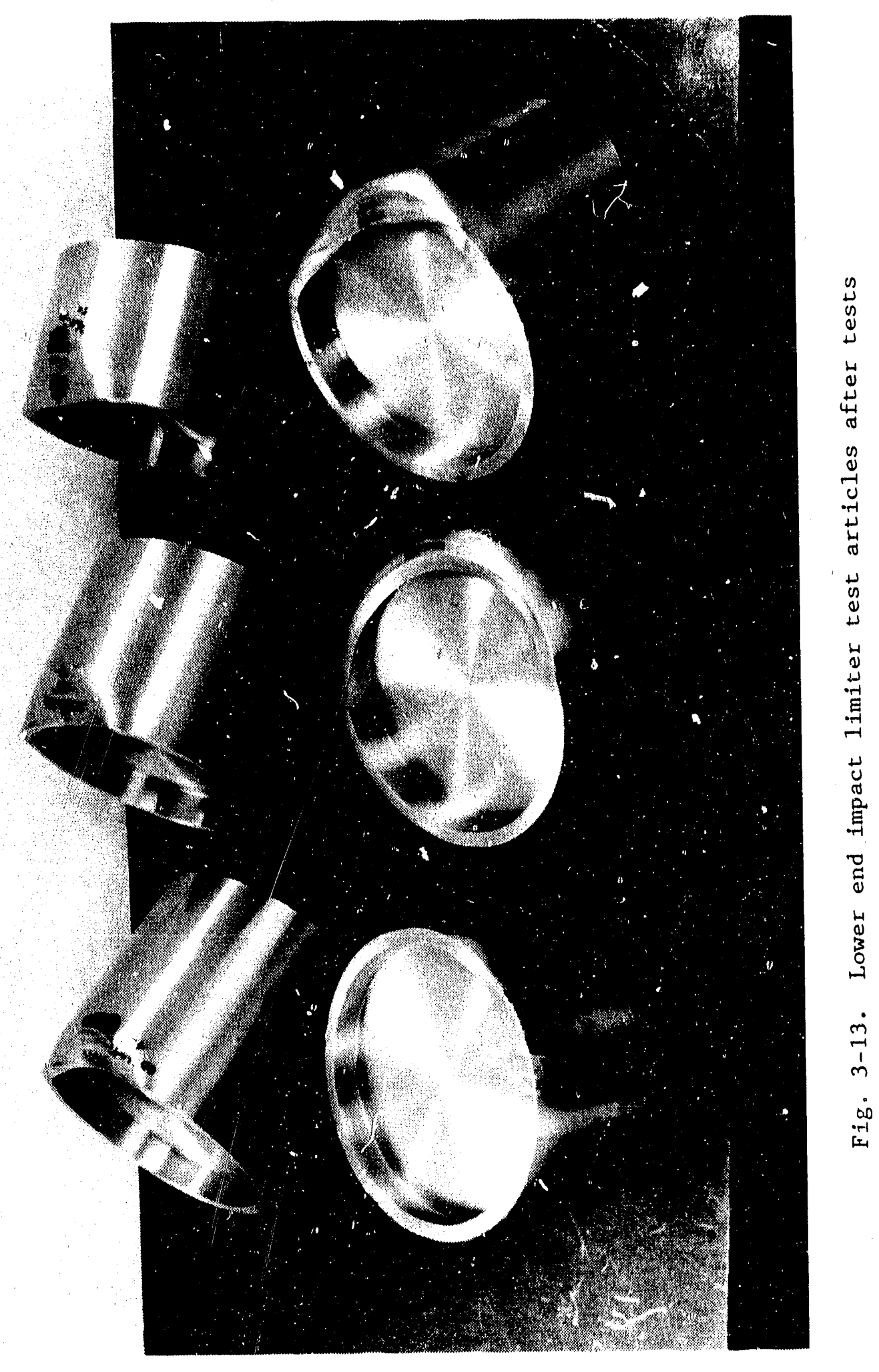




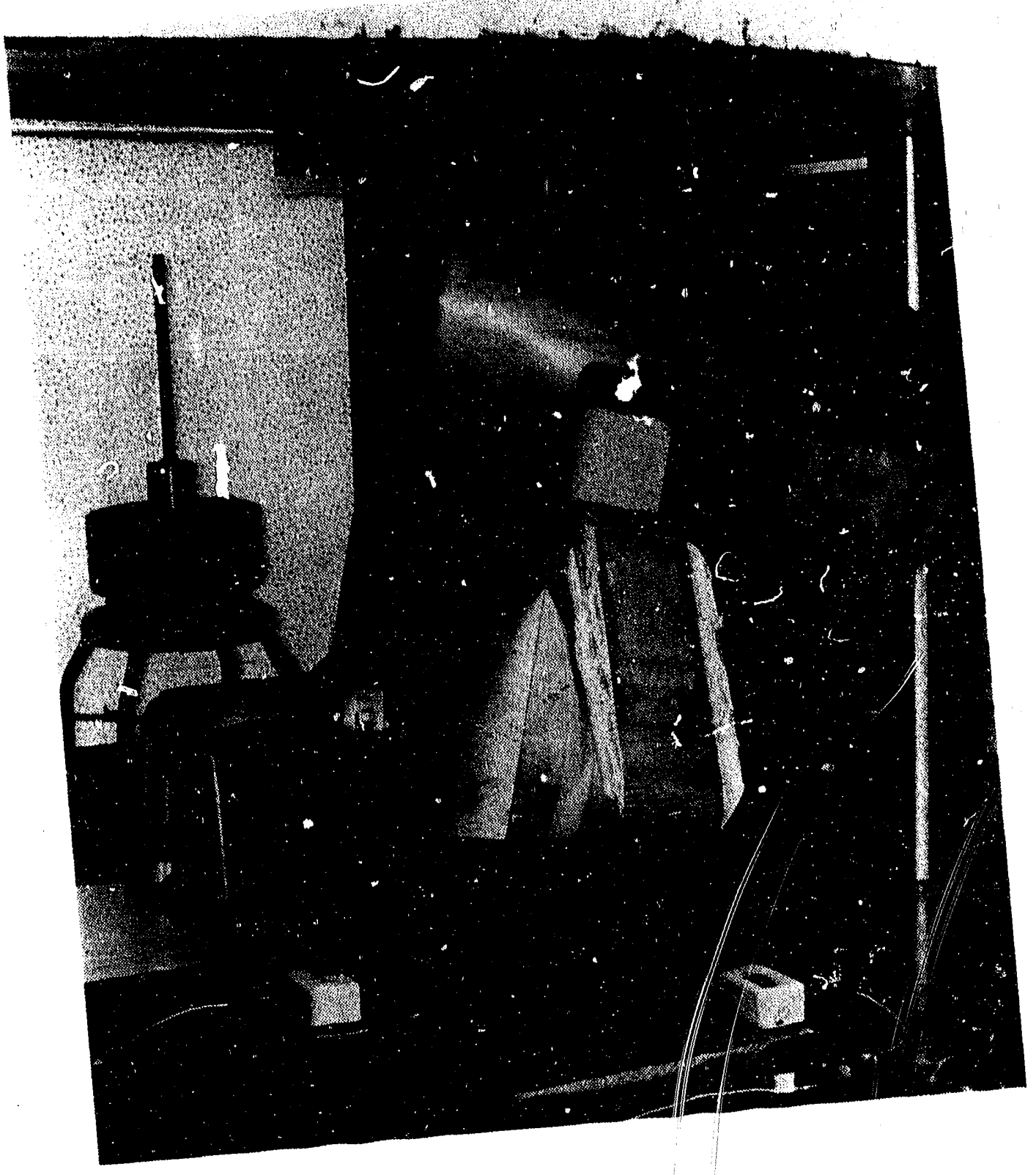

F1g. 3-14. Circumferential impact 11m

deg crush footprint 


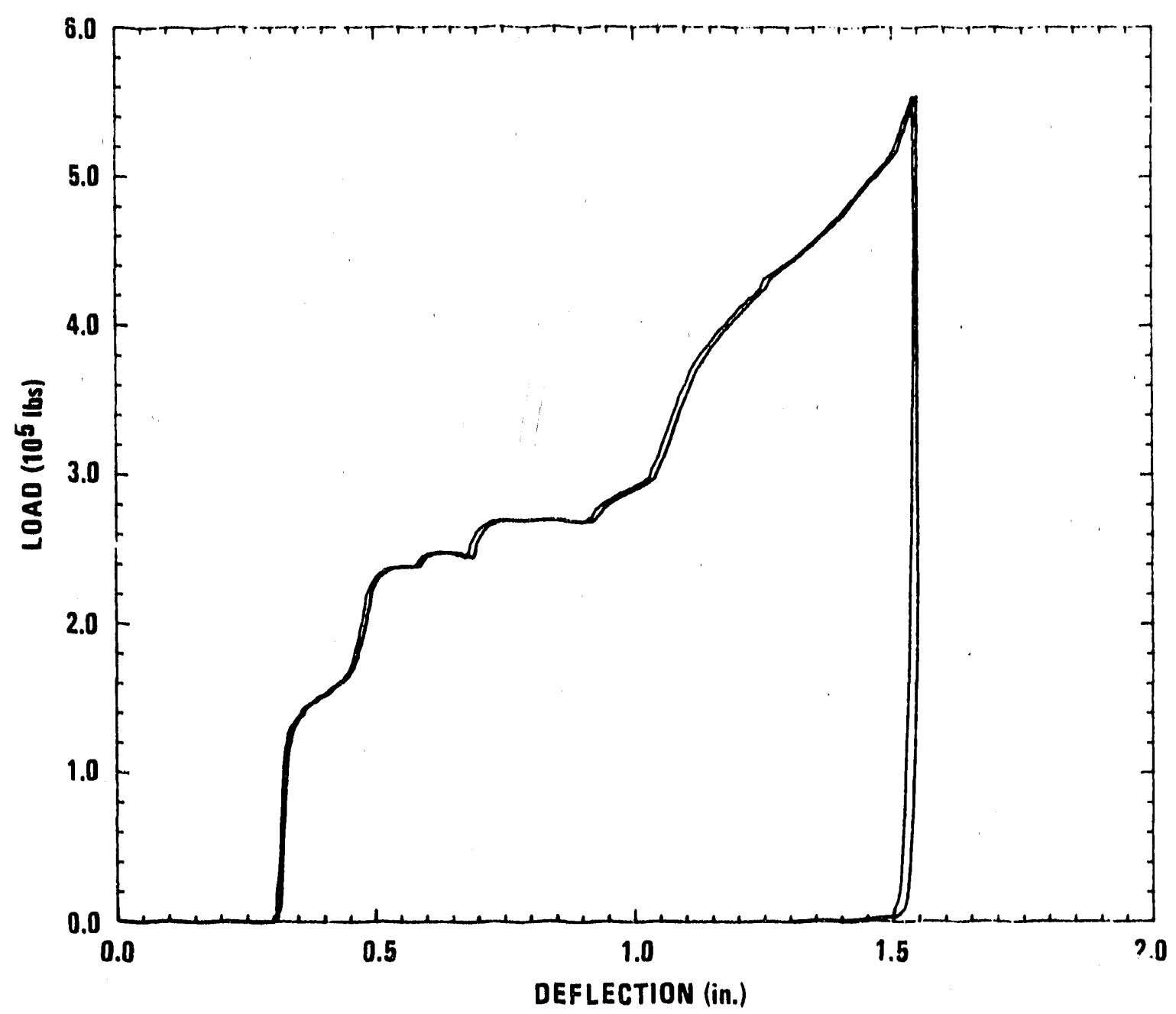

Fig. 3-15. 1/6-scale notched impact limiter, load-deflection curve at 0 deg (flat end orientation. 


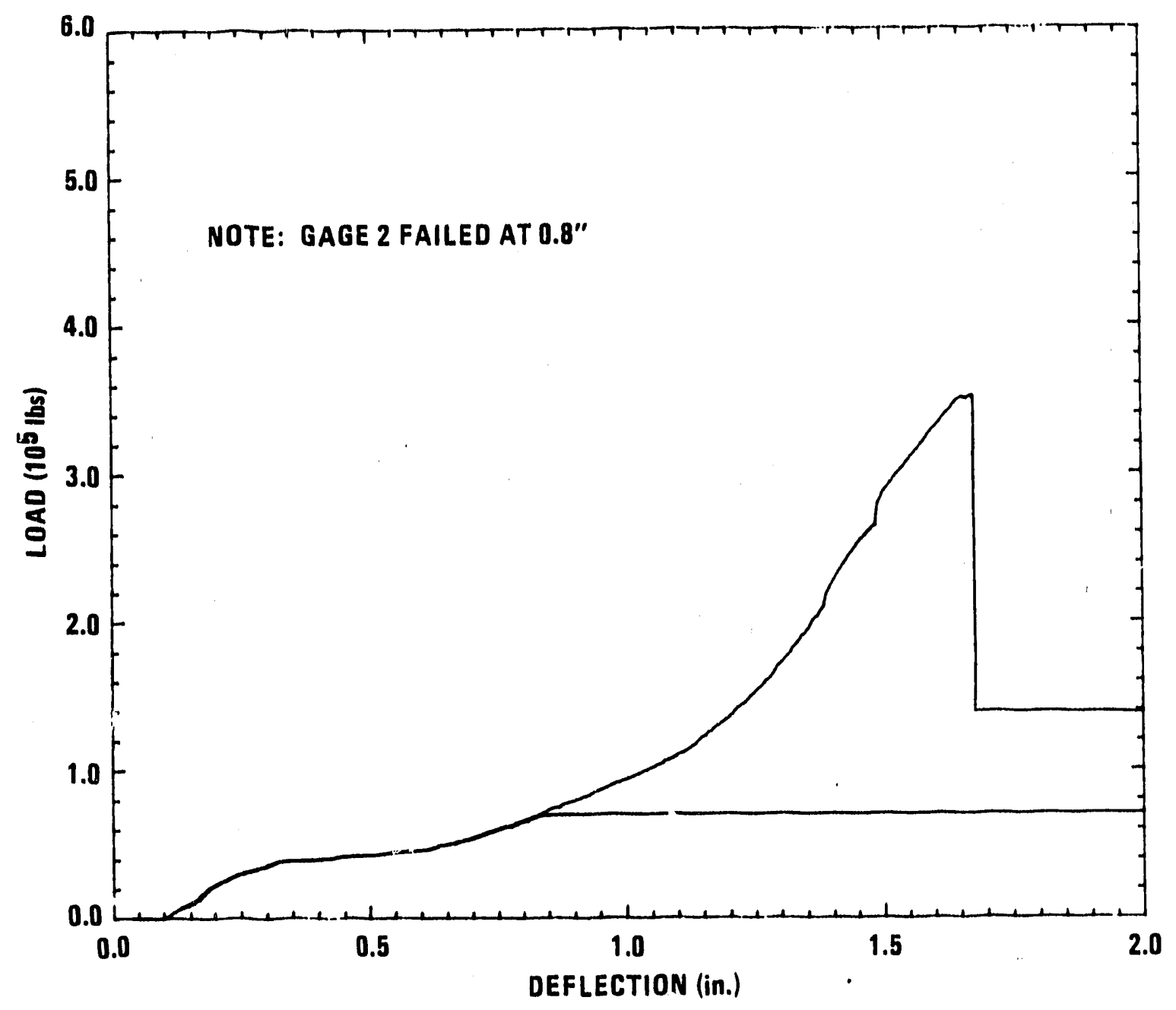

Fig. 3-16. 1/6-scale notched impact limiter, load-deflection curve at $73.4 \mathrm{deg}$ (CG over corner orientation) 


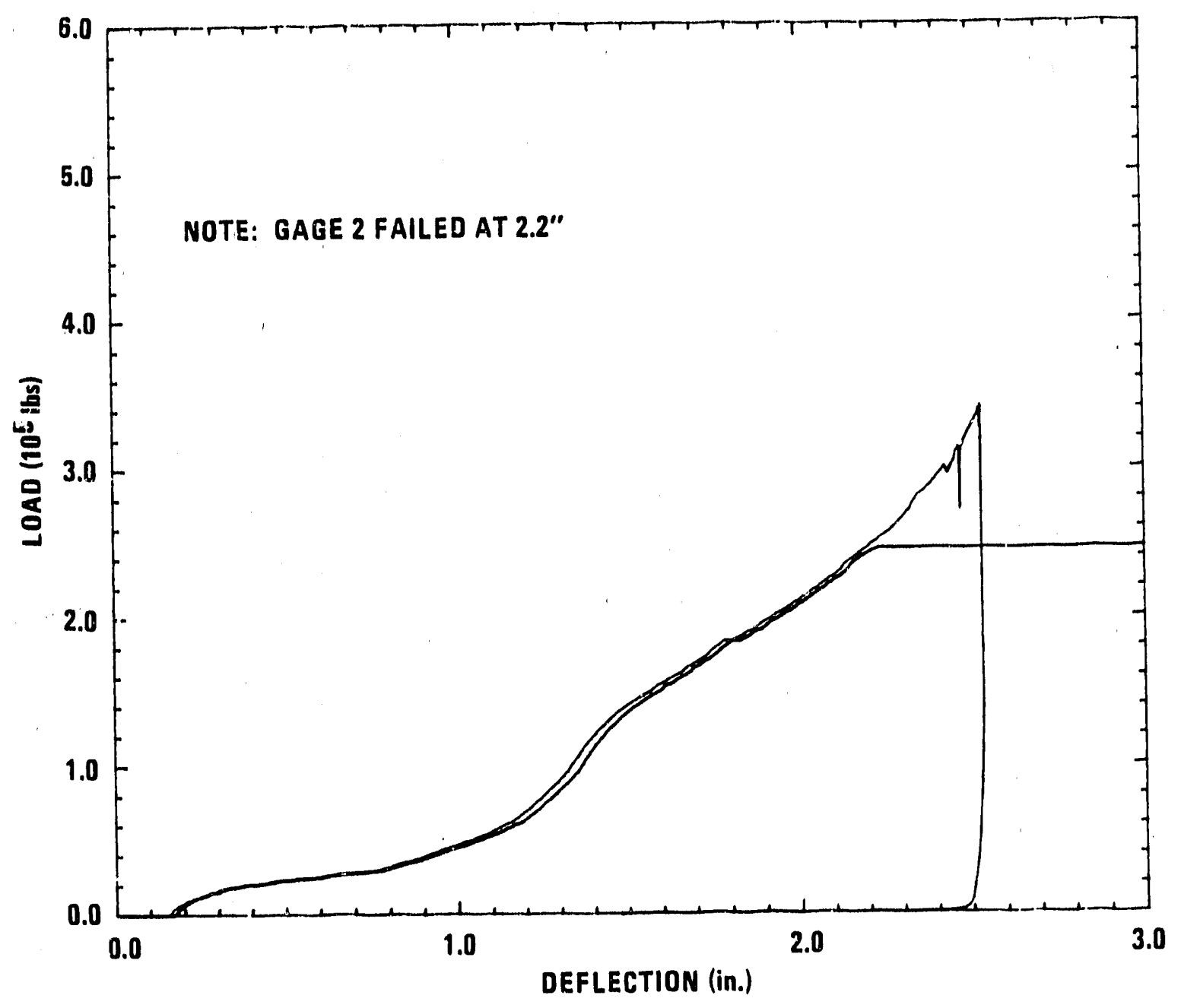

Fig. 3-17. 1/6-scale notched Impact 11miter, load-deflection curve at $60 \mathrm{deg}$ 


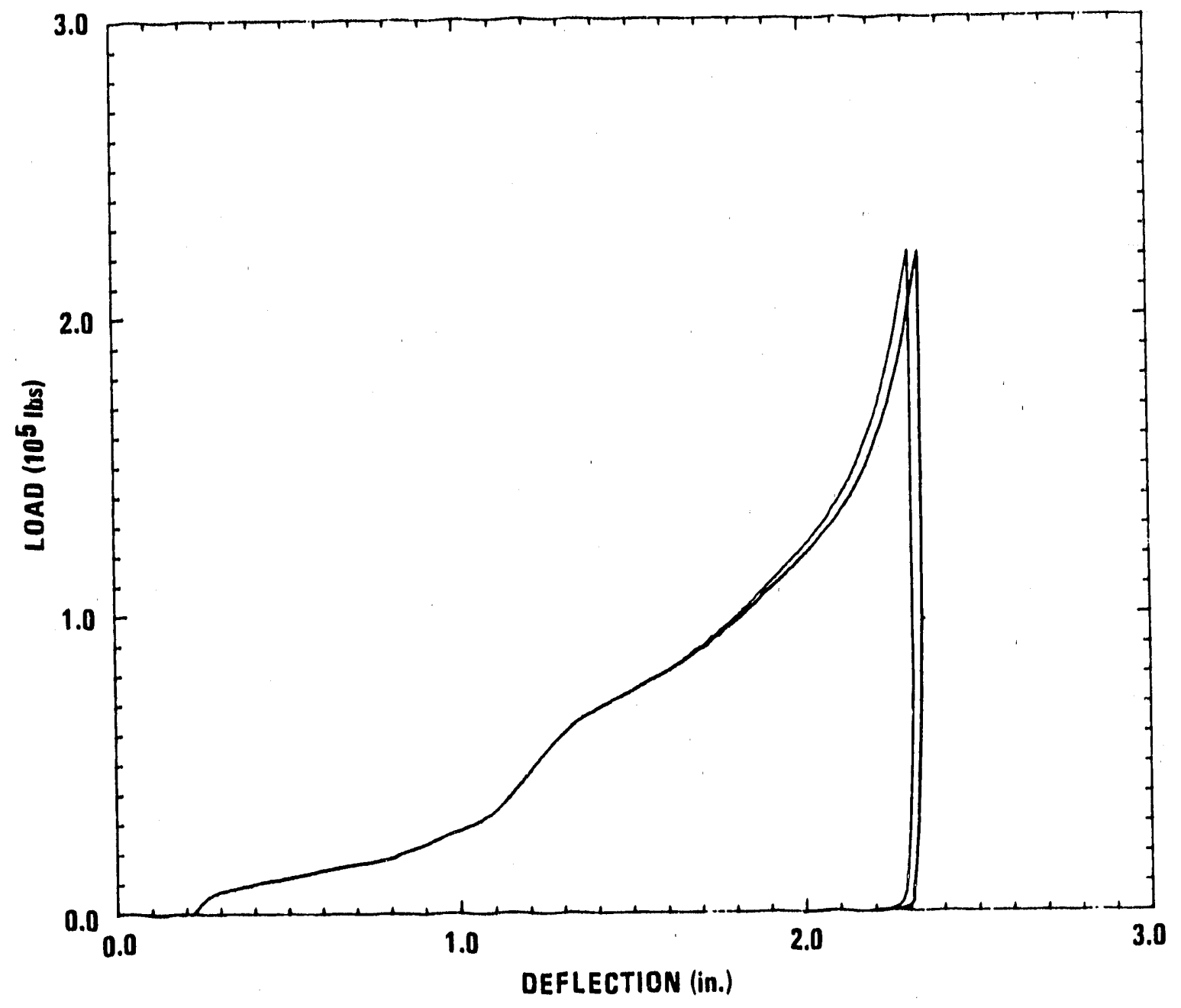

Fig. 3-18. 1/6-scale notched impact 1imiter, load-deflection curve at $45 \mathrm{deg}$ 


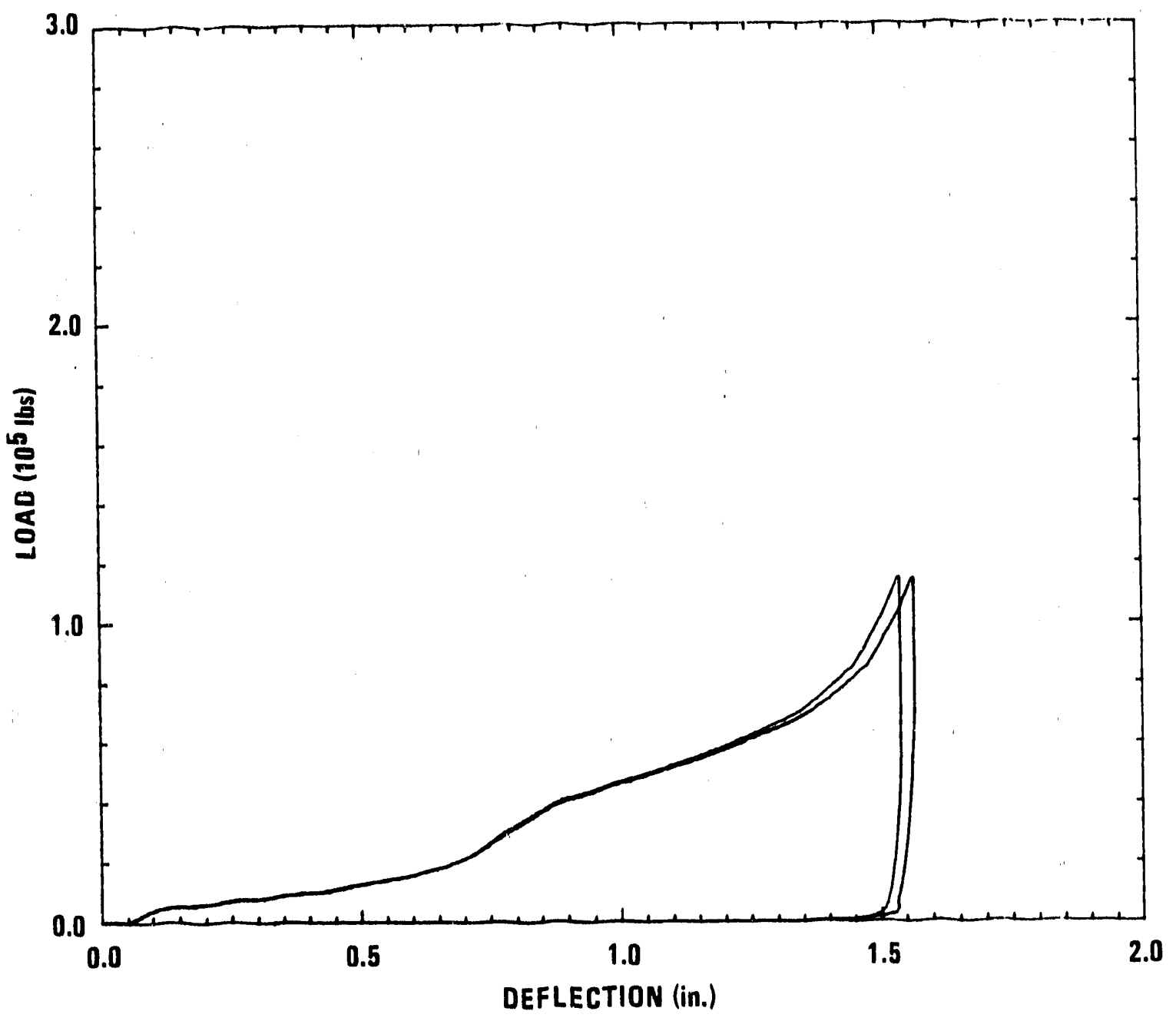

Fig. 3-19. 1/6-scale notched impact limiter, load-deflection curve at $30 \mathrm{deg}$ 


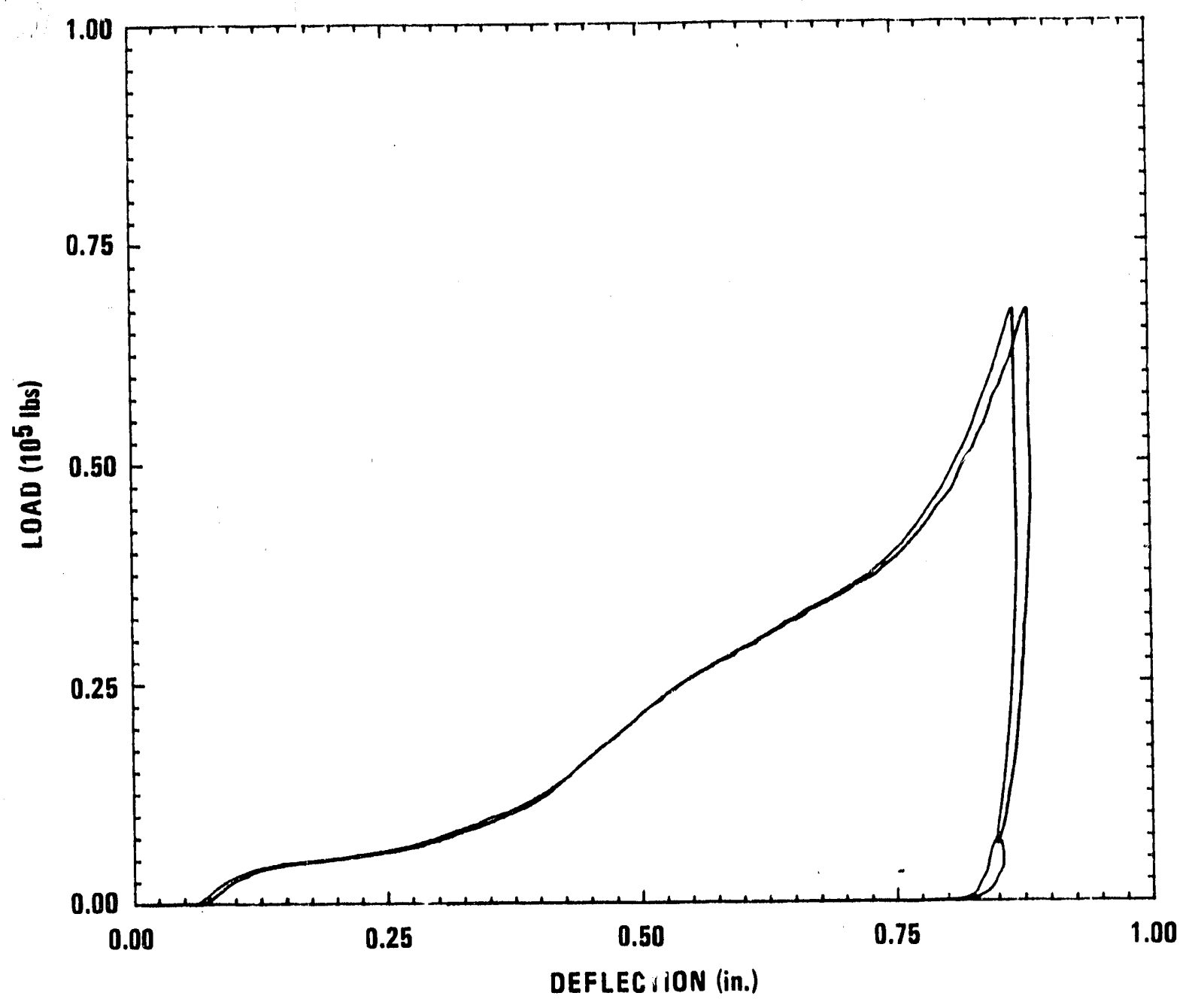

Fig. 3-20. 1/6-scale notched impact limiter, load-deflection curve at $15 \mathrm{deg}$ 


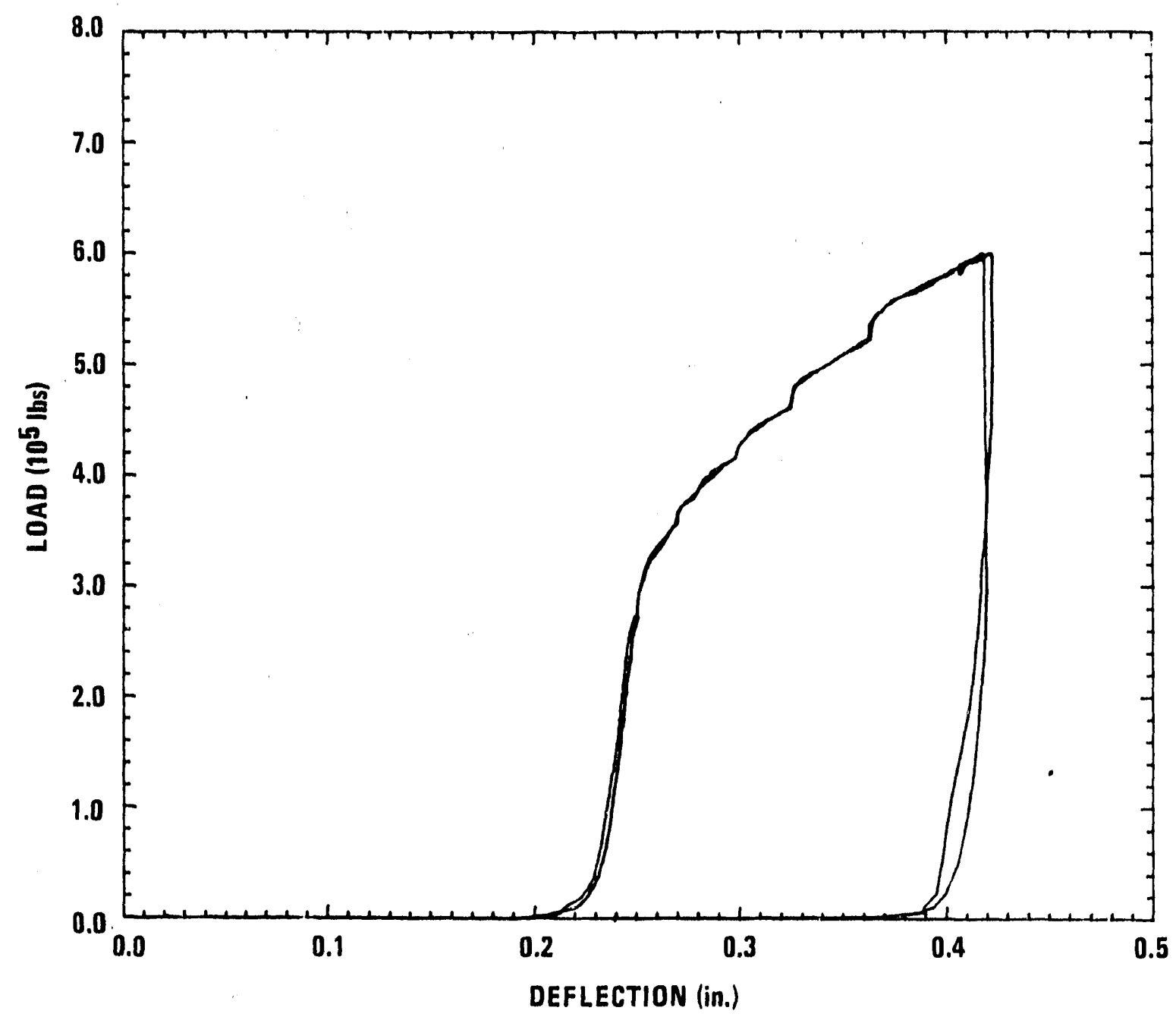

Fig. 3-21. 1/6-scale lower end impact limiter, load-deflection curve at $90 \mathrm{deg}$ (flat end orfentation) 


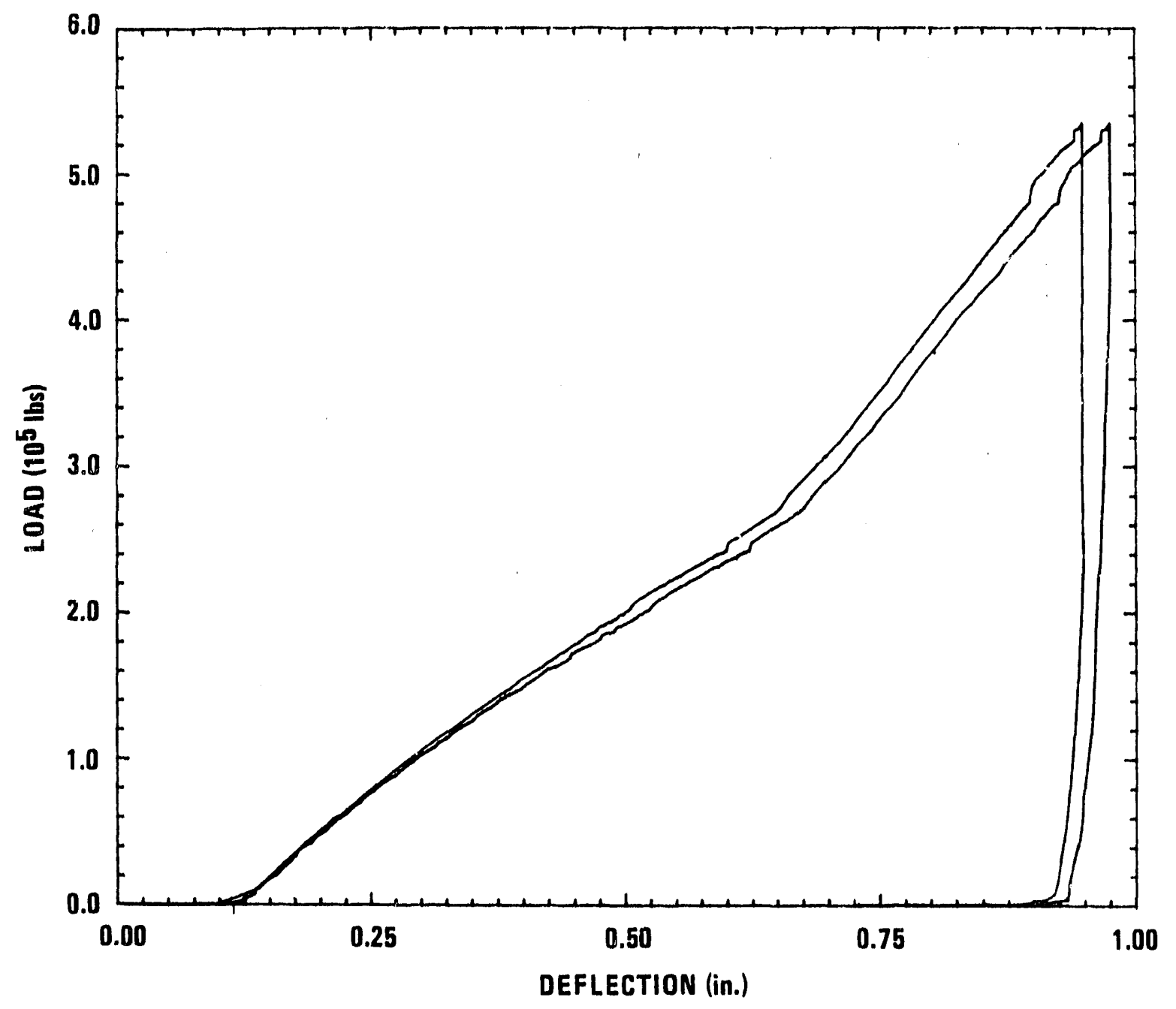

Fig. 3-22, 1/6-scale lower end impact limiter, load-deflection curve at 75.7 deg (CG over corner orientation) 


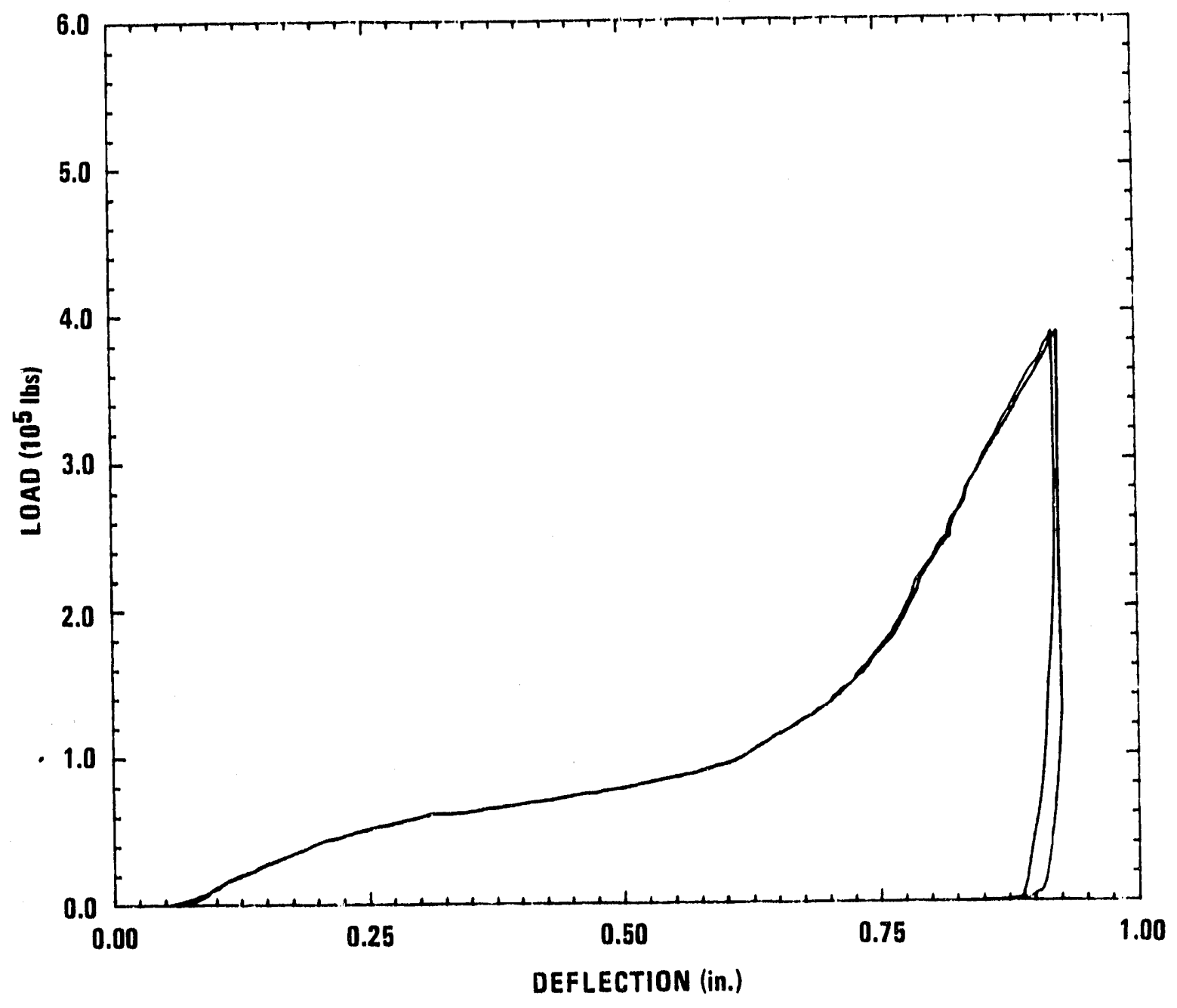

Fig. 3-23. 1/6-scale lower end impact limiter, load-deflection curve at $60 \mathrm{deg}$ 


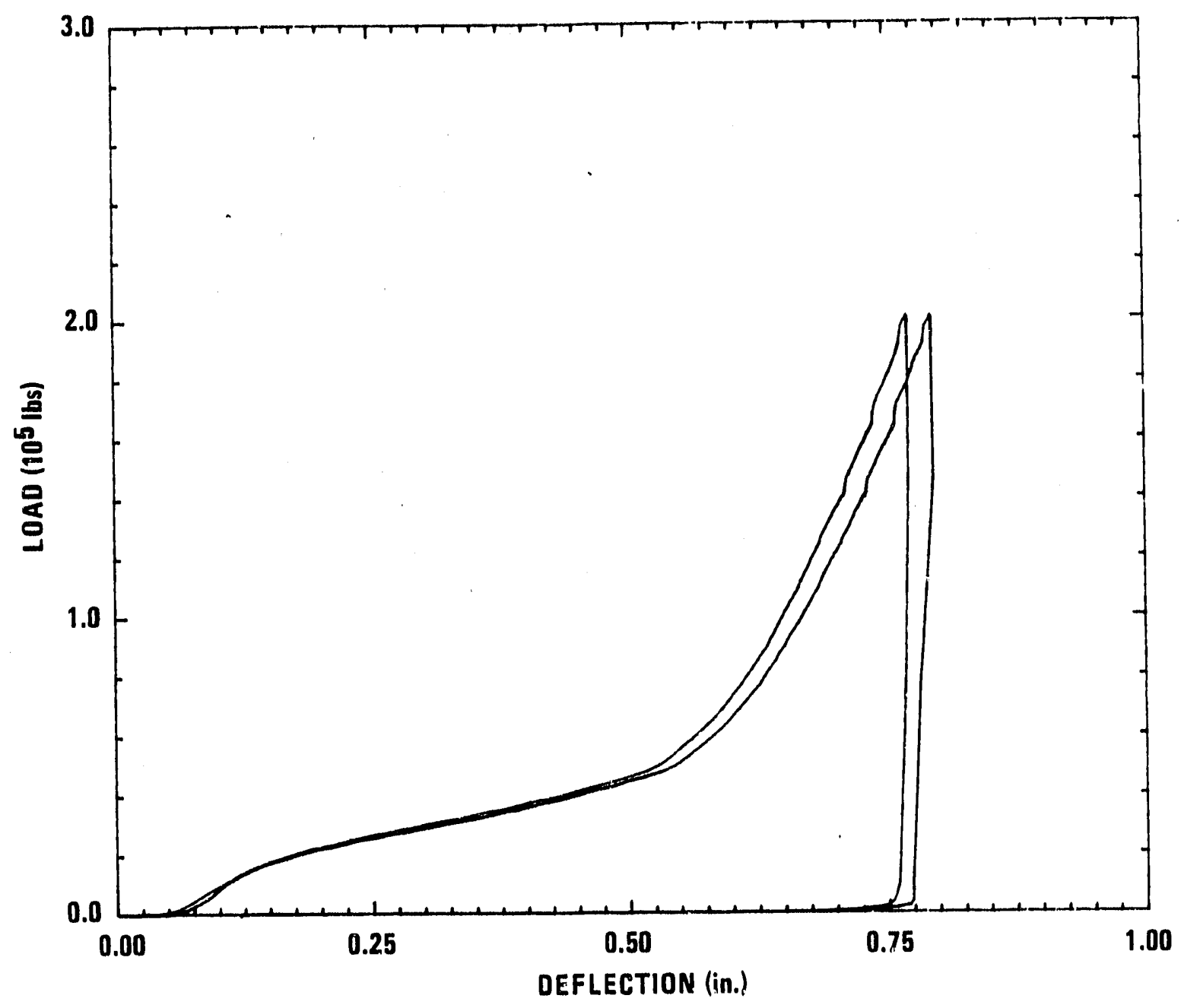

Fig. 3-24. 1/6-scale lower end impact limiter, load-deflection curve at $45 \mathrm{deg}$ 


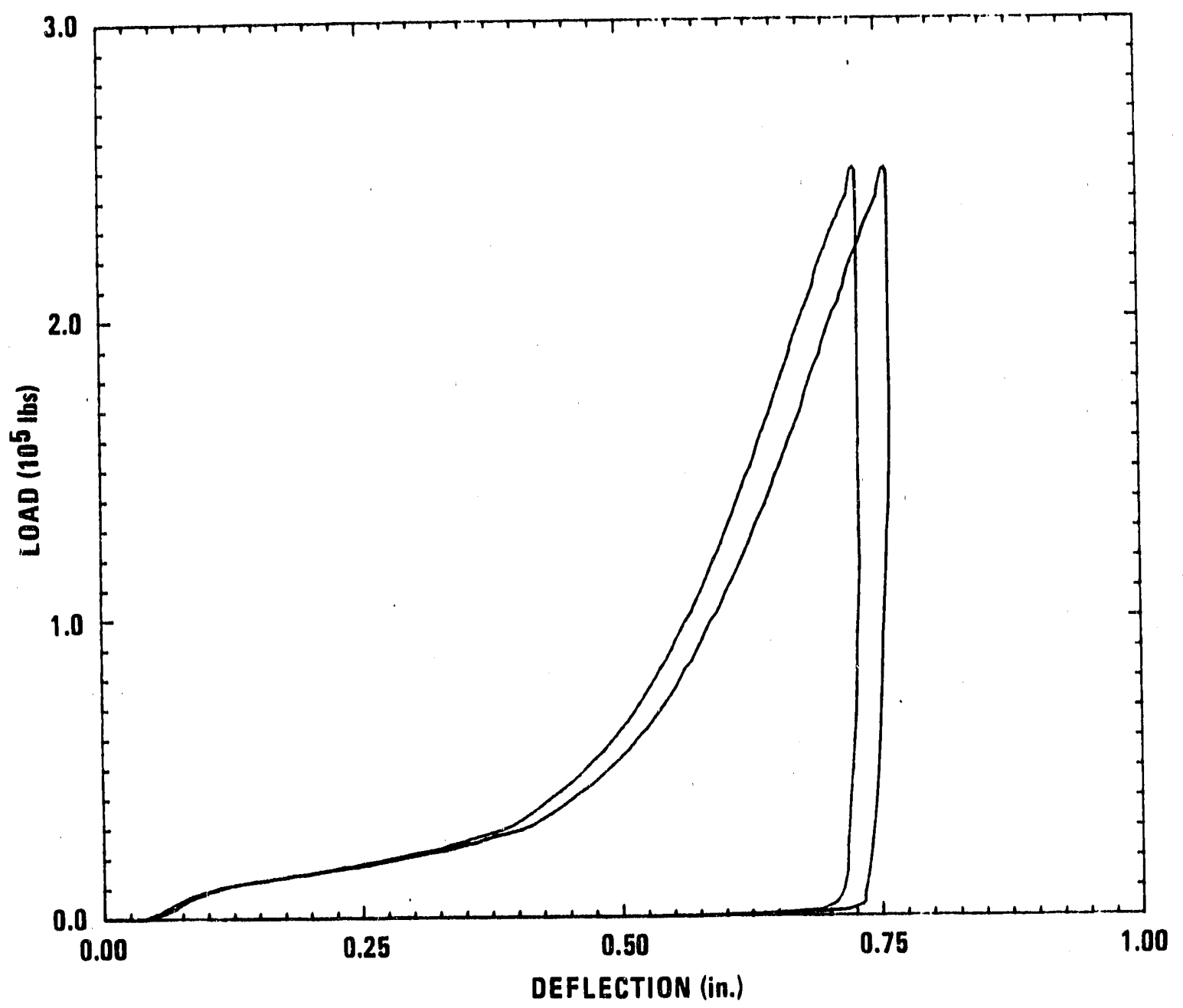

Fig. 3-25. 1/6-scale lower end impact limiter, load-deflection curve at $30 \mathrm{deg}$ 


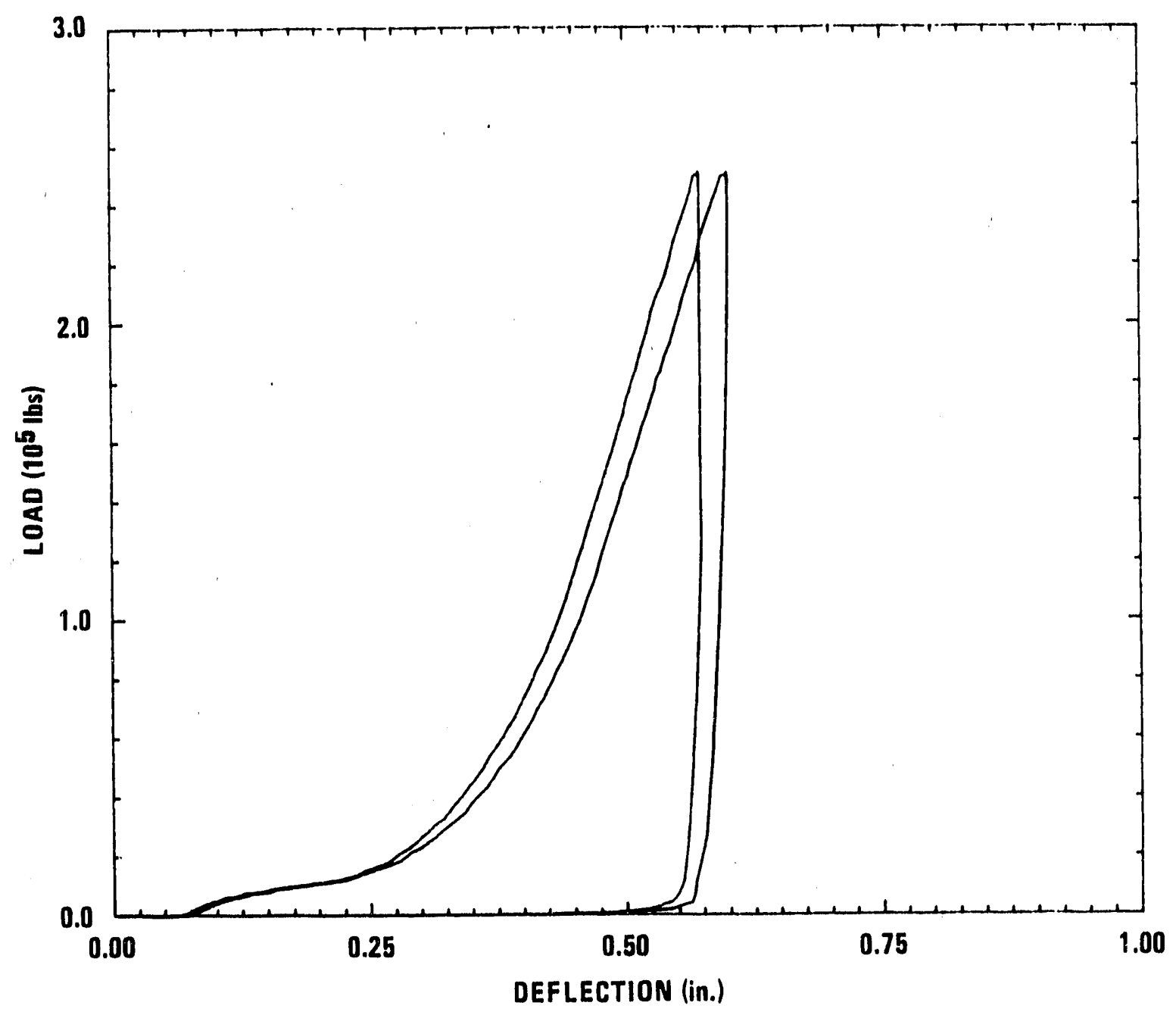

Fig. 3-26. 1/6-scale lower end impact limiter, load-deflection curve at $15 \mathrm{deg}$ 


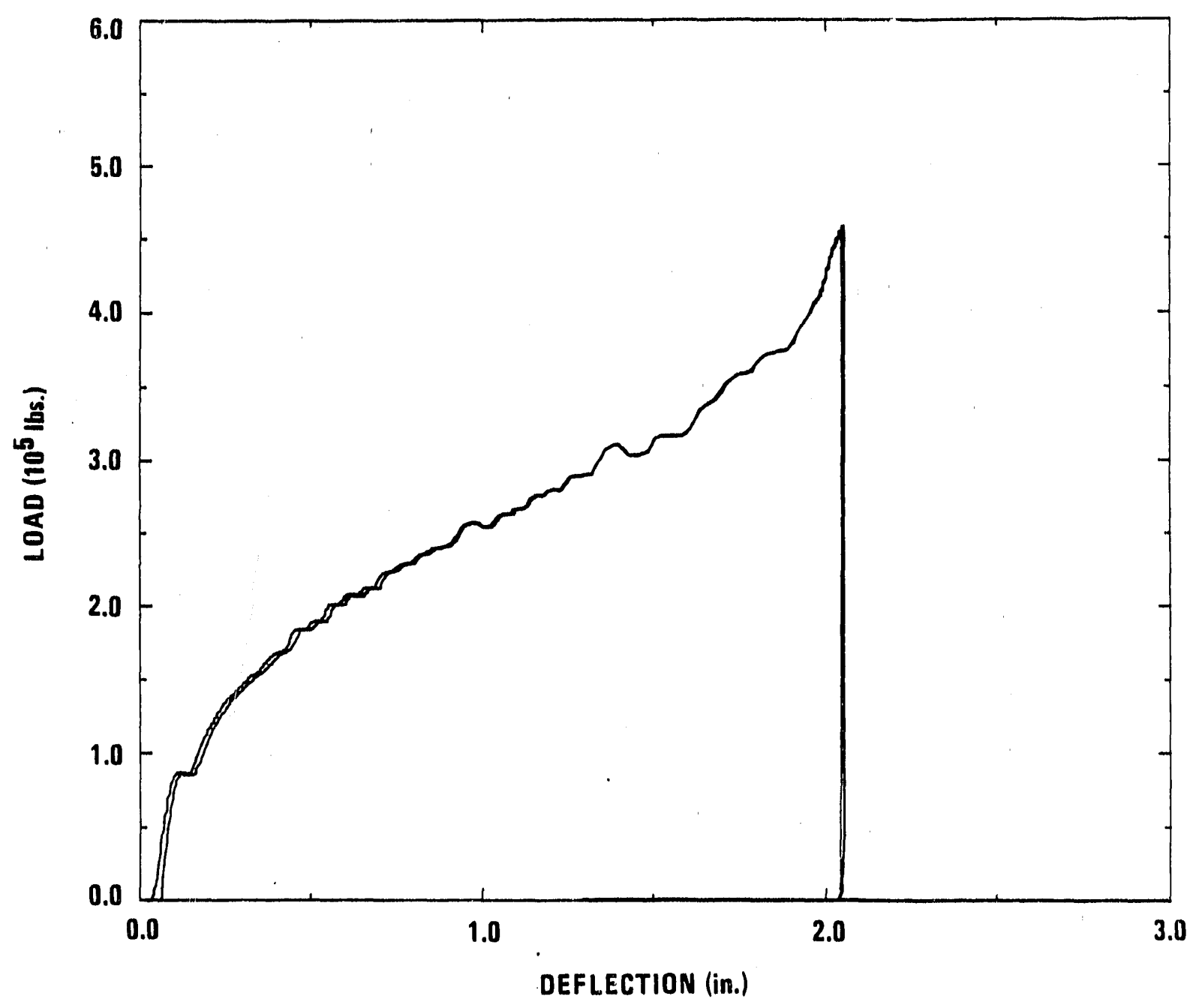

Fig. 3-27. 1/3-scale ctrcumferential impact limiter, load-deflection curve at 0 deg (side drop orfentation) 


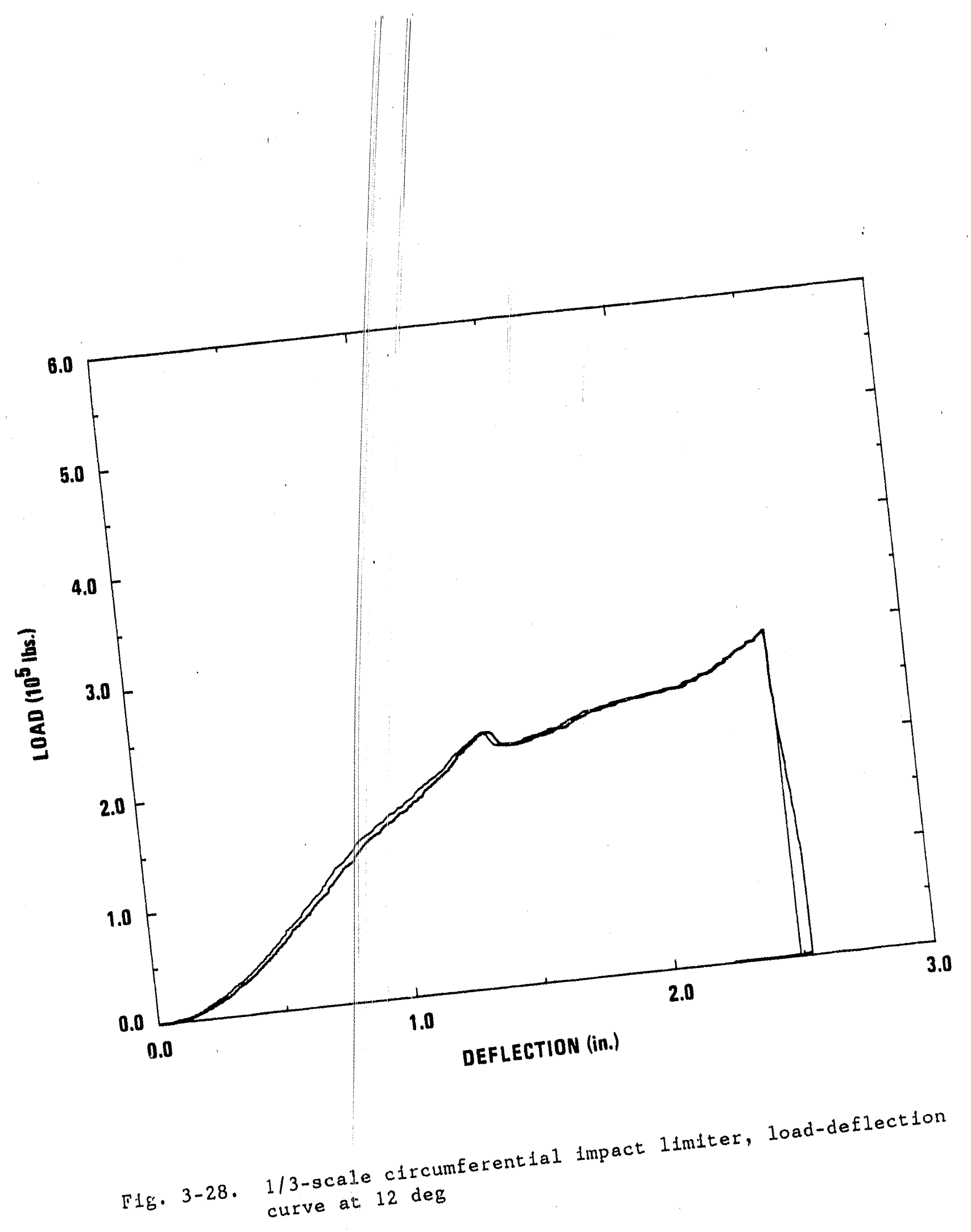




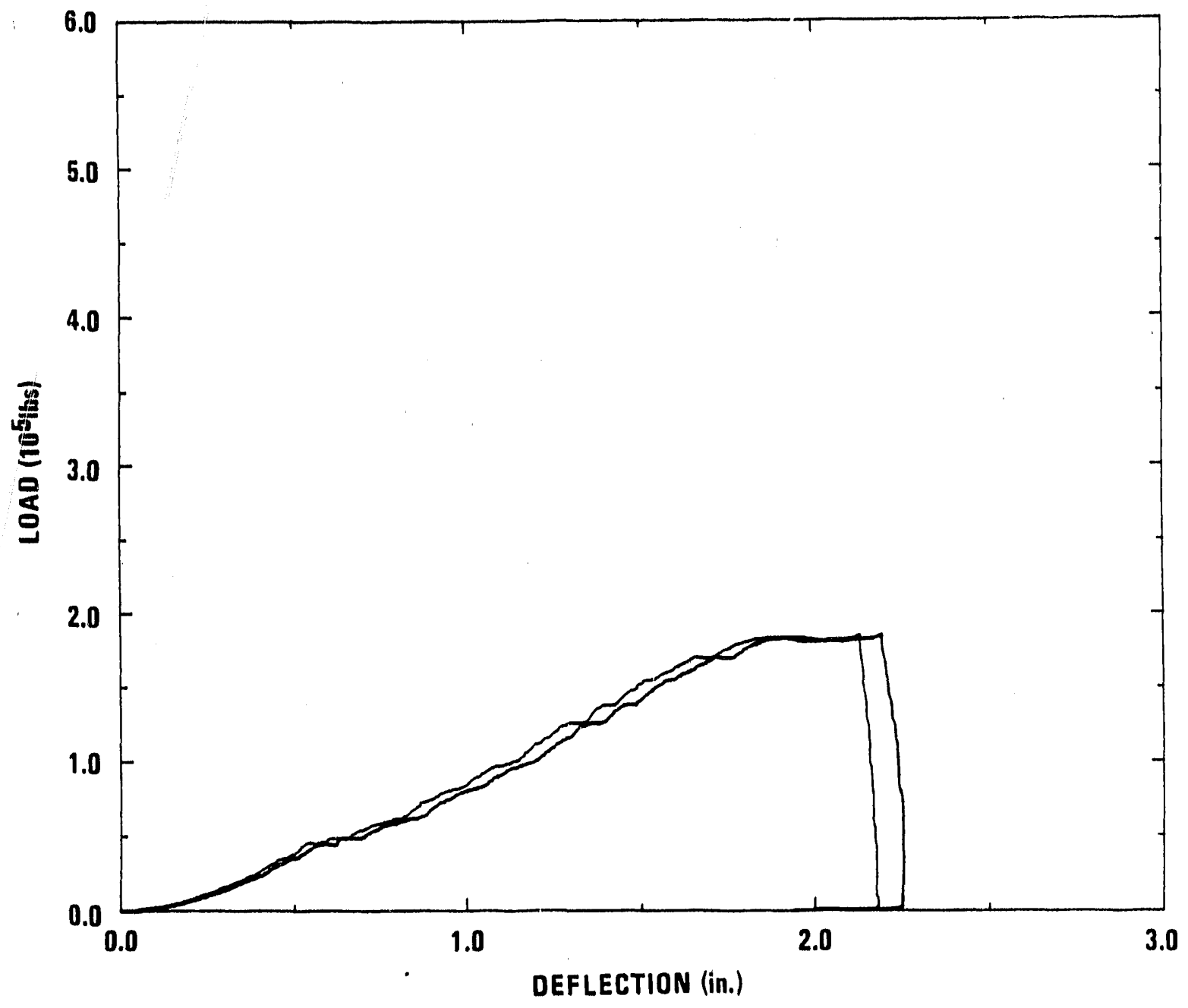

Fig. 3-29. 1/3-scale circumferential impact limiter, load-deflection curve at $24 \mathrm{deg}$ 
To convert the data Into a form useful for GACAP analysis, we performed the following steps:

1. Shlft the vertical axis so that zero deflection colncides with zero load.

2. Since the test article was approximately midway between the two deflection transducers, the two deflections are averaged to obtain the correct load-deflection curve.

3. Multiply the load by 36 (nine for the circumferential impact Iimiter) and the deflection by six (three for the circumferential impact limiter) to obtain full-scale data.

4. Multiply the load by 1.2 to account for strain-rate effects for notched and lower end impact limiters. Multiply the upper bound load for the circumferential impact limfter by 1.2 to account for dynamic loading effects. The lower bound load is not multiplied by the 1.2 dynamic load factor to be conservative.

5. Convert the test data to the upper and lower bound material yield range to envelop the variation in the notched and lower end impact limiter properties.

Notched impact 1imiter, upper and lower bound factors:

- Actual yleld: $37.4 \mathrm{ksl}$ (test article)

- Maximum yleld: $35.0 \mathrm{ks} 1$

- Minimum yleld: $30.0 \mathrm{ksi}$

- To obtain upper bound load-deflection curve, multiply loads by $35.0 / 37.4$. 
- To obtaln lower bound load-deflection curve, multiply loads by $30.0 / 37.4$.

Lower end Impact 11 miter:

- Actual yield: $41.8 \mathrm{ks}$ (test article)

- Maximum yleld: $40.0 \mathrm{ks}$

- Minimum yleld: $30.0 \mathrm{ks}$

- To obtain upper bound load-deflection curve, multiply loads by $40.0 / 41.8$.

- To obtain lower bound load-deflection curve, multiply loads by $30,0 / 41.8$.

Figures 3-30 through 3-41 show the upper and lower bound toaddeflection curves for the GACAP analyses (In Section 3.3.2) for the notched and lower end impact limiters.

6. Convert the test data to the upper and lower bound material yleld range to envelop the variation in the circumferential Impact limiter properties.

C1rcumferential Impact 1imiter upper and lower bound factors:

- Actual crush strength: $6170 \mathrm{psi}$ (test article at $70^{\circ} \mathrm{F}$ )

- Maximum crush strength: $7500 \mathrm{psi}$

- Minimum crush strength: 5500 psit

- To obtain upper bound load-deflection curve, multiply loads by $7500 / 6170$.

- To obtain lower bound load-deflection curve, multiply loads by $5500 / 6170$. 


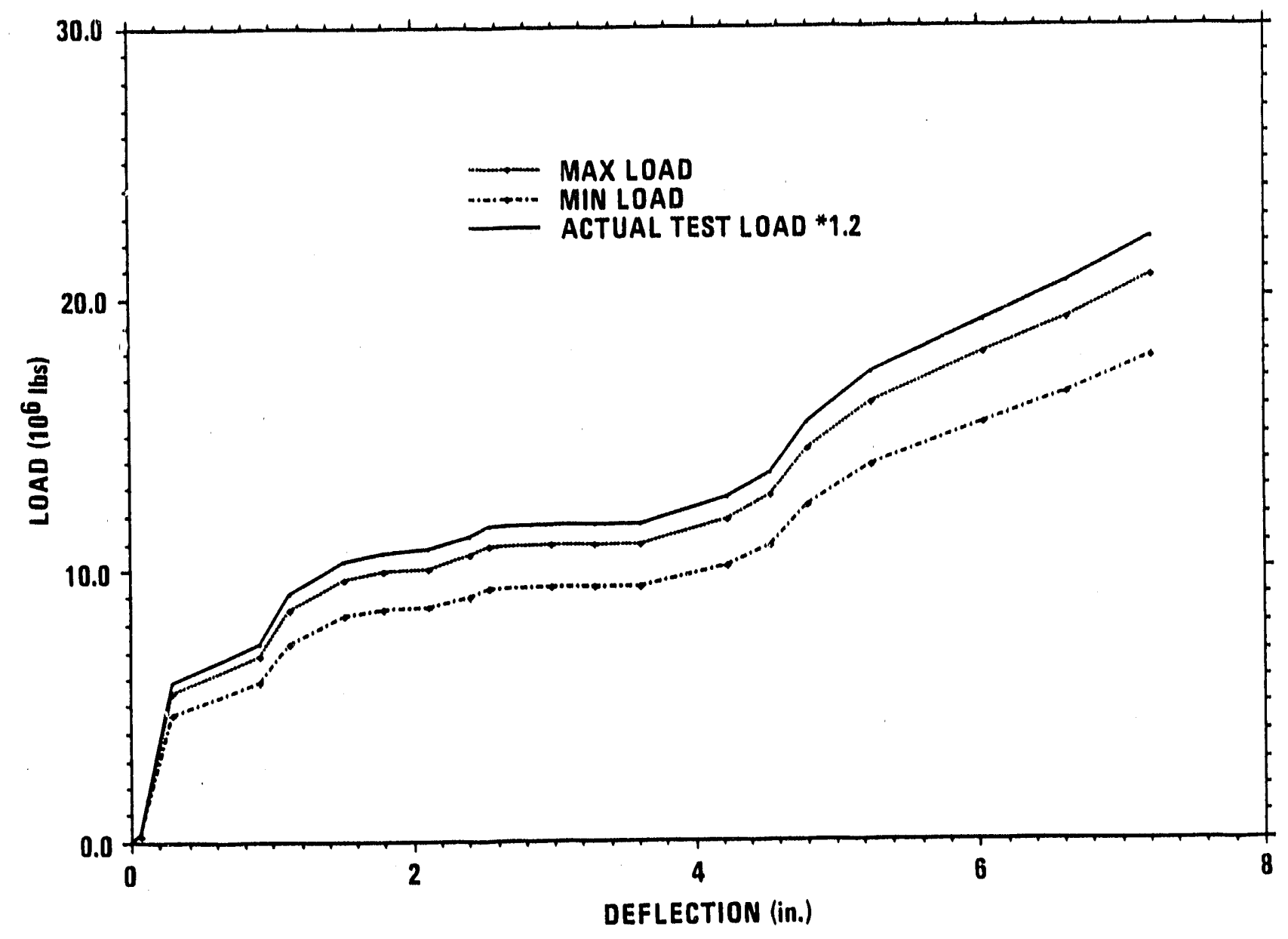

Fig. 3-30. Notched Impact limiter load-deflection curve (full-scale), 90 deg orlentation 


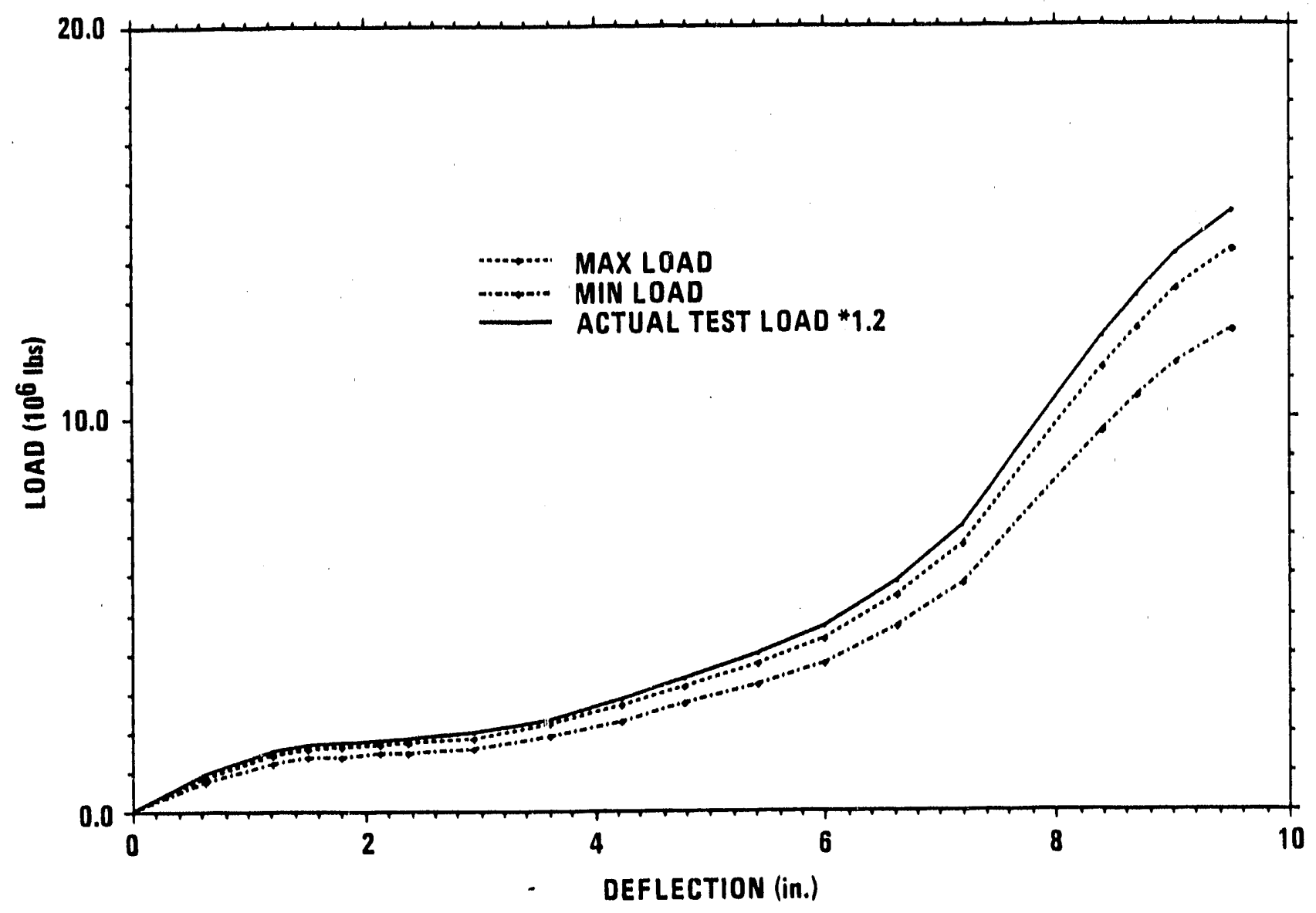

F1g. 3-31. Notched impact 1imiter load-deflection curve (ful1-scale), $73.4 \mathrm{deg}$ orientation 


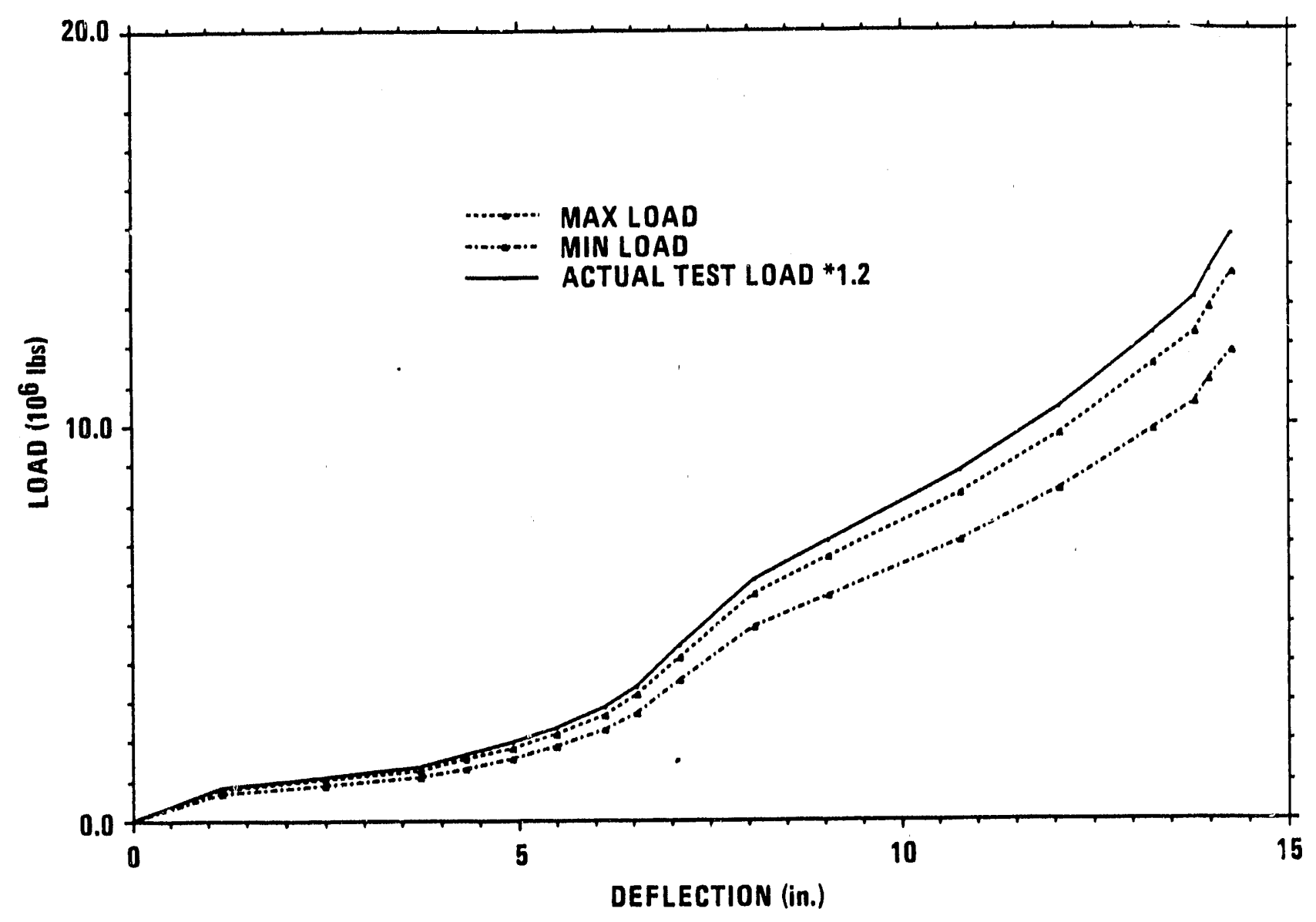

Fig. 3-32. Notched impact limiter load-deflection curve (full-scale), 60 deg orientation 


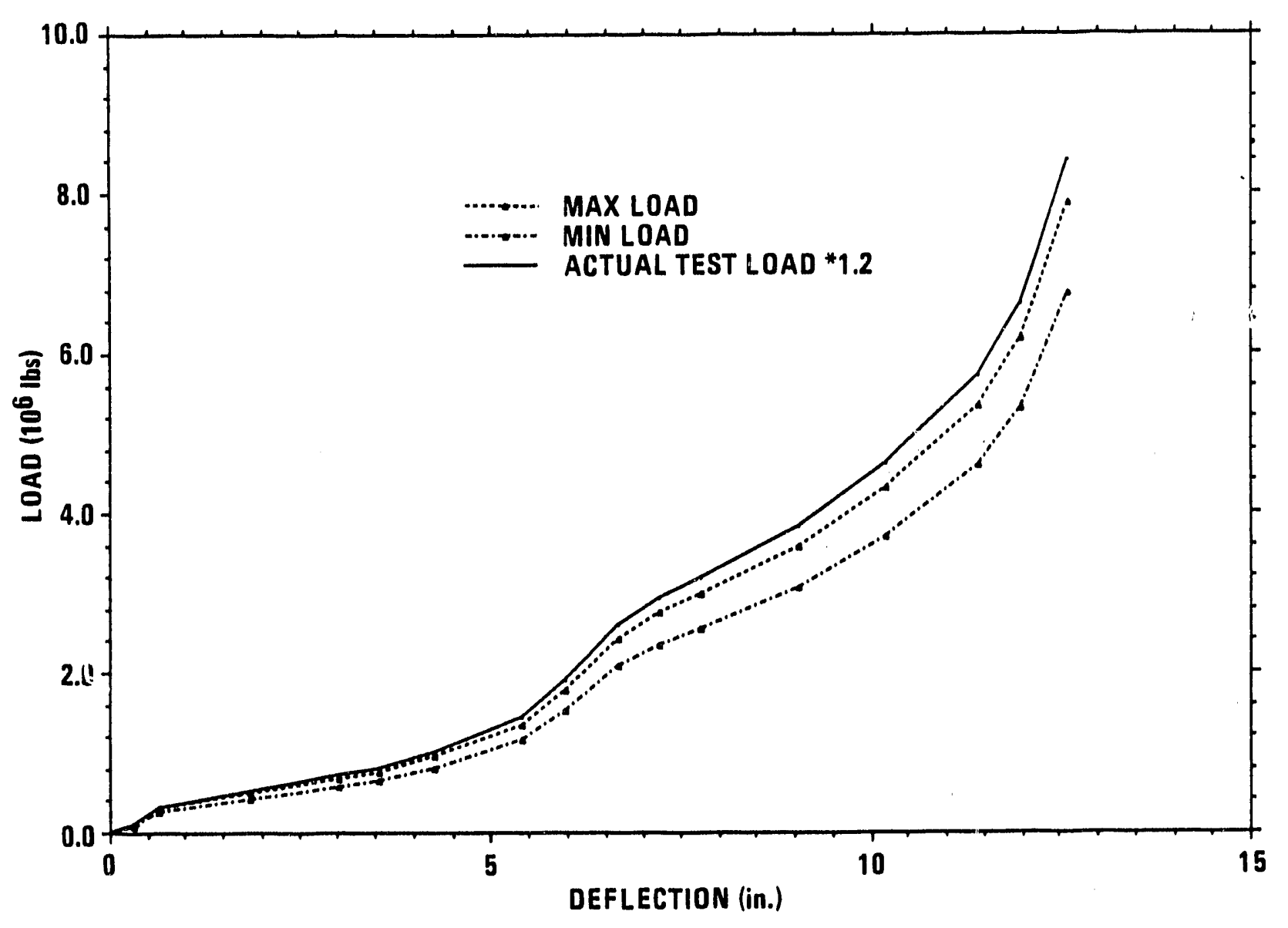

Fig. 3-33. Notched impact limiter load-deflection curve (full-scale), 45 deg orientation 


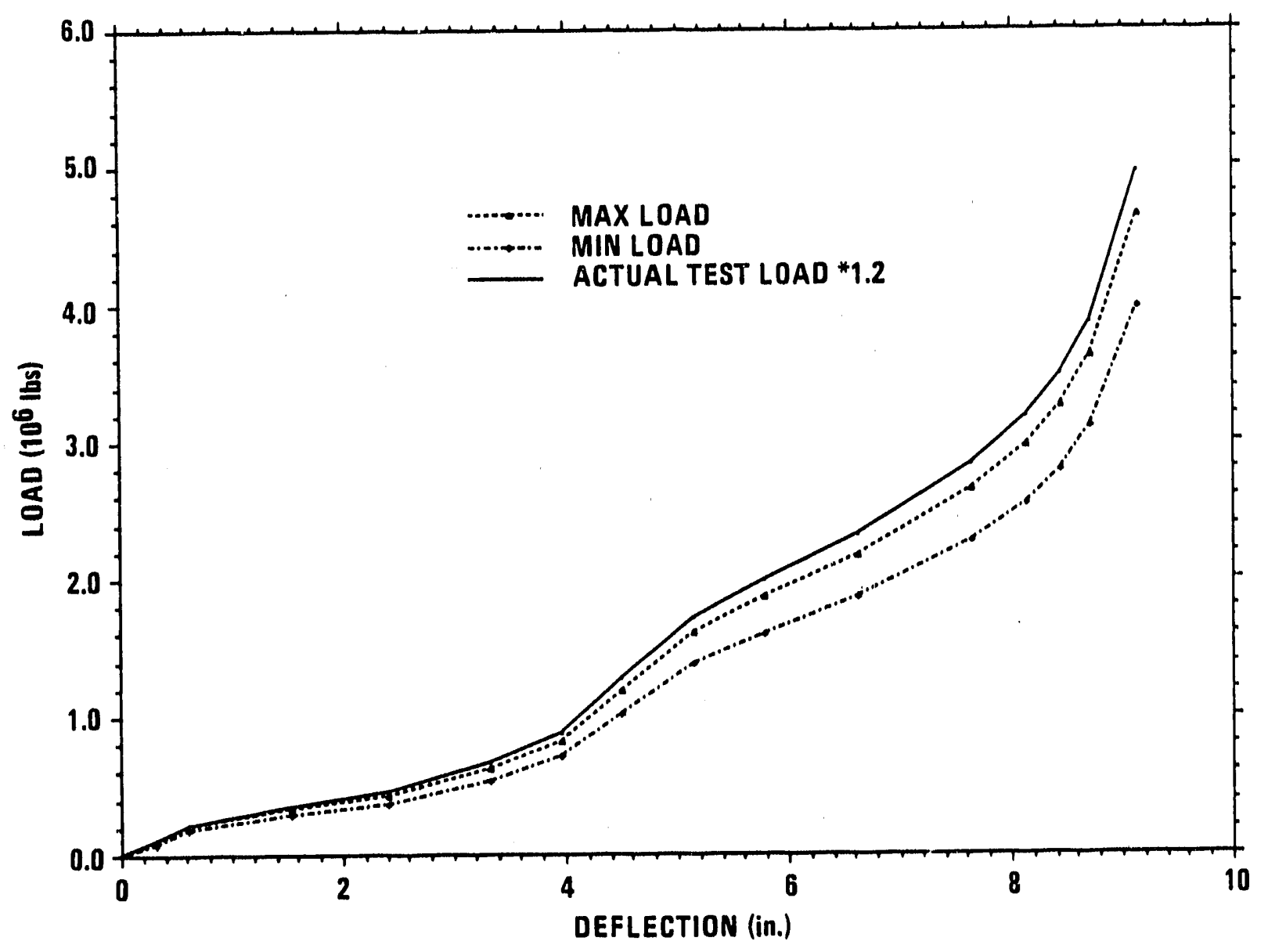

Fig. 3-34. Notched impact limiter load-deflection curve (ful1-scale), 30 deg orientation 


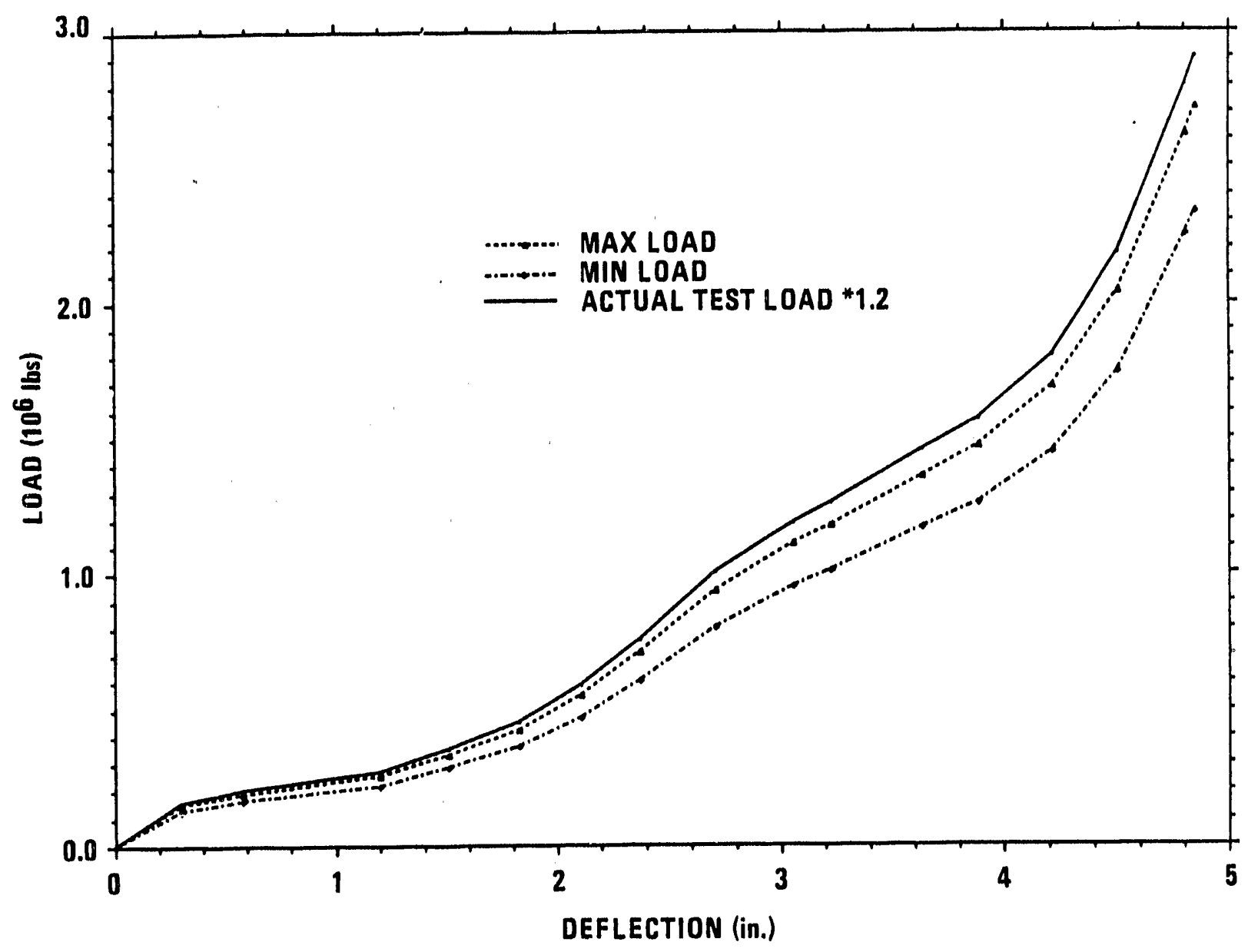

Fig. 3-35. Notched impact limiter load-deflection curve (fuil-scale), $15 \mathrm{deg}$ orlentation 


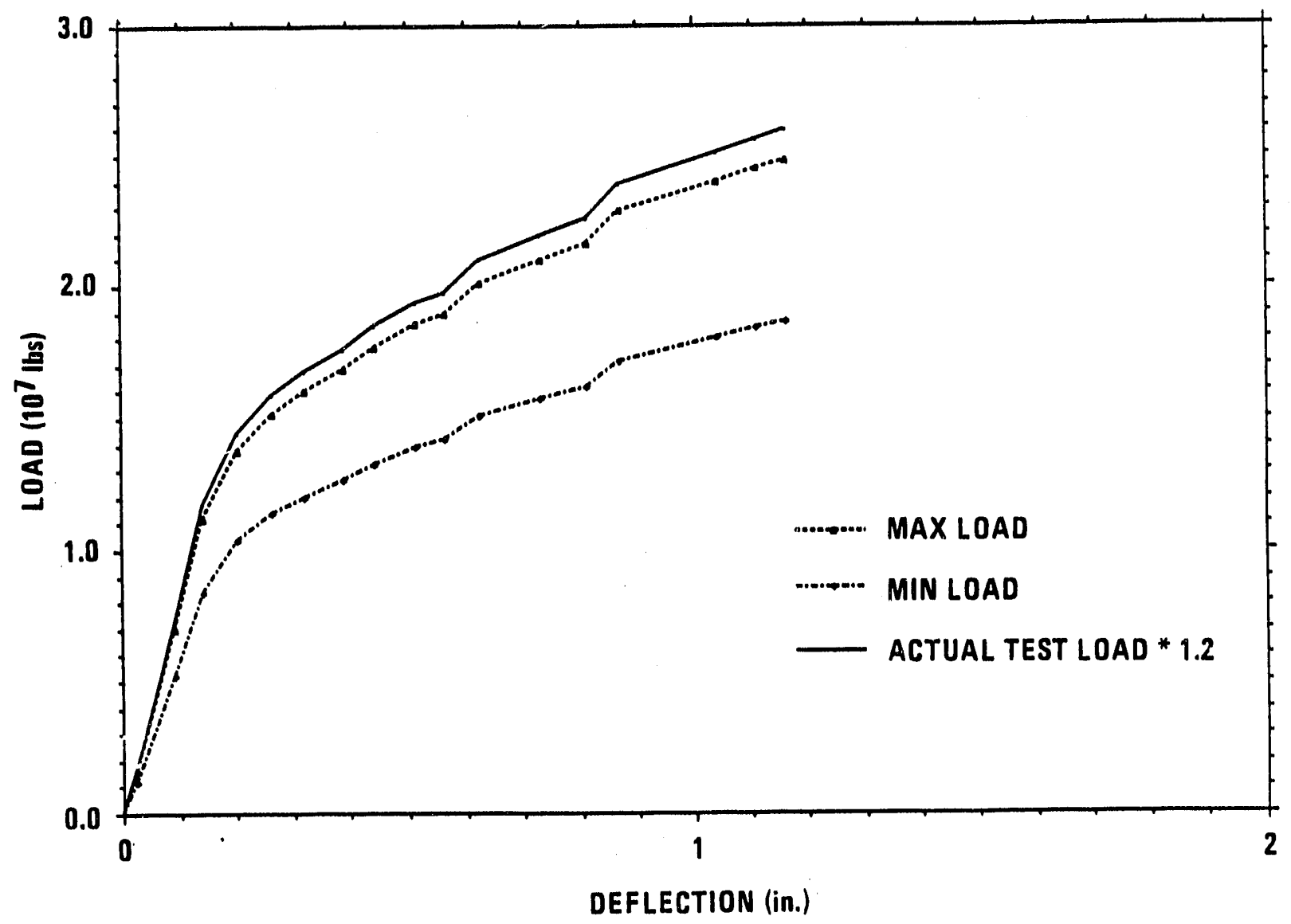

Fig. 3-36. Lower end impact limiter load-deflection curve (full-scale), 90 deg orientation 


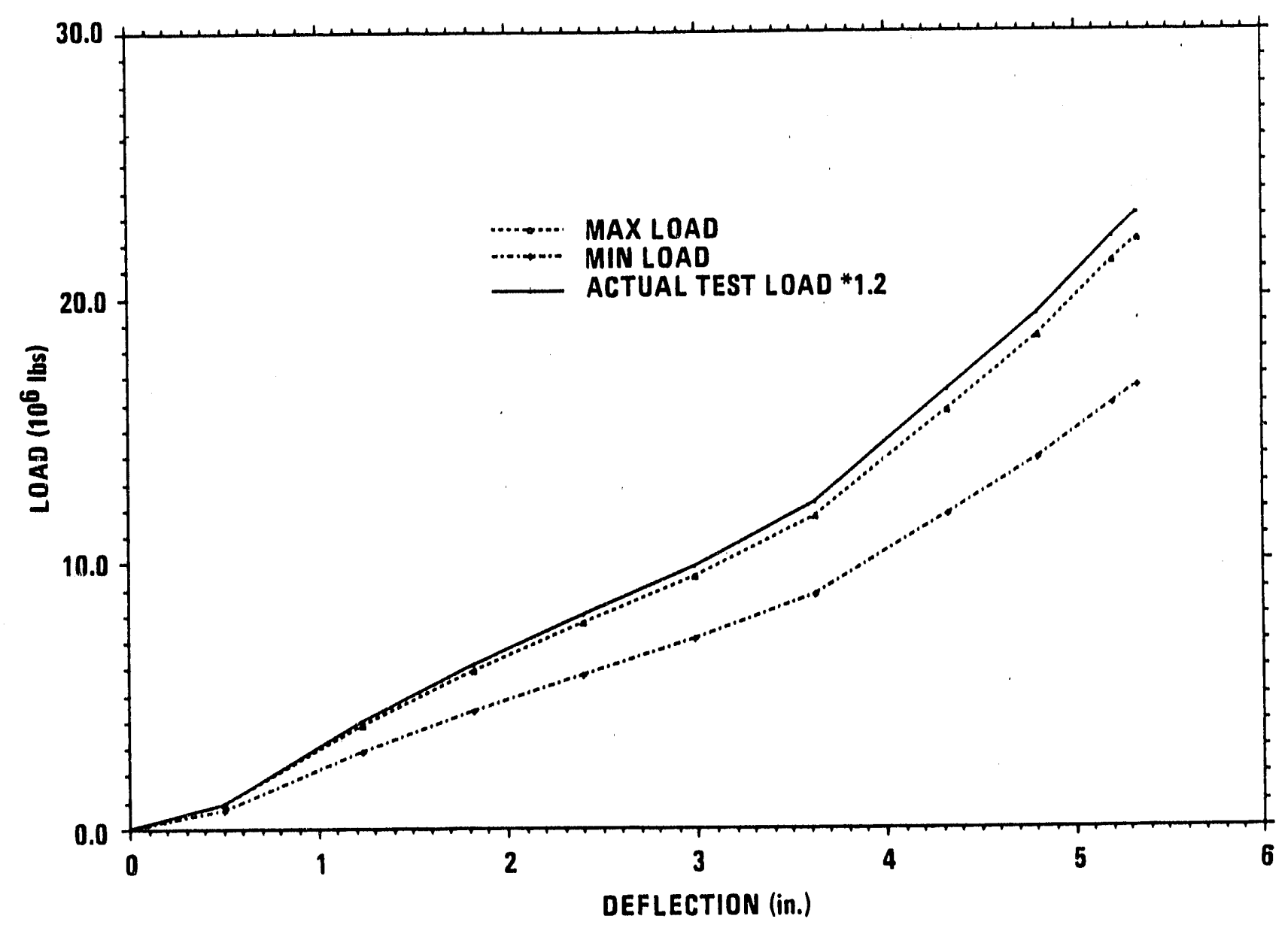

Fig. 3-37. Lower end impact limiter load-deflection curve (full-scale), 75.7 deg orfentation 


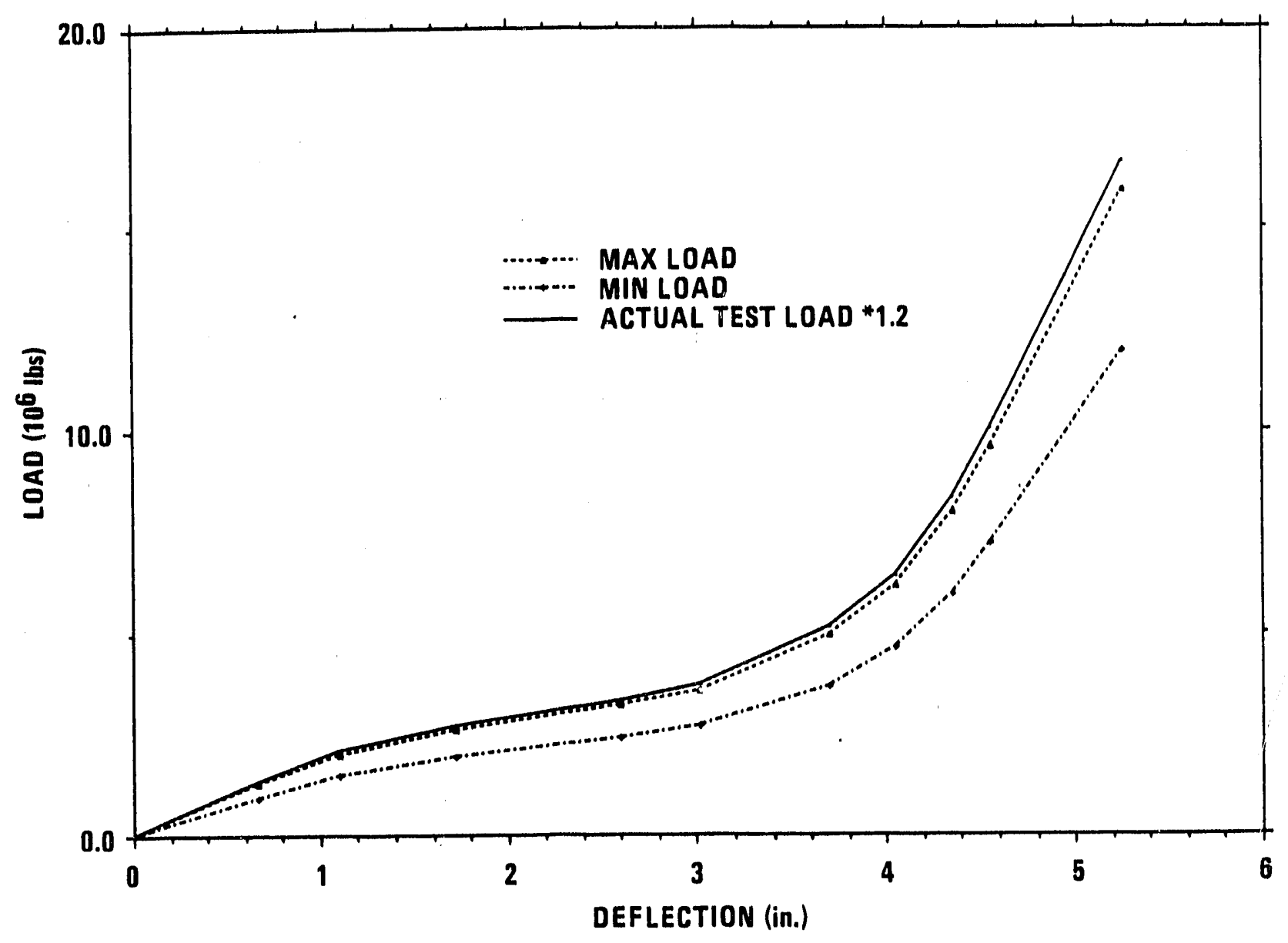

Fig. 3-38. Lower end impact limiter load-deflection curve (full-scale), 60 deg orientation 


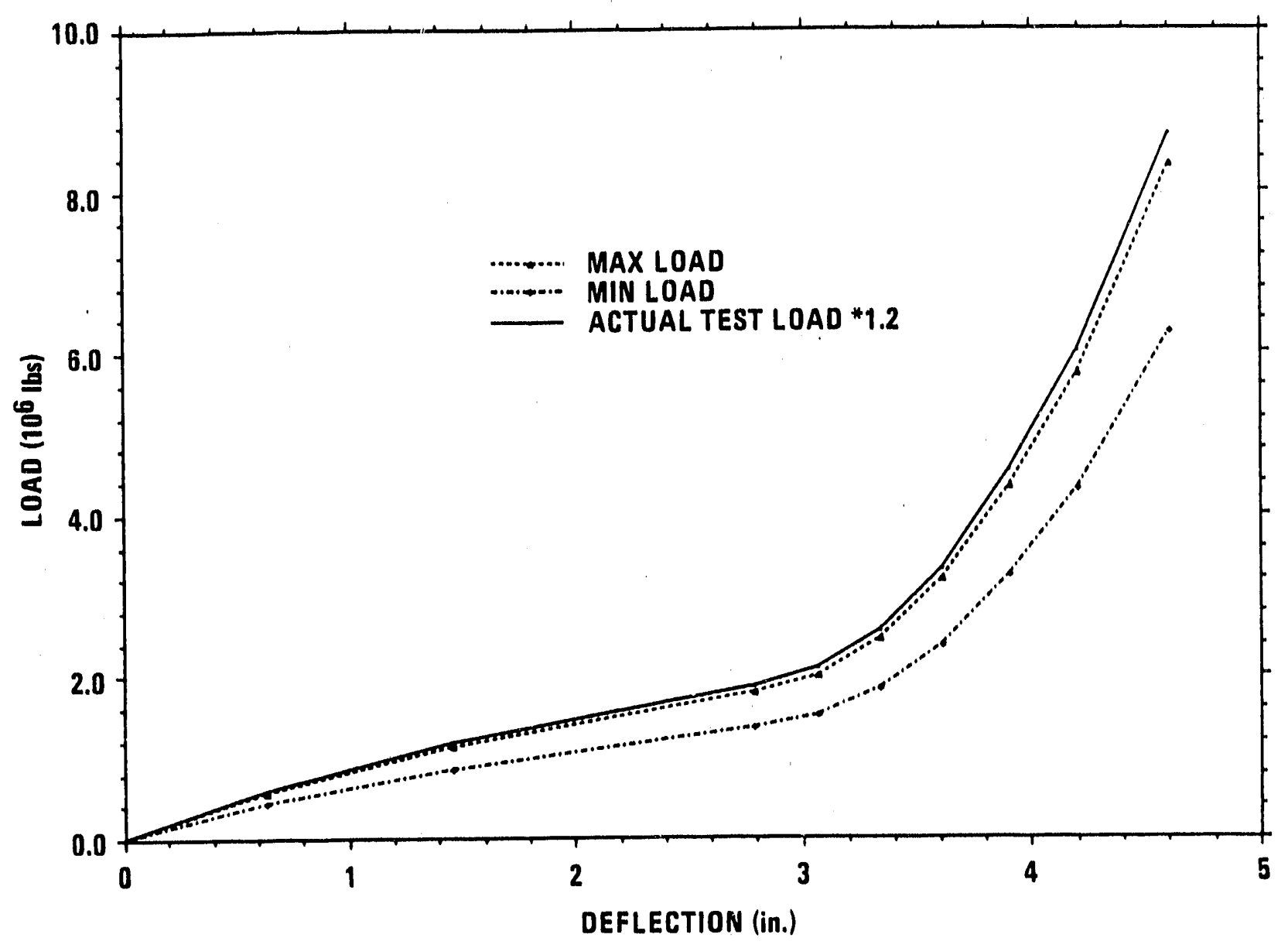

Fig. 3-39. Lower end Impact 1imiter load-deflection curve (full-scale), 45 deg orientation 


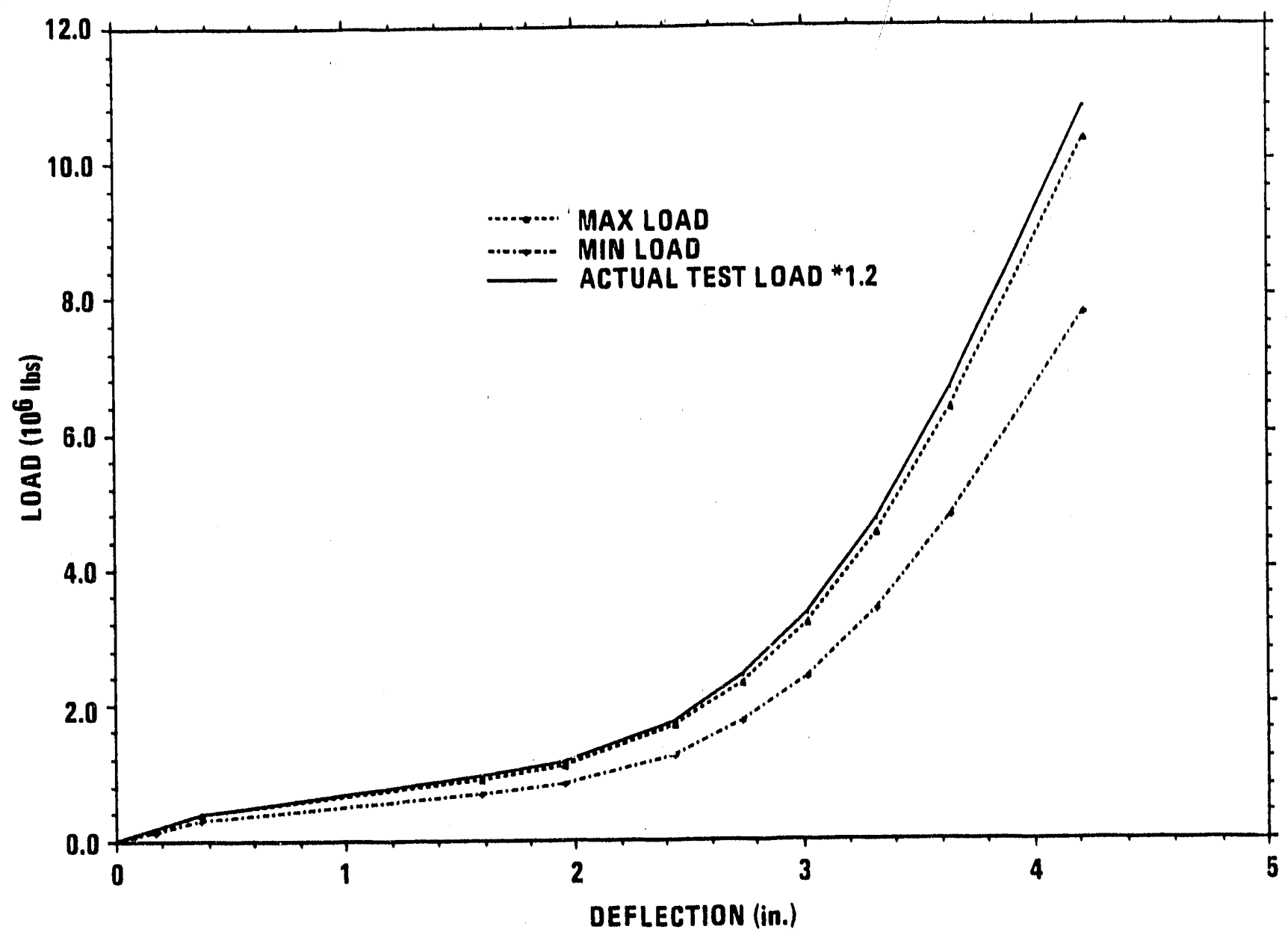

Fig. 3-40. Lower end impact limiter load-deflection curve (ful1-scale), $30 \mathrm{deg}$ orientation 


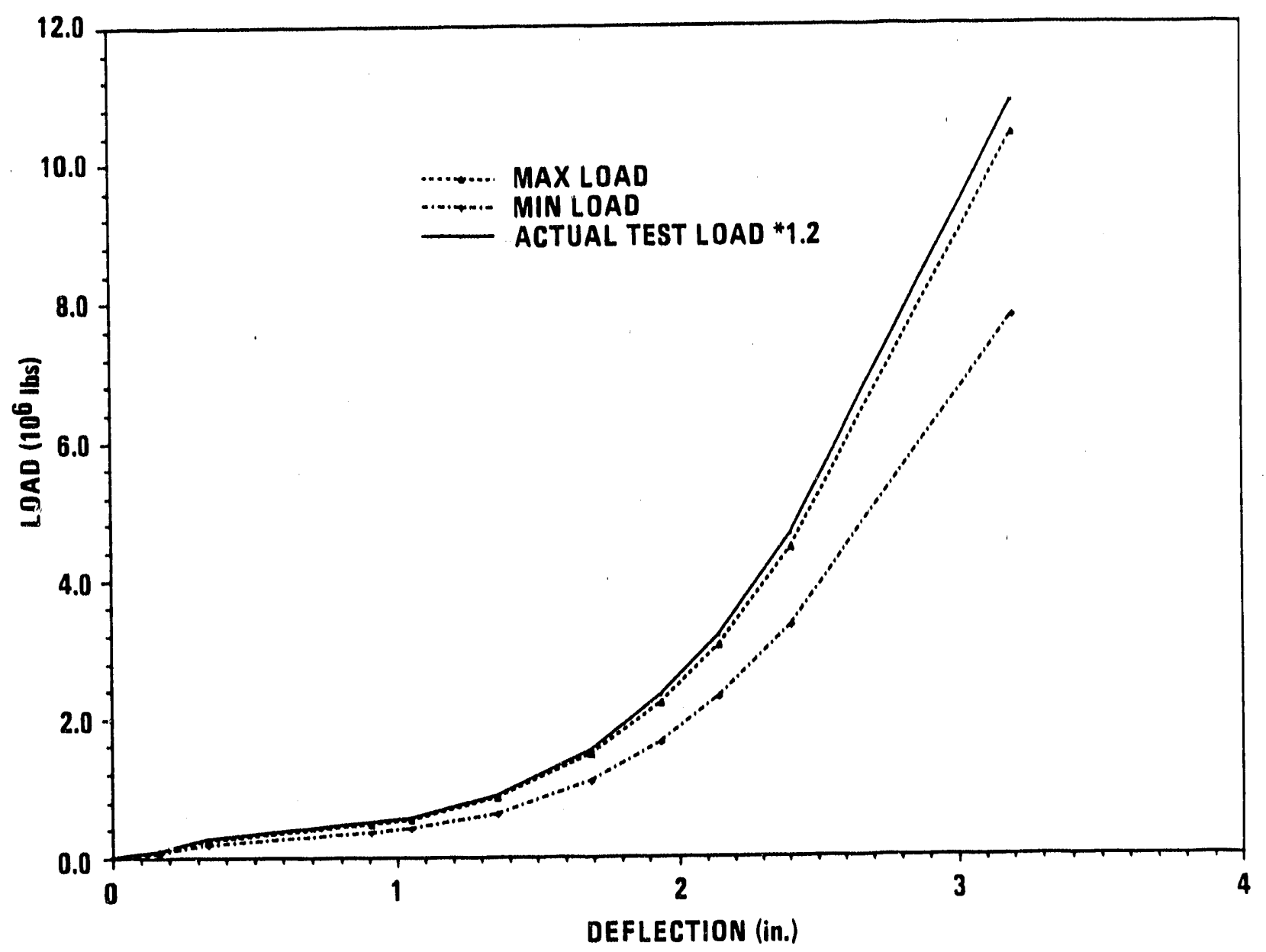

Fig. 3-41. Lower end Impact limiter load-deflection curve (full-scale), 15 deg orfentation 
Figures 3-42 through $3-44$ show the maximum and mintmum bound loaddeflection curves for the upper circumferential impact liniter developed using the test results and the given factors. We also developed the loud-deflection values for the upper circumferential impact limtter with the GA code ILMOD (Ref, 3-2). The ILMOD code uses as input the actual geometry of the impact 1 imfter and the strength characterfstics of the honeycomb with a dynamic load factor of 1.2 applied to the upper bound honeycomb crush strength. The results of the ILMOD code were slightly conservative to the test results and, therefore, used 1 , the GACAP analysis. The lower ctrcumferential impact limiter load-deflection values were also developed using the ILMOD computer code. The lower circumferential impact limiter geometry along with the strength characterlscs used for the upper circumferential impact limfter were Input to the ILMOD code.

Figures 3-45 through 3-53 show the maximum and minimum bound loaddeflection curves for the upper and lower clrcumferentlal Impact $1 \mathrm{Im}$ iters developed by ILMOD and used as input to GACAP. 


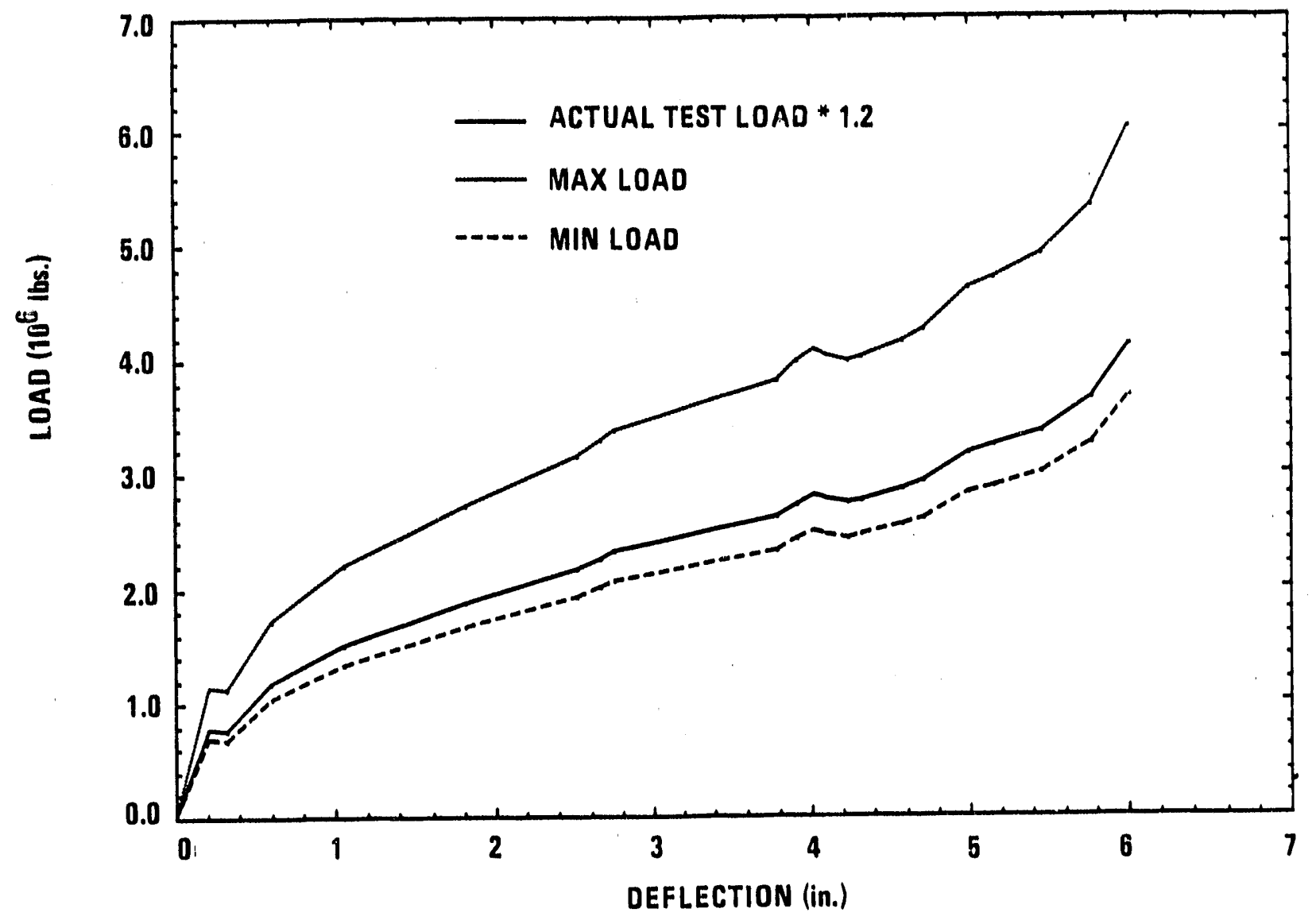

Fig. 3-42. Upper circumferential impact 1imiter, load-deflection curve (full-scale), 0 deg side drop orlentation 


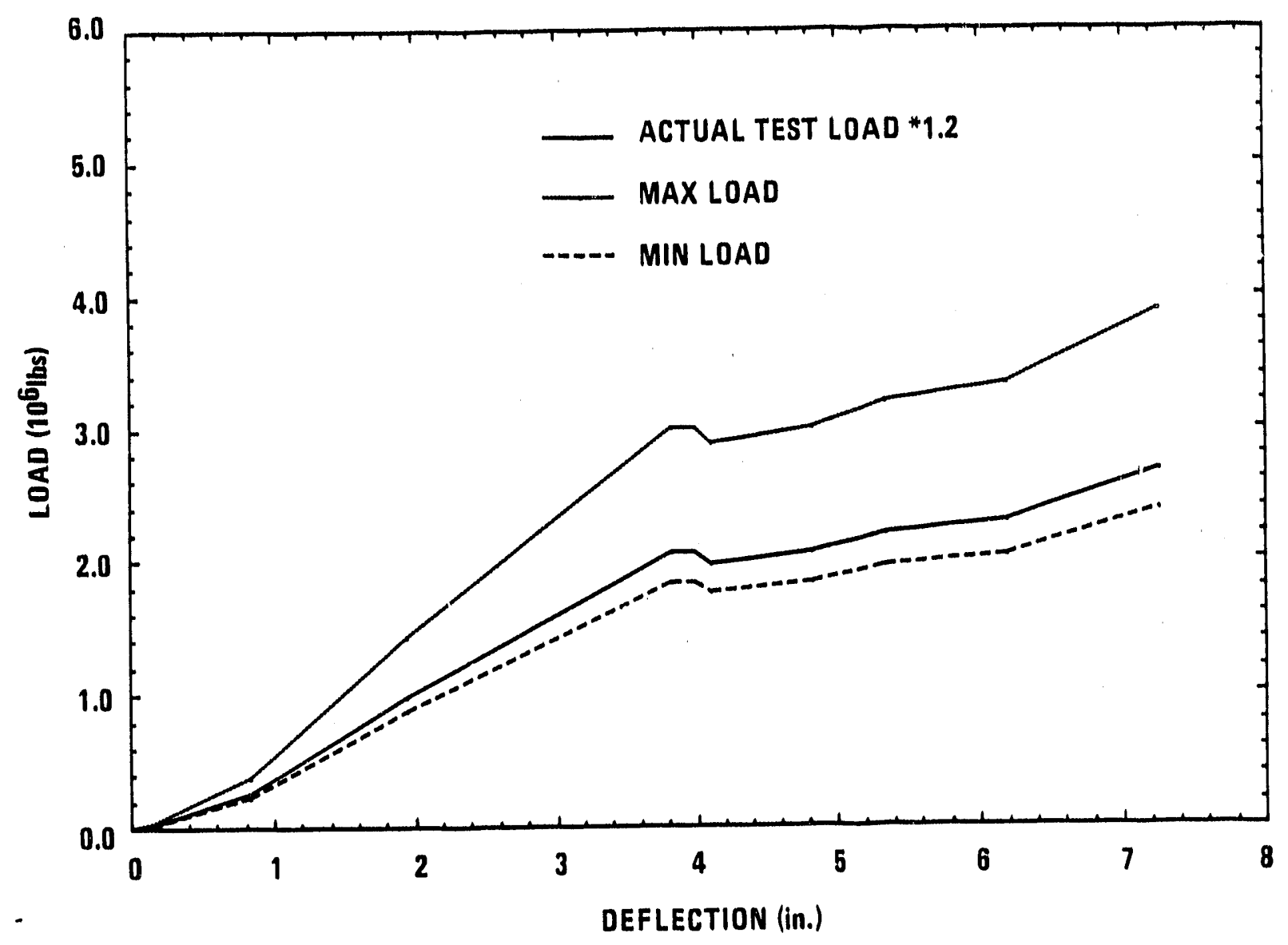

Fig. 3-43. Upper circumferential impact 1imiter, load-deflection curve (full-scale), 12 deg side drop orlentation 


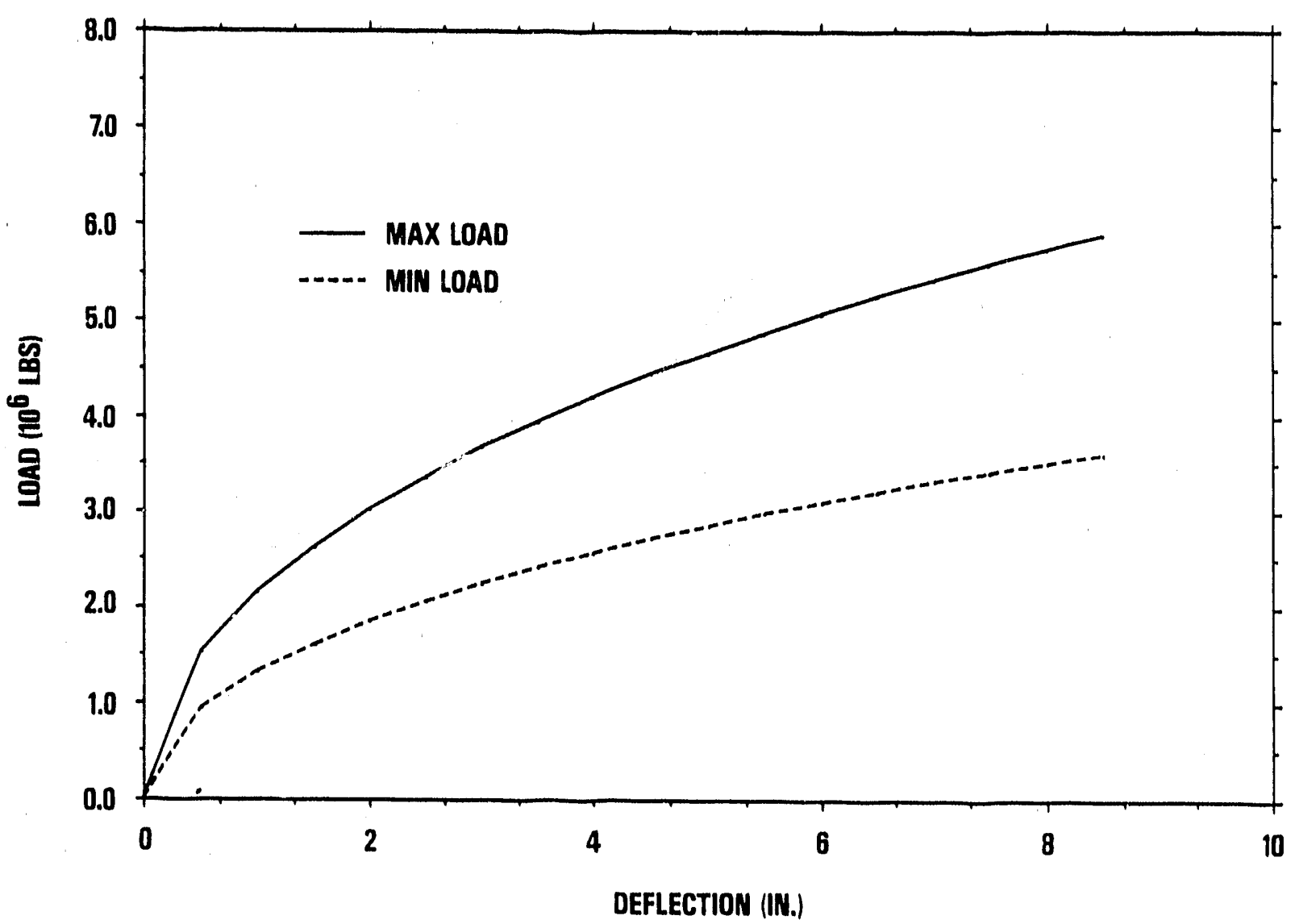

Fig. 3-45. Upper clrcumferential tmpact 1imiter, load-deflect fon curve (full-scale) from ILMOD, 0 deg side drop orfentation 


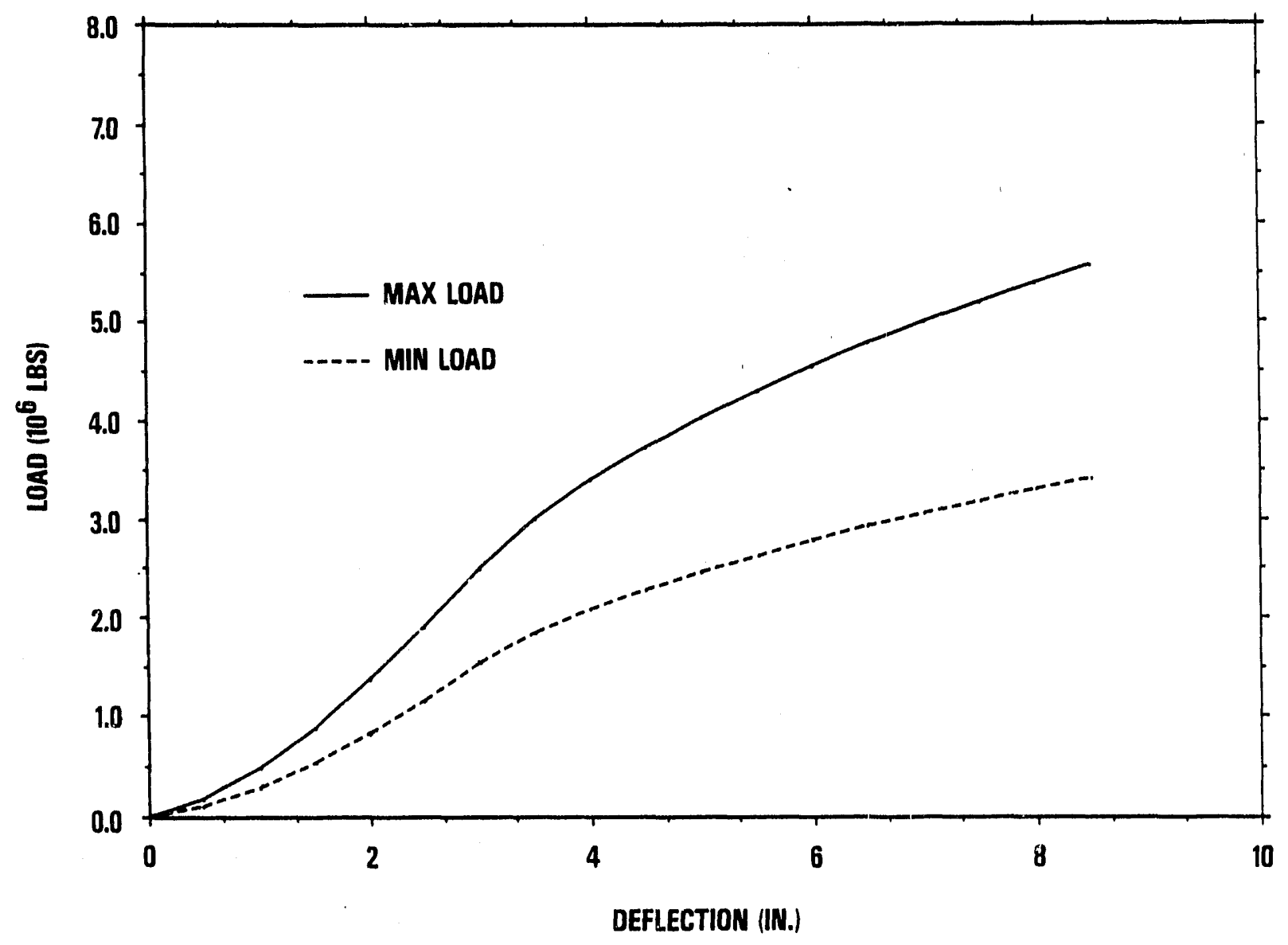

Fig. 3-46. Upper circumferential impact limiter, load-deflection curve (ful1-scale) from ILMOD, 12 deg side drop orfentation 


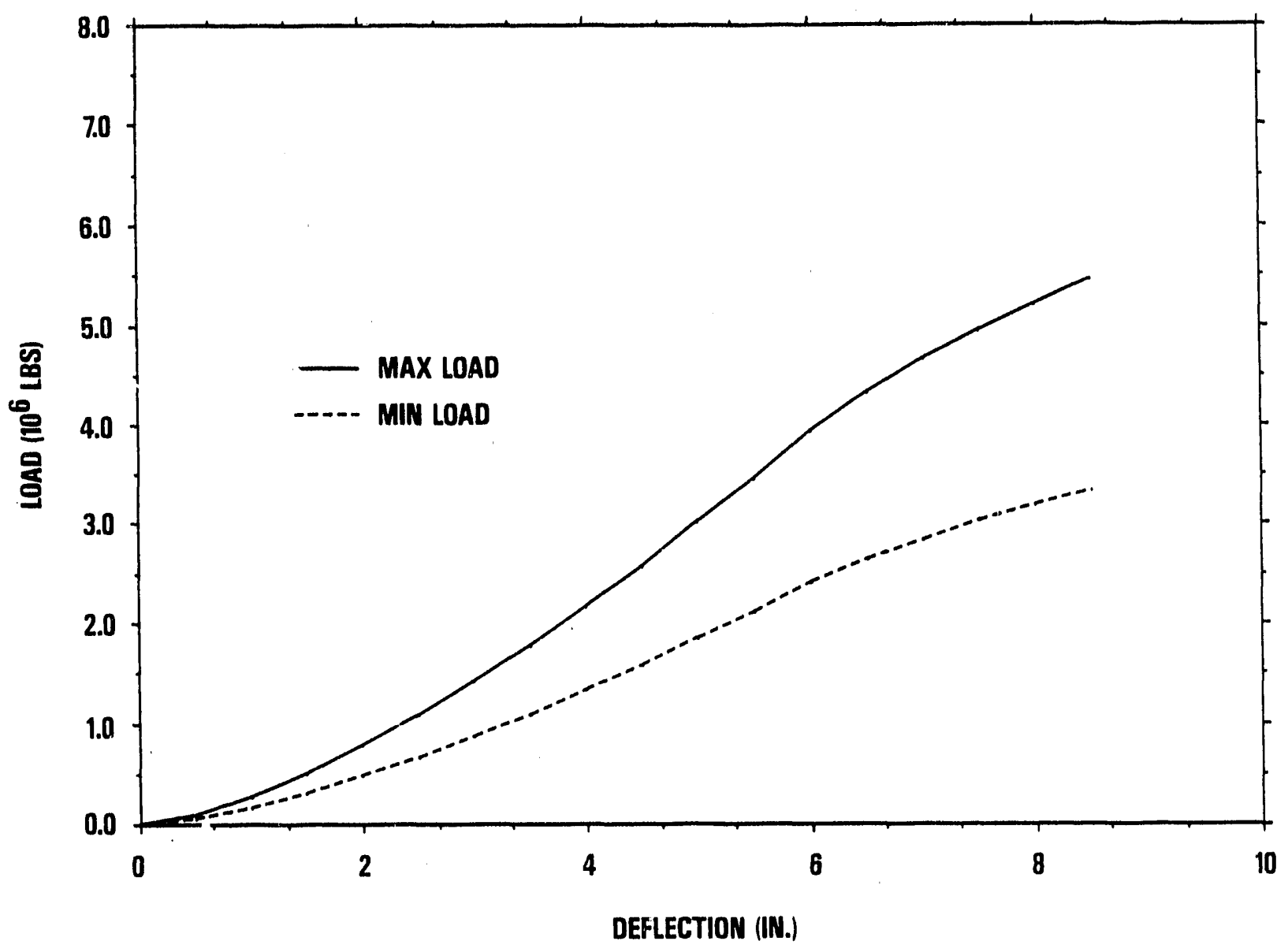

Fig. 3-47. Upper circumferential impact 1imiter, load-deflection curve (full-scale) from ILMOD, 24 deg side drop orientation 


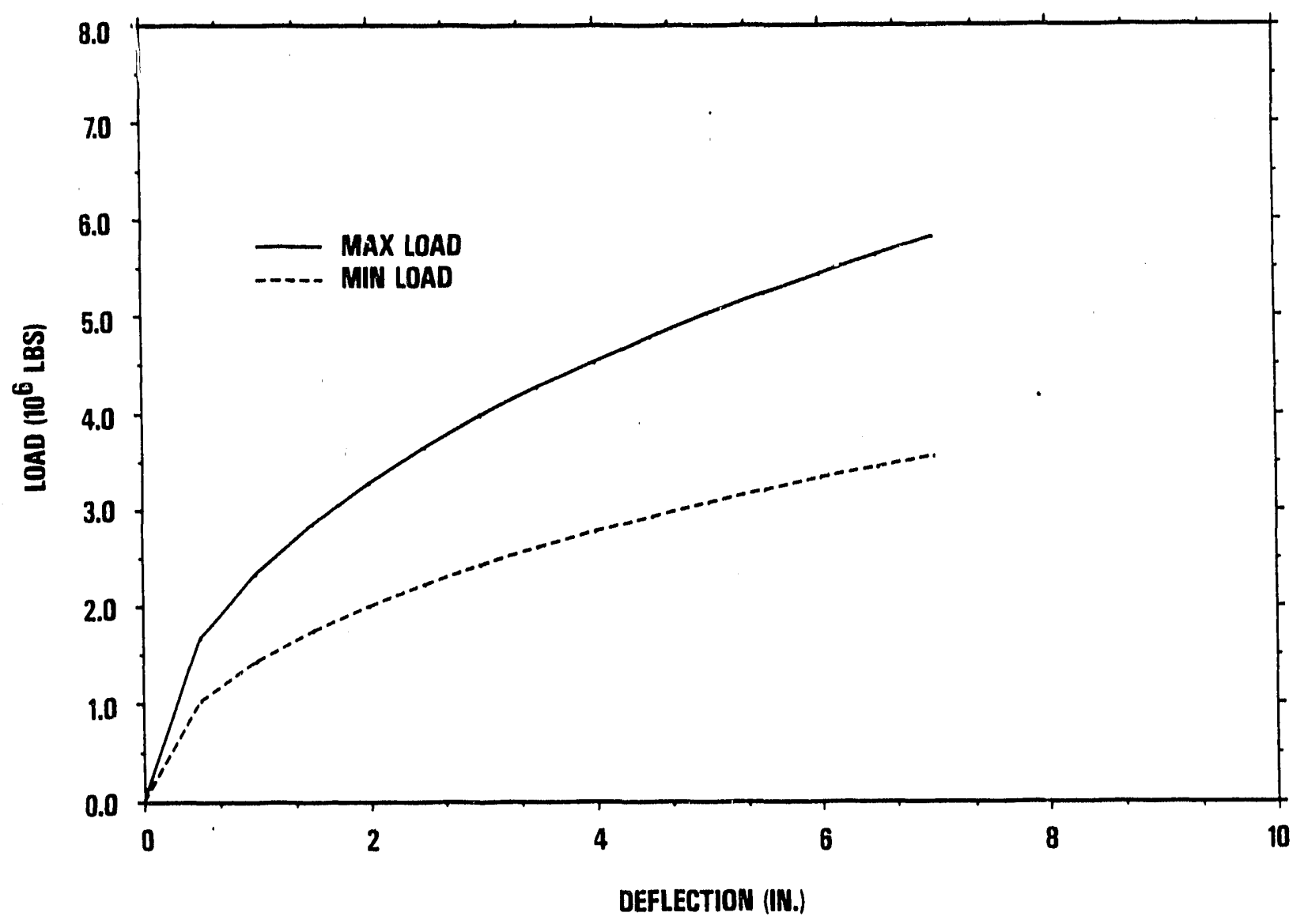

Fig. 3-48. Lower circumferential impact limfter (smal1 diameter), load-deflection curve (full-scale) from ILMOD, 0 deg side drop orientation 


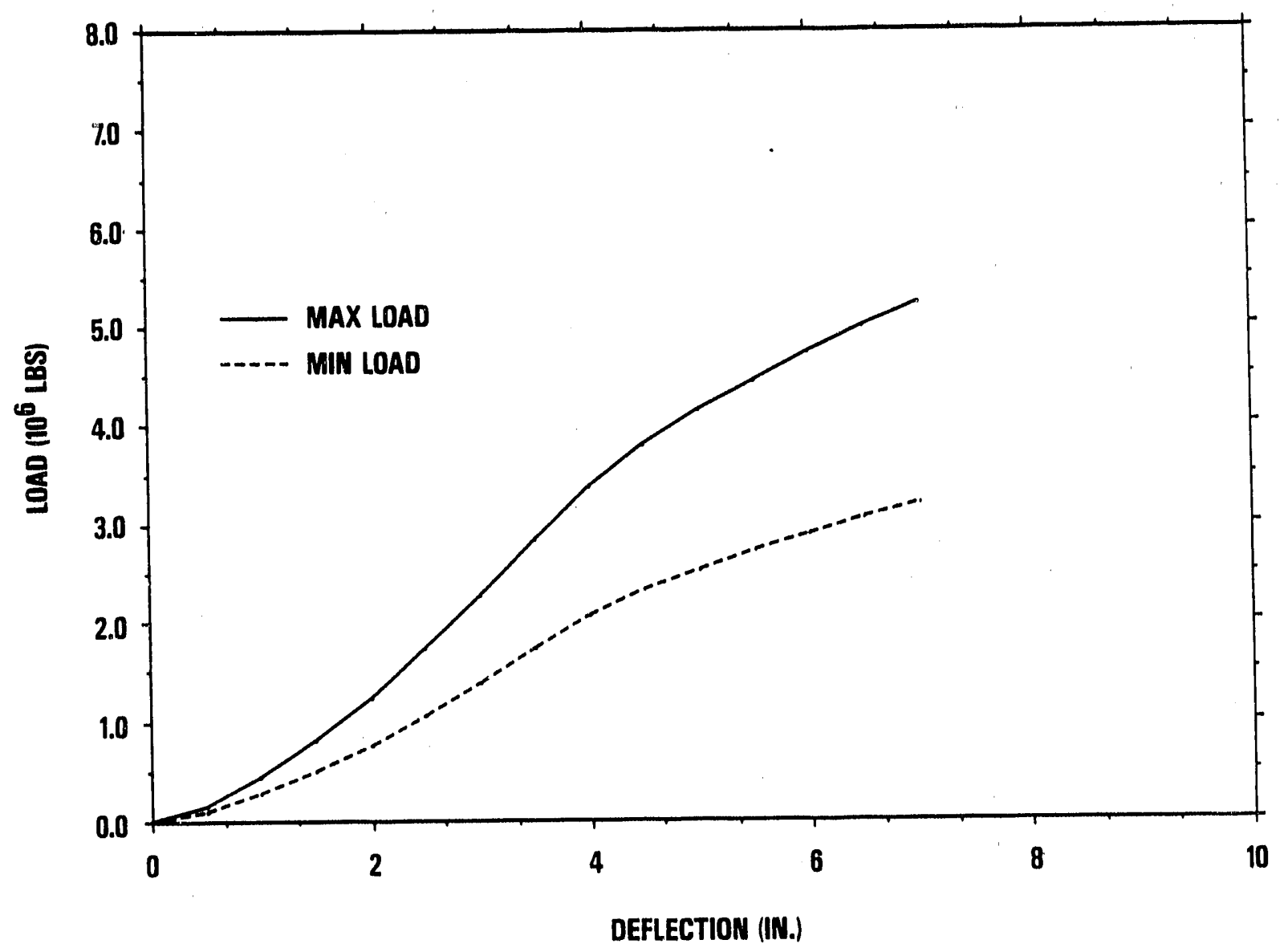

Fig. 3-49. Lower circumferential impact limiter (small diameter), load-deflection curve (full-scale) from ILMOD, $12 \mathrm{deg}$ side drop orientation 


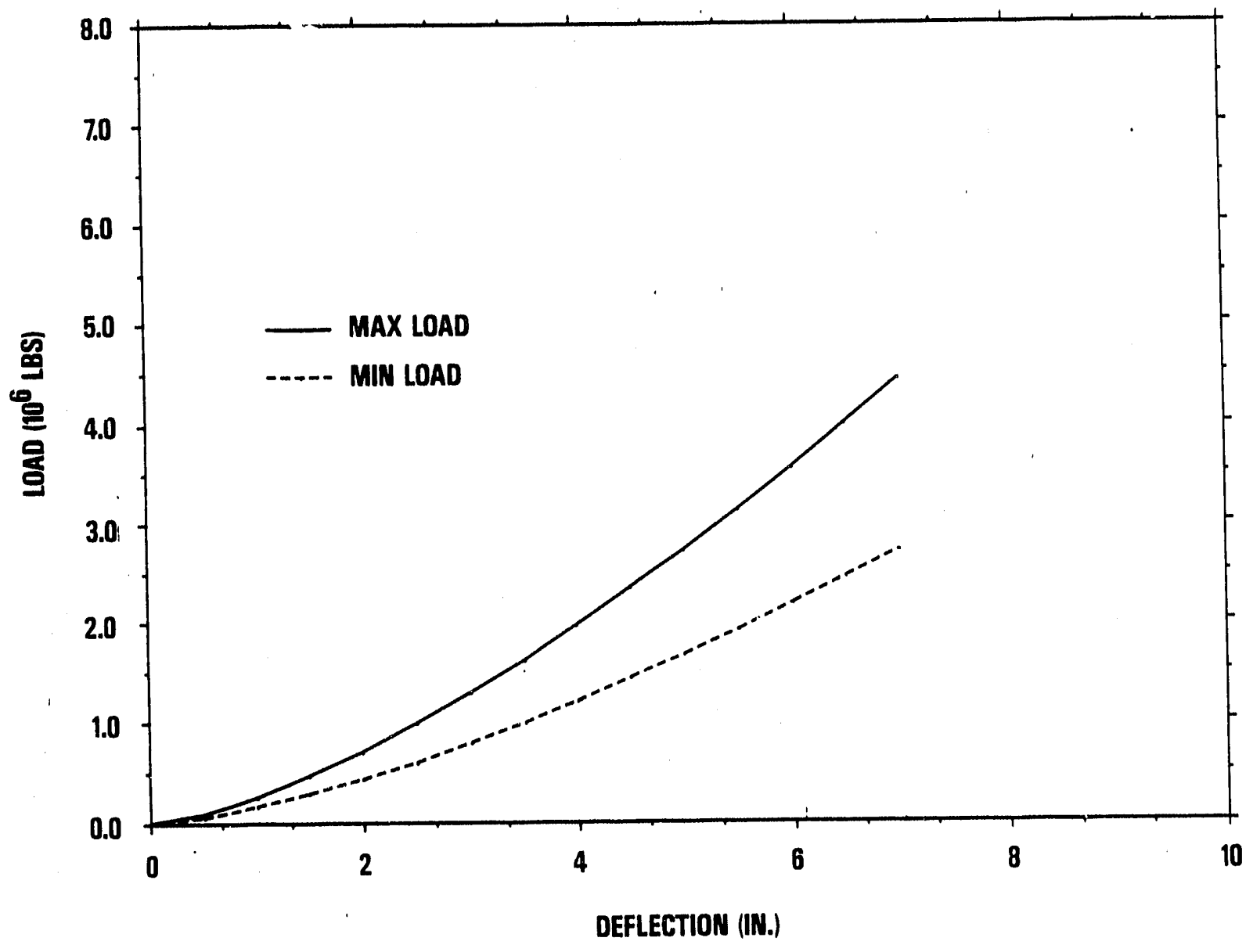

F1g. 3-50. Lower circumferential impact limiter (smal1 diameter), load-deflection curve (ful1-scale) from ILMOD, 24 deg side drop orientation 


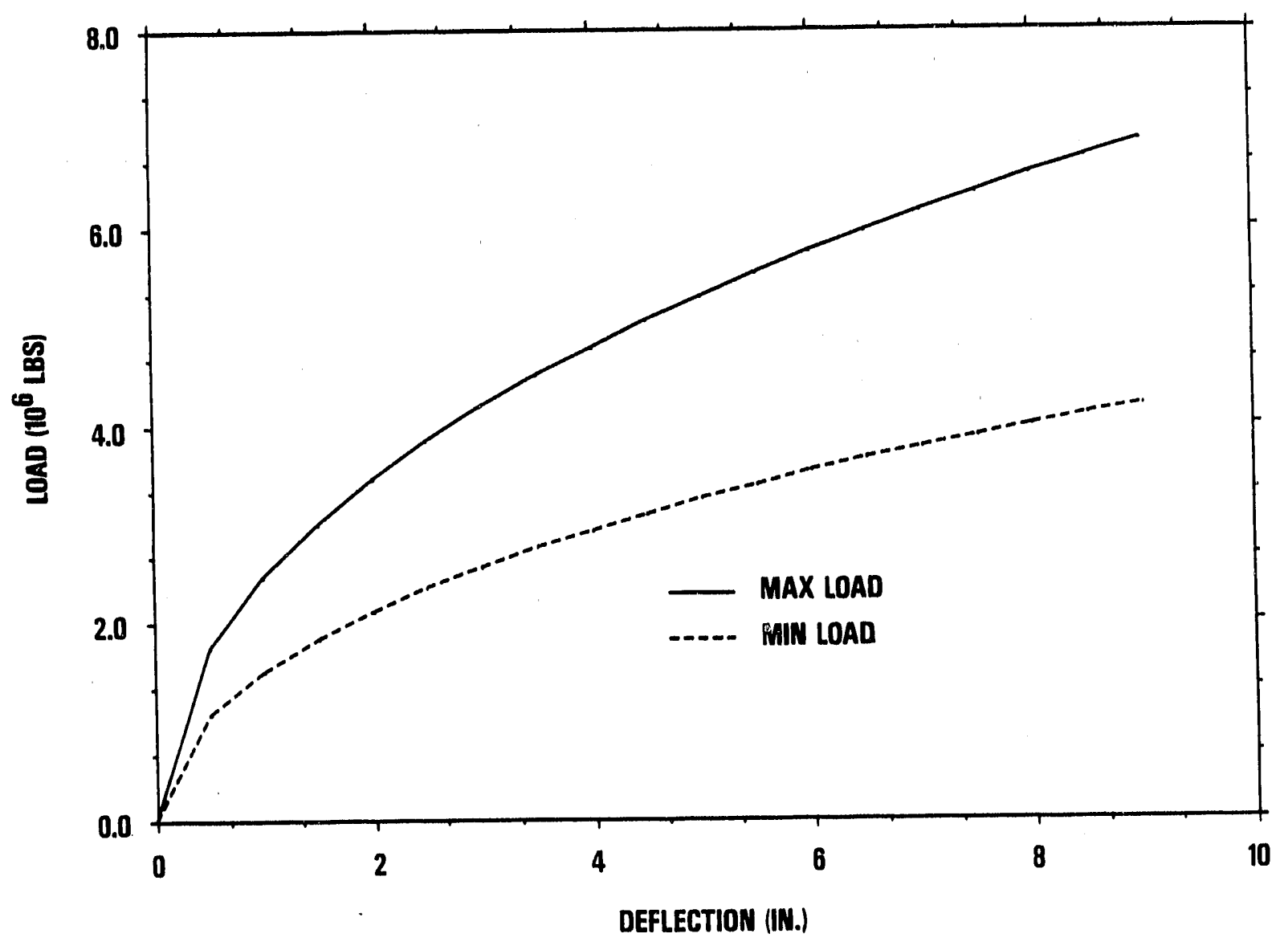

Fig. 3-51. Lower circumferential impact limiter (large diameter), load-deflection curve (full-scale) from ILMOD, 0 deg side drop orientation 


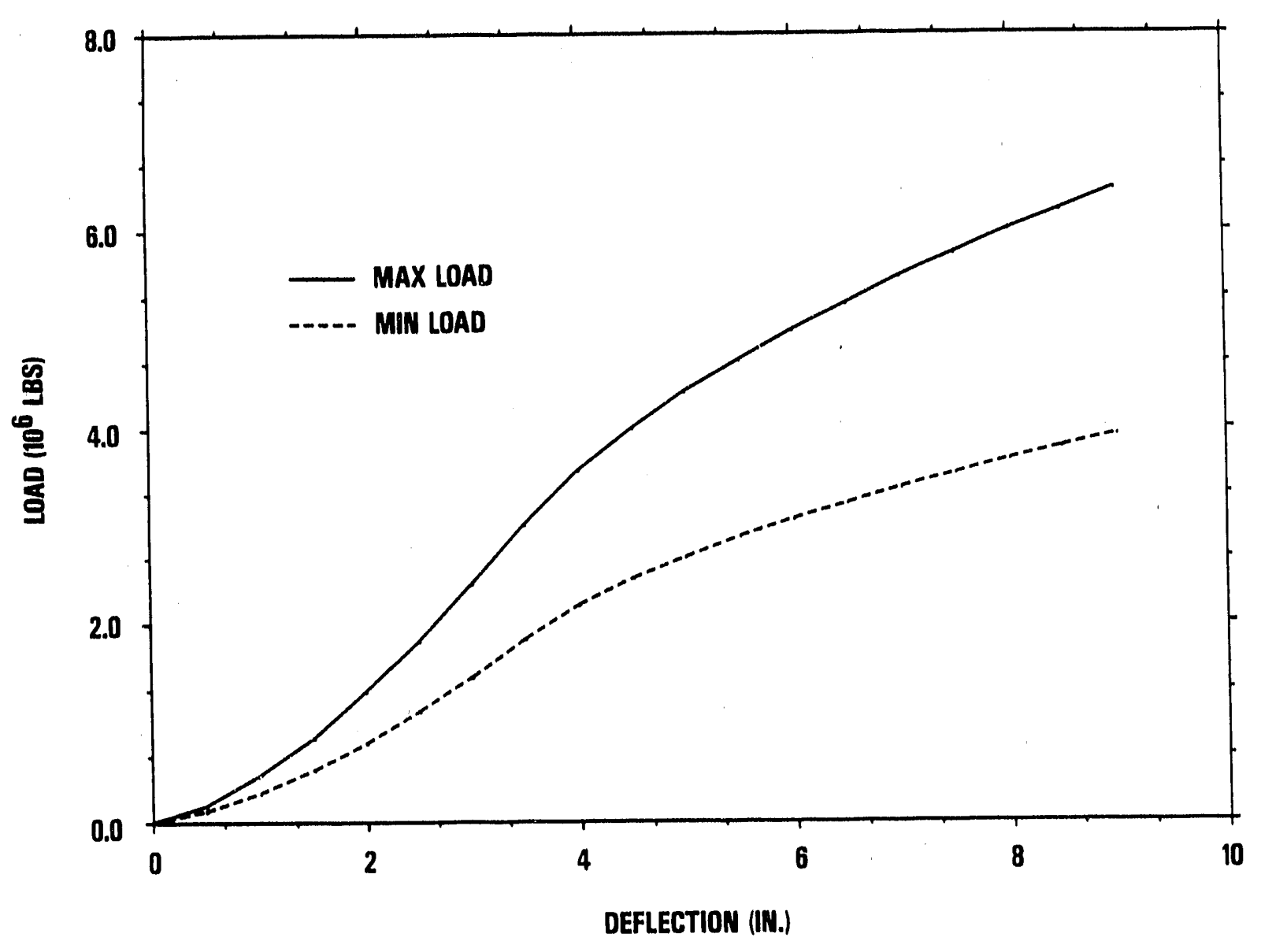

Fig. 3-52. Lower circumferential impact limiter (large diameter), load-deflection curve (full-scale) from ILMOD, 12 deg side drop orientation 


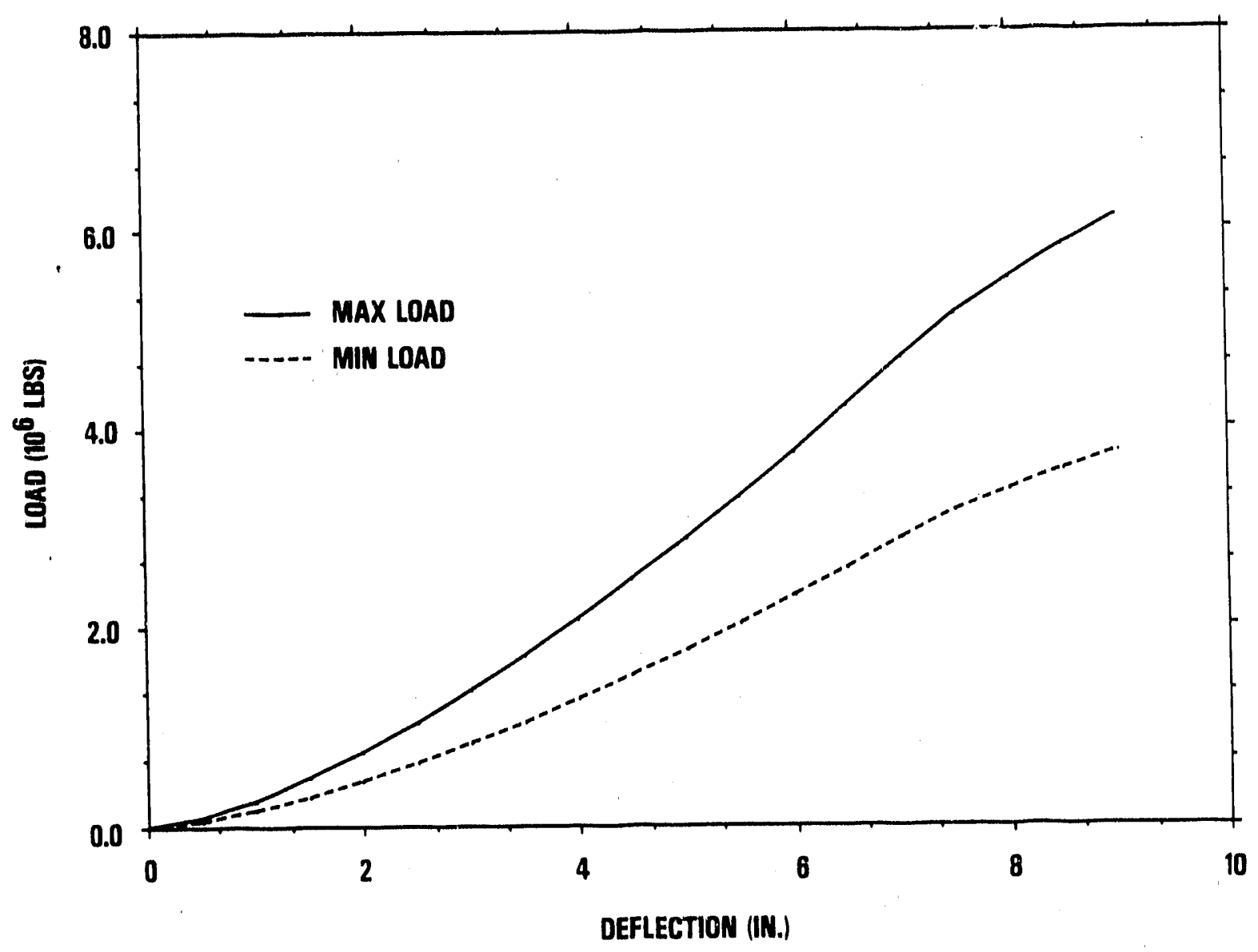

Fig. 3-53. Lower circumferential impact limiter (large diameter), load-deflection curve (full-scale) from ILMOD, 24 deg side drop orientation 


\subsubsection{Thirty-Foot Free Drop Elastic Analysis}

The DHLW cask elastic analysis used the GACAP computer code described in Section 3.2 for the $9-\mathrm{m}(30-\mathrm{ft})$ hypothetical accident condition free drops. GACAP output provides cask body wall stresses directly. Stresses in the closure, closure bolts, bottom plate and internals are obtained using the GACAP accelerations to calculate dynamic loading on those components. Following is a description of the model and results of the analyses.

3.3.2.1. GACAP Mode1. The GACAP mode1 represents the DHLW cask with 12 beams positioned within the cavity of the cask as shown in Fig. 3-54. The section properties of the cask body beam elements are calculated by GACAP using the actual cask dimensions.

The cask mass is distributed to each GACAP model node according to the location of the cask component relative to the node as shown in Fig. 3-54. The DU shield Iner is modeled as a nonstructural mass applied at each node, providing loading to the cask contalnment boundary. Since the contents and shield liner are not tied to the containment boundary, they bear directly on the bottom plate during the bottom end drops. Therefore, the cask body wall axial stresses are reduced to reflect the actual load path of the contents and shield liner.

The GACAP model includes two impact limiters in the bottom end region, (1) the lower end $r$ ing, and (2) the lower circumferential honeycomb impact Iinfter.

In most cases, the reaction point of the impact 1 imiters is located at the point of Initial contact. Figure 3-54 summarizes the location of the impact limiter reaction points relative to the node to which they are attached. The reaction point on the circumferential impact limiters is either at the center or the lower edge of the outside surface ince crushing w11l always occur at a low angle (less than $20 \mathrm{deg}$ ). The reaction point on the lower end and notched impact limiters is at the point 


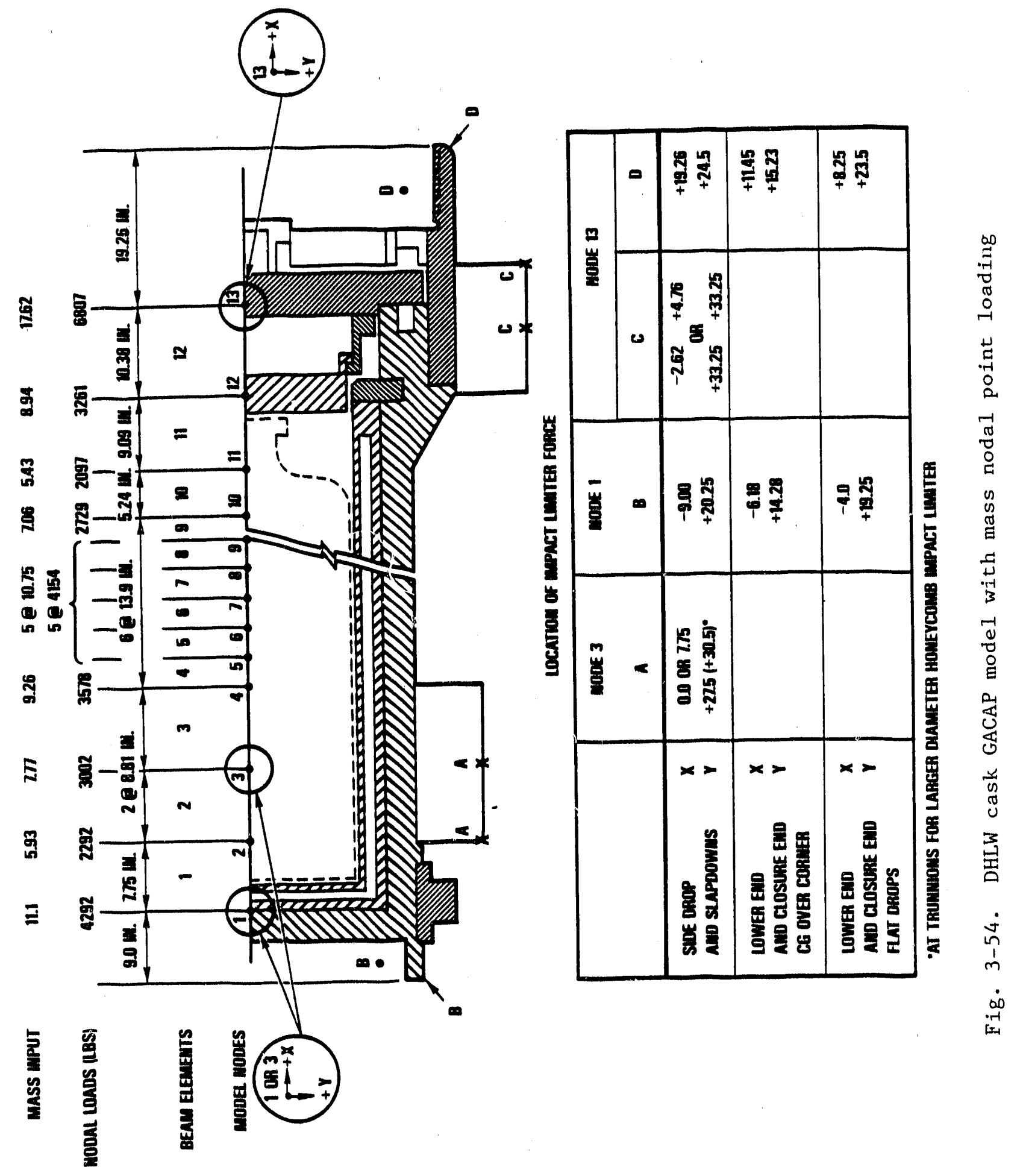


of Inftial contact except for the CG over corner drops. For these drops, locating the reaction polnt at the polnt of inftial contact is too conservative since the centrold of the deformed Impact 1imfter moves toward the centerline of the cask. Therefore, we located the reaction polnt at the centrold of the footprint of the deformed Impact IImiter at the point of maximum deformation.

3.3.2.2. Impact Limfter Load Deflection Data. Section 3.3.1 explains In detall the development of the load deflection curves for the impact Limiters. Figures 3-30 through 3-41 show the load deflection curves for the maximum and mintmum yleld of the lower end and notched impact 1 imiters. Figures $3-45$ through $3-53$ show the load deflection curves for the upper and lower bound honeycomb crush strengths for the clrcumferential Impact limiters. All the curves are input to GACAP.

3.3.2.3. GACAP Results. The GACAP analysis provides both rigid body and flextble body solutions. During the rigld body analysis, the cask is modeled as a single rigid beam element with three degrees of freedom at the CG, as shown in FIg. 3-3. In the flexible-body analysis, each node has 1 ts own acceleration computed from the $3^{*}$ n degree of freedom model (as shown in Fig. 3-3). A comparison of the rigid-body results with the flexible-body results provides information on the dynamic amplification factor (DAF).

The DAFs provided by the GACAP analysis are considered to be unrealistically conservative for the following reasons:

1. The dynamic behavior is obtalned elastically and it is well documented in the 11terature, Ref, 3-3, Sections 2.7 and 2.8 that after the onset of ylelding, the DAFs decrease rapldiy.

2. The damping inherent in the materials is ignored. In reality, there will be structural and frictional damplng in the cask which will reduce the calculated DAF. 
3. The DU and 1iner structure is treated very conservatively in the analysis by ignoring tts stiffness. In realtty, the DU is very strong and will provide stiffness to the cask. Even if It were to crack, which is unlikely based on test results, the cracking of the DU will provide damping which will reduce the DAFs and absorb energy whtch will reduce the total loads.

Because the DAFs obtalned from GACAP are so conslervative, the rigld-body stresses are used to represent the cask stress state durfing the Impact events. The maximum stresses produced are presented in Tables 3-4 through 3-7 for the closure end impacts and Tables 3-8 through 3-11 for the bottom end impacts. These tables also include the stress intensities when the stresses due to the destgn pressure of 50 psig are combined.

In Table 3-9, the $101 / 2$ deg drop angle case duplicates the angle used in the 1/2-scale model test program (see Section 4). The model configuration used in that test did not have the lower circumferential impact limiter. This test was performed to give conservative loading on the closure end during secondary impact. This GACAP model produced the highest flexible-body stress intensities. The DAF was 1.54 producing a stress intensity of $71.3 \mathrm{ksl}$ versus the rigid body results of $46.2 \mathrm{ks}$. The test results of the $30-\mathrm{ft}$ drop of the DHLW model reported no local deformation of the cask contalnment wall indicating no permanent set for the reglon. Therefore, based on the test results the flexlble-body results are very conservative, as mentioned, and the rigld-body results are more representative of the actual response of the cask.

The 10 deg drop angle analysis was also performed to duplicate the angle used in the $10 \mathrm{deg}$ drop angle test. For this test, the lower circuinferential impact limiter was on the model. Because the circumferentlal Impact limfter has a "softer" load-deflection curve, the resulting stresses are lower. 
TABLE $3-4$

MOMENT AND STRESS COMPONENTS FOR MAXIMUM PRIMARY STRESS INTENSITY 1-ft CLOSURE END ORIENTATION DROP - DHLW CASK - MAXIMUM CRUSH STRENGTH

\begin{tabular}{lcccccc}
\hline $\begin{array}{c}\text { Drop } \\
\text { Angle }\end{array}$ & $\begin{array}{c}\text { Moment } \\
\left(\text { In-1b) } 10^{6}\right.\end{array}$ & $\begin{array}{c}\sigma \\
\text { Ks1 } \\
\text { Moment }\end{array}$ & $\begin{array}{c}\sigma \\
\text { Ks1 } \\
\text { Axial }\end{array}$ & $\begin{array}{c}\tau \\
\text { Ks1 } \\
\text { Shear }\end{array}$ & $\begin{array}{c}\text { Ks1 } \\
\text { S.I. } \\
\text { No Pressure }\end{array}$ & $\begin{array}{c}\text { Ks1(a) } \\
\text { S.I. } \\
\text { W/Pressure }\end{array}$ \\
\hline-2.89 & 21.95 & 7.34 & 0.03 & 0.44 & 7.42 & 7.62 \\
10 & 5.54 & 1.85 & 0.08 & 0.3 & 2.02 & 2.25 \\
15 & 5.83 & 1.95 & 0.12 & 0.15 & 2.09 & 2.29 \\
30 & 5.0 & 1.67 & 0.22 & 0.2 & 1.93 & 2.13 \\
45 & 2.89 & 0.96 & 0.23 & 0.22 & 1.27 & 1.46 \\
60 & 4.59 & 1.53 & 0.57 & 0.58 & 2.40 & 2.58 \\
73.4 & 8.79 & 2.94 & 0.94 & 0.60 & 4.06 & 4.25 \\
90 & 0 & 0 & 4.12 & 0 & 4.12 & 4.37 \\
\hline
\end{tabular}

(a) Stresses due to 50 psig cavity pressure: Hoop stress $=+0.3 \mathrm{ks} 1$

Axial stress $=+0.1 \mathrm{ks} 1$ 
TABLE $3-5$

MOMENT AND STRESS COMPONENTS FOR MAXIMUM PRIMARY STRESS INTENSITY 30-ft CLOSURE END ORIENTATION DROP - DHLW CASK - MAXIMUM CRUSH STRENGTH

\begin{tabular}{|c|c|c|c|c|c|c|c|}
\hline $\begin{array}{l}\text { Drop } \\
\text { Angle }\end{array}$ & $\begin{array}{c}\text { Moment } \\
(1 \mathrm{n}-1 \mathrm{~b}) 10^{6}\end{array}$ & $\begin{array}{c}\sigma \\
\text { Ks1 } \\
\text { Moment }\end{array}$ & $\begin{array}{c}\sigma \\
\text { Ks1 } \\
\text { Axial }\end{array}$ & $\begin{array}{c}\tau \\
\text { Ks1 } \\
\text { Shear }\end{array}$ & No & $\begin{array}{l}\text { Ksi } \\
\text { S.I. } \\
\text { Pressure }\end{array}$ & $\begin{array}{c}\text { KsI(a) } \\
\text { S.I. } \\
\text { W/Pressure }\end{array}$ \\
\hline-2.89 & 70.51 & 23.6 & 0.1 & 1.38 & & 23.8 & 24.06 \\
\hline 10 & 31.45 & 10.5 & 0.36 & 6.49 & & 16.92 & 17.05 \\
\hline 15 & 39.68 & 13.3 & 0.59 & 1.0 & & 14.03 & 14.23 \\
\hline 30 & 36.48 & 11.6 & 0.76 & 6.50 & & 17.94 & 18.08 \\
\hline 45 & 38.76 & 13.0 & 0.61 & 2.08 & & 14.23 & 14.42 \\
\hline 60 & 57.85 & 19.3 & 1.33 & 1.61 & & 20.88 & 21.08 \\
\hline 73.4 & 43.31 & 14.5 & 4.74 & 3.05 & & 20.18 & 20.37 \\
\hline 90 & 0 & 0 & 8.62 & 0 & & 8.62 & 8.8 \\
\hline
\end{tabular}

(a) Stresses due to 50 psig cavity pressure: Hoop stress $=+0.3 \mathrm{ksl}$ Axial stress $=+0.1 \mathrm{ksl}$ 
TABLE 3-6

MOMENT AND STRESS COMPONENTS FOR MAXIMUM PRIMARY STRESS INTENSITY 30-Et CLOSURE END ORIENTATION DROP - DHLW CASK - MINIMUM CRUSH STRENGTH

\begin{tabular}{lcccccc}
\hline $\begin{array}{l}\text { Drop } \\
\text { Angle }\end{array}$ & $\begin{array}{c}\text { Moment } \\
\text { in-1b) } 10^{6}\end{array}$ & $\begin{array}{c}\sigma \\
\text { Ksi } \\
\text { Moment }\end{array}$ & $\begin{array}{c}\sigma \\
\text { Ksi } \\
\text { Axial }\end{array}$ & $\begin{array}{c}\tau \\
\text { Ksi } \\
\text { Shear }\end{array}$ & $\begin{array}{c}\text { Ksi } \\
\text { S.I. } \\
\text { No Pressure }\end{array}$ & $\begin{array}{c}\text { Ksi(a) } \\
\text { S.I. } \\
\text { W/Pressure }\end{array}$ \\
\hline-2.89 & 51.22 & 17.1 & 0 & 1 & 17.3 & 17.42 \\
10 & 24.01 & 8.03 & 0.27 & 1.01 & 8.54 & 8.74 \\
15 & 23.25 & 7.78 & 0.27 & 4.79 & 12.51 & 12.64 \\
30 & 40.08 & 13.4 & 0.47 & 2.15 & 14.52 & 14.71 \\
45 & 44.63 & 14.9 & 0.58 & 1.58 & 15.80 & 16.0 \\
60 & 62.43 & 20.9 & 1.25 & 1.37 & 22.32 & 22.52 \\
73.4 & 44.58 & 14.9 & 4.89 & 3.14 & 20.76 & 7.94 \\
90 & 0 & 0 & 7.74 & 0 & 7.74 & 7.94 \\
\hline
\end{tabular}

(a) Stresses due to 50 psig cavity pressure: Hoop stress $=+0.3 \mathrm{ks} 1$ Axial stress $=+0.1 \mathrm{ksi}$ 
TABLE $3-7$

MOMENT AND STRESS COMPONENTS FOR MAXIMUM PRIMARY STRESS INTENSITY 30-ft CLOSURE END ORIENTATION DROP - DHLW CASK - MAXIMUM CRUSH STRENGTH LOWER CIRCUMFERENTIAL IMPACT LIMITER WITH LARGE DIAMETER

\begin{tabular}{lcccccc}
\hline $\begin{array}{l}\text { Drop } \\
\text { Angle }\end{array}$ & $\begin{array}{c}\text { Moment } \\
\text { in-1b) } 10^{6}\end{array}$ & $\begin{array}{c}\sigma \\
\text { Ks1 } \\
\text { Moment }\end{array}$ & $\begin{array}{c}\sigma \\
\text { Ks1 } \\
\text { Axial }\end{array}$ & $\begin{array}{c}\tau \\
\text { Ks1 } \\
\text { Shear }\end{array}$ & $\begin{array}{c}\text { Ks1 } \\
\text { S.I. } \\
\text { No Pressure }\end{array}$ & $\begin{array}{c}\text { Ks1(a) } \\
\text { S.I. } \\
\text { W/Pressure }\end{array}$ \\
\hline-2.89 & 74.0 & 24.7 & 0.02 & 1.58 & 25.0 & 25.12 \\
10 & 43.08 & 14.4 & 0.02 & 0.89 & 14.53 & 14.73 \\
15 & 31.09 & 10.4 & 0.25 & 6.87 & 17.38 & 17.51 \\
30 & 36.92 & 12.3 & 0.58 & 6.59 & 18.43 & 18.57 \\
45 & 36.11 & 12.1 & 0.47 & 2.06 & 13.23 & 13.42 \\
60 & 27.01 & 8.99 & 3.73 & 3.83 & 14.85 & 15.02 \\
\hline
\end{tabular}

(a) Stresses due to 50 psig cavity pressure: Hoop stress $=+0.3 \mathrm{ksi}$ Axial stress $=+0.1 \mathrm{ks} 1$ 
TABLE 3-8

MOMENT' AND STRESS COMPONENTS FOR MAXIMUM PRIMARY STRESS INTENSITY 1-ft BOTTOM END ORIENTATION DROP - DHLW CASK - MAXIMUM CRUSH STRENGTH

\begin{tabular}{lcccccc}
\hline $\begin{array}{l}\text { Drop } \\
\text { Angle }\end{array}$ & $\begin{array}{c}\text { Moment } \\
\left(\text { In-1b) } 10^{6}\right.\end{array}$ & $\begin{array}{c}\sigma \\
\text { Ks1 } \\
\text { Moment }\end{array}$ & $\begin{array}{c}\sigma \\
\text { Ks1 } \\
\text { Axia1 }\end{array}$ & $\begin{array}{c}\tau \\
\text { Ks1 } \\
\text { Shear }\end{array}$ & $\begin{array}{c}\text { Ks1 } \\
\text { S.I. } \\
\text { Noresure }\end{array}$ & $\begin{array}{c}\text { Ksi(a) } \\
\text { S.I. } \\
\text { W/Pressure }\end{array}$ \\
\hline 10 & 7.12 & 2.38 & 0.15 & 1.13 & 3.39 & 3.54 \\
15 & 2.28 & 0.76 & 0.17 & 0.81 & 1.87 & 1.98 \\
30 & 7.08 & 2.37 & 0.29 & 0.13 & 2.72 & 2.87 \\
45 & 3.06 & 1.02 & 0.67 & 0.98 & 2.16 & 2.72 \\
60 & 13.72 & 4.59 & 1.51 & 1.40 & 6.71 & 6.89 \\
75.7 (b) & 17.54 & 5.86 & 2.28 & 1.0 & 8.38 & 8.58 \\
90 & 0 & 0 & 10.43 & 0 & 10.43 & 10.63 \\
\hline
\end{tabular}

(a) Stresses due to 50 psig cavity pressure: Hoop stress $=+0.3 \mathrm{ks} 1$ Axial stress $=+0.1 \mathrm{ks} 1$

(b) GACAP calculates bending stresses near the end of the cask for steep angles in a conservative manner; therefore, the stresses shown are at a distance equal to approximately $1 / 2$ * cask diameter from the botioni of the cask. 
TABLE 3-9

MOMENT AND STRESS COMPONENTS FOR MAXIMUM PRIMARY STRESS INTENSITY 30-ft BOTTOM END ORIENTATION DROP - DHLW CASK - MAXIMUM CRUSH STRENGTH

\begin{tabular}{lcccccc}
\hline $\begin{array}{l}\text { Drop } \\
\text { Angle }\end{array}$ & $\begin{array}{c}\text { Moment } \\
\text { (n-1b) } 10^{6}\end{array}$ & $\begin{array}{c}\sigma \\
\text { Ks1 } \\
\text { Moment }\end{array}$ & $\begin{array}{c}\sigma \\
\text { Ks1 } \\
\text { Axial }\end{array}$ & $\begin{array}{c}\tau \\
\text { Ks1 } \\
\text { Shear }\end{array}$ & $\begin{array}{c}\text { Ks1 } \\
\text { S.I. } \\
\text { No Pressure }\end{array}$ & $\begin{array}{c}\text { Ks1 (a) } \\
\text { S.I. } \\
\text { W/Pressure }\end{array}$ \\
\hline 10.5 & 129.7 & 43.4 & 2.22 & 3.7 & 46.2 & 46.41 \\
10 & 37.44 & 12.5 & 0.717 & 6.18 & 18.10 & 18.24 \\
15 & 45.07 & 15.1 & 1.43 & 2.08 & 17.05 & 17.24 \\
30 & 88.82 & 29.7 & 3.83 & 1.98 & 33.76 & 33.96 \\
45 & 57.42 & 19.2 & 6.08 & 2.73 & 25.86 & 26.06 \\
60 & 85.65 & 28.6 & 9.63 & 9.13 & 42.37 & 42.55 \\
75.7 (b) & 95.08 & 31.8 & 12.4 & 5.44 & 45.5 & 45.7 \\
90 & 0 & 0 & 30.5 & 0 & 30.5 & 30.7 \\
\hline
\end{tabular}

(a) Stresses due to 50 psig cavity pressure: Hoop stress $=+0.3 \mathrm{ks} 1$ Axial stress $=+0.1 \mathrm{ksi}$

(b) GACAP calculates bending stresses near the end of the cask for steep angles in a conservative manner; therefore, the stresses shown are at a distance equal to approximately $1 / 2$ * cask diameter from the bottom of the cask. 
TABLE $3-10$

MOMENT AND STRESS COMPONENTS FOR MAXIMUM PRIMARY STRESS INTENSITY 30-FT BOTTOM END ORIENTATION DROP - DHLW CASK - MAXIMUM CRUSH STRENGTH LOWER CIRCUMFERENTIAL IMPACT LIMITER WITH LARGE DIAMETER

\begin{tabular}{lcccccc}
\hline $\begin{array}{l}\text { Drop } \\
\text { Angle }\end{array}$ & $\begin{array}{c}\text { Moment } \\
(\text { in-1b)106 }\end{array}$ & $\begin{array}{c}\sigma \\
\text { Ks1 } \\
\text { Moment }\end{array}$ & $\begin{array}{c}\sigma \\
\text { Ks1 } \\
\text { Axia1 }\end{array}$ & $\begin{array}{c}\tau \\
\text { Ks1 } \\
\text { Shear }\end{array}$ & $\begin{array}{c}\text { Ks1 } \\
\text { S.I. Pressure }\end{array}$ & $\begin{array}{c}\text { Ks1 }(a) \\
\text { S.I. } \\
\text { W/Pressure }\end{array}$ \\
\hline 10 & 41.91 & 14.0 & 0.77 & 6.66 & 19.89 & 20.04 \\
15 & 49.18 & 16.4 & 0.04 & 1.08 & 16.58 & 16.78 \\
30 & 63.41 & 21.2 & 3.62 & 2.64 & 25.38 & 25.57 \\
45 & 30.66 & 10.2 & 7.19 & 10.7 & 27.57 & 27.7 \\
60 & 85.65 & 28.6 & 9.63 & 9.13 & 42.37 & 42.55 \\
\hline
\end{tabular}

(a) Stresses due to 50 psig cavity pressure:

Hoop stress $=+0.3 \mathrm{ksl}$

Axial stress $=+0.1 \mathrm{ksl}$ 
TABLE $3-11$

MOMENT AND STRESS COMPONENTS FOR MAXIMUM PRIMARY STRESS INTENSITY 30-ft BOTTOM END ORIENTATION DROP - DHLW CASK - MINIMUM CRUSH STRENGTH

\begin{tabular}{|c|c|c|c|c|c|c|c|}
\hline $\begin{array}{l}\text { Drop } \\
\text { Angle }\end{array}$ & $\begin{array}{c}\text { Moment } \\
(1 \mathrm{n}-1 \mathrm{~b}) 10^{6}\end{array}$ & $\begin{array}{c}\sigma \\
\text { Ks1 } \\
\text { Moment }\end{array}$ & $\begin{array}{c}\sigma \\
K s 1 \\
\text { Axial }\end{array}$ & $\begin{array}{c}\tau \\
\text { Ksi } \\
\text { Shear }\end{array}$ & No & $\begin{array}{l}\text { Ks1 } \\
\text { S.I. } \\
\text { Pressure }\end{array}$ & $\begin{array}{c}\text { Ksi (a) } \\
\text { S.I. } \\
\text { W/Pressiure }\end{array}$ \\
\hline 10 & 37.90 & 12.7 & 0.71 & 2.03 & & 14.01 & 14.2 \\
\hline 15 & 57.89 & 19.4 & 1.22 & 1.59 & & 20.86 & 21.06 \\
\hline 30 & 85.39 & 28.6 & 3.62 & 1.82 & & 32.42 & 32.62 \\
\hline 45 & 45.74 & 15.3 & 4.82 & 2.16 & & 20.58 & 20.77 \\
\hline 60 & 92.09 & 30.8 & 10.33 & 9.77 & & 45.54 & 45.72 \\
\hline $75.7(b)$ & 86.05 & 28.8 & 11.36 & 4.94 & & 41.36 & 41.55 \\
\hline 90 & 0 & 0 & 24.1 & 0 & & 24.124 .3 & \\
\hline
\end{tabular}

(a) Stresses due to 50 psig cavity pressure:

Hoop stress $=+0.3 \mathrm{ks} 1$

Axial stress $=+0.1 \mathrm{ksi}$

(b) GACAP calculates bending stresses near the end of the cask for steep angles in a conservative manner; therefore, the stresses shown are at a distance equal to approximately $1 / 2 *$ cask diameter from the bottom of the cask. 
The $-2.89 \mathrm{deg}$ drop angle for the Impacts on the closure end represents the side drop orientation. The angle is not $0^{\circ}$ because of the difference in the lower and upper circumferentlal impact 11miter diameters. The CG over corner for the closure end and the bottom end are 73.4 and $75.7 \mathrm{deg}$, respectively. The tables present the results for the maximum and minimum crush strengths and the larger radius on the lower circumferential impact limiter (LCIL) with and without pressure. GACAP conservatively applies the impact moment at the end of the cask. In reality, this moment develops over some distance from the point of Impact. Therefore, we have quoted the stresses at a point equal to half the cask diameter from the end of the cask for the CG over bottom corner drop angle. To be conservative, we have presented the bending stresses for all other drop angles, near the end of the cask.

The stress calculated from the moment presented in Tables $3-4$ through 3-11 represents the stress at the midwall of the cask or the primarv membrane stress $\left(P_{m}\right)$. The resulting stress intensities for the 1 - and 30-ft drops are well below the primary membrane allowables. The highest stress resulting from bending occurred in the 60 deg angled slapdown drop (Table 3-9). This orlentation was bounded by the 10.5 deg slapdown half-scale model drop test with the lower circumferential Impact limiter removed. The test results indicated no permanent set In the wall region and no breach of the contalnment wall.

The bottom end impacts produced the highest axial stress in the cask body wall because of the stiffer lower end impact limiter (Tables 3-8 through 3-11). The 1-ft drop stress levels were al1 under the normal condition allowables. The highest axial stress of $30.7 \mathrm{ks} 1$ occurred during the 30-ft drop (using the maximum crush strength lmpact limiters, Table 3-9). 
4. HALF-SCALE MODEL TEST DATA

The primary objective of the half-scale model test program for the DHLW shipping cask was to verffy the safety of the design following the hypothetical 9-m $(30-f t)$ drop and puncture accldents specified in 10CFR71.73. GA designed the half-scale model and developed the test plan while SNL procured the model and performed all the tests. Reference 4-1 describes the tests and test results. Only the 9-m (30-ft) drop test data is presented in this report for comparison with the inelastic and elastic analyses.

\subsection{MODEL DESCRIPTION}

The selected scale for the model of the DHLW truck shipping cask was one-half. This scale factor was chosen because it allowed direct scaling of all critical cask components and allowed enough space for the instrumentation to be placed in the model. Figure 4-1 shows the test model used. Figure 4-2 shows different model components. The cask body In this picture lacks the circumferential honeycomb impact limiters.

In general, the half-scale model was achleved by reduclng the fullscale design dimensions by one-half. With some exceptions, the halfscale model reflects all significant structural characteristics of the final design. The following ttems were omftted from the model: tiedown trunnions, lifting attachments, and tamper-indicating device. These items do not affect the final outcome of the testing.

The circumferential impact Iiniters were not included in some of the tests because they were not active during the event or the test conditions were more severe for the critical cask components. For example, during the bottom end, closure end, and puncture drop events, most of 

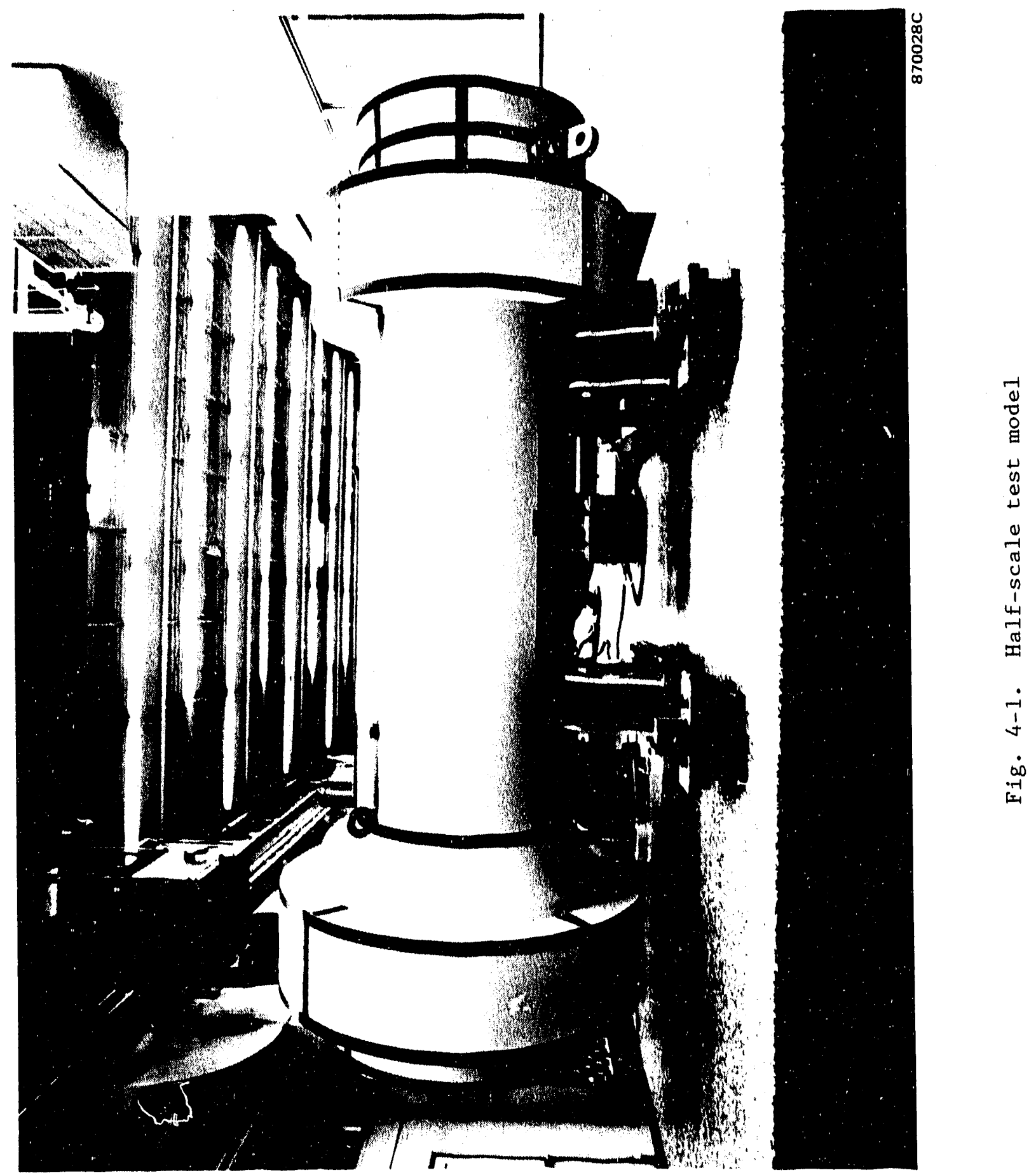


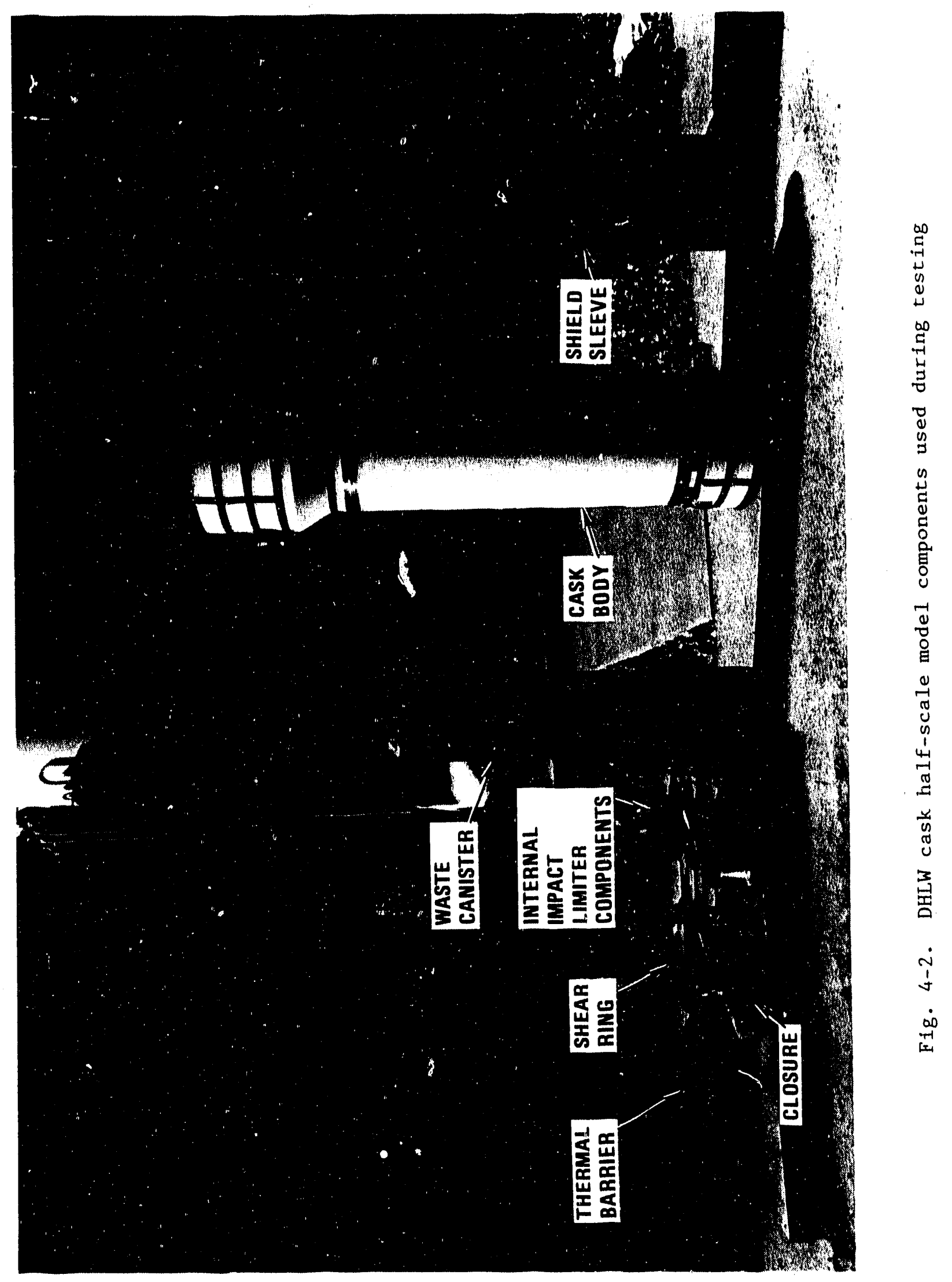


the drop energy ts absorbed during main impact. Damage to the circumferential impact IImiters by the secondary impacts is negliglble compared to the damage caused during slapdown tests.

Durlng the CG over bottom corner and the second slapdown drop test, the cask was more severely tested by removing the lower clrcumferential impact limiter. The lower circumferential impact 1imiter was tested durfing the first slapdown drop test. See the description of tests in Section 4.2 .

Some aditional differences include the following:

1. The test model included some holes, keys, and grooves in the cask and other components, whtch were used as access for the Instrumentation wires, and/or to prevent damage to the instrumentation. These features produce only local stress concentrations and do not affect the final test results, since they are located away from the critical stress areas.

2. The final design of the thermal barrier attached to the outside of the closure was changed to provide additional thermal protection for the closure bolts and seals and is structurally stronger than the design tested.

3. The full-scale closure bolt design includes a spring that holds the bolt in a ralsed pcisition that allows easier use during remote handling operations. This spring was not included in the model since it has no structural function. The tested bolts have $5 \%$ smaller tensile area than the fullscale which is conservative.

4. The simulated waste canisters used in the tests were scale models of the DWPF waste canisters but had some layers of lead 
In the simulated waste glass to Increase the welght above the maximum deslgn welght.

5. There were other minor differences that had no impact on the structural response of the cask to the $9-m(30-f t)$ drop test.

\subsection{TEST SEQUENCE AND PROCEDURE}

Table 4-1 and the 11 st below summarize the tests that were conducted for the half-scale model. They enveloped the worst case $9-m$ $(30-f t)$ drop and puncture orfentations:

1. Bottom end $9-m(30-f t)$ drop.

2. Closure end $9-\mathrm{m}(30-\mathrm{ft})$ drop at $-29^{\circ} \mathrm{C}\left(-20^{\circ} \mathrm{F}\right)$.

3. Oblique puncture onto gas sample port $102-\mathrm{cm}(40-1 \mathrm{n}$.$) .$

4. First slde 9-in (30-ft) drop with slapdown.

5. Puncture on center of closure $102-\mathrm{cm}(40-\mathrm{in}$.).

6. Center of gravity over bottom corner $9-m(30-f t)$ drop.

7. Second side $9-m(30-f t)$ drop with slapdown.

The following pairs of tests were performed as a sequence: tests 2 and 3,4 and 5 , and 6 and 7 . This means that the cask was not dismantled between each pair of tests; the only part of the cask that was removed was the thermal barrfer in order to leak test the closure 0-ring seals and perform closure to seal surface and closure to notched impact limter measurements. The same thermal barrier and thermal barrier bolts were put back in place for the second test in the sequence. All the tests except test No. 2 were conducted at amblent temperature. The first two pairs of tests (tests 1 and 3 , and tests 4 and 5 ) were regulatory sequences of a $9-\mathrm{m}(30-\mathrm{ft})$ free drop followed by a $102-\mathrm{cin}(40-\mathrm{in}$.) puncture drop.

The test sequence is summarlzed pictorlally in Figs. 4-3 through 4-20. Reference 4-1 contains a complete description of the tests and the test procedures. 


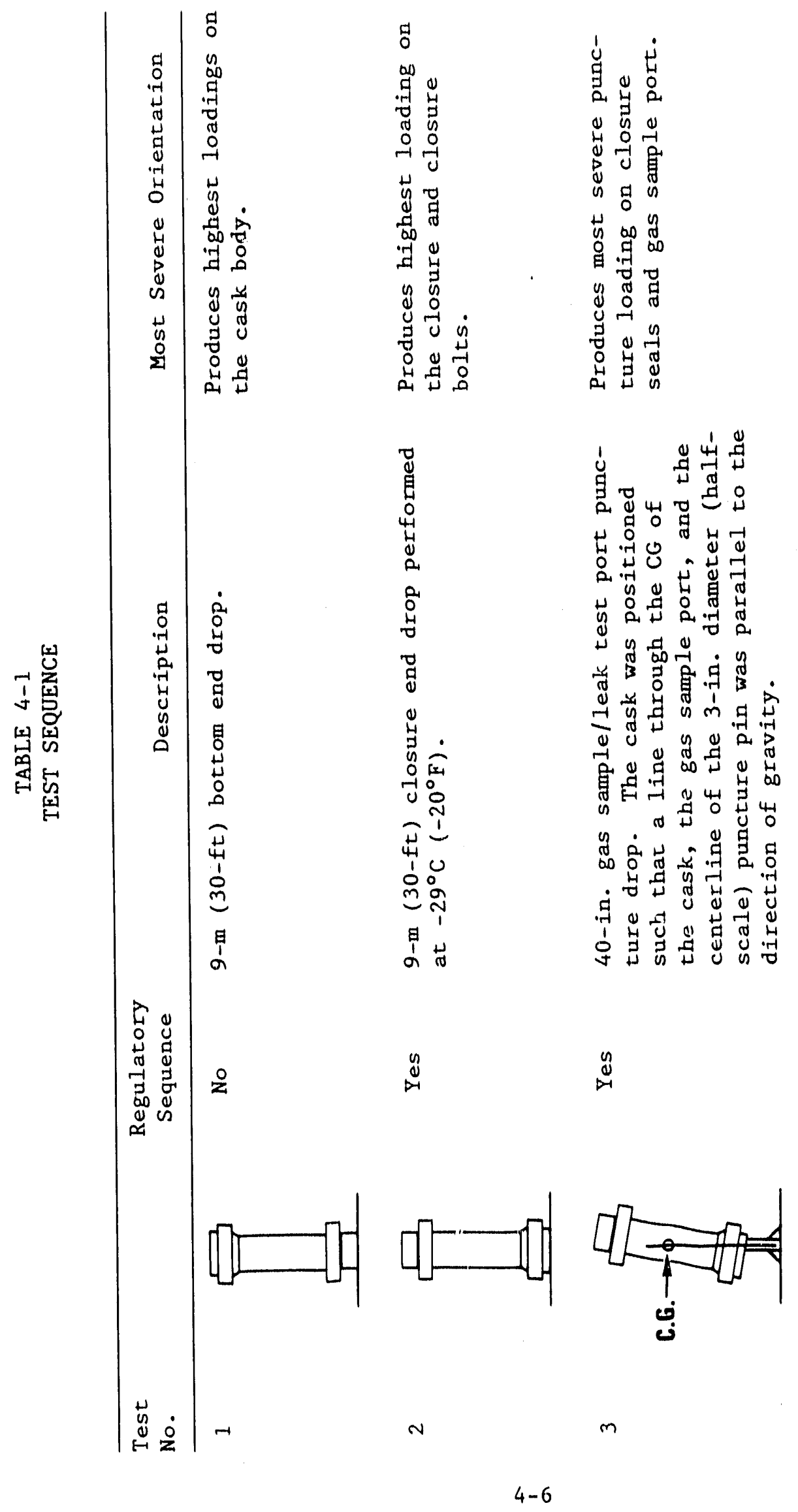




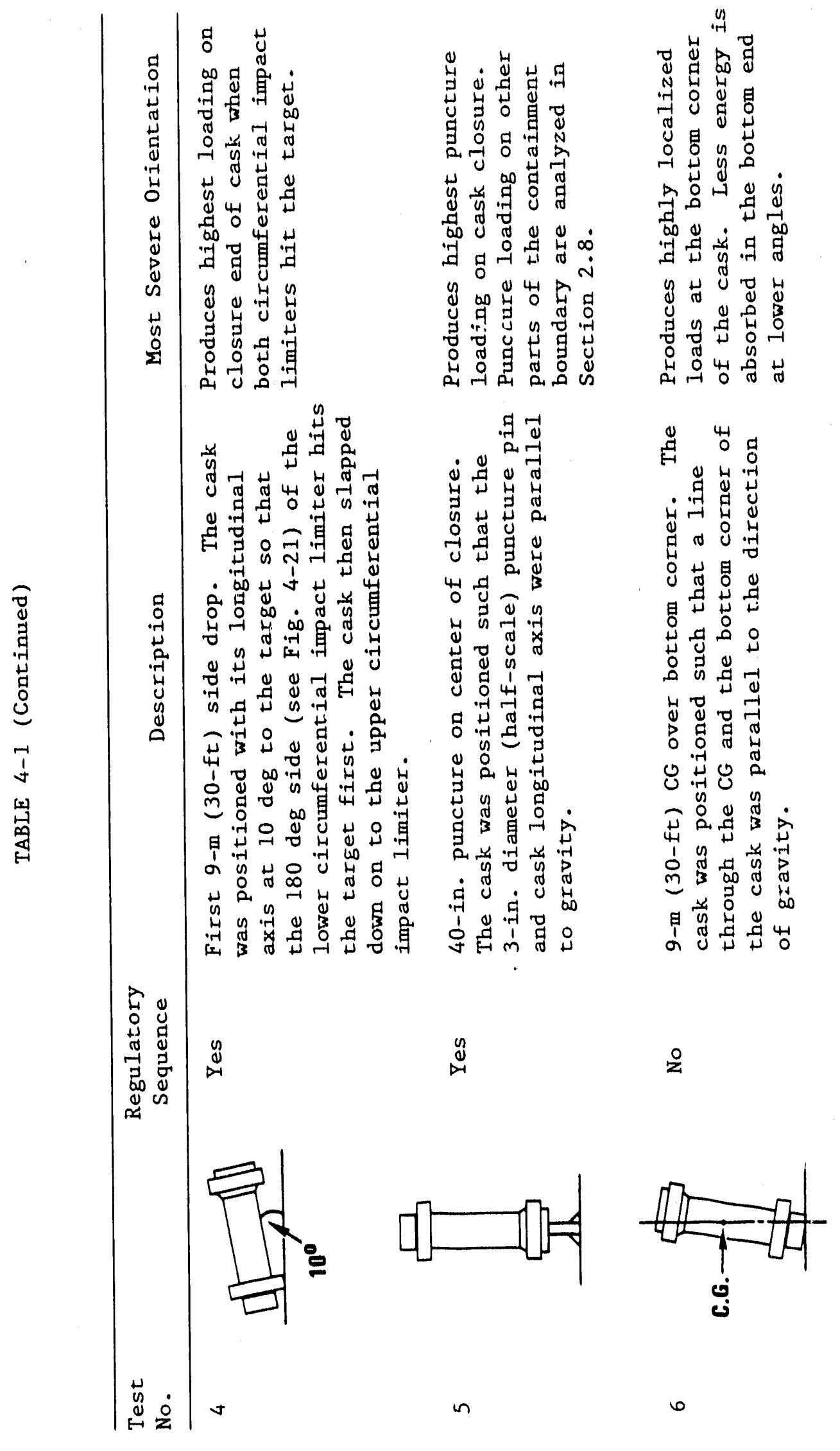




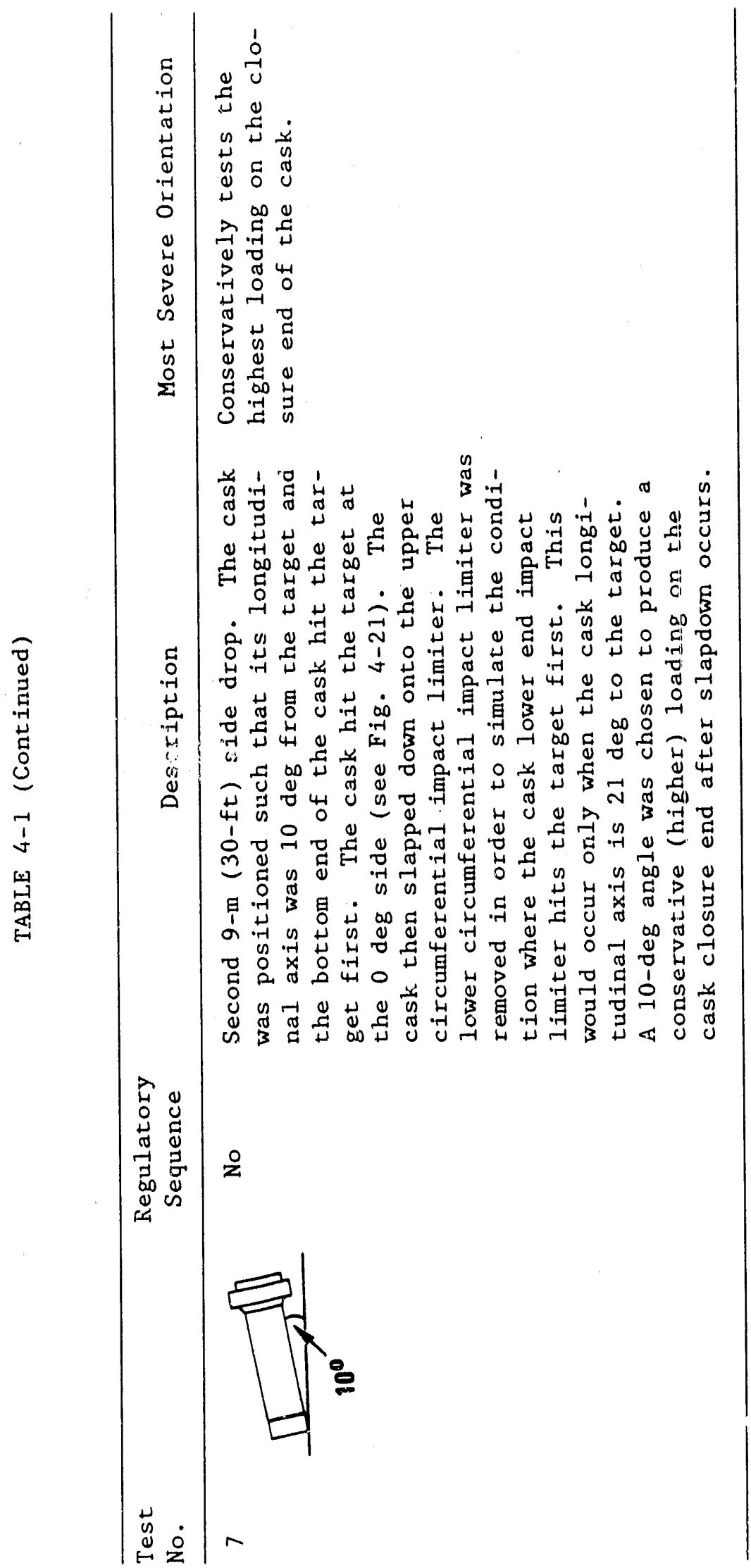




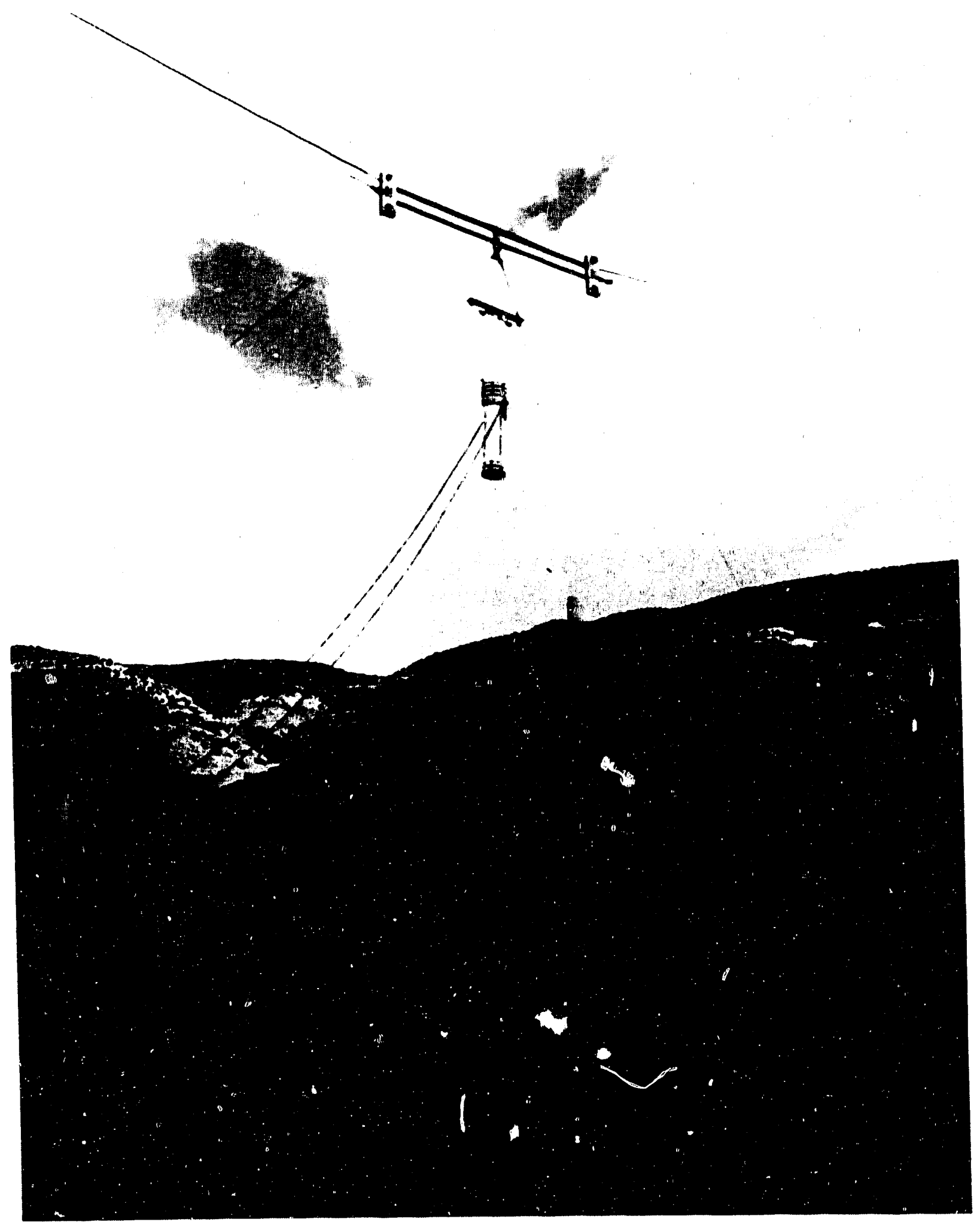

Fig. 4-3. Bottom end drop test setup 


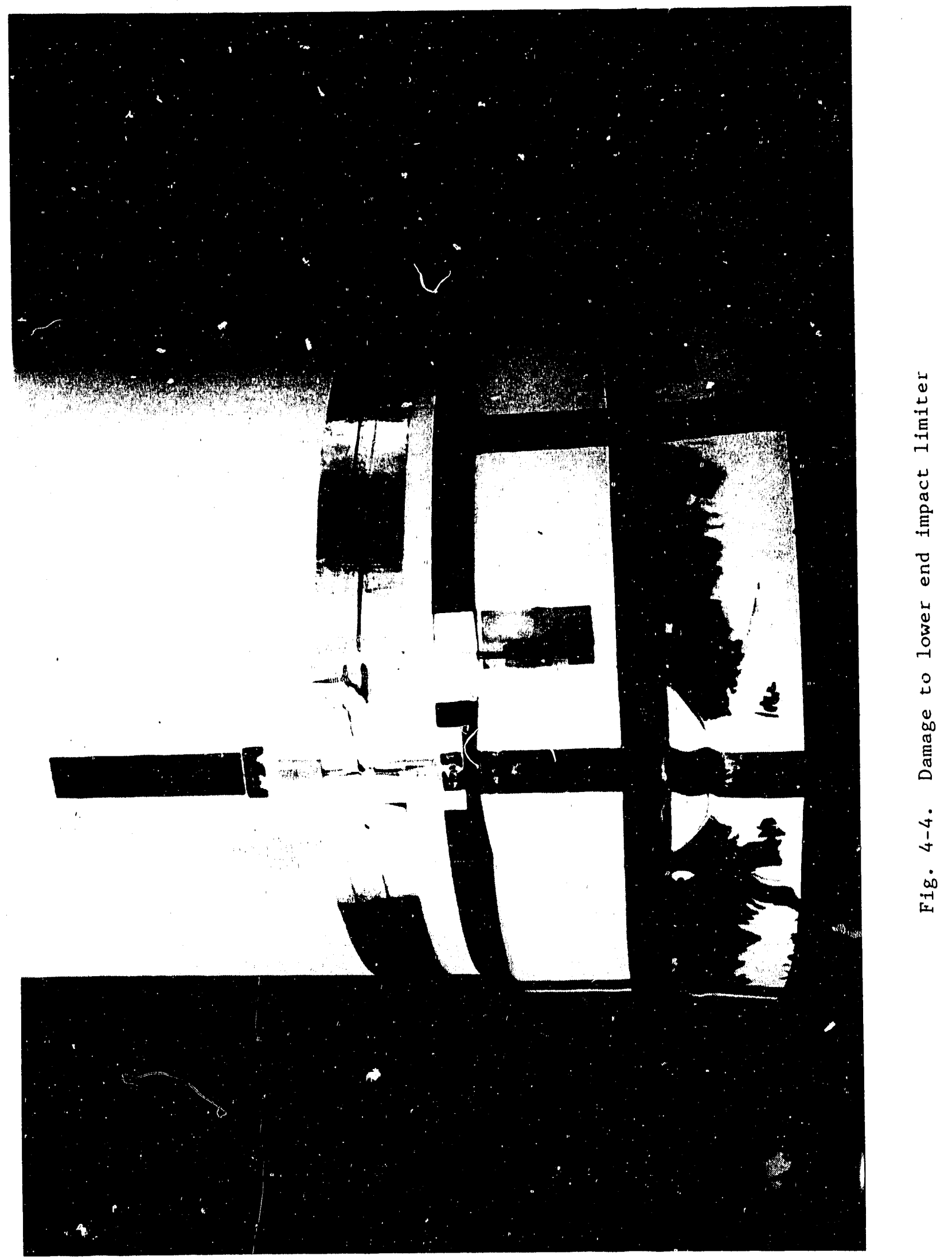




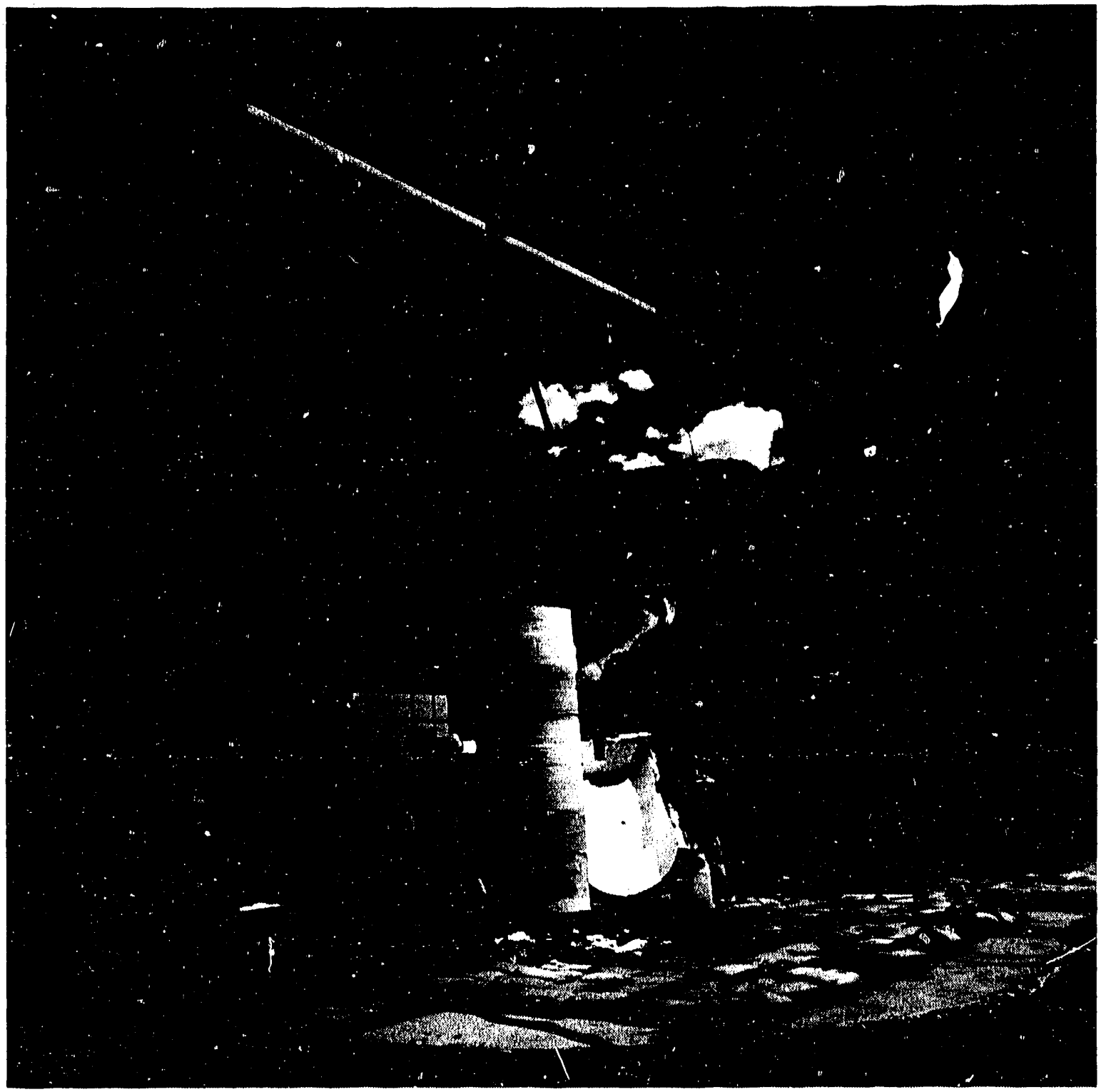

Fig. 4-5. Preliminary rigging in preparation for closure-end drop test. Cask in refrigeration package to reduce temperature to $-29^{\circ} \mathrm{C}$ $\left(-20^{\circ} \mathrm{F}\right)$. 


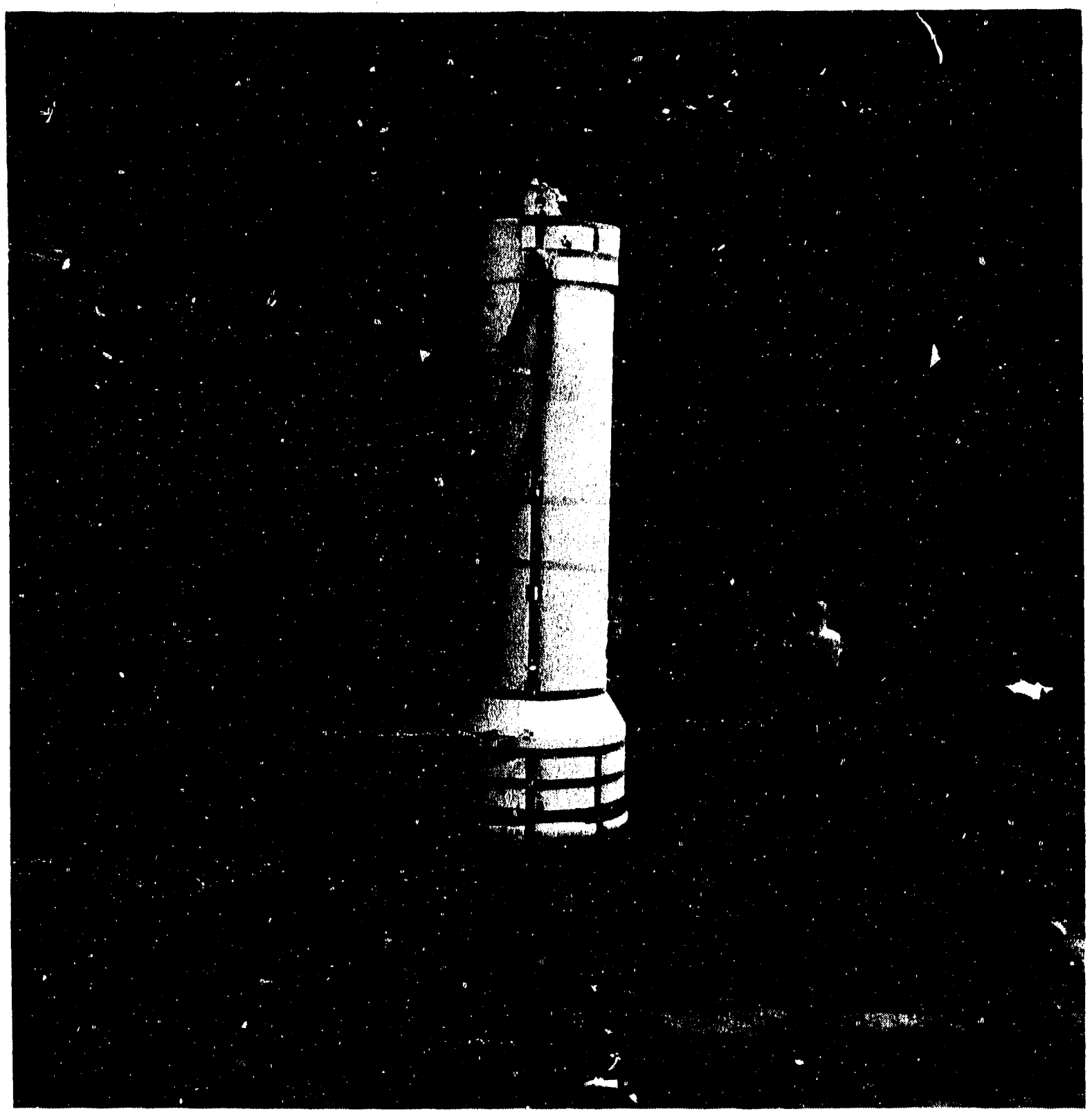

Fig. 4-6. Cask on top of target after 9-m (30-ft) closure-end drop test 


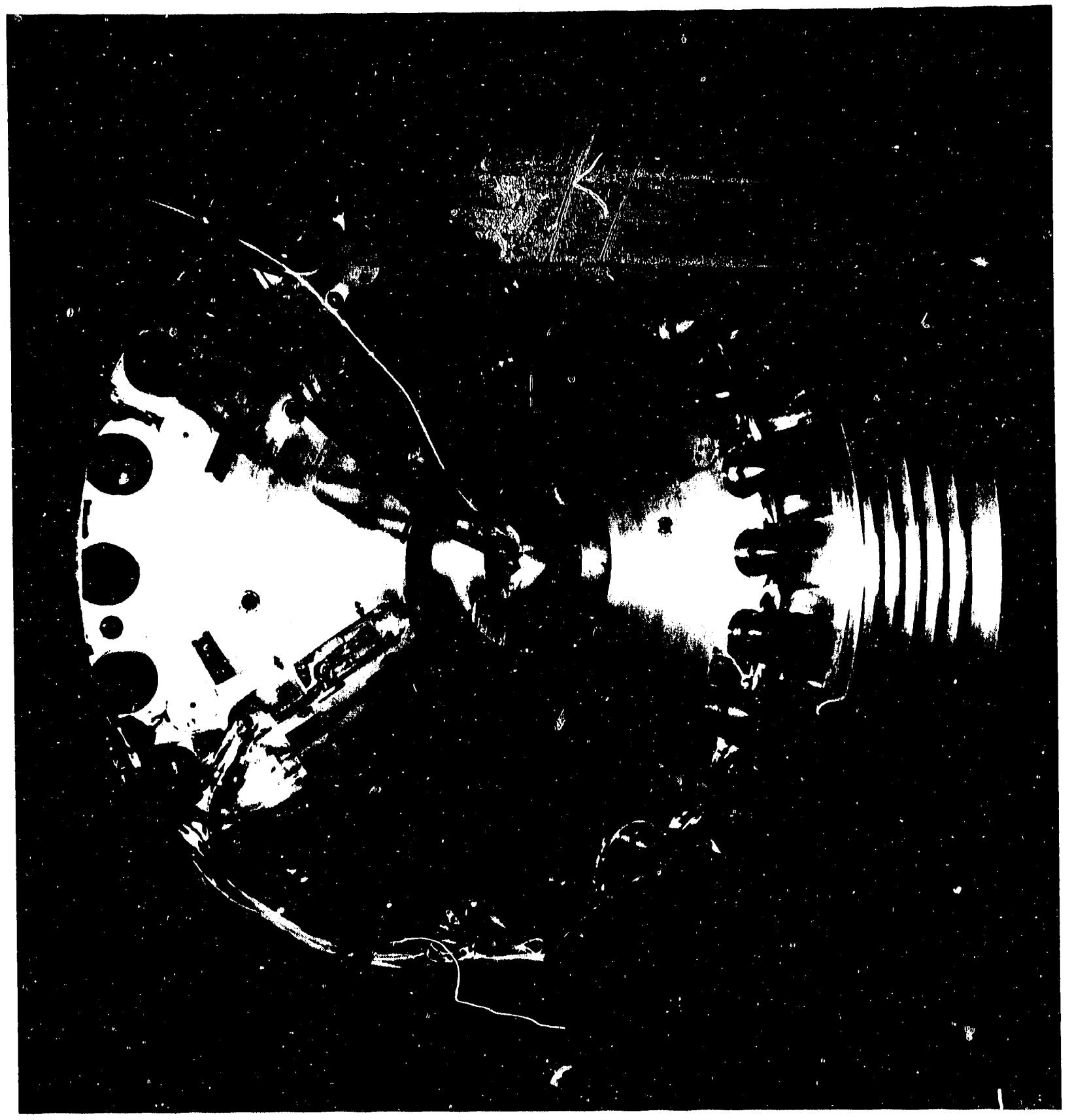

Fig. 4-7a. Notched impact limiter and closure before closure end 9-m $(30-f t)$ drop test 


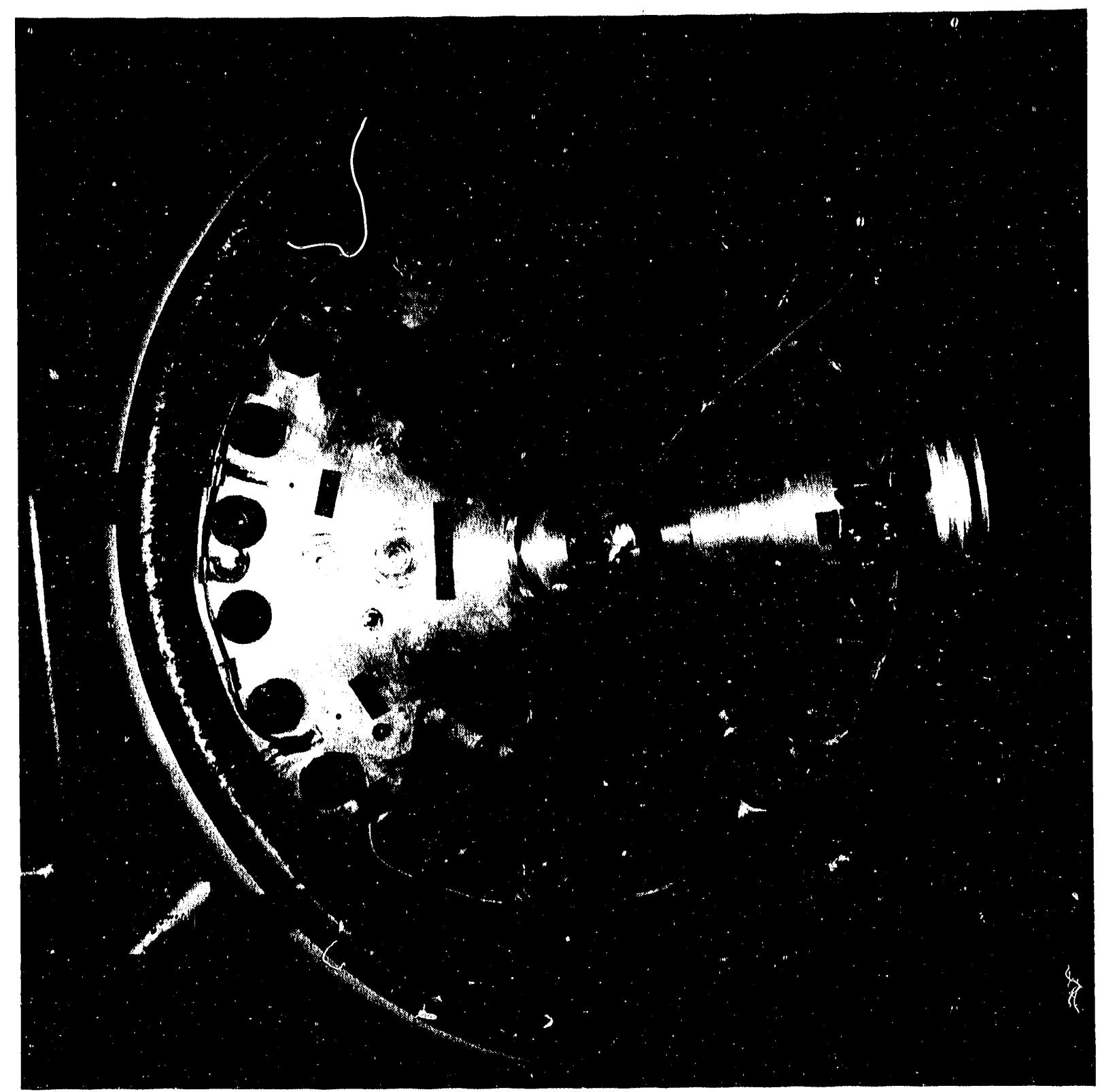

Fig. 4-7b. Notched impact 1imiter and closure after closure end 9-m $(30-f t)$ drop test 


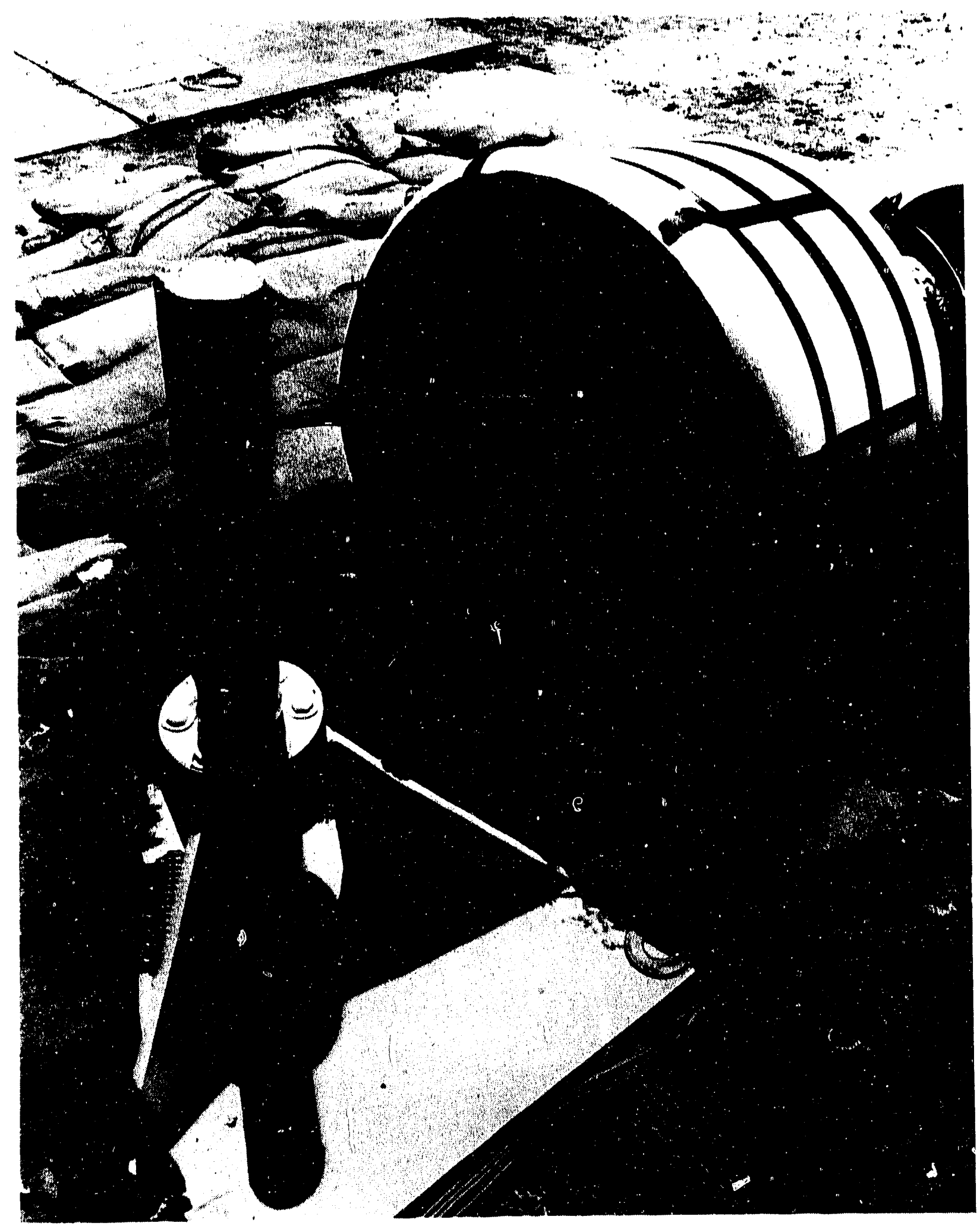

Fig. 4-8. Cask and puncture pin after gas sample/leakage test port puncture drop 


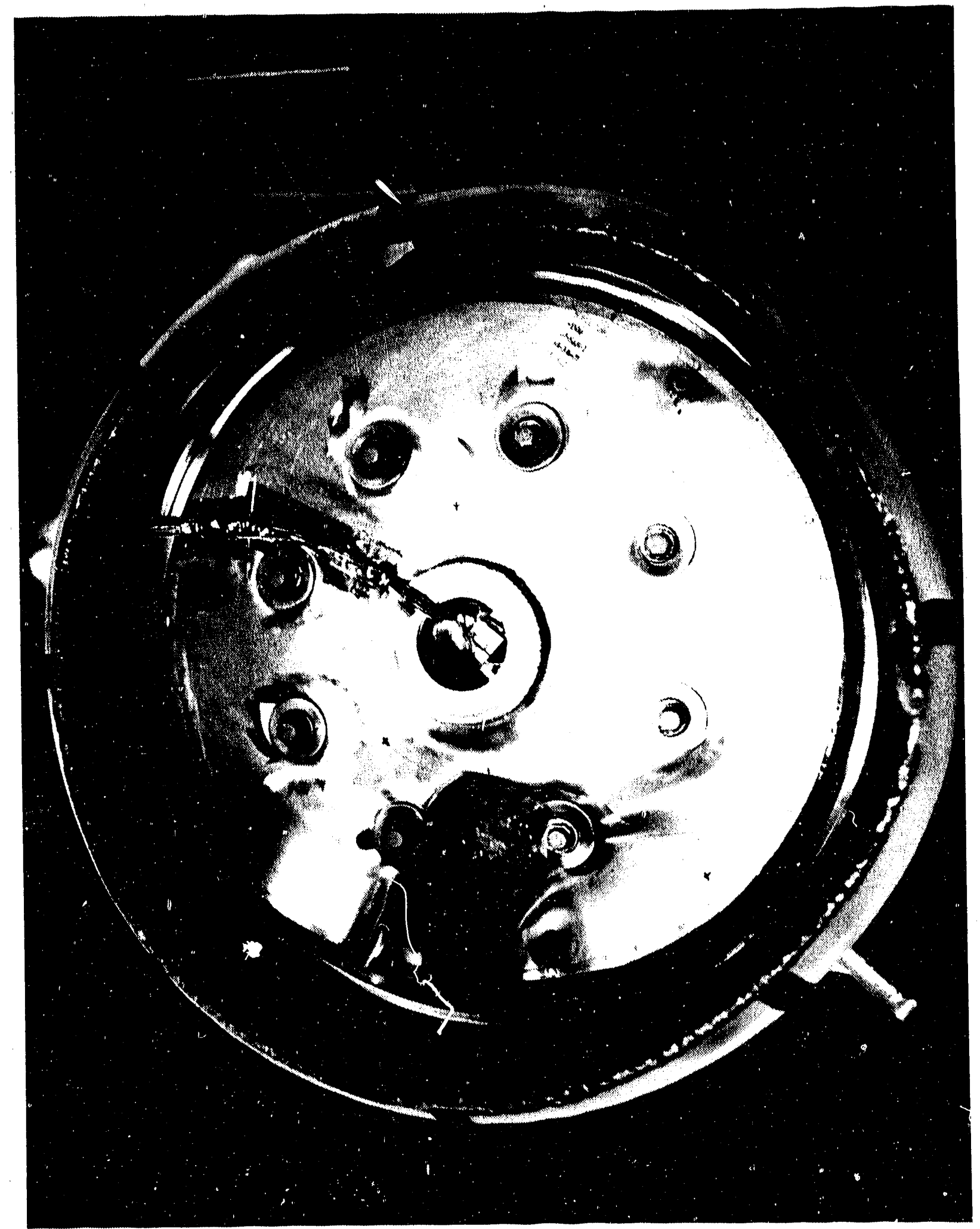

Fig. 4-9. Damage to thermal barrier after gas sample/leakage test port puncture drop 


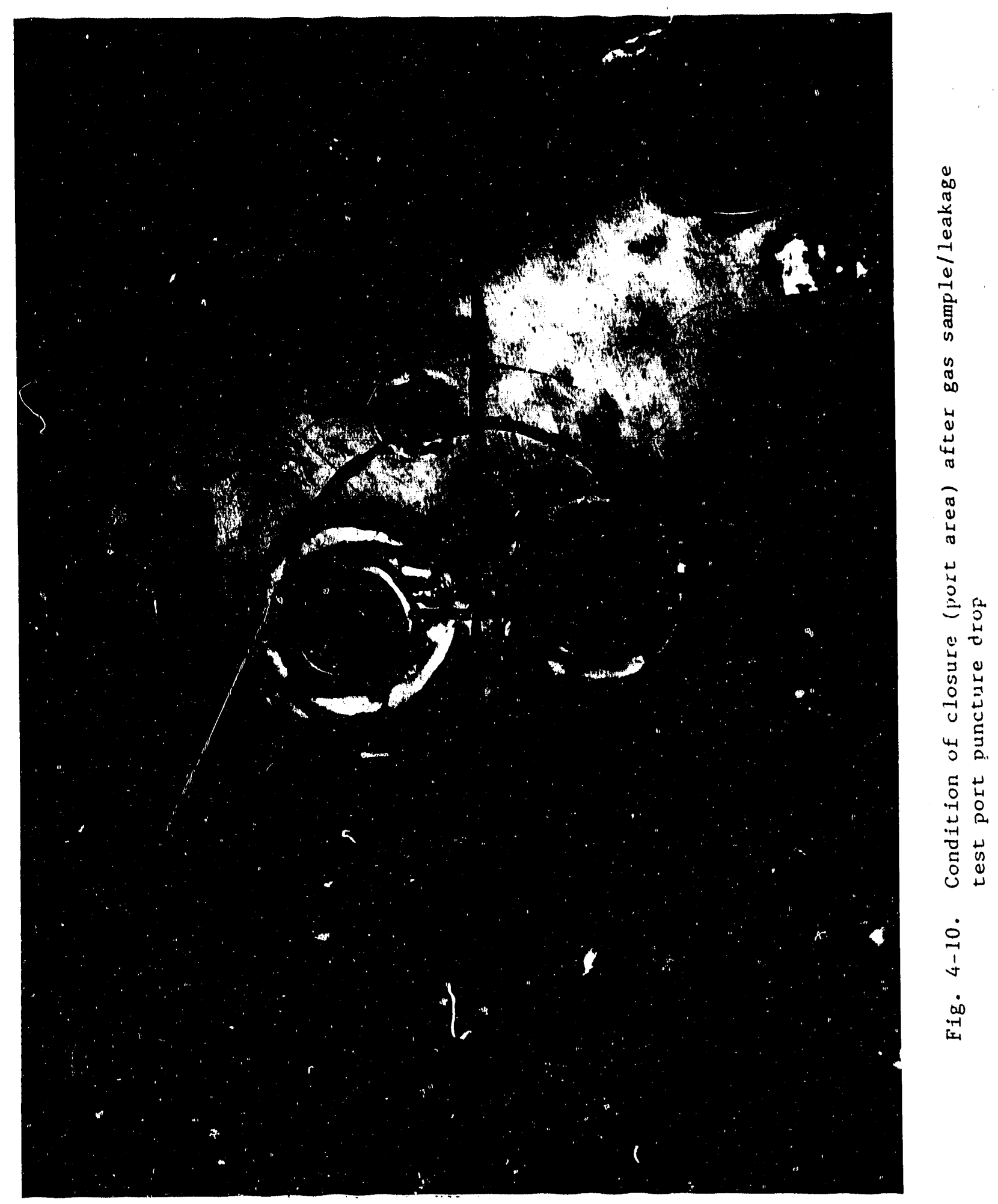




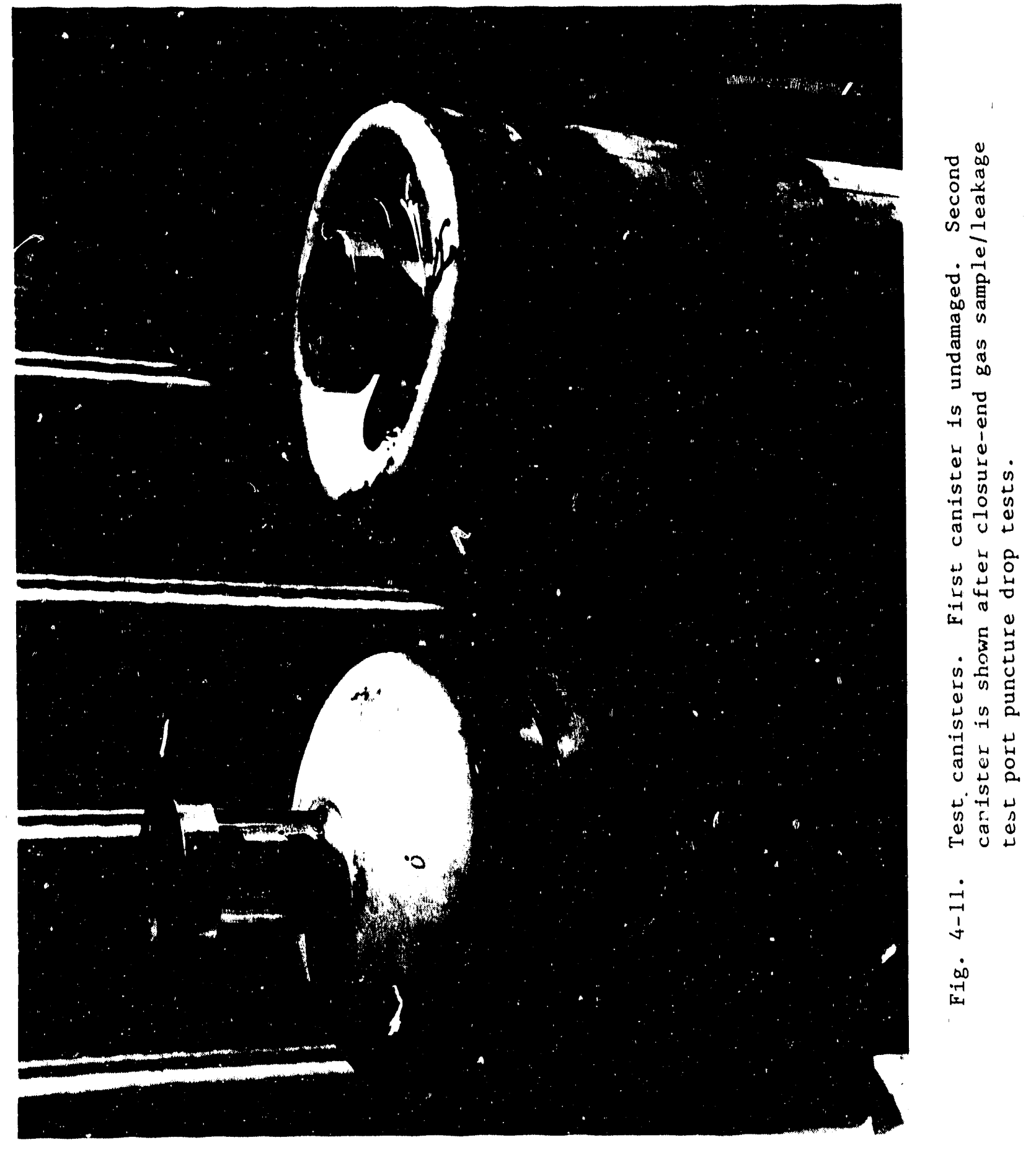




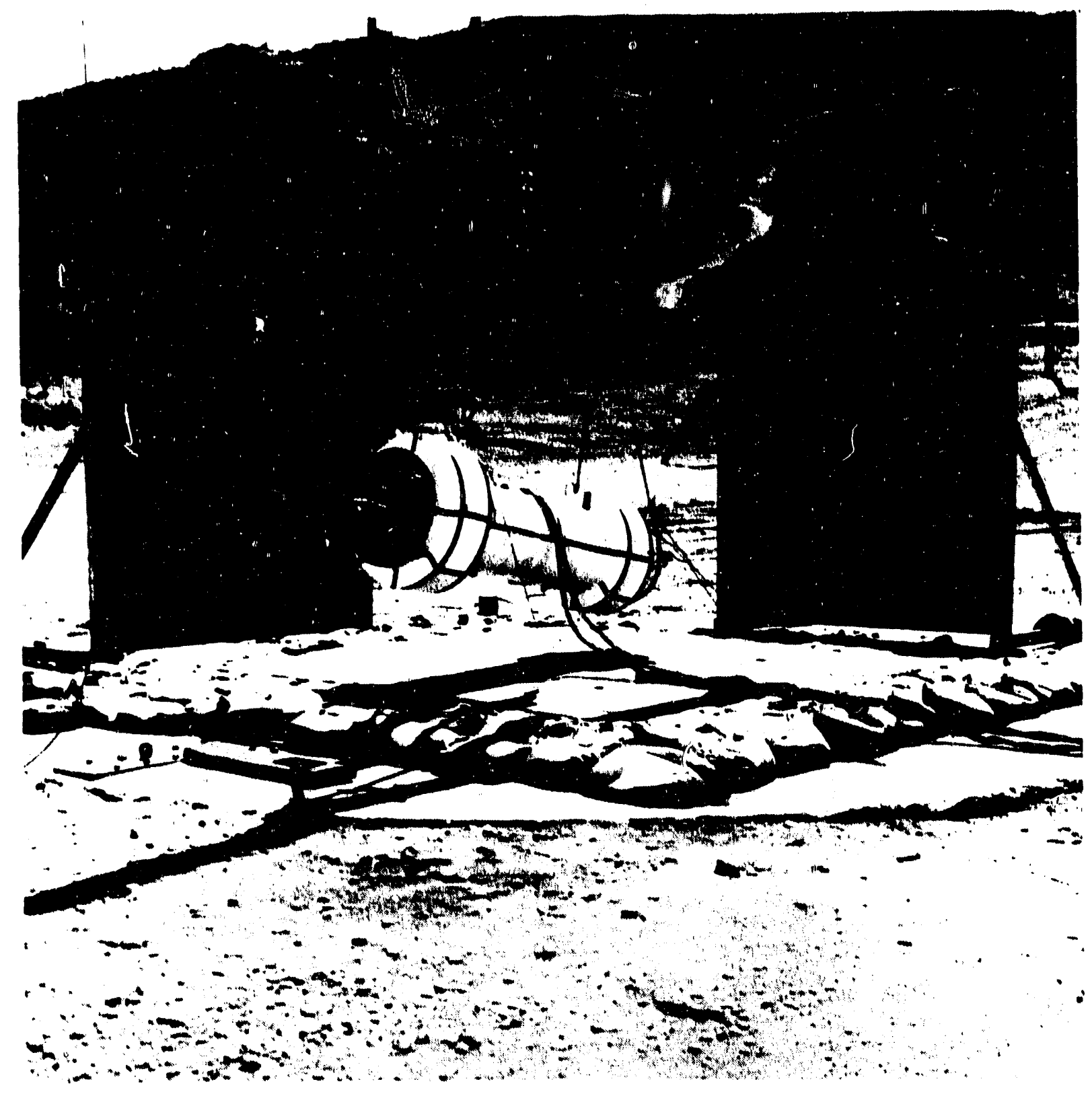

Fig. 4-12. Cask being ralsed into position before first side arop test 


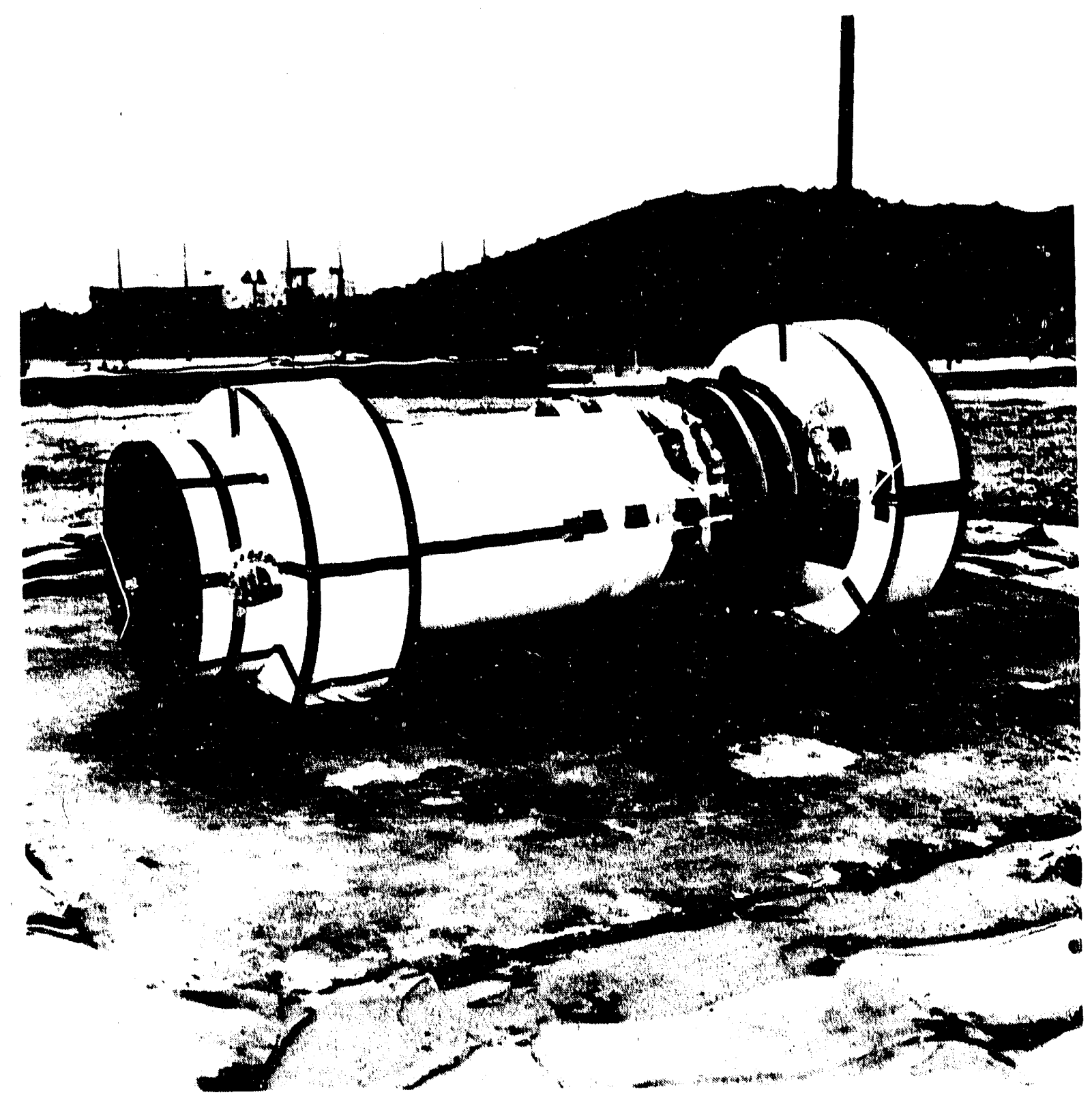

Fig. 4-13. Cask after first side drop test 


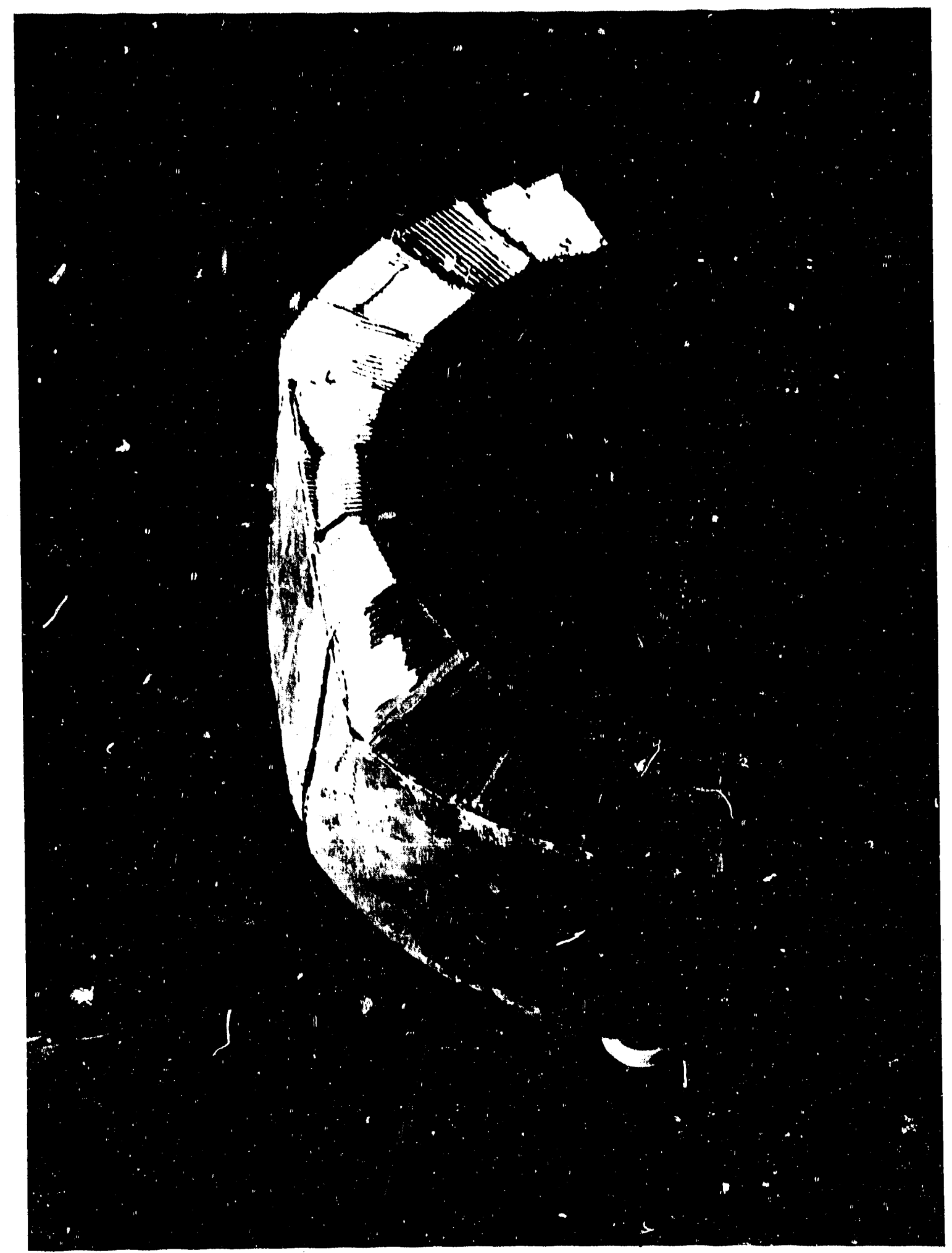

F1g. 4-14. Honeycomb from lower circumferential impact limiter after first side drop test 


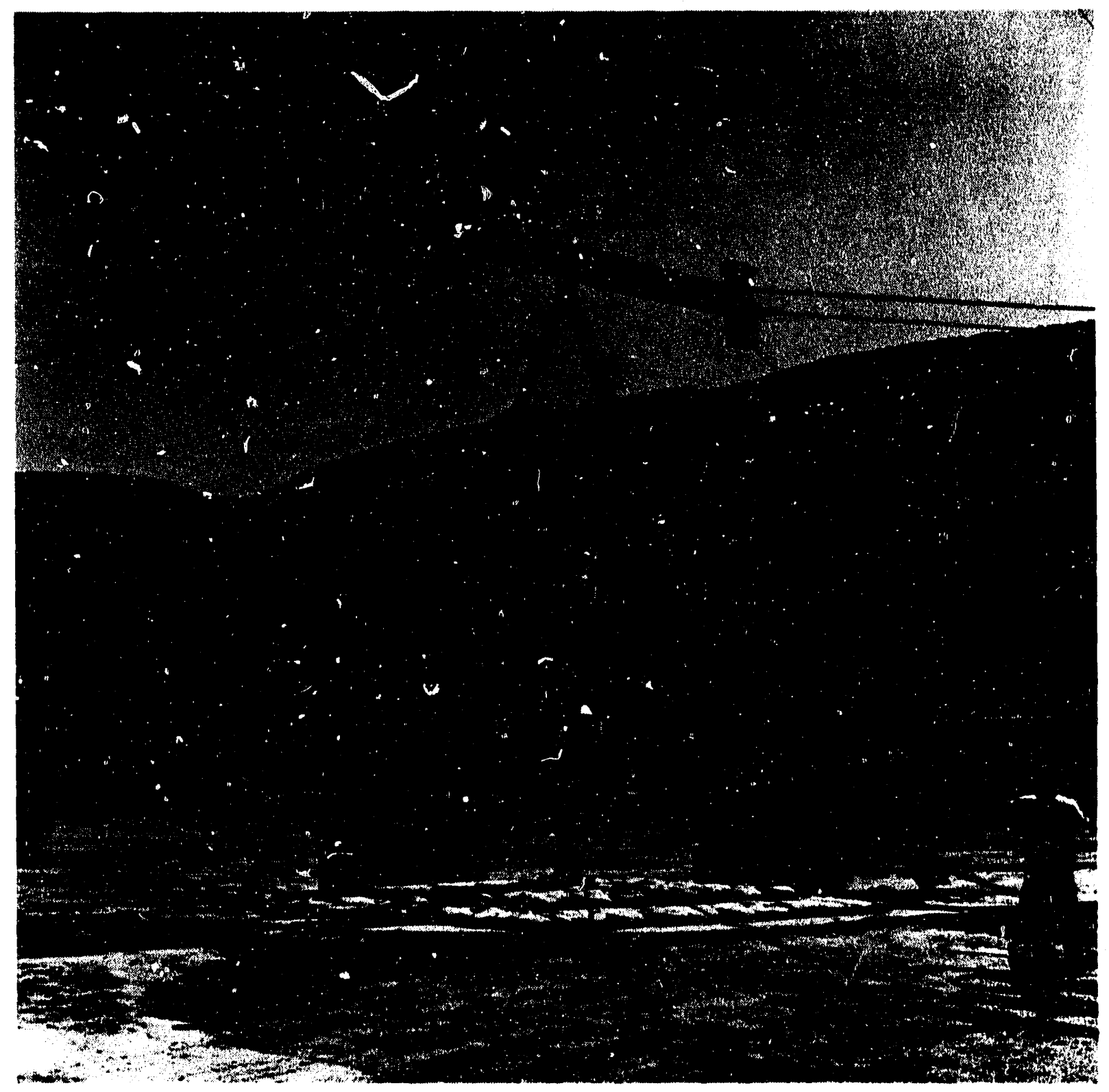

Fig. 4-15. Test setup before center puncture drop 


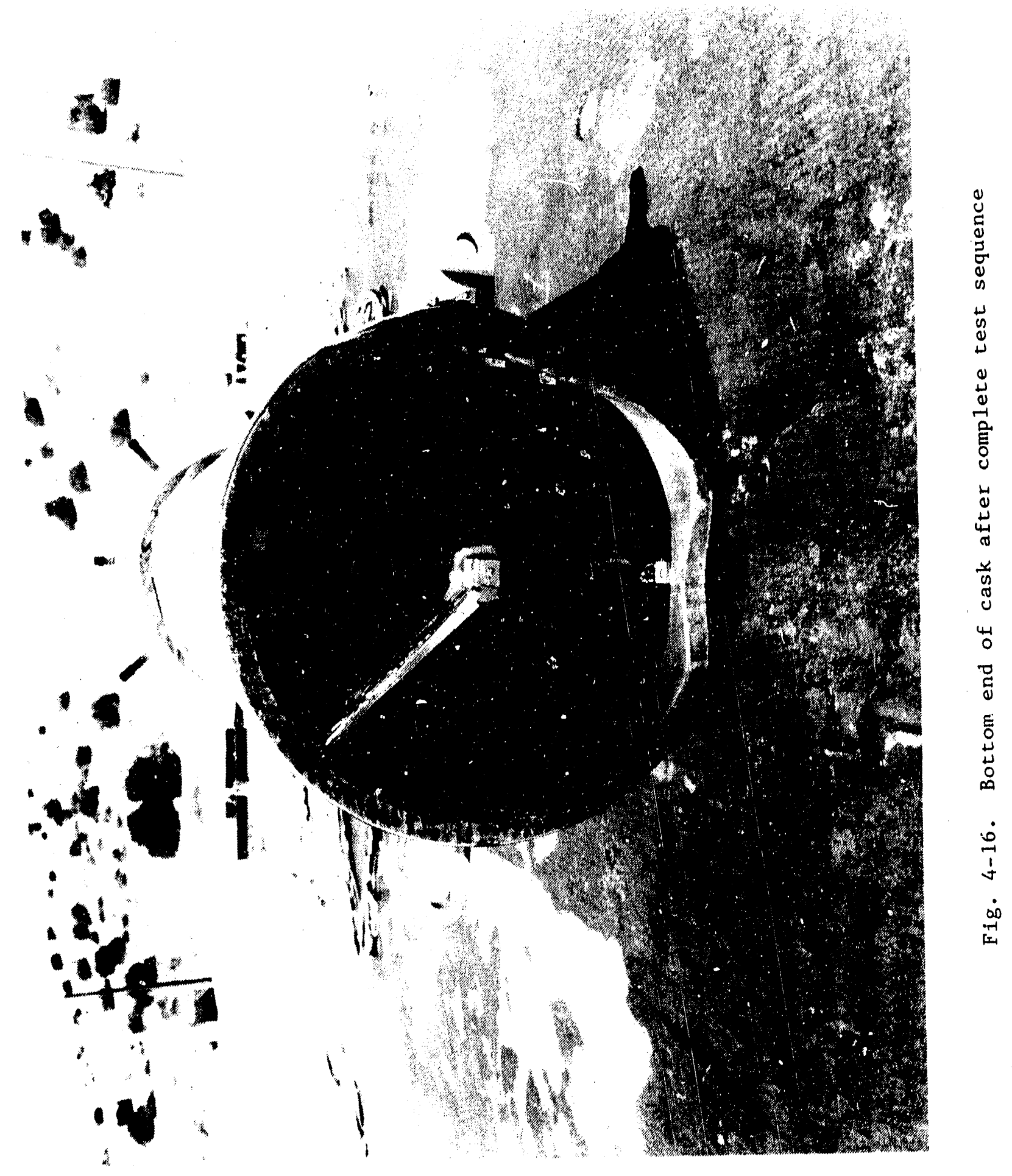




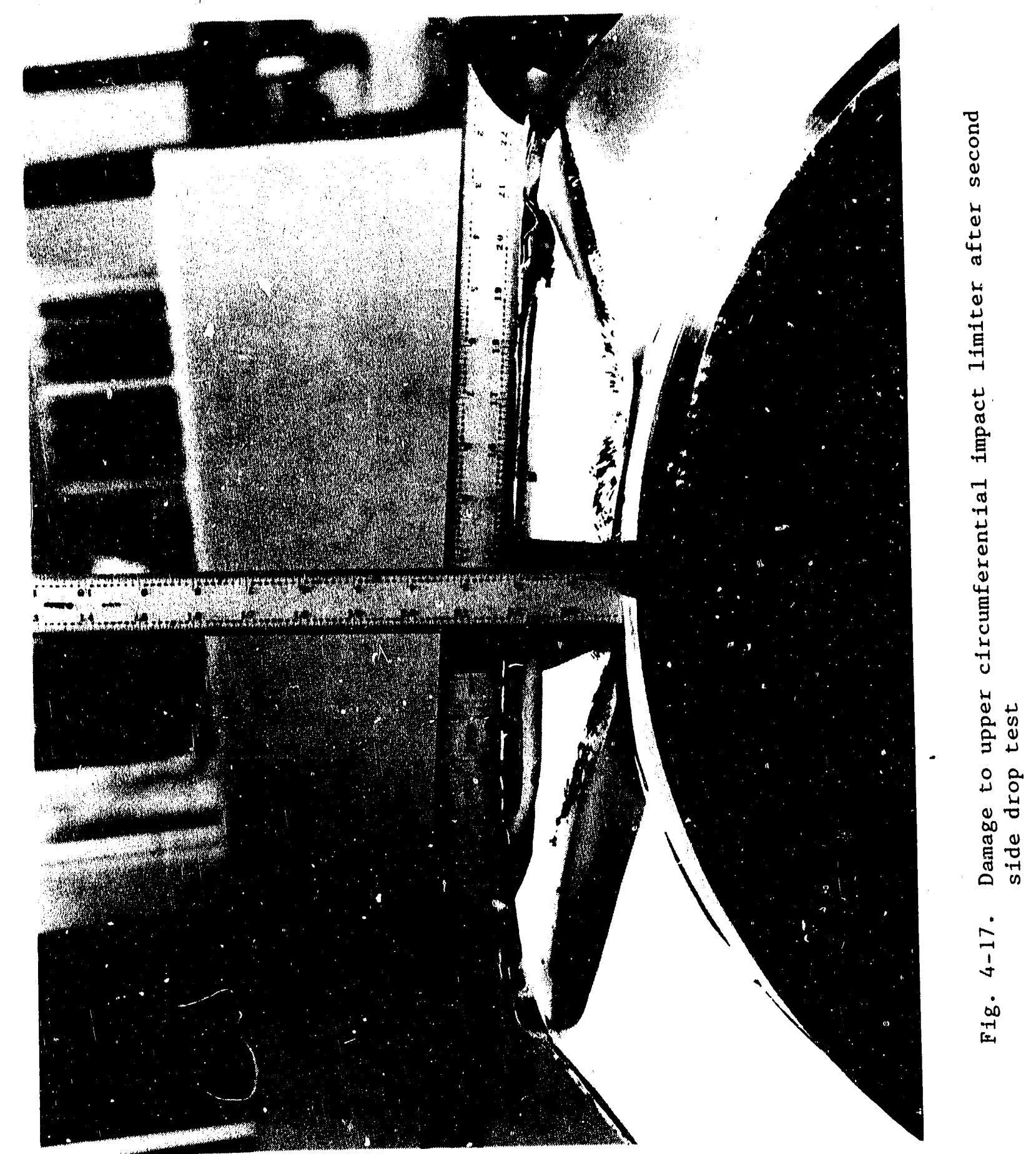




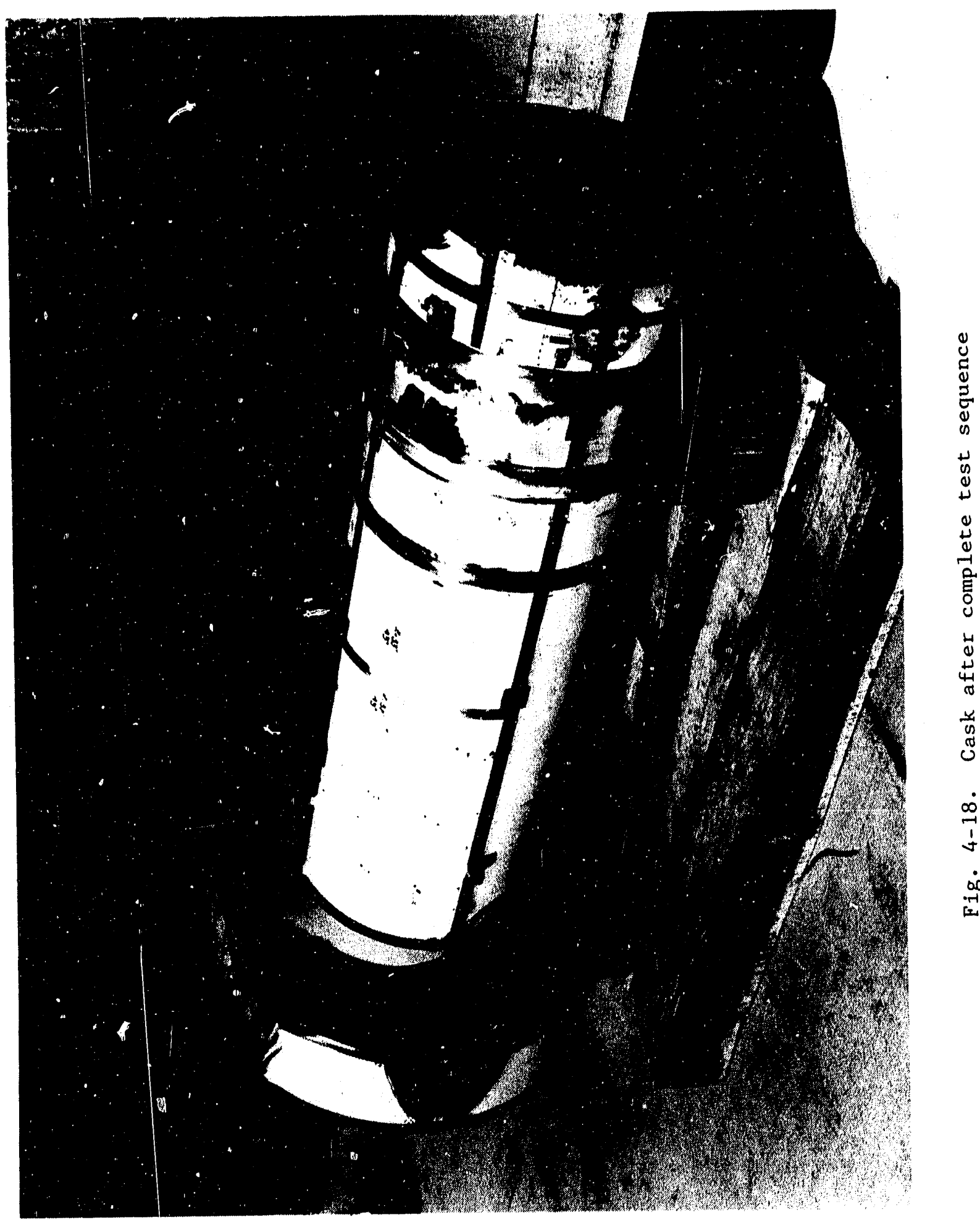




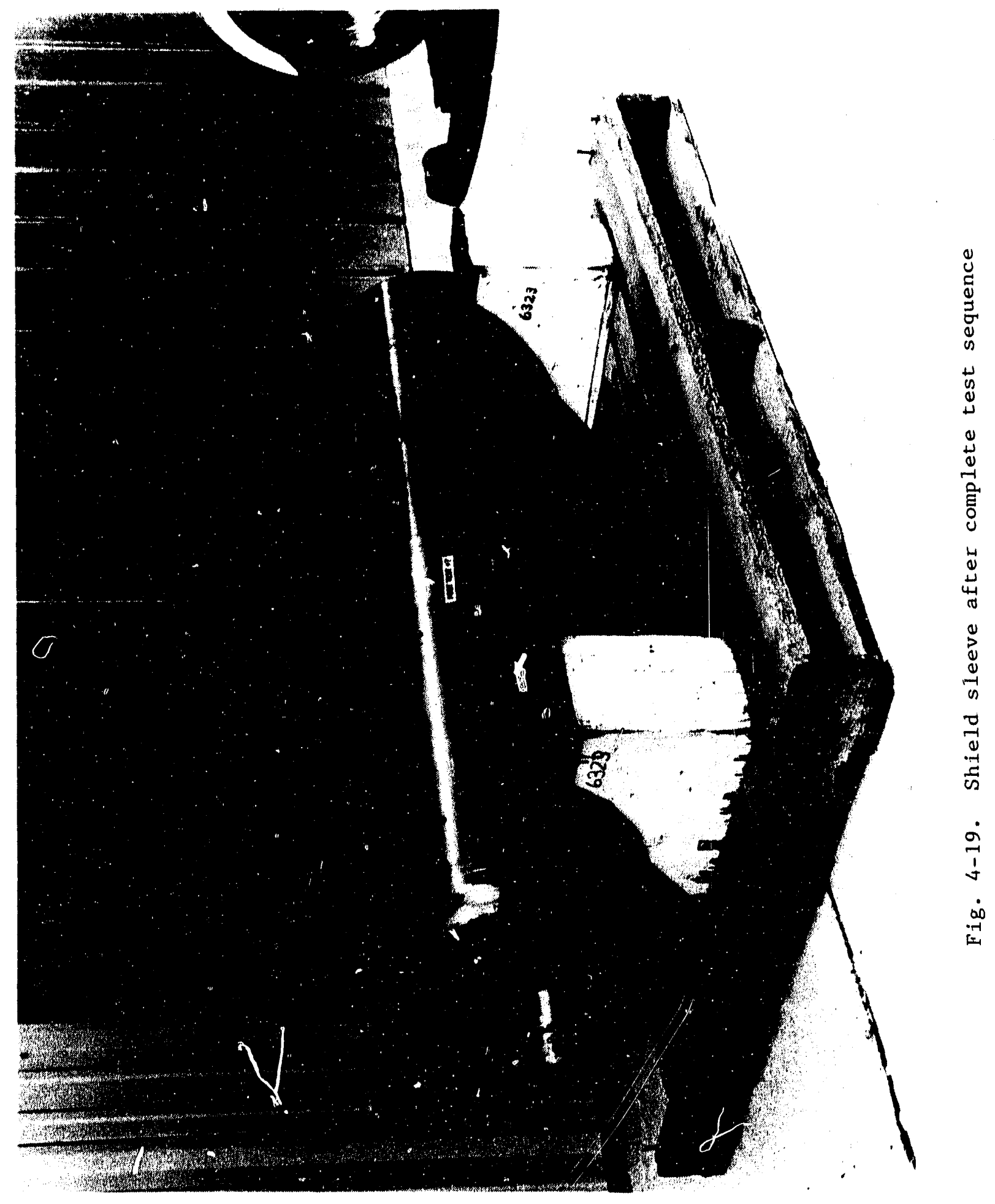




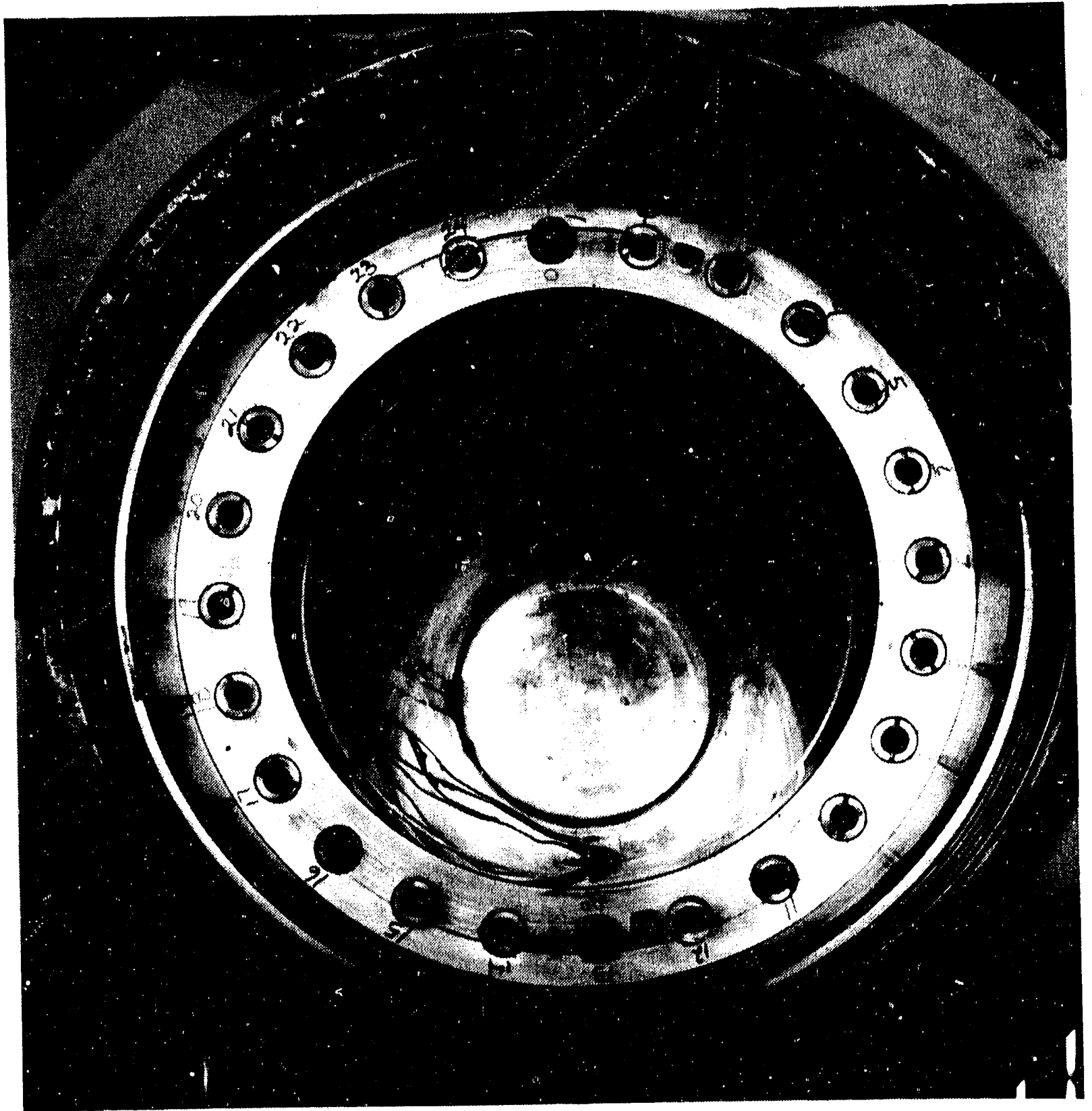

Fig. 4-20. Interior of cask body after complete test sequence 


\subsubsection{Scaling Laws}

The results from the half-scale model tests can be related to the full-scale prototype using a specific set of scaling laws. These laws are derived from the Buckingham $\pi$ theorem (Ref. 4-2), and they incorporate both material and geometric scaling. Since the model is constructed from materials that are elther identical to the prototype materials, or have the same mechanical properties, and since the geometric scale is one-half of the prototype, the following relationships between model and prototype exist:

1. Model impact time is one-half prototype impact time.

2. Model angular displacements are the same as prototype angular displacements.

3. Model linear displacements are one-half prototype linear displacements at scaled times and homologous locations.

4. Model velocities are the same as prototype velocities at scaled times.

5. Model accelerations are twice the prototype accelerations at scaled times.

6. Stresses and strains at homologous locations are the same for model and prototype at scaled times.

7. Model natural frequencles are twice that of the prototype. 


\subsubsection{Information Gathered from Tests}

The half-scale model was instrumented during the test to record its structural response. Photographs and dimensional measurements provided additional data.

The data gathered during the tests included information from the following sources:

1. Uniaxial piezoresistive accelerometers used to record the deceleration of at least four cask components: cask body, closure, shield liner, and contents. For their locations, refer to Table $4-2$.

2. Strain gauges mounted on the cask body, located in high stress areas, used to obtain local strain measurements. The number and location varied with each test (see Table 4-2).

3. Strain gauged bolts which monttored axial closure bolt loads during some of the tests.

4. $A C-A C$ linear variable differential transformers (LVDTs) mounted in the closure, which monitored the opening of the interfaces around the closure O-ring seals.

5. Radiographs of the depleted uranium (DU) performed before the test sequence and after tests $1,3,5$, and 7 to determine the DU postaccident condition.

6. Radiographs of the cask body forging welds performed before and after the complete test sequence to determine the condition of the welds after the tests. 
THIS PAGE LEFT INTENTIONALLY BLANK

$4-30$ 


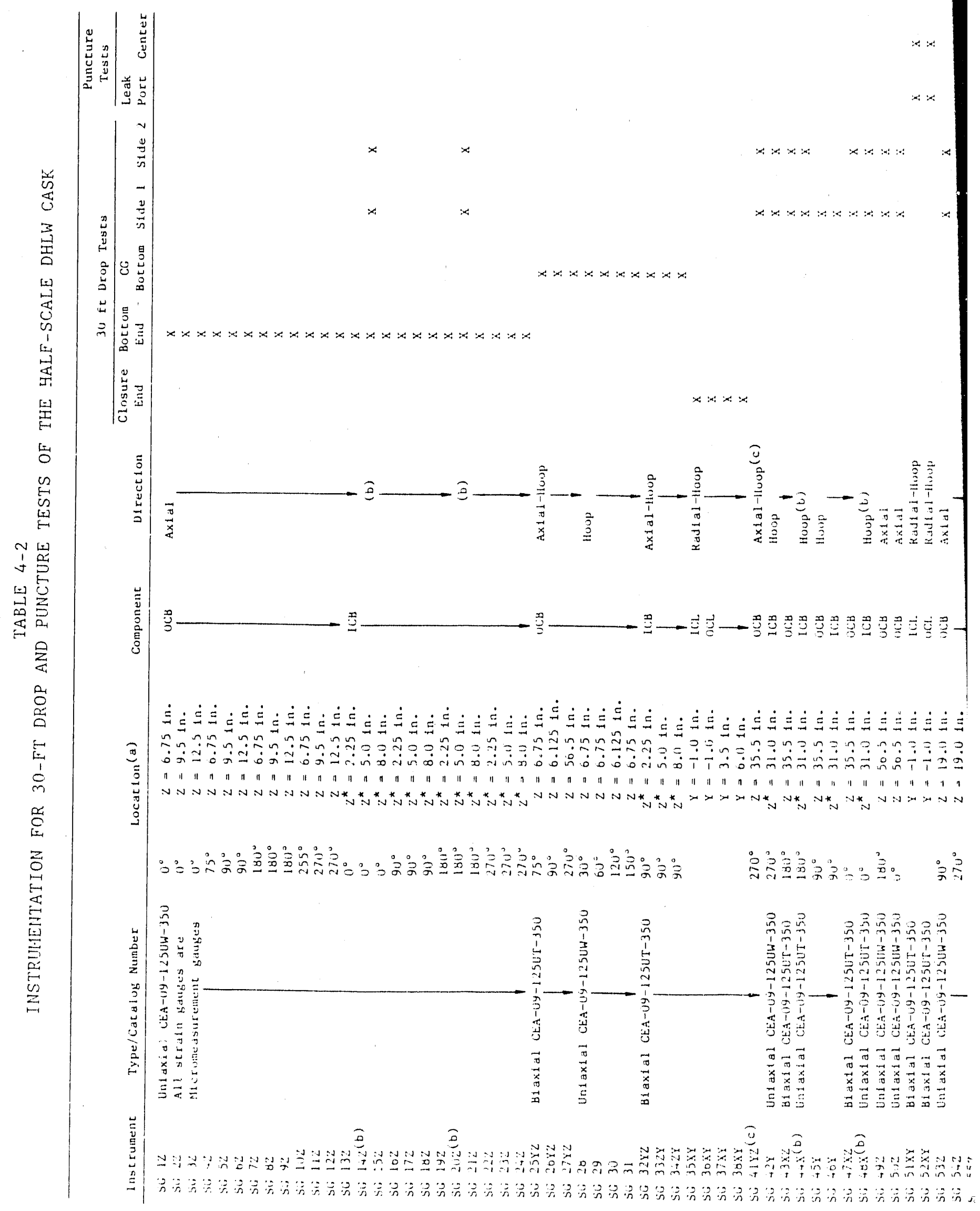




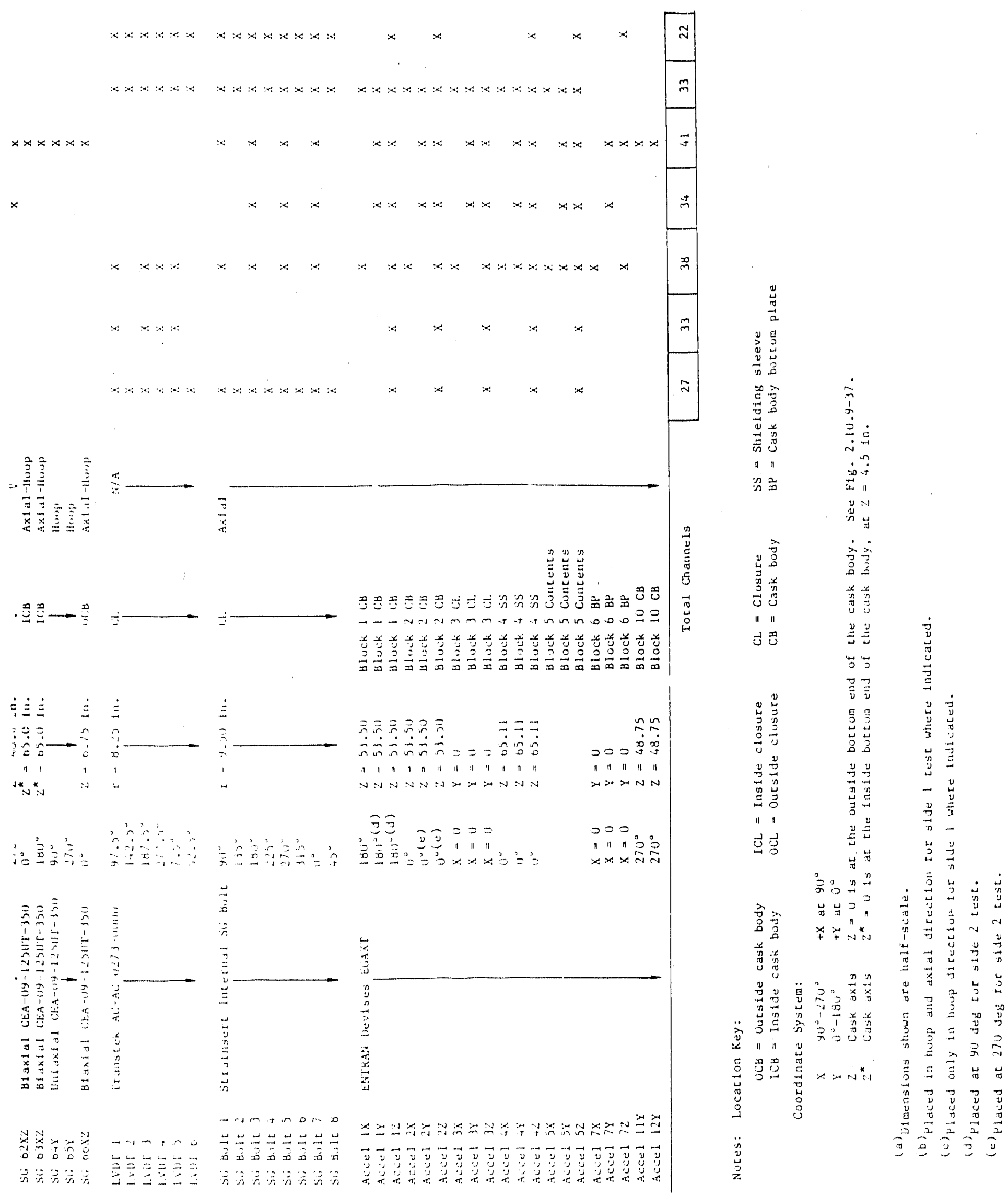




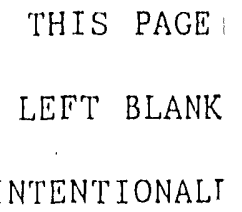

INTENTIONALT 
$4-3$.

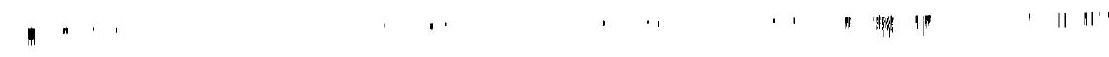


7. Seal leakage tests performed after each drop test to help evaluate the performance of the o-ring seals during and after the tests.

8. Cask body and gas sample port weldment leakage tests performed to evaluate performance of welds.

9. Dimenstonal measurements of the closure/cask body seal separation used to determine permanent separation of closure/cask body seal surfaces.

10. Dimensional measurements used to determine the damage and deformation that occurred during the tests.

11. Strain gauges mounted on the mild steel puncture pin used durIng the two puncture tesis and used to determine bending and membrane strain components as the puncture pin deforms during the test.

12. Both still shots and high-speed film of the drop and the condition of the cask components.

A schematic of the instrumented cask appears in Fig. 4-21. Instrumentation locations are 1dentified, as is the cask body coordinate system shown In the figure. Positive Body $Z$ axis is directed along the cask axis towards the closure end of the package. Table 4-2 shows the instrumentation used in each test.

\subsubsection{Test Results}

The complete details of the testing and test results are reported in Ref. 4-1 a SNL report. That reference presents in detail the test procedures, detailed records of data obtained including accelerometer, LVDT, strain gauge bolts, and strain gauge response histories, 
THIS PAGE LEFT INTENTIONALLY BLANK 


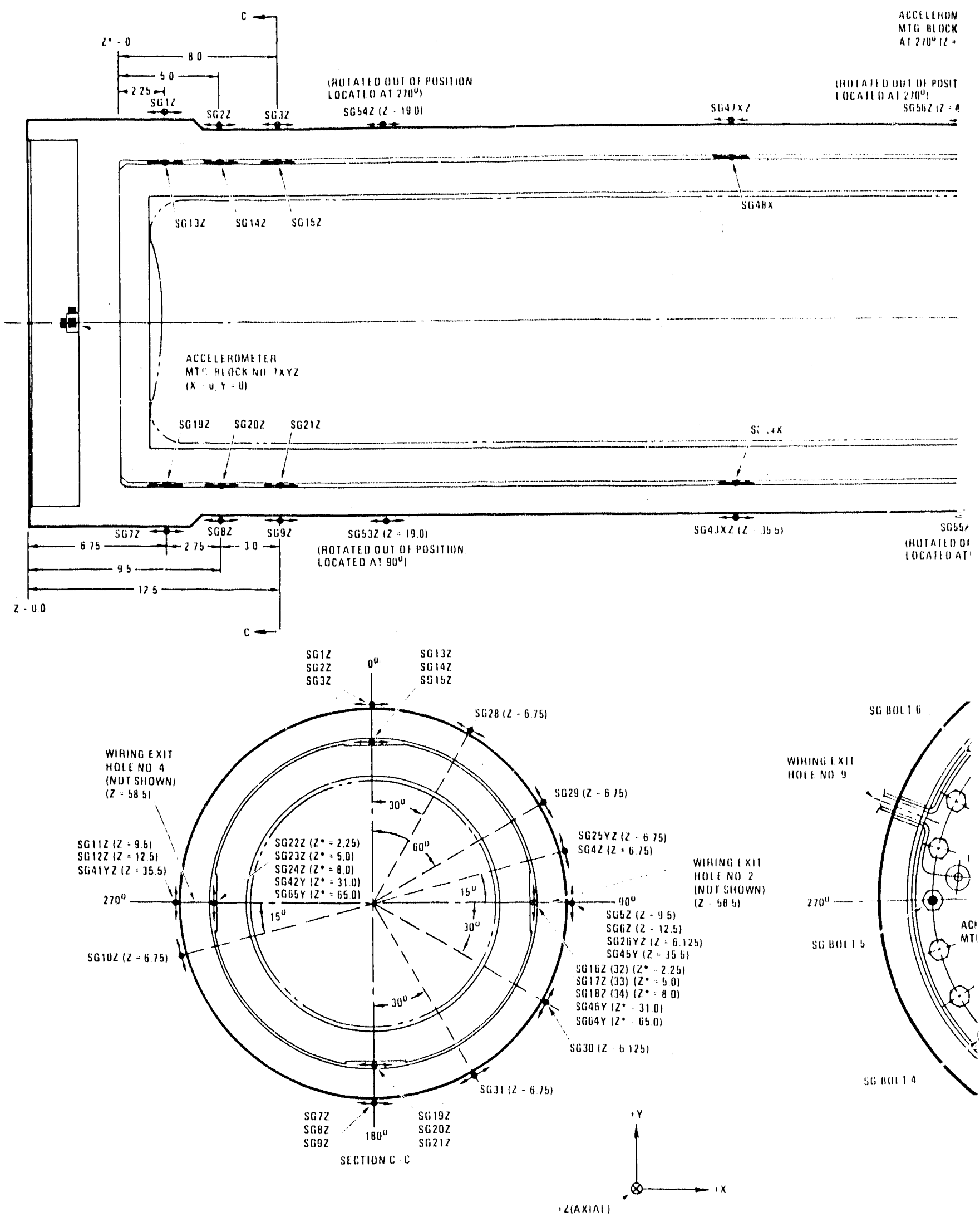




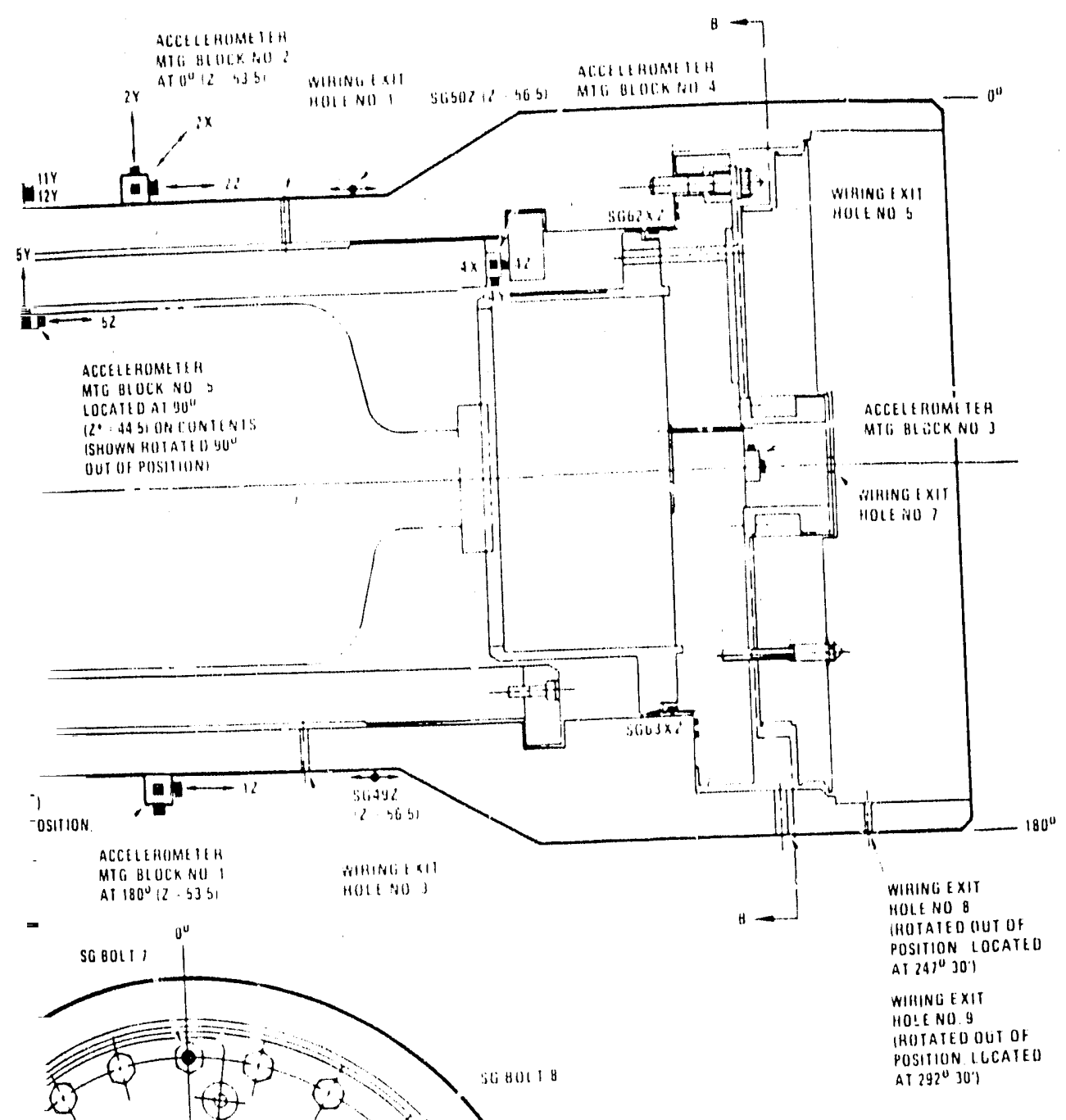

I NUIIS

$$
\begin{aligned}
& 1 \text { CoUHOINAIE SYSTIM } \\
& \left.x+90^{\prime \prime}\right) 210^{\circ}+x \text { AT } 90^{\circ} \\
& \text { Y. } 0^{\prime \prime} 180^{1} \cdot \text {. YATO } \\
& \text { C. CiAJK AXIS. } \\
& \text { 1. DAT OUSIOH HOTIOM } \\
& \text { INU OF CASK } \\
& \text { - ual inside bottom } \\
& \text { iNU Or CASK }
\end{aligned}
$$

Fig. 4-il. Schematic of test inst rtmentat ion 
THIS PAGE

LIFT BLANF

INTENTIONALLY 
information regarding installation and calibration of the instrumentation, $x$-ray inspection, physical measurements, and leakage test results. This full set of data is not specifically repeated in this report. Instead, a summary of the peak and rigid body values, the trends, and description of damage is presented. Data that did not pass functional and evaluation checks are not inciuded.

\subsubsection{Accelerations and Impac: Durations. The test results were} filtered at $2000 \mathrm{~Hz}$, using a low pass filter. This frequency level was chosen because it is in the linear range of measurements for the type of Entran accelerometers used. Two thousand hertz includes the first modes of response of the main components of the cask, and ensures that the fundamental behavior of the cask is included. Filtering the test data at $2000 \mathrm{~Hz}$ is equivalent to filtering the analytical results at $1000 \mathrm{~Hz}$, since half-scale model natural frequencies are twice that of the fullscale prototype.

Table 4-3 presents the peak accelerometer test results converted to full-scale values for bottom and closure-end 9-m (30-ft) drop tests. Table 4-4 presents the results for the CG over bottom corner and the two side drop tests.

Evaluation of the accelerometer data shows that the duration of the closure end drop is $10.1 \mathrm{~ms}$, for the bottom end drop is $5.0 \mathrm{~ms}$, and for the CG over bottom corner drop is $11.1 \mathrm{~ms}$. The primary impact and slapdown duration on the first side drop are 11.1 and $17.4 \mathrm{~ms}$, respectively and 8 and $12 \mathrm{~ms}$ for the second side drop.

The results show that the bottom end $9-\mathrm{m}(30-\mathrm{ft})$ drop causes the largest accelerations. This is expected since tt is the shortest duration impact event and since the same amount of energy is absorbed in a shorter amount of time, the $g$ levels are higher to reduce the velocity faster. 
TABLE $4-3$

TIST RESULTS - ACCELEROMETER DATA

\begin{tabular}{|c|c|c|c|}
\hline \multirow[b]{2}{*}{$\begin{array}{c}\text { Accelerometer } \\
\text { No. }\end{array}$} & \multirow[b]{2}{*}{$\begin{array}{l}\text { Accelerometer Location } \\
\text { (Refer to FIg. } 4-21 \text { ) }\end{array}$} & \multirow{2}{*}{$\begin{array}{l}\text { Bottom End Drop } \\
\text { Peak } \\
\text { Acceleration } \\
\text { (g) }\end{array}$} & \multirow{2}{*}{$\begin{array}{c}\text { Closure End Drop } \\
\text { Peak } \\
\text { Acceleration } \\
\text { (g) }\end{array}$} \\
\hline & & & \\
\hline $\mathrm{A} 1 \mathrm{z}$ & $\begin{array}{l}\text { Cask body } \\
\theta=180 \mathrm{deg}, \\
Z=53.5 \mathrm{in} .\end{array}$ & 530 & 275 \\
\hline $\mathrm{A} 2 \mathrm{z}$ & $\begin{array}{l}\text { Cask body } \\
\theta=0 \text { deg } \\
z=53.5 \mathrm{in} .\end{array}$ & 525 & 245 \\
\hline $\mathrm{A} 3 \mathrm{z}$ & Closure center top & -- & 475 \\
\hline $\mathrm{A} 4 \mathrm{z}$ & Shield sleeve & 940 & 288 \\
\hline$A 5 z$ & Contents & 890 & 93 \\
\hline
\end{tabular}




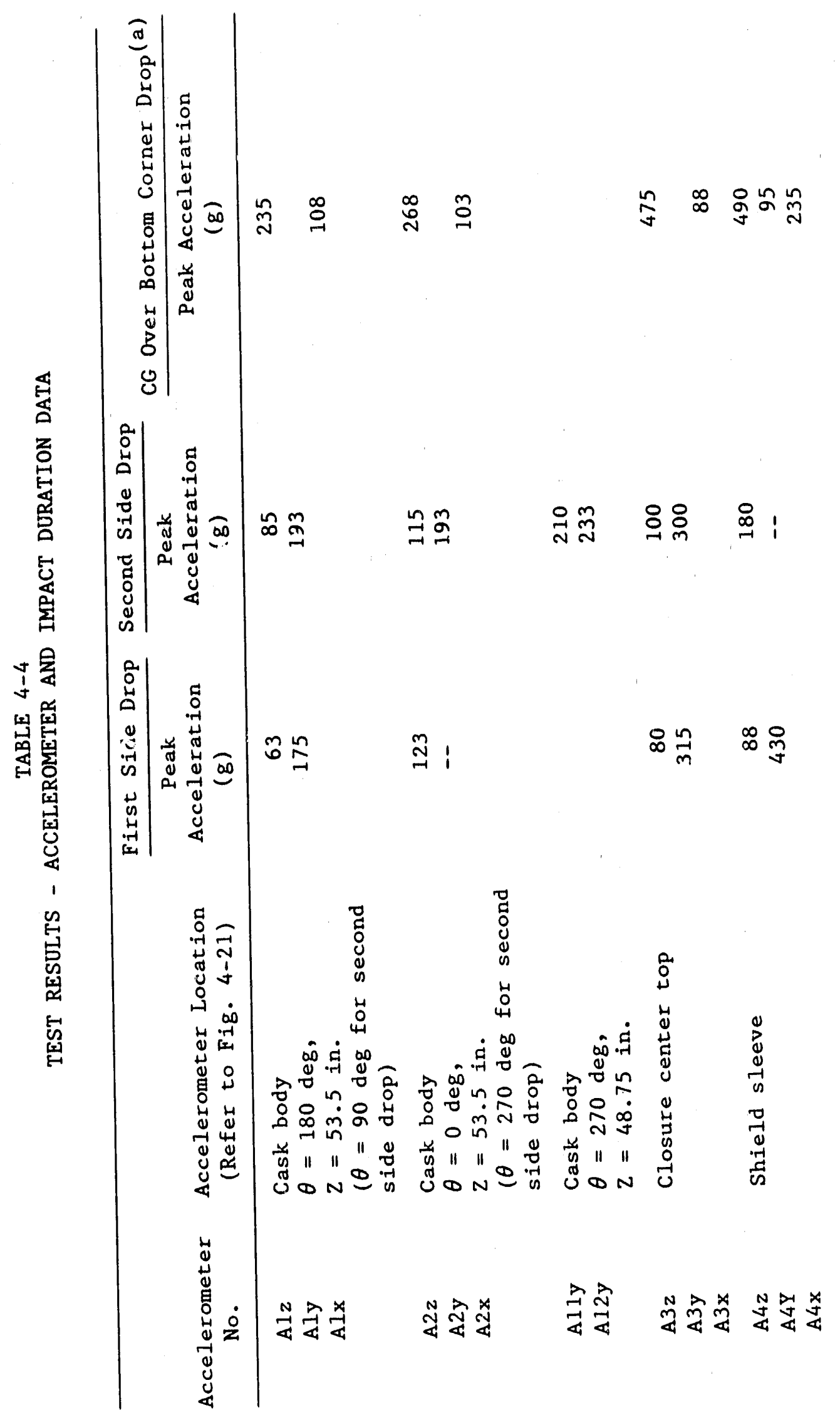




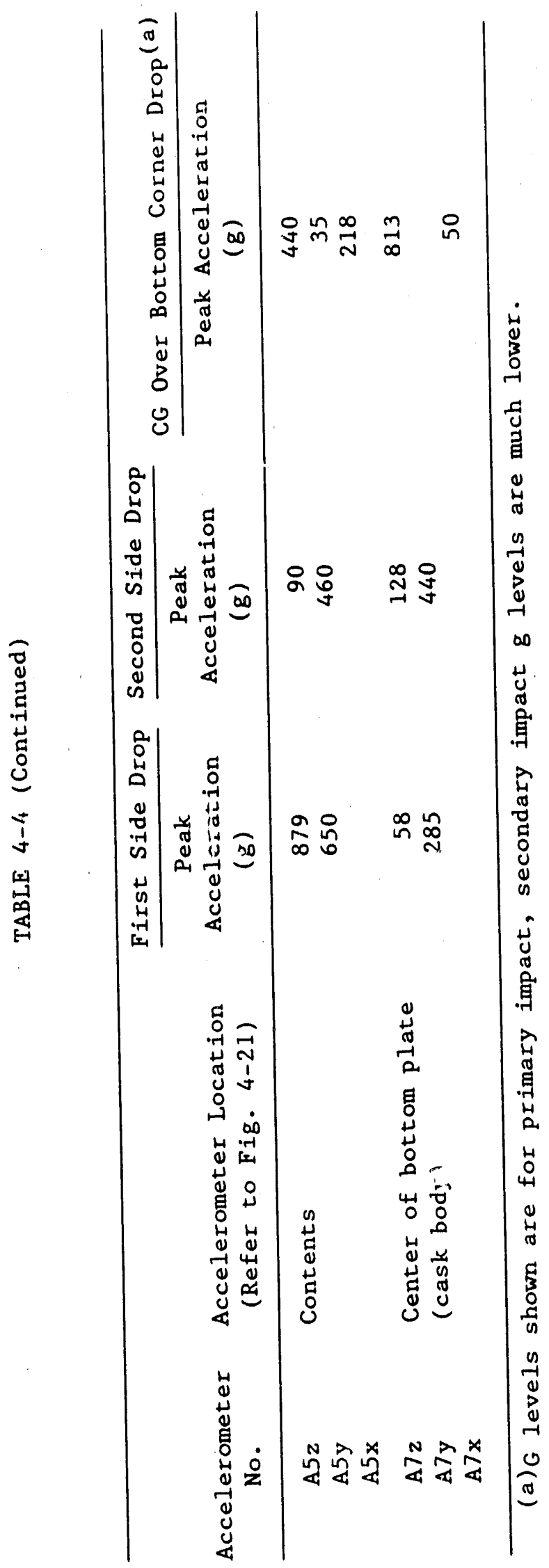


4.3.3.2. Strain Gauges. Strain gauges were used during the tests to measure strains in critical areas. The results were filtered at $10,000 \mathrm{~Hz}$ and are summarjed below and show that only minor damage occurs in the cask during any of the drop events:

1. Bottom end drop test. During this test, axial strain gauges were located on the inside and outside of the cask body near the bottom end at the levels shown in FIg. 4-22. There were four strain gauges at each of the designated locations, at 0 , 90,180 , and $270 \mathrm{deg}$. The test was not perfectly axisymmetrical; the cask hit first near the 270 deg side. To demonstrate the axisymmetrical behavior of the cask, the peak strain recorded by the four strain gauges at each level were averaged and shown in Fig. 4-22. Even though the peak strains do not occur at the same time in all of the gauges, this average strain conservatively reflects the behavior of the bottom of the cask. Fnr example, an important feature of the behavfor is that at the inside corner of the sask, the strains are positive (tension) and at the outside of the cask, the strains are negative. This shows that there is a bending moment at the junction of the sidewall and bottom plate.

The strain offset recorded by- most of the gauges is within the $200 \mu \epsilon$ uncertainty band level, except for the gauges inside the cask body at $z=12.5 \mathrm{in}$. The average of these gauges measures a permanent strain offset of $456 \mu \mathrm{E}$. The largest axial peak strain measured during the event was $2450 \mu \epsilon$ or $0.245 \%$ strain, which is near yleld as defined by the $0.2 \%$ strain offset method.

2. Closure end drop test. During this test, strain gauges were located on the closure. The gauges were mounted on the exterior of the closure on a line at $1,3.5$, and $6 \mathrm{in}$. from the center of the closure, and also on the inside at $1 \mathrm{in.}$ from 


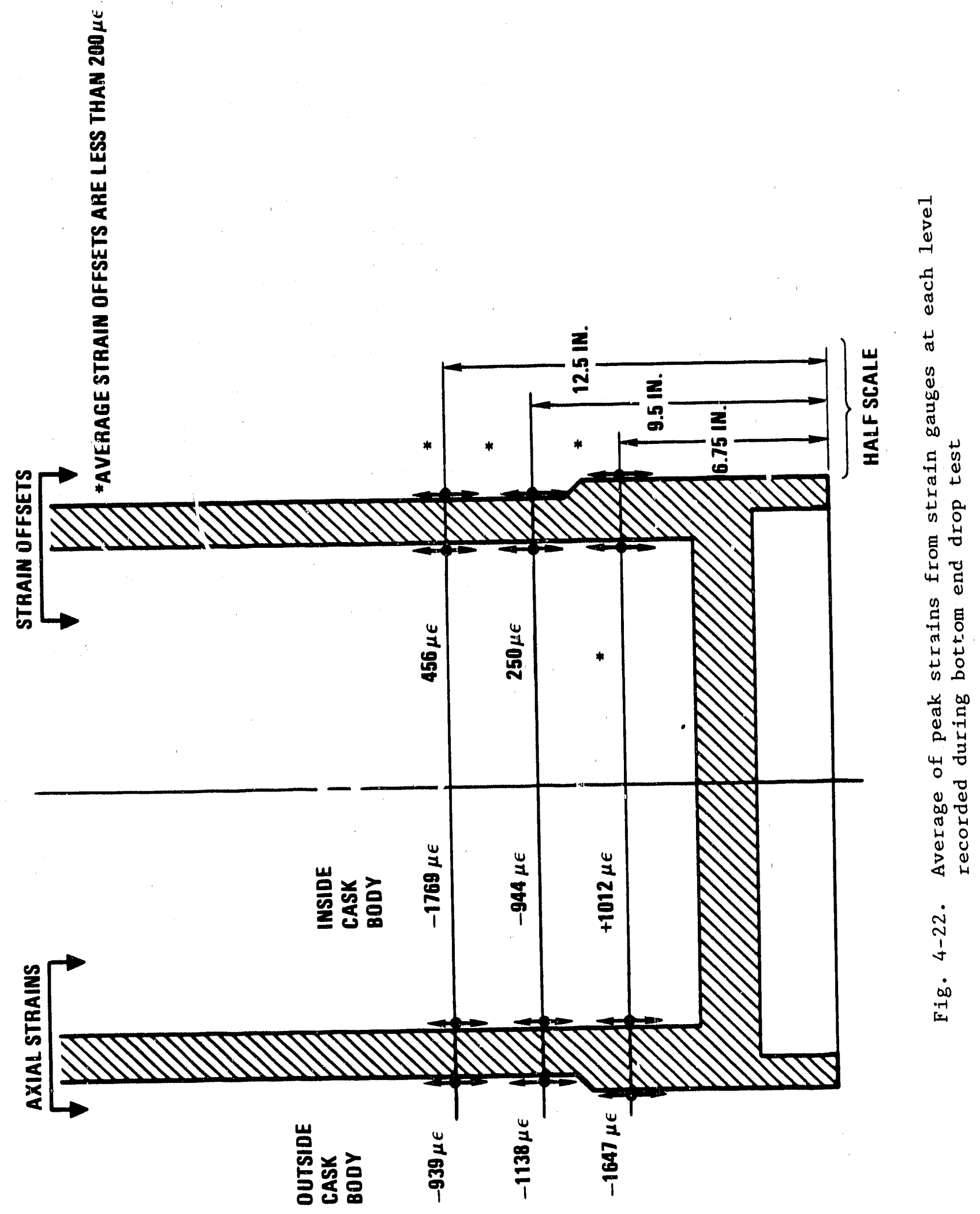


the center of the closure. The gauges at each location measured strains in both radial and hoop directions. All the gauges registered peak strains below yleld and had no permanent strain offset at the end of the event. The highest measured strain on the exterfor of the closure was less than $500 \mu \epsilon$.

3. First side drop. During this test, strain gauges were located on the interfor and exterior of the cask body as shown in Table 4-2. Axial and hoop strains were measured. All of these strain gauges recorded peak strains below yleld and no permanent strain offset. The highest strain recorded was $1075 \mu \epsilon$ which is below yleld, and had a permanent straln offset of $100 \mu \epsilon$. This value is within the uncertainty band level for the strain gauges.

4. CG over bottom corner drop. During this test, plastic strains were measured locally near the bottom end atound the point of impact (90 deg). Figures $4-23$ and $44-24$ show the results of the measurements. The highest strain measured on the cask body was $3300 \mu \epsilon$ in the axial direction. This amount of strain is minimal for a ductile material such as Type 304 stainless steel.

5. Second side drop. During this test, strain gauges were located on the interfor and exterfor of the cask at the locations described in Table 4-5 to record hoop and axial stralns. The highest strain measured near the seal surfaces was $1725 \mu \epsilon$ in the hoop direction which is below the yield point as defined by the $0.2 \%$ offset method. There was a permanent strain offset on the same gauge of $350 \mu \epsilon$. This offset is not unusual in material like stainless steel in which the stress-strain curve is not linear near the defined yield point, as defined by the $0.2 \%$ offset method. When the 


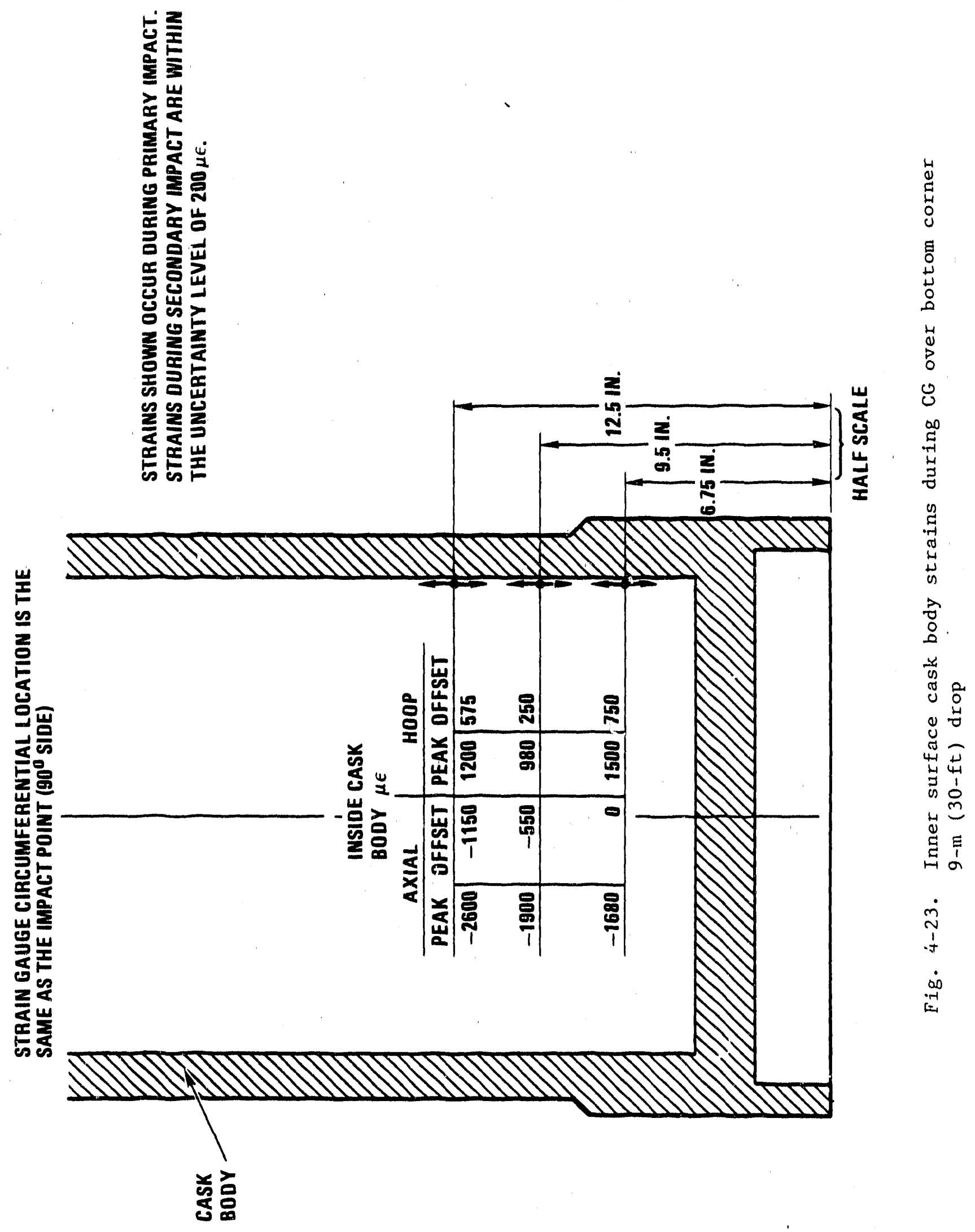




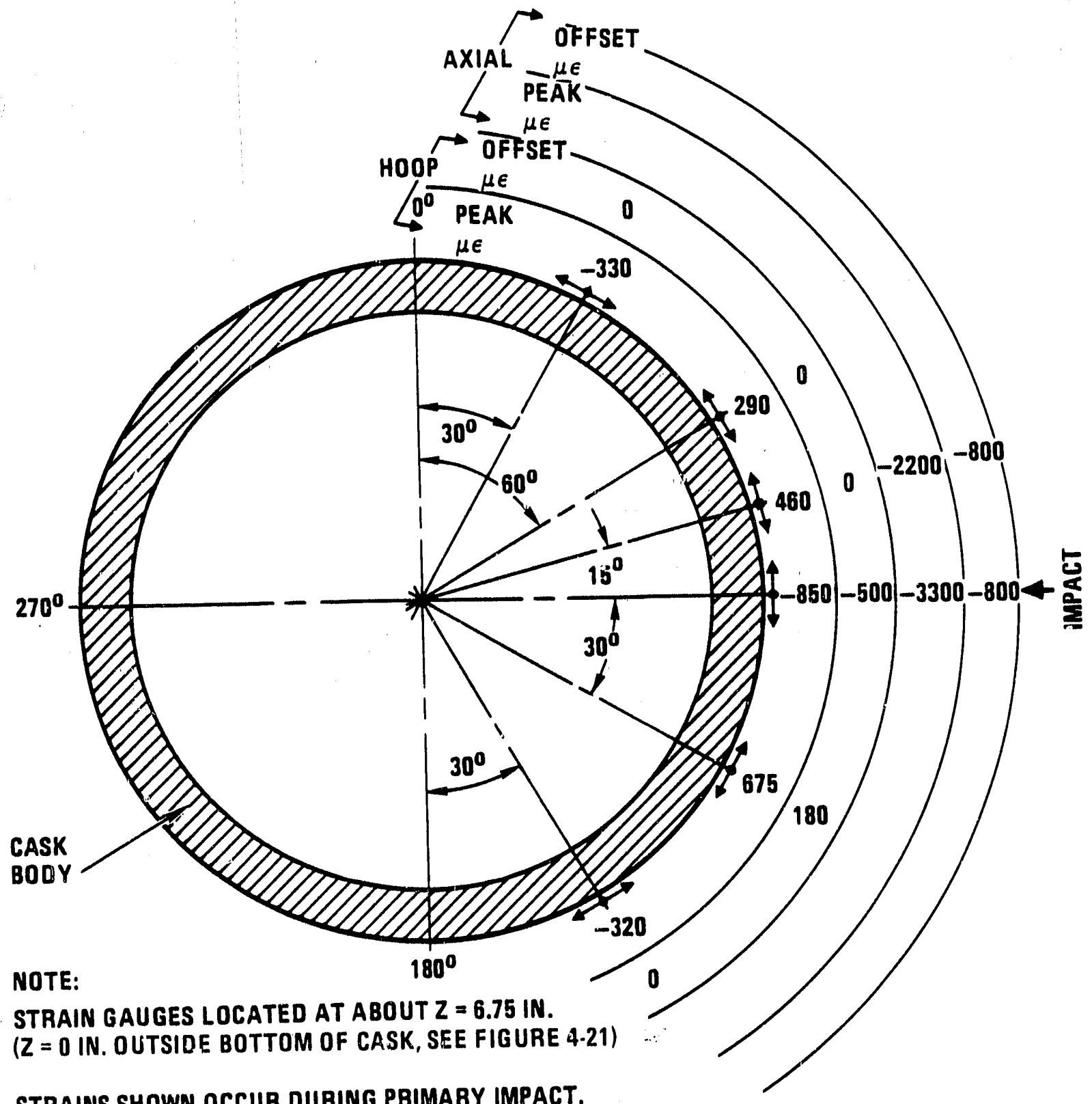

STRAINS SHOWN OCCUR DURING PRIMARY IMPACT. STRAINS DURING SECONDARY IMPACT ARE WITHIN THE UNCERTAINTY LEVEL OF $200 \mu \epsilon$.

Fig. 4-24. Outer surface cask body strains during CG over bottom corner $9-m(30-f t)$ drop 


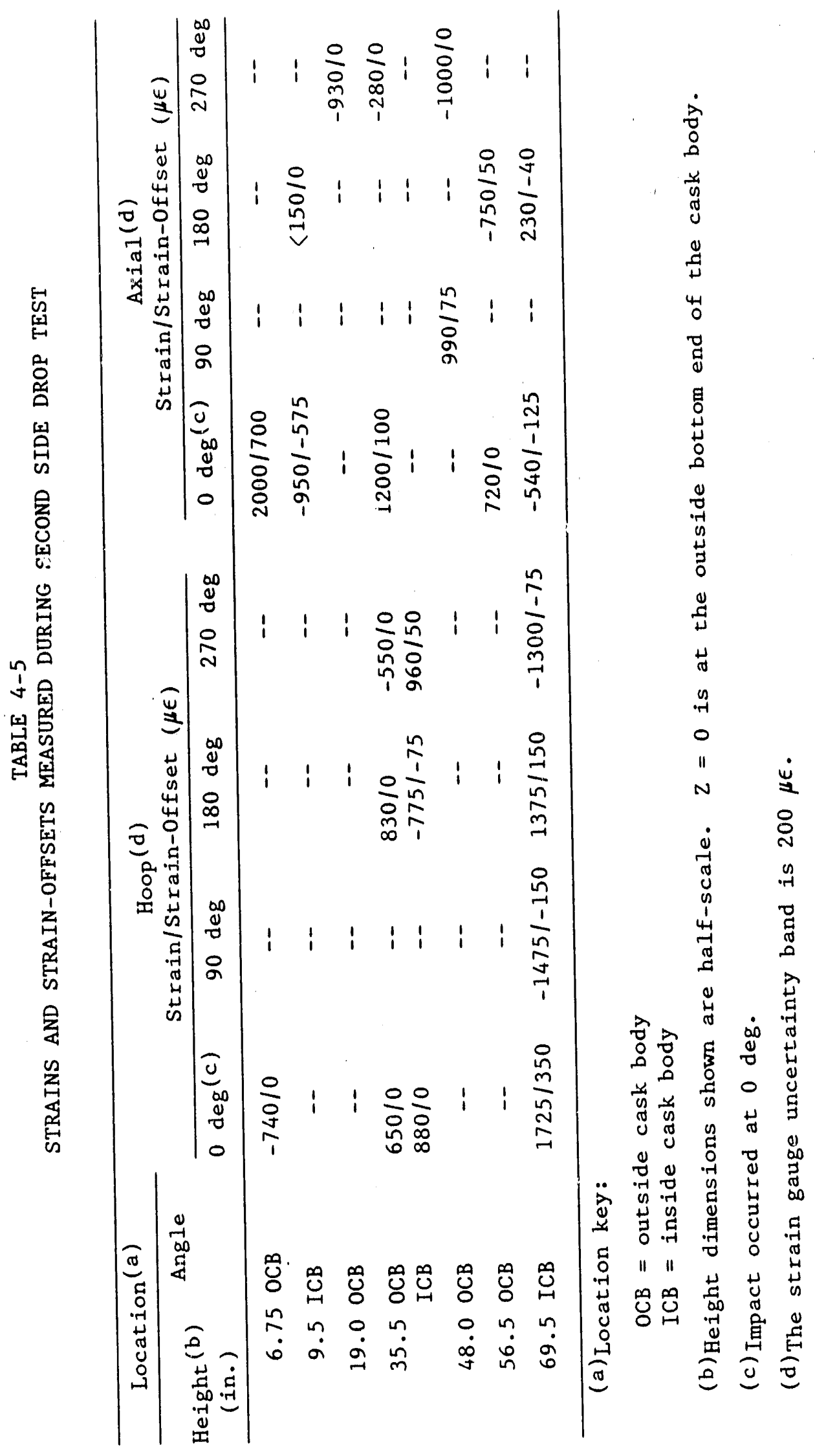


material is loaded in the elastic regime and then unloaded, the return slope is not equal to the original loading slope, causing a small strain offset. The measurements of the cask dimensions discussed in Section 4.3.3.4 show that the deformations near the seals are small and therefore consistent with these strain data.

4.3.3.3. Strain Gauged Closure Bolts. Strain gauged closure bolts were used for all tests except the bottom end drop to determine the axial load on the closure bolts during accident events. The results show that the axial loads on the closure bolts remain well below allowables. In addition, the bolt length and straightness were measured after all test sequences and showed that the closure bolts did not yield in tension or bending.

The highest bolt loads measured occurred during the 9-m (30-ft) closure-end drop test. The highest peak load recorded was $3280 \mathrm{lb}$. This load represents an additional load above the initial preload on the bolts. The :ominal stress on the bolts due to the Initial $1000 \mathrm{ft}-\mathrm{lb}$ full-scale pretorque is $28,500 \mathrm{psi}$. The increase on the bolt stress due to the peak load can be calculated as follows:

$$
\Delta \sigma_{\text {bolt }}=\Delta \mathrm{P} / \mathrm{A}
$$

where $\Delta P=$ highest peak load recorded $=32.80 \mathrm{lb}$,

$A=$ minimum tensile area of the half-scale bolt $(0.75-10$ UNC $)=$ c.334 in. ${ }^{2}$. (Conservative because area of full-scale bolt is proportionally larger.)

Substituting

$$
\Delta \sigma_{\text {bolt }}=3280 / 0.334=9820 \text { psi. }
$$

Therefore, the maximum total stress on the closure bolt due to any accident drop even: is $28,500+9820$, or 38,220 psi. This stress 
level is well below the yield stress of the bolt material at $160^{\circ} \mathrm{F}$, whtch 1s $146.4 \mathrm{ksl}$ per Ref. 2-5. Allowable membrane stress on the bolts is $124.6 \mathrm{ks} 1$ during accident conditions.

Also, the torque on the bolts was measured before and after the tests. The measurements show that all the bolts remained preloaded after the tests. The lowest posttest torque measured on any one bolt was $60 \mathrm{ft}-1 \mathrm{~b}$ or half of the origlnal assembly torque. Therefore, the tests proved that the closure bolts w111 retain preload after the hypothetical accident drop events.

\subsubsection{Dimensional Measurements. Extensive dimensional measurements} were performed on the cask model throughout the test sequence. Complete sets of measurements were taken after test Nos. 1, 3, 5, and 7. Following is a summary of the damage measured on each of the cask components after the tests:

1. All dimensions quoted in this section have been converted to ful1-scale by mul-iplying the model dimensions by two. Rotational measurements remain the same.

2. Due to the extensive handling and repeated assembly and disassembly of the cask during the test sequence, minor Indentations and deflections are expected in the cask, causing sma11 changes in the measurements. Even though these changes. are small, the measurements in the critical areas are reported for completeness:

a. Closure plate. There was no deformation of the closure plate after any or all of the tests, except for local indentations during the puncture drop tests. During the gas sample/leakage test port puncture drop test, there was a maximum indentation of $0.022 \mathrm{in}$. under the punch and a maximum indentation of $0.008 \mathrm{in}$. under the pintle 
after the center puncture event. This kind of damage is superficlal. There was no damage to the port plug, and 1ts safety function was not impaired. Figure 4-10 shows the condition of the port area after the port puncture drop test.

There was no flatness or dimensional change in the sea1Ing surface during any of the tests; all measurements were within $0.008 \mathrm{in}$.

The tests showed that the closure plate can withstand 9-m $(30-f t)$ drop and puncture hypothetical accident events without damage.

b. Cask body. During all the tests there was no damage to the sealing surface. All diameter changes within the first $12 \mathrm{in}$. of the cask were less than $0.020 \mathrm{in.} \mathrm{After}$ the complete test sequence, the dimenstons on the upper $10 \mathrm{ln}$. of the model, including the seal surfaces, were st1ll within manufacturing tolerances. There was also small deformation through the length of the cask body (not including the integral impact limiters); for details see discussion of individual cests below. After all tests, the measurements from the seal surface to the shear ring slot remained unshanged within 0.006 in.

The tests show that the cask body will withstand the 9-m $(30-f t)$ drop and puncture hypothetical accident events withedit significant damage or change in internal volume. 
Following is a description of the measurements after each test sequence:

(1) After test No. 1 - bottom end drop. The cask body decreased in length an average of $0.034 \mathrm{in}$. The length was obtained by measuring from the top of the cask body to the bottom of the bottom plate at the outside of the cask side wall. The measurements made from the top of the cask body (seal surface) to the top of the bottom plate at the inside of the cask side wall increased $0.092 \mathrm{in}$. This increase in length is consistent with the positive strains measured and predicted at the inside bottom corner of the cask. There was no change in length on the upper part of the cask, as demonstrated by the shear ring slot measurements. Most deformations occurred near the lower impact Iimiter.

The center of the bottom plate bowed $0.34 \mathrm{in}$. and at a radius of $9 \mathrm{in}$. the bottom plate bowed an average of $0.24 \mathrm{in}$. There was an average decrease in the length of the bottom impact limiter of $0.53 \mathrm{in}$.

(2) After tests No. 2 and 3 -closure end drop and puncture over gas sample port drop. All diameter changes in the cask body were within $0.020 \mathrm{fn}$. The overall average change in length of the cask body was $0.0015 \mathrm{in}$. There was no bowing of the bottom plate.

(3) After tests No. 4 and 5 - first side drop and center puncture drop. The maximum ovalization measured on the top of the cask body was $-0.018 \mathrm{in}$. In the 0 - to 180-deg diameter; 1.e., in line with the first side 
drop test impact at the $180 \mathrm{deg}$ side; +0.008 in. were measured in the 90- to 270-deg diameter, perpendicular to the impact. After test No. 4, first side drop, measurements show a maxtmum possible movement of the closure relative to the cask body of $0.034 \mathrm{In}$. Including the ovalization reported above. This movement will not result in a change In the contalnment capabilities of the cask since it Involves only about $14 \%$ of the surface contact width of the o-ring seals. The half-scale cask model remained leaktight.

There was also a small deformation of the cask body bottom plate; the change in length from the seal surface to the center of the bottom plate measured $0.014 \mathrm{in.}$ There was a local change in length in the bottom Impact limiter near the side of impact during the side drop of 0.16 in.

(4) After tests No. 6 and 7 - CG over bottom corner drop and second side drop. The measurements in the cask body showed that there was negliglble deformation of the cask body side wall diameter as measured by maximum ovalization of 0.010 in the diameter at the top of the cask body near the seal area. All other changes in the cask body measurements were within $0.026 \mathrm{in}$. on the diameter. There was negligible bowing of the cask body bottom plate since measurements showed that the distance from the top of the cask body to the center of the bottom plate changed $0.004 \mathrm{in}$. The largest change in length of the cask body wall occurred on the same side as the side drop Impact ( 0 deg); it measured $0.348 \mathrm{in}$. The lower Impact limiter deformed $2.6 \mathrm{in}$, at the location of 
the CG over bottom corner drop impact in the direction of the impact. During the side drop it deformed $2.3 \mathrm{in}$.

c. Shield sleeve assembly. Only minor measurement changes were recorded on the shield sleeve assembly after any of the tests. The maximum change in diameter was $0.076 \mathrm{in}$. There was a maximum measured bowing of the bottom plate of $0.202 \mathrm{in}$. during the bottom end drop. A11 welds and joints were intact. Figure 4-19 shows the condition of the shield sleeve after the complete test sequence.

d. Shear ring. The damage on the shear ring was minor since after all the tests, the flatness of ary shear ring untt was st111 within $0.044 \mathrm{in}$. Throughout any tests, the bottom surface remalned parallel to the top surface within $0.044 \mathrm{in}$.

e. Internal honeycomb impact limiter assembly. The same honeycomb impact limiter, shield plate and support cylinder were used for all the tests. The measured changes in the shield plate were within $0.006 \mathrm{in}$. on all the tests; the maximum change in length recorded on the internal honeycomb impact limiter was $0.022 \mathrm{in}$. which is a negligible amount for the honeycomb material since it can crush close to $5 \mathrm{in}$. before bottoming out.

f. Closure/cask body seal separation. Measurements from the top of the closure to the top of the cask body using Linear Variable Differential Transformers (LVDTs; were taken to determine if there was a permanent separation or indentation between the cask body and the closure surfaces. The measurements were taken after every test. A1l measurements showed that the two surfaces did not 
separate or indent after all tests, as measured to an accuracy of $0.002 \mathrm{in}$. There was a local change measured after the port/puncture test, but this change was due to the indentation on the closure outer surface caused by the punch and not due to deformation of the seal surfaces. This measurement is consistent. with the indentation measured on the closure outer surface after the port/puncture test.

g. Notched impact 1imiter. The notched impact 1imiter performed as expected during the test sequence. There was negligible damage to it during all the tests, except the closure end drop.

During the closure end drop, the first two notches closed up around the complete circumference. The third notch closed up in some areas and not in others. The notched tmpact limiter decreased in length an average of $1.81 \mathrm{in}$. The maximum radial increase measured was $1.248 \mathrm{in}$.

h. Circumferential impact limiters. Figures 4-25 and 4-26 show the damage to the circumferential impact limiters during tests 4 and 7. The maximum crush of the lower circumferential Impact IImiter measured $4.56 \mathrm{in.} \mathrm{(full-}$ scale) out of the inftial $8.26 \mathrm{in.} \mathrm{(full-scale)} \mathrm{thickness}$ of the honeycomb. The average crush in the lower circumferential Impact 1 imiter was $3.32 \mathrm{ln}$. (full-scale). The maximum crish in the upper circumferential impact Iimiter resulted during the second side drop, when the cask was tested without the lower circumferential impact limiter. The maximum crush obtained was $4.86 \mathrm{In}$. (fu11-scale), and the average crush was $4.48 \mathrm{in.} \mathrm{(full-scale).} \mathrm{The} \mathrm{orlg1-}$ nal honeycomb thickness in the impact limiter was $7.75 \mathrm{in}$. 

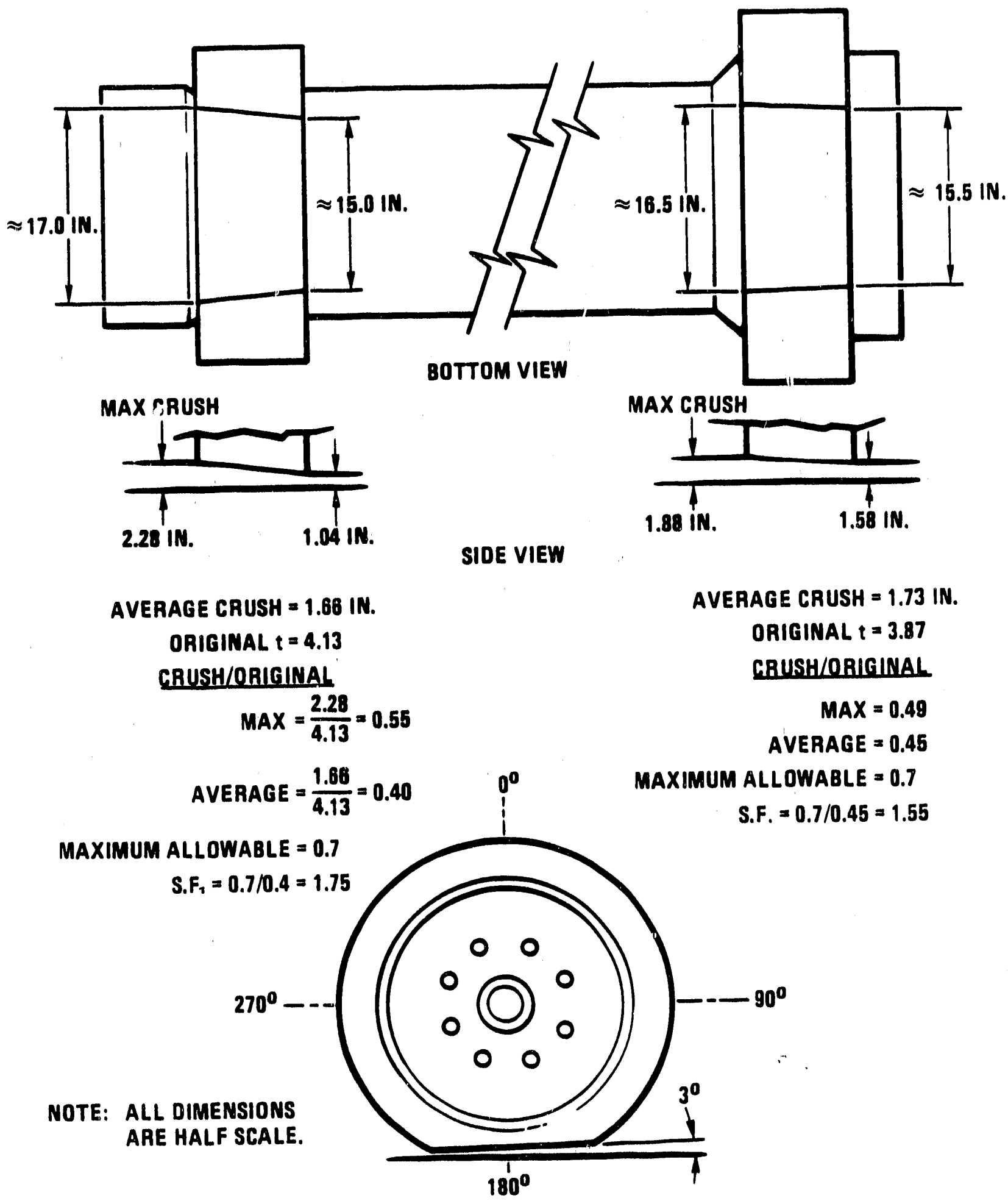

MAX CRUSH

FRONT VIEW

Fig. 4-25. First side drop test circumferential impact limiter deformation 


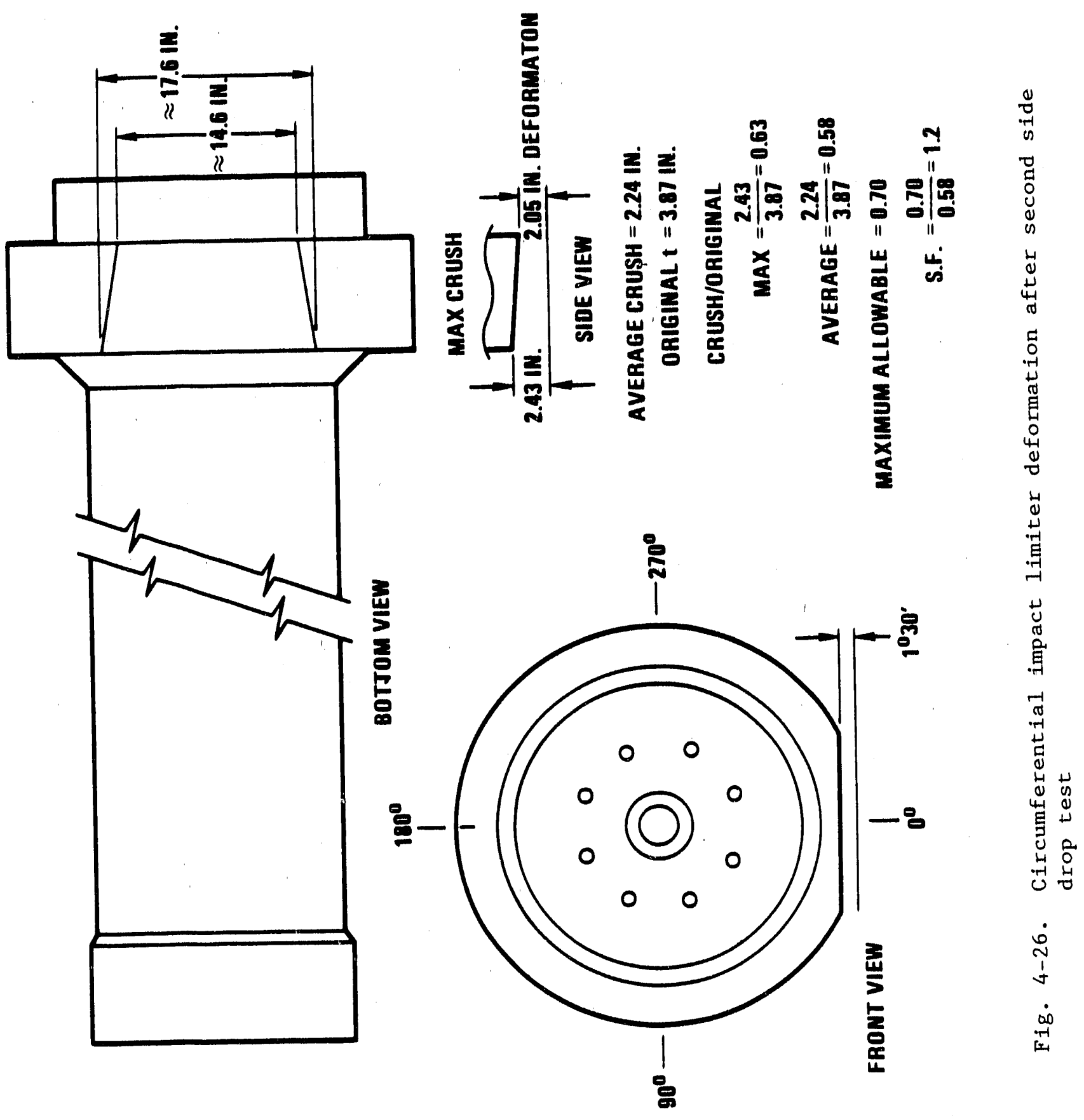


It is desirable to keep the maximum crush below $70 \%$ of the initial honeycomb thickness. After this amount of crush, the honeycomb "bottoms out;" 1.e., the strength of the honeycomb rapldly increases from 1ts crush strength to the strength of aluminum in compression. The lower clrcumferential impact 1 imfter has an average design margin of 1.75 agalnst reaching this maximum crush. The upper circumferential impact limiter shows an average design margin of 1.2 against reaching the $70 \%$ maximum crush allowed. This is very conservative, espectally In light of the fact that the test was more severe than expected since the lower circumferential impact limiter had been removed.

The test conflrms that impacting the hard lower end Impact 1 imiter pruduces higher loads on the upper end than impacting the lower circumferential impact limiter first. 


\section{COMPARISON OF TEST RESULTS WITH ANALYTICAL RESULTS}

This section compares the elastic GACAP analysis and the inelastic analysis results with half-scale model test results. Not all drop orlentations were tested or analyzed (using Inelastic methods) but all drop orfentations were analyzed using GACAP. This comparison shows that there is good agreament on the alternate verffication methods. The results show that the analytical approaches are conservative and that both inelastic and elastic analyses can be used to analyze a cask during the $9-\mathfrak{m}(30-\mathrm{ft})$ drop hypothetical accident events. Results also show that the inelastic structural criteria based on the ASME Code can be used for the containment boundary away from the sealing surfaces and results in a safe cask.

The exhaustive analyses and tests performed on the DHLW cask show that casks with compact integral impact limiters are not only easier to handle and operate but also result in rugged, safe casks in which the increased thickness of the containment boundary wall offers added safety, since the austenitic stainless steel can absorb large amounts of energy when subjected to extra-regulatory events.

\subsection{ACCELERATIONS AND DURATION}

The results show good comparison between the accelerations obtalned by test and elastic and inelastic analyses. The cask body accelerations are summarized in Table 5-1. The differences were expected and explained as follows: the inelastic analysis and test acceleration information were filtered at the same equivalent frequency $(1000 \mathrm{~Hz}$, full-scale). Filtering of the inelastic analysis accelerations was performed using the Corley-Tukey Fourler transform program developed by Brenner and presented in Ref. 5-1. The flltered data contain higher 


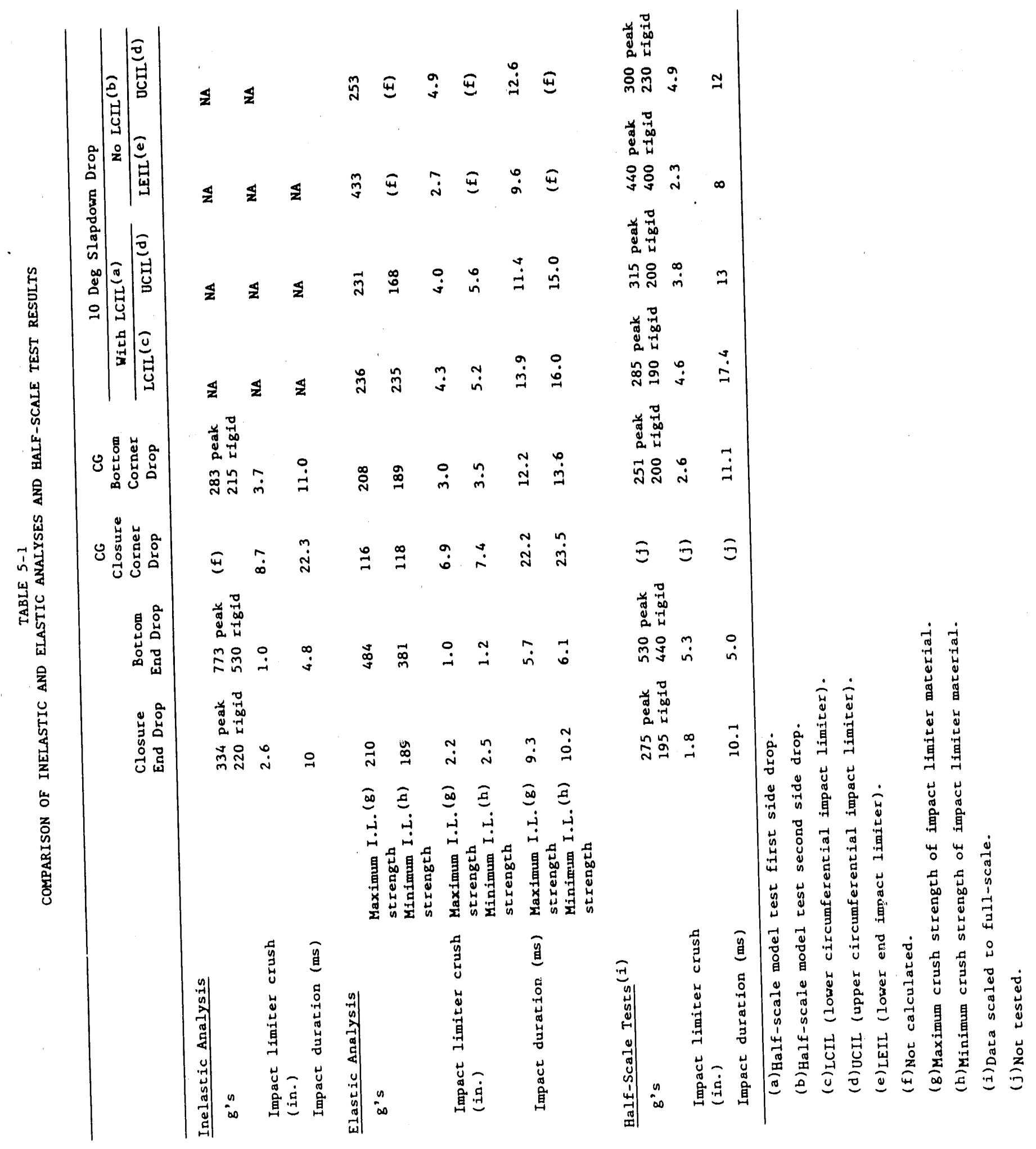


frequency accelerations in addition to the rigid body acceleration, which produce temporary peaks. These temporary peaks are caused by ringing, chattering and wave propagation. The elastic analysis g levels shown in Table 5-1 are rigid body accelerations and therefore 9 :ould be less than the peak inelastic analysis and half-scale test $g$ levels. In order to do a valid comparison, we determined the rigid body accelerations for the test and inelastic analyses as shown in Figs. 5-1 and $5-2$, respectively. As shown in Table 5-1, the rigid body test and inelastic analysis $g$ 's compare well with the GACAP rigid boay g's. Also, the Inelastic analysis $g$ levels are higher than the test $g$ levels. Th1s occurs because the analysis does not include internal damping and friction that occur in the test:

For the Inelastic analyses, we only compared accelerations for the closure end drop, the bottom end drop, and the CG over bottom corner drop. These analyses gathered acceleration information at a rate of 100 points per ms during the event. This is the same rate at which the test data were recorded. For the $C G$ over closure corner three-dimensional analyses, no acceleration information was gathered.

The definition of the impact duration reported in Table 5-1 is slightly different for each type of analysis and test. Test and inelastic analysis impact durations were determined by measuring the width of the acceleration pulse as shown in FIgs, 5-1 and 5-2. GACAP analysis impact durations were measured at the point of zero force on the impact limiter. In spite of the differences in time definition, the times correlate closely. This indicates that both the analyses and the test model have the same dynamic behavior.

\subsection{STRAINS}

Only the test and inelastic analysis strains were compared since the GACAP analysis is elastic. It is difficult to compare the magnitude of the strains between test and inelastic analysis for strains below the 


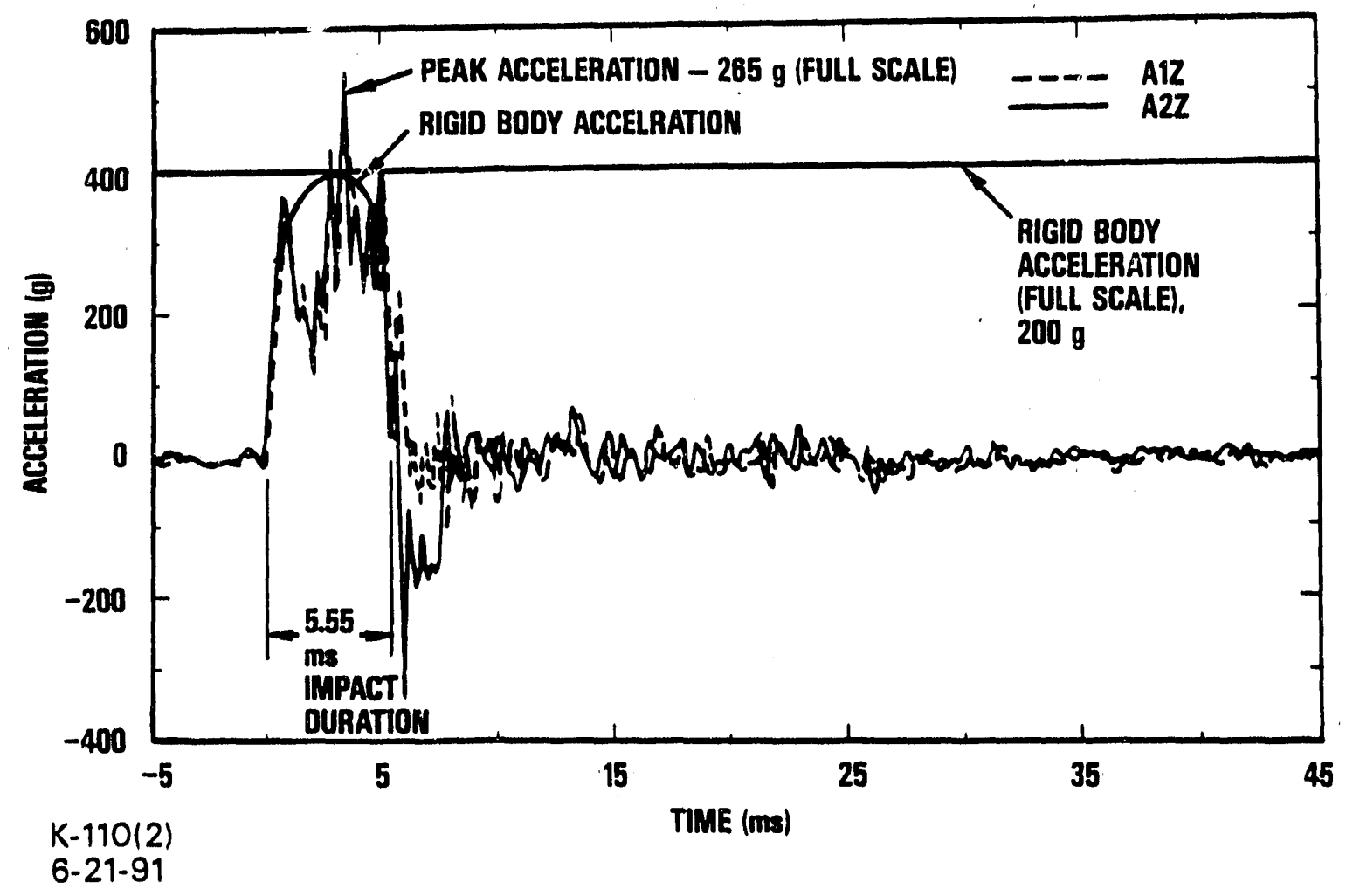

Fig. 5-1. Half-scale model CG over bottom corner 9-m (30-ft) drop acceleration 


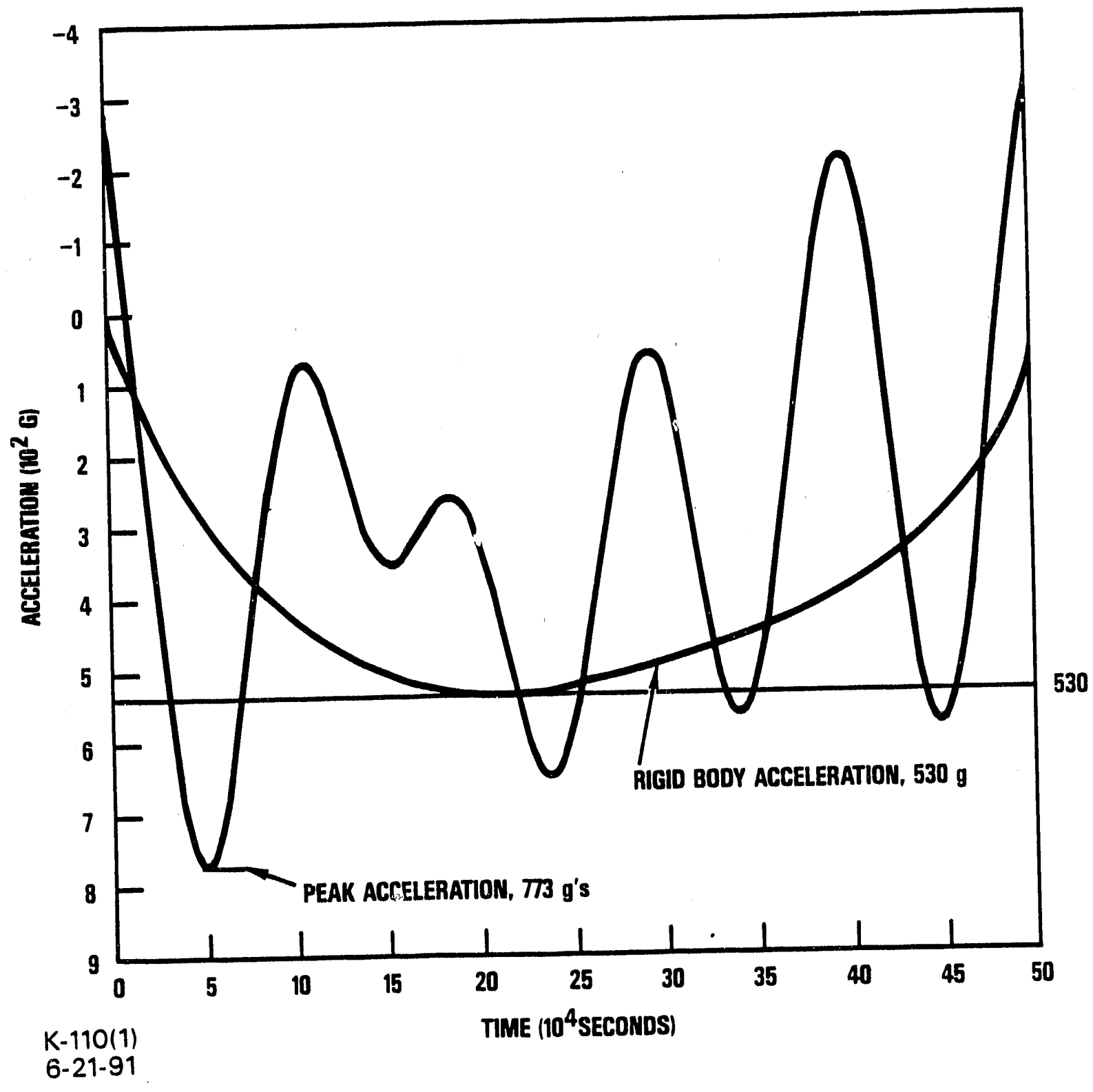

Fig. 5-2. Elastic-plastic bottom end 9-m (30-ft) drop acceleration 
elastic limit. In the inelastic analysis, a yleld stress of $35 \mathrm{ks}$ and an elastic modulus of $28.3 \times 10^{6}$ psi were used. Therefore, the material ylelds when a strain of $1237 \mu \epsilon$ is reached. Yleld is normally defined by the $0.2 \%$ offset method whlch gives a strain at yleld greater than $2000 \mu \mathrm{\epsilon}$. In stress-strain curves obtained by testing, after an initial Inear slope, the stress-strain curve starts to become nonlinear while still In the theoretical elastic range. Therefore the test will show plastic strains while still remaining below the theoretical yield. In addition to this difference between modeling and test, there are differences in the strain obtained in each. The test measures the strain at the location of the strain gauge on the surface of the cask. The axisymmetrical analyses performed with HONDOII (bottom and closure end drops) plot the strain gradient of the element. This gradient is generally smaller than the strain measured by the strain gauge, since the gauge reflects only onc point in the gradient matrix. Therefore, when comparing strain below yield, differences are expected in the values obtained for the tests and analyses. These differences are not significant since the stresses are well below allowables. The distribution of strains and strain trends are important to compare, since these wi11 show if the behavior of the cask is modeled correctly in the analysis:

1. Bottom end drop. As seen In Fig. 5-3, the axisymmetrical strain distribution in the bottom of the cask is similar for both test and aralysis. The Inside bottom corner of the cask shows a positive (tension) strain, while the rest of the strains are negative (compression).

All the strains remain below the defined theoretical yield.

The analytical strains shown were obtained by plotting the $z$-strain gradients of the elements on a section, and then extrapolating the plot to the surface. The $z$-strain gradients are obtained directly from the HONDOII output tapes. 


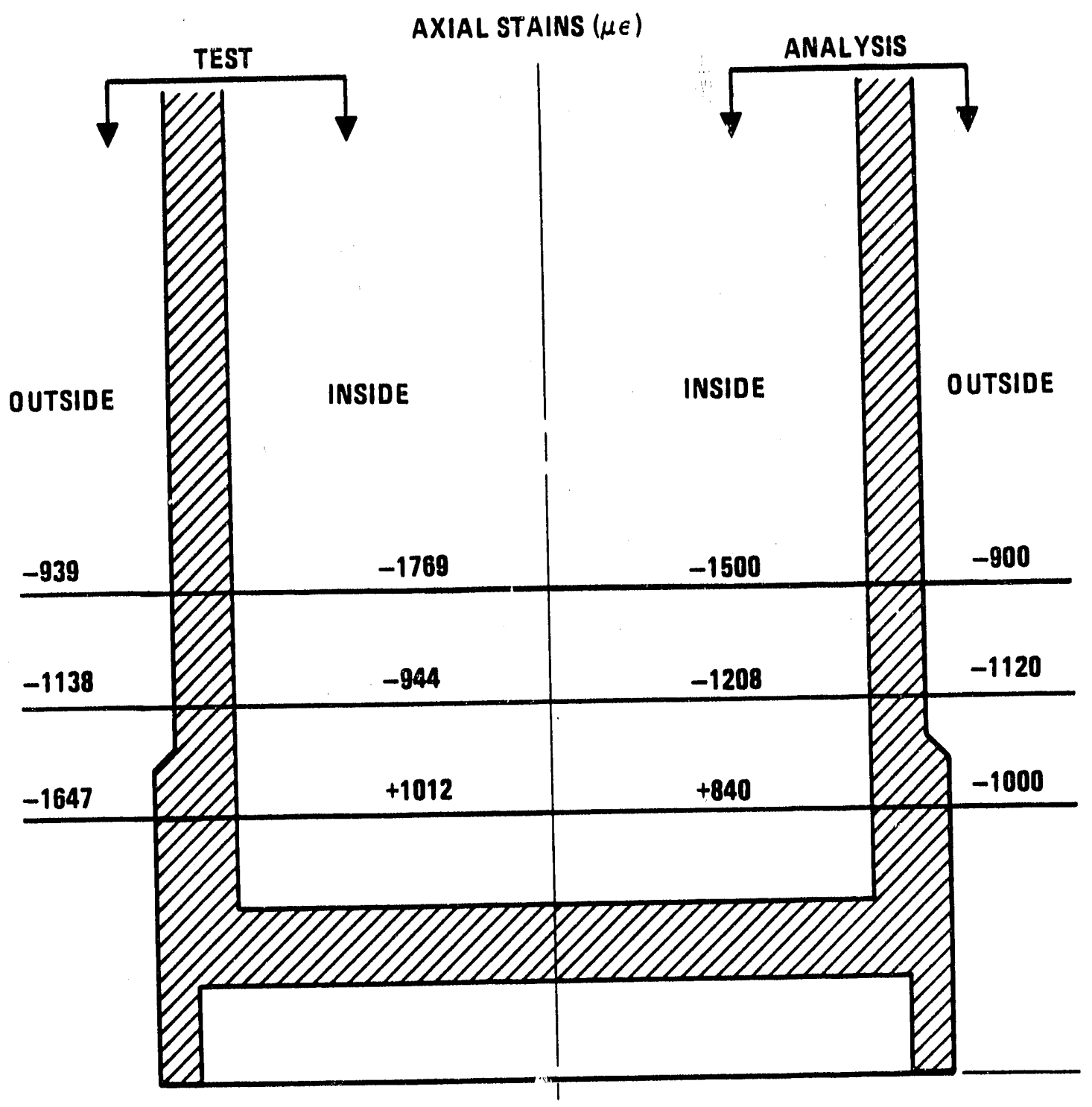
Fig. 5-3. Comparison of strain results in cask body during bottom end
drop 
2. Closure end drop. The strains in the closure were greater in the analysis than in the test. This is expected because in the analysis, the contents are rigid and do not absorb any of their own energy, while in the test the waste canister absorbs its own drop energy.

The maximum element strain at the outside of the closure produced by the analysis is $+1450 \mu \epsilon$ while during the test, the maximum strain measured was $+500 \mu \epsilon$ (f11tered at $10,000 \mathrm{~Hz}$ ).

3. CG over bottom corner. The highest strain measured during this test was $3300 \mu \epsilon$ in the axial direction. This strain level represents a minimal strain for Type 304 stainless steel since the minimum ultimate strain is $400,000 \mu \mathrm{E}$. A permanent strain offset of 800 He was recorded on that gauge. It occurs at the lowest point measured $(13.5 \mathrm{in}$. from the bottom of the cask, ful1-scale) at the location of the impact. Figure 5-4 shows the effective plastic strains obtained in the analysis, plotted at the end of the primary impact. Since these are plastic strains, they show only the magnitude of strain above yield. At 13.5 in. from the bottom of the cask, the analysis shows an effective plastic strain of less than $2222 \mu \epsilon$. As discussed earlier in this section, in the analysis, yield occurs at a strain equal to $1237 \mu \epsilon$ (In one dimension). A total analytical strain can then be approximated as follows: $2222 \mu \epsilon+1237 \mu \epsilon=3459 \mu \epsilon$. Therefore, both the analysis and the test produce strains simflar in magnitude.

\subsection{DISPLACEMENTS}

Comparisons in Table 5-1 show that the elastic and inelastic analytical deformations are consistently larger than the measurements on al1 tests. Most of the deformation occurred in the area of the impact 


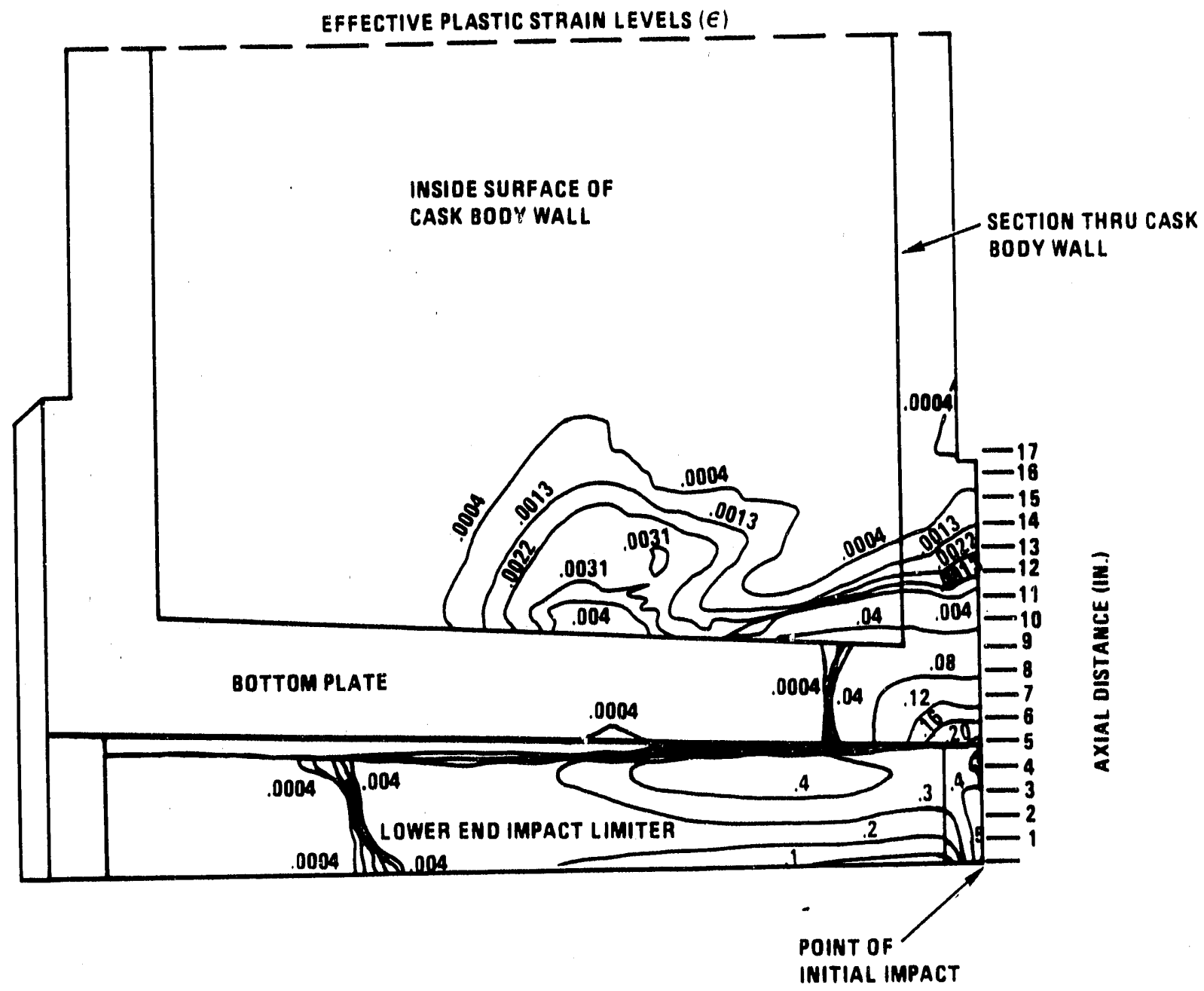

Fig. 5-4. CG over bottom corner strain analytical results 
limiters. The cask body deformations were minimal, and there was negligible deformation on the closure seal area as had been predicted by analysis.

It was expected that the analysis would produce higher deformations than the test for the following reasons:

1. The modeling of the contents was very conservative.

2. There was no friction between interfaces and no materlal damping modeled in the analyses. These analytical assumptions are conservative because the energy of the drop cannot be absorbed by any other mechanism except displacement. Therefore, the analytical displacements are expected to be larger than the test results.

For a one-degree-of-freedom system, the equation of motion can be written as follows:

$$
\begin{aligned}
& M \ddot{x}=F_{\text {int }}+F_{\text {ext }}+F_{\text {fric }}, \\
& F_{\text {lnt }}=K x+c \dot{x},
\end{aligned}
$$

where

$$
\begin{aligned}
M & =\text { mass, } \\
\ddot{x} & =\text { acceleration, } \\
F_{\text {int }}, F_{\text {ext }}, F_{\text {fric }} & =\text { internal, external, and frictional force, } \\
& \text { respectively, } \\
K & =\text { spring constant, } \\
x & =\text { displacement, } \\
c & =\text { damping coefficient, } \\
\dot{x} & =\text { velocity. }
\end{aligned}
$$


The finite element codes used in the analysis do not include Ffric and $c \dot{x}$; therefore, the energy of the drop has to be absorbed by deformation. In cases such as the $9-\mathrm{m}(30-\mathrm{ft})$ drop events in which the normal force is very high, friction between two steel surfaces, as exists between the target and the cask at the point of impact, can have a slgnificant effect. Ignoring friction is conservative.

Damping becomes more Important as the duration of an event increases. Therefore, it plays a bigger role on longer events such as the closure end drop and the CG over bottom corner drop. It is conservative to ignore damping.

1. Bottom end drop. Figure 5-5 shows the deformed shape of the bottom of the cask for both test and irelastic analysis. Table 5-1 shows that the lower end impact limiter deformation for both elastic and inelastic analyses is larger than for the test.

2. Closure end drop. The deformation on the notched impact $1 \mathrm{fm}$ fter due to the closure end drop also shows that the elastic and Inelastic analyses are conservative. During this drop, the analyses predicted more inward deformation of the notched impact limiter than occurred during the test. In the test the notched impact limiter bent, closing two notches all around the Impact limiter, as well as closing up the third notch in some areas. In contrast, the inelastic analysis predicted that four notches would close completely.

3. CG over closure corner drop. This drop orientation was not tested. The deformation on the closure end impact limiter is slightly lower in the elastic analysis compared to the inelastic ana.ysis. The reason for this difference is that the GACAP elastic analysis uses load-deflection curves to model the closure end impact limiter that are based on 


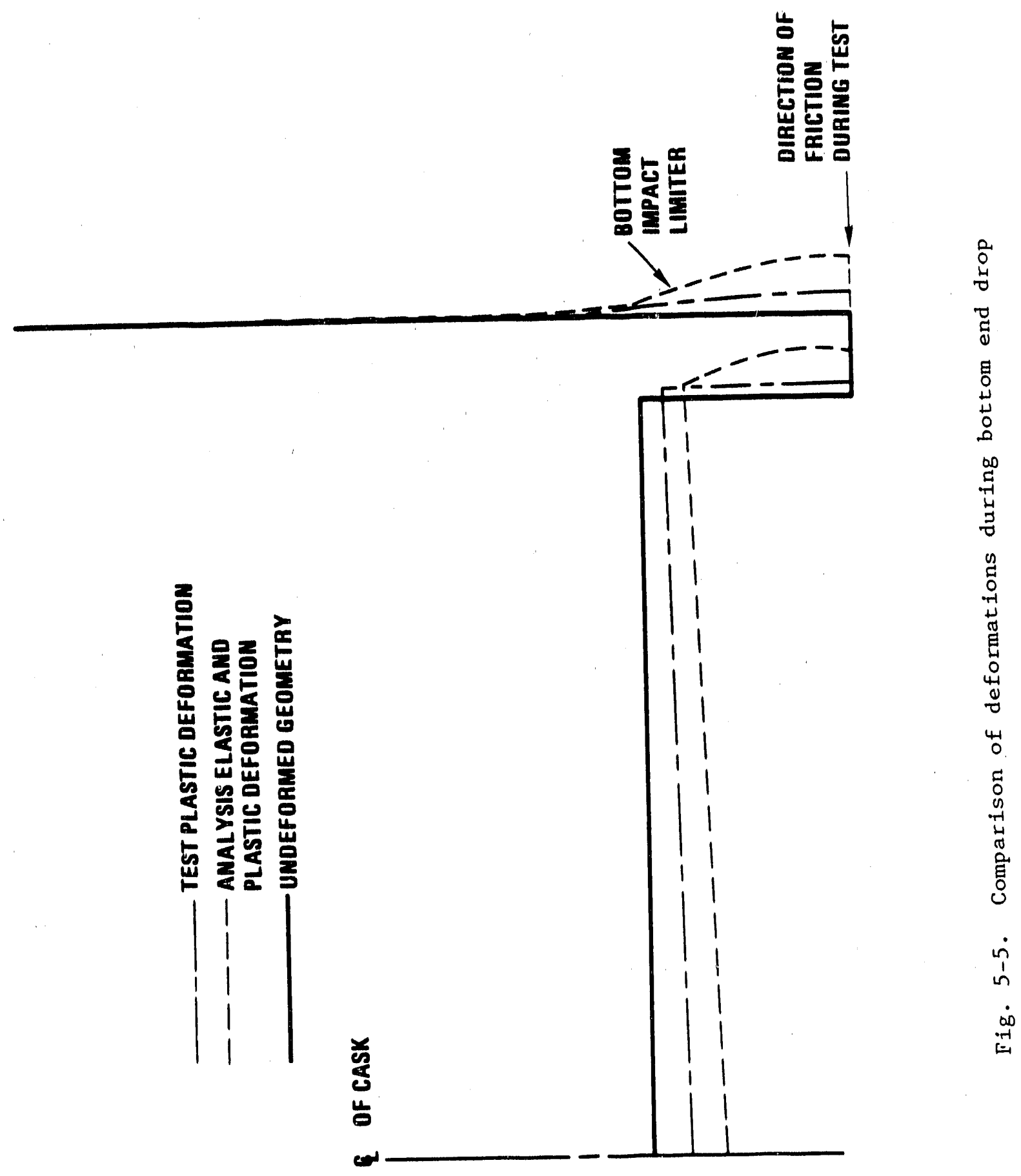


1/6-scale model tests. The model tests include friction between the lower end impact 1 imfter and the target and Internal dampln's and will therefore absorb more energy with less deflection.

4. CG over bottom corner drop. The deformation of the lower end impact Iimiter is lowe- for both the GACAP elastic analysis and the test than the Inelastic analysis pecause of the presence of friction in the test. In addition, the GACAP ana1ysis deformation is lower than that for the inelastic analysis because of the presence of friction between the lower end Impact IImfter and the unylelding target.

The results confirm that the drop energy not only is absorbed by plastic deformation, but also by other mechanisms such as friction at the interface between the Impact Iimiter and the target, damplng, heat generation, etc., which helps to explain the reduced deflection in the test.

\subsection{MATERIAL PROPERTIES}

Figure 5-6 plots the results of the half-scale model Type 304 stainless steel material tests, compared to the values used in the elastic-plastic analysis. Both the cask body materlal and notched impact limiter material were tested in tension and compression, at strain rates of $1 \times 10^{-3} \mathrm{~s}^{-1}$ and $5 \mathrm{~s}^{-1}$. Reference $4-1$ contains the complete results.

During the tests, the high strain rate increased the stainless steel yield stresses about $20 \%$ above static results. This is a typical increase in strength due to dynamic events. In the inelastic analyses, a yleld strength of $35 \mathrm{ks} 1$ was used. 


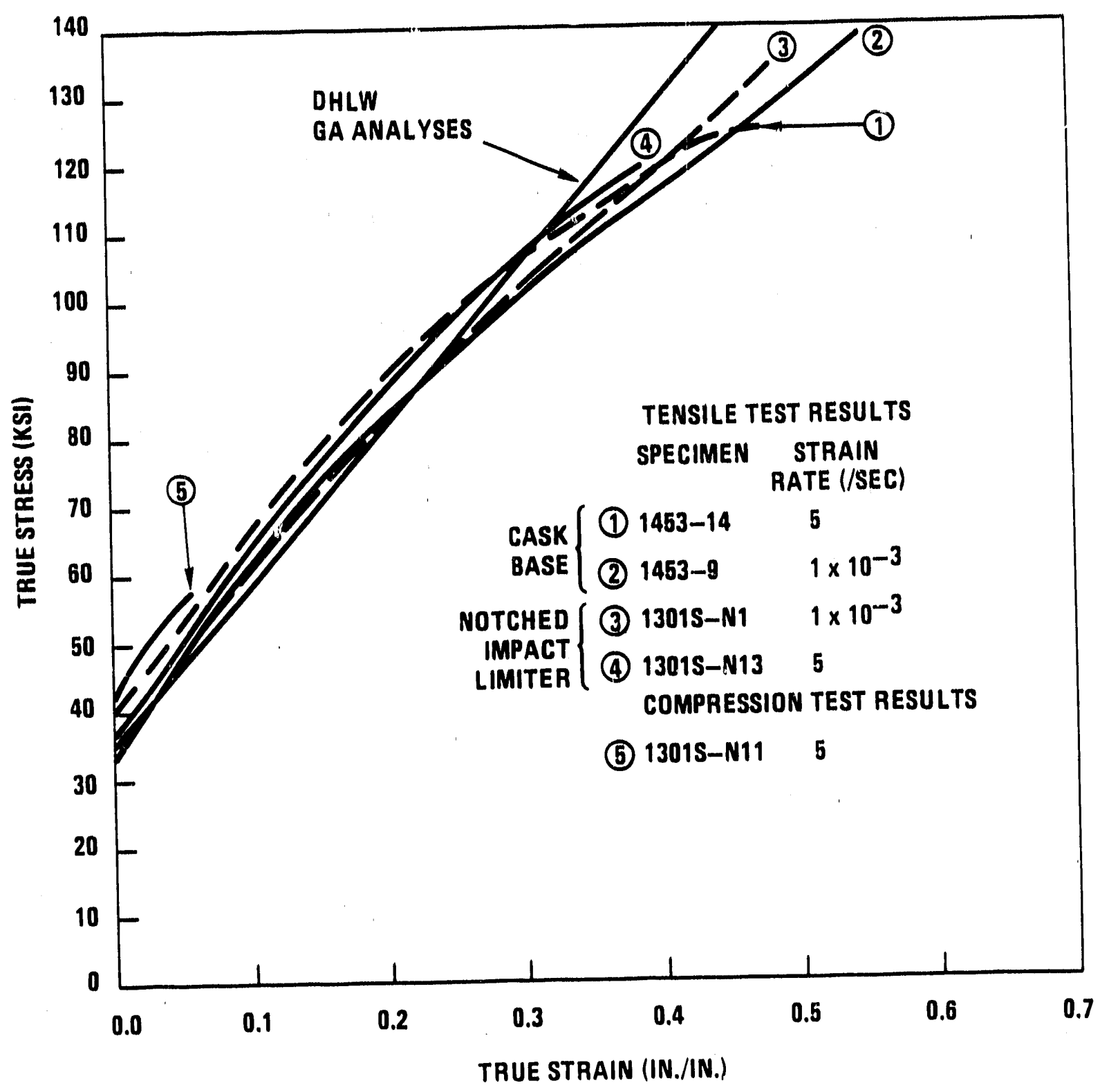

Fig. 5-6. Comparison of material test results with analytical properties used 
Th1s higher dynamic yleld stress results in an increase in the energy that was absorbed during the closure and bottom end drop tests in comparison to the analyses for a given deflection. This also helps to explain the reduced deflection in the test. 


\section{REFERENCES}

1-1. Koploy, M., et a1., "Validation of Elastic-Plastic Computer Analyses for Use in Nuclear Waste ShIpping Cask Design," Waste Management 1987, p. 433, Vo1. 3.

1-2. Shatoff, H. D., "GACAP - A Theoretical and Users Manua1," GA Document 909764, Rev. N/C, October 17, 1988.

2-1. Cooper, W. E., "Rationale for a Standard on the Requalification of Nuclear Class 1 Pressure Boundary Components," EPRI NP-1921.

2-2. Conway, T. B., et a1., "Fatigue, Tensile, Relaxation Behavior of Stainless Steels," Report 110-26135, USAEC, Technical Information Center, Office of Information Services, Oak RIdge, Tennessee, 1981.

2-3. Key, S., Z. E. Belsinger, and R. D. Kreig, "HONDOII - A FInite Element Computer Program for the Large Deformation Dynamic Response of Axisymmetric Solids," Sandia National Laboratories SAND 78-0422, October 1978.

2-4. Hallquist, J. 0., "Preliminary User's Manuals for DYNA3D and DYNAP, " Report UCID-19156; University of California, Lawrence Livermore Laboratory, July 1981.

2-5. American Soclety of Mechanica1 Engineers (ASME) Boller and Pressure Vessel Code, 1983 Edition with Summer and Winter Addenda for 1983.

3-1. "SCANS A Microcomputer Based Analysis System for Shipping Cask Design Review," Theory Manuals, Vols. 2 and 3, January 1989.

3-2. Taylor, C. S., "ILMOL Manual and Validation Document," GA Document 910158, Rev. A, January 3, 1991.

3-3. Biggs, J. M., "Introduction to Structural Dynamics, "McGraw Hill, 1964 . 
4-1. Uncapher, W. L., M. M. Madsen, and D. R. Stenberg, "Test of the Half-scale Model of the Defense High Level Waste Transportation Cask," SAND 86-1130, Sandia National Laboratories.

4-2. Buckingham, E., "Model Experiments and the Forms of Empiricai Equations," Trans., ASME 37265 (1915).

5-1. Brenner, N. M., "Three Fortran Programs That Perform the CooleyTukey Fourier Transform," Massachusetts Institute of Technology, AD 656 019, Lexington, Massachusetts, Ju1y 1967. 

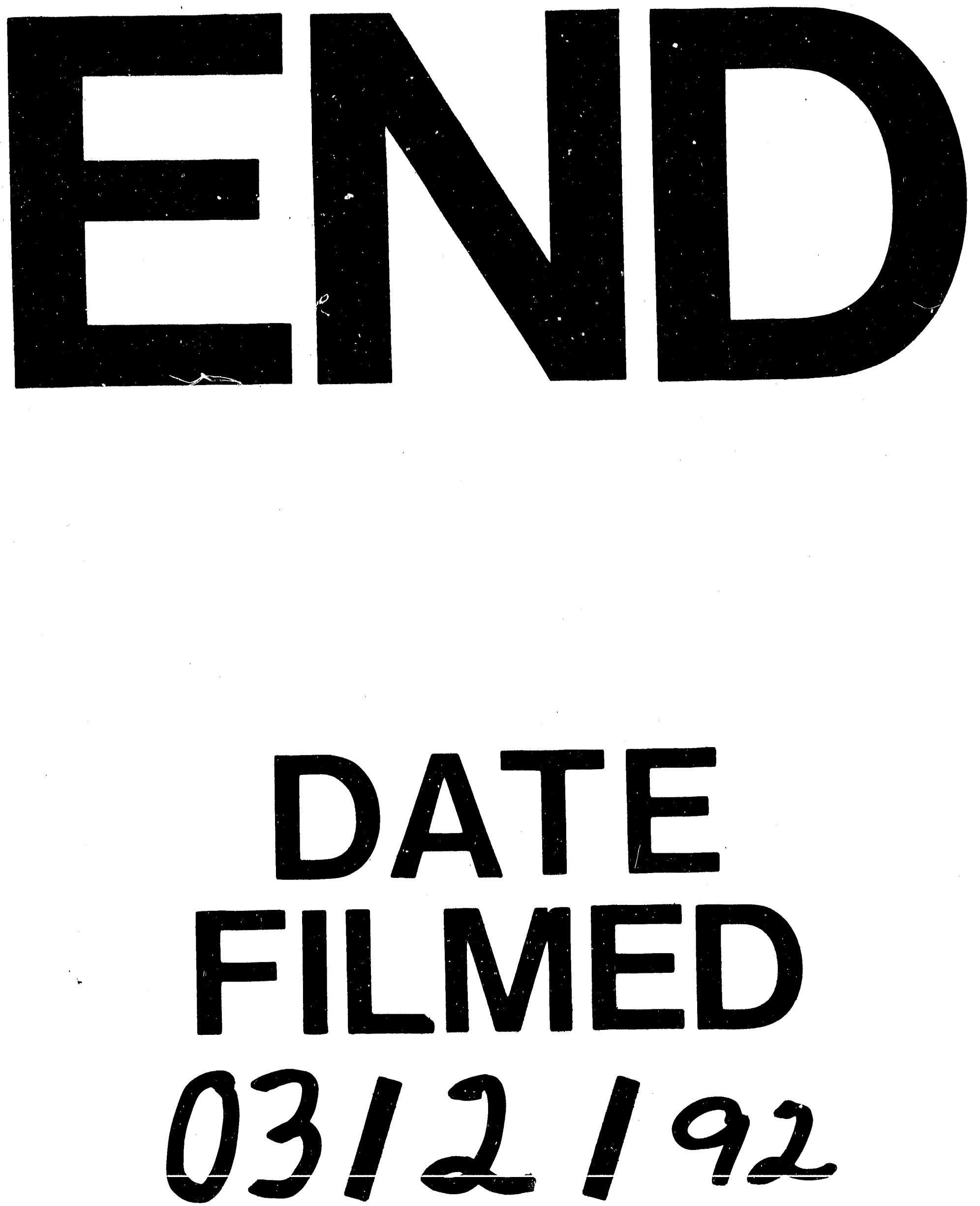
